\title{
THE BIOLOGY OF Senescence
}





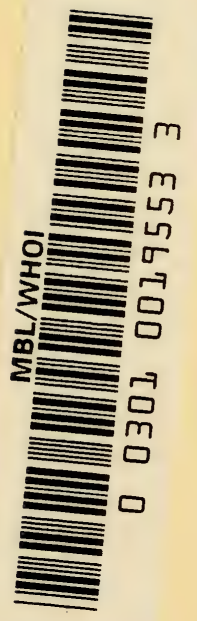



THE BIOLOGY OF SENESGENGE 



\title{
THE BIOLOGY OF
}

SENESGENGE

\author{
by \\ Alex Comfort
}

RINEHART \& GOMPANY, INC.

Publishers $1956 \quad$ New Tork 
Printed in Great Britain

by Butler \& Tanner Ltd

Frome and London 
To the question propounded..., I can make only one answer: yes, it is useful to prolong human life.

ILYA METCHNIKOFF (1907)

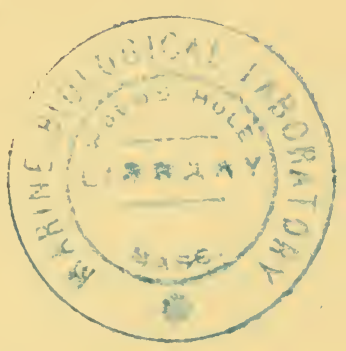





\section{PREFAGE}

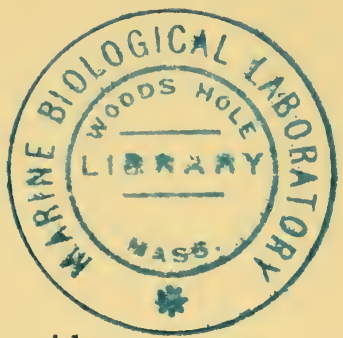

This book is a compilation. It was written as an aid to my own research, in a subject where it is difficult to know where to begin, but I hope that the references, at least, will be useful to others.

The denunciation of a subject and its current theoretical basis as 'unsatisfactory' is a relatively easy exercise-dealing with it satisfactorily is quite another matter. No biological treatment of senescence can hope to be satisfactory in the absence of a great deal of factual information which at present is not there. I have attempted to collect as much of this information as possible: since most of it comes from fields in which I have no experience, there are bound to be errors both of fact and of deduction in such a survey, and I hope that they will be pointed out to me.

I am deeply grateful to Professor Peter Medawar, F.R.S., under whom I have worked, to Professor J. B. S. Haldane, F.R.S., for kindly drawing my attention to a number of references I would not otherwise have seen, and to many colleagues whom I have molested for information or criticism, and whose help and advice has been invaluable, though they bear no responsibility for the result. I am also profoundly indebted to the Nuffield Foundation for several years' financial support, to Dr. Harrison Matthews, Director of the London Zoo, for access to its records, and to Miss Rosemary Birbeck for much help in preparing the manuscript and bibliography.

\section{ALEX COMFORT}

December 1954 



\section{CONTENTS}

PREFACE

vii

INTRODUCTORY AND HISTORICAL

1 THE NATURE AND GRITERIA OF SENESCENCE

1.1 The Measurement of senescence

$1 \cdot 2$ Forms of senescence

1.2.1 Mechanical senescence 34

1.2.2 'Accumulation' and 'depletion' 35

1.2.3 Morphogenetic senescence 36

$1 \cdot 3$ Senescence in evolution 37

2 THE DISTRIBUTION OF SENESCENCE

2.1 Character of the evidence 42

2.2 Maximum longevities in animals 45

2.2.1 Mammals 46

$2 \cdot 2 \cdot 2$ Birds 49

$2 \cdot 2 \cdot 3$ Reptiles 51

2.2.4 Amphibians $\quad 52$

$2 \cdot 2 \cdot 5$ Fish 53

$2 \cdot 2 \cdot 6$ Invertebrates 54

2.3 Maximum life-span in man $\quad 59$

2.4 Distribution of senescence in vertebrates 63

$2 \cdot 4 \cdot 1$ Fish 68

2.4.2 Reptiles $\quad 77$

2.5 Distribution of senescence in invertebrates $\quad 79$

$2 \cdot 5 \cdot 1$ Porifera 80

$2 \cdot 5 \cdot 2$ Coelenterates 81

$2 \cdot 5 \cdot 3$ Sundry invertebrates 83

2.5.4 Rotifers 84

2.5.5 Arthropods 92

2.5.6 Molluscs $\quad 102$ 


\section{Contents}

$2 \cdot 6$ Senescence in wild populations

$2 \cdot 6 \cdot 1$ Vertebrates

2.6.2 Invertebrates

3 SENESGENGE IN PROTOZOA

$3 \cdot 1$ Individual cells

$3 \cdot 2$ The 'senescence' of clones

4 THE INFLUENGE OF GENETIC CONSTITUTION ON SENESGENGE AND LONGEVITY

$4 \cdot 1$ Inheritance of life-span

$4 \cdot 1 \cdot 1$ General

$4 \cdot 1 \cdot 2$ Parental age $\quad 125$

$4 \cdot 2$ Heterosis or hybrid vigour

$4 \cdot 3$ Sex differences

4.4 Progeria

4.5 Choice of material for the experimental study of age effects

5 GROWTH AND SENESCENCE

$5 \cdot 1$ 'Rate of living'

5.2 Experimental alteration of the growth rate

$5 \cdot 2 \cdot 1$ Invertebrates

$5 \cdot 2 \cdot 2$ Insect metamorphosis and senescence

$5 \cdot 2 \cdot 3$ Vertebrates

5.3 Growth-cessation and mammalian senescence

6 THE MECHANISMS OF SENESGENCE

$6 \cdot 1$ Senescence in cells

$6 \cdot 1 \cdot 1$ 'Irreplaceable' enzymes

6.1.2 Cell turnover

$6 \cdot 1 \cdot 3$ Somatic mutation

$6 \cdot 1 \cdot 4$ Specificity

6.2 Endocrine senescence

$6 \cdot 2 \cdot 1$ General

$6 \cdot 2 \cdot 2$ Gonad-pituitary system

6.2.3 Hormonal regulation of growth in vertebrates. $\quad 182$

GONGLUSION

BIBLIOGRAPHY 


\section{ILLUSTRATIONS}

1 Annual rate of mortality per 1,000 by sex: United States, 1939-41

2 Number of survivors out of 100,000 born alive, for each race by sex: United States, 1939-41

3 Number of Survivors out of 100,000 male live births, from recent life-tables for selected countries

4 Frequency distribution of ages at death in a cohort starting with 100,000 live births, based on the mortality of white males: United States, 1939-41

5 (a) Survival curve at a constant rate of mortality

(b) Survival curve of a population which exhibits senescence

6 Types of survival curve

7 Survival curves of a German population

8 Survival curves for cafeteria tumblers

9 African Ibis (Threskiornis aethiopicus). Survival of 21 individuals

Night Heron (Nycticorax nycticorax). Survival of 17 individuals

10 Orkney Vole (Microtus orcadensis). Survival of 24 individuals

11 Patagonian Gavy (Dolichotis patagona). Survival of 55 individuals

12 Mouflon Sheep (Ovis musimon). Survival of 77 individuals

13 Irish Wolfhounds. Survival of 67 individuals from 12 months of age-sexes combined

14 The decline in egg production in successive years of laying -domestic fowls

15 (a) Growth in length of male fish of the genera Xiphophorus, Lebistes and Heterandria during the first year of life

(b) Growth in length of female fish of the genera Xiphophorus, Lebistes and Heterandria during the first year of life

16 Growth of trout in Windermere and the small tarns 


\section{Illustrations}

17 (a) Growth-constant for growth in length of the sturgeon, Acipenser stellatus, at various ages

(b) Growth in weight of the sturgeon (Acipenser stellatus) and the bream (Abramis brama)

(c) Growth in weight of the Bream (Abramis brama) 74

18 (a) Life-table of Lebistes reticulatus

75

(b) Growth of female Lebistes reticulatus

76

19 Growth of Emys

78

20 Survival curves for Lecane inermis

86

21 Growth in length of Philodina citrina

22 Life-span and egglaying of Philodina citrina over 6 generations in normal culture

23 Progressive decline in life-span of a strain of Philodina citrina (Rotifera) raised in each generation from eggs laid by old mothers

24 Life-span of successive generations of Philodina reared in each generation from the eggs of 4,11 , and 17 day old mothers

25 (a) Growth of Daphnia magna-first type

(b) Growth of D. magna-second type

(c) Growth of D. magna-third type

26 Survival curves of 143 isolated virgin females and 44 isolated, fertilized females of the moth Fumea crassiorella

27 Egg production of Eulota fruticum

28 Life-span of the pulmonate Limnaea columella

29 Growth and longevity of Patella vulgata in various stations, showing the short life of rapidly-growing populations

30 Smoothed survival curve for the vole, Microtus agrestis in captivity

31 Survival curves of mice in laboratory culture-breeding females

32 Drosophila subobscura. Strain K. Survival curves of flies raised in each generation from eggs laid by adults which had passed the 30th day of imaginal life

33 Drosophila subobscura-hybrid vigour and longevity. Survival curves for the inbred lines $B$ and $K$, and for the reciprocal hybrids between them

34 Survivorship curves for 82 males and 45 females of the black widow spider Latrodectes mactans 


\section{Illustrations}

35 Survivorship, death and death-rate curves for the black widow.

36 Survivorship curves for male and female Tribolium madens

37 Effect of restricted food upon the longevity of Daphnia longispina

38 Effect of restricted food upon the duration of instars in Daphnia longispina

39 Effect of restricted food upon the rate of senile change in the heart rate of Daphnia longispina

40 Survival curves of normal and retarded male and female rats, showing the effect of dietary restriction

41 Neutral 17-Ketosteroids, 24-hour urinary excretion of human males

42 The postnatal growth in weight of male children

43 Annual growth increment in boys, from the data of Quetelet 



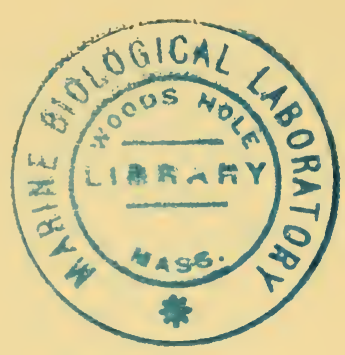

\section{INTRODUGTORY AND HISTORIGAL}

MAN throughout history, and every individual since his childhood, has been aware that he himself, and those animals which he has kept in domestication, will undergo an adverse change with the passage of time. Their fertility, strength and activity decreases, and their liability to die from causes which, earlier in life, they could have resisted, increases.

This process of change is senescence, and senescence enters human experience through the fact that man exhibits it himself. This close involvement with human fears and aspirations may account for the very extensive metaphysical literature of ageing. It certainly accounts for the profound concern with which humanity has tended to regard the subject. To a great extent human history and psychology must always have been determined and moulded by the awareness that the life-span of any individual is determinate, and that the expectation of life tends to decrease with increasing age. The Oriental could say 'O King, live for ever!' in the knowledge that every personal tyranny has its term. Every child since the emergence of language has probably asked 'Why did that man die?' and has been told 'He died because he was old.'

Interesting psychological and historical speculation could be made on the part which this awareness has played in human affairs. From the biologist's standpoint, its main importance has been the bias which it has injected into the study of senescence. The child who asks the question, and receives the answer, is familiar with 'old' clothes and 'old' toys. He has always known that he, his pets, his cattle and his neighbours will become increasingly prone to breakdown and ultimate death the older they get. He has observed from the nursery that inanimate and 


\section{The Biology of Senescence}

mechanical systems also deteriorate with the passage of time. He appears at a later age to derive some degree of comfort from the contemplation of the supposed generality, universality and fundamental inherence of ageing-or alternatively from drawing a contrast between Divine or cosmic permanence and his own transience. However inspiring this type of thinking may have been-and it features largely in the past artistic and philosophical productions of all cultures - its influence and its incorporation as second nature into the thought of biologists throughout history has seriously handicapped the attempt to understand what exactly takes place in senescence, which organisms exhibit it, and how far it is really analogous to processes of mechanical wear. One result of the involvement of senescence with philosophy and the 'things that matter' has been the prevalence of attempts to demonstrate general theories of senile change, including all metazoa and even inanimate objects, and having an edifying and a metaphysical cast. Prominent among these have been attempts to equate ageing with development, with the 'price' of multicellular existence, with hypothetical mechano-chemical changes in colloid systems, with the exhaustion induced by reproductive processes, and with various concepts tending to the philosophical contemplation of decline and death.

It is not unreasonable to point out that these theories have for the most part deeper psychological and anthropological than experimental and observational roots. Some of them have a few facts on their side. 'Reproductive exhaustion' does appear to induce senescence in fish and in mollusca, and flowering is a proximate cause of death in monocarpic plants, but the general concept, especially when it is made a universal, owes a large debt to the widespread belief in human cultures that sexuality 'has its price'. Extensions of mechanical analogies from the wearing out of tools to the wearing out of animal bodies are justifiable in a limited number of cases where structures such as teeth undergo demonstrable wear with use, and where this process limits the life of the organism; but they have also shown a tendency to become generalized in the hands of biologists who are devoted for philosophical, political or religious reasons, to mechanism in the interpretation of human behaviour. State- 


\section{Introduction and Historical}

ments that 'senescence is no more than the later stage of embryology' resemble Benjamin Rush's great discovery, that all disease is disordered function. They belong to the category of word-rearrangement games, which have long been played in those fields of study where there is as yet no 'hard news'.

Although the religious, poetic, metaphysical and philosophical literatures of senescence will not be examined here, the detection and examination of analogies based upon them, which have had a great, and generally adverse, influence on the growth of our knowledge of age processes, must clearly play a large part in any critical examination of the subject. The comments of Francis Bacon, who was both a philosophical originator of the scientific method, and the first systematic English gerontologist, ${ }^{1}$ provide one of the best critiques of the influence of such analogies and thought-patterns, and they will be quoted without scruple here.

The practical importance of work upon the biology of senescence, beyond the fundamental information which such work might give about the mechanisms of cell differentiation and renewal, can best be seen from the diagrams at Fig. 1-3 and 7 . The advance of public health has produced a conspicuous shift in the shape of the survival curve in man so far as the privileged countries are concerned, from the oblique to the rectangular form. This has been due almost entirely to a reduction in the mortality of the younger age groups-the human 'specific age' and the maximum life-span have not been appreciably altered. The medical importance of work on the nature of ageing lies at present less in the immediate prospect of spectacular interference with the process of senescence than in the fact that unless we understand old age we cannot treat its diseases or palliate its unpleasantness. At present age-linked diseases are coming to account for well over half the major clinical material in any Western medical practice. The physician is constantly referring to the biologist for a scientific basis for geriatrics, and finding

${ }^{1}$ I dislike this word, but it is probably too well grown for eradication. It should mean 'a student of old men' ( $\gamma \varepsilon \dot{\varrho} \varrho \nu$ ) and gerontology the study of old men. For the study of age itself, the subject of this book, we require geratology $(\gamma \tilde{\eta} \varrho \alpha \varsigma)$, upon which it would be fruitless to insist. 


\section{The Biology of Senescence}

that it is not there. The amount of material on which such a foundation could be built has increased, though not very rapidly, during the present century. Its quantity is still inversely proportional to the importance of the subject.

There are not many adequate reviews of the modern biological literature. The most recent are those of Lansing $(1951,52)$. A previous review of mine contains little which is not repeated here (Comfort, 1954). Some of the more celebrated 'general theories' have received spirited treatment in a review by Medawar (1945). The literature of animal population statistics has been reviewed by Deevey (1947) and that of invertebrate senescence by Szabó (1935) and by Harms (1949). It is a pleasure to acknowledge my indebtedness to these reviews and to the bibliography of Shock (1951). A great deal of clinicopathological material upon the age-incidence of various human diseases and the weights of organs throughout life has been collected by Bürger (1954). In a depressingly large number of fields, there has been little new information in the last twenty years. Other reviews of specific topics will be cited in their place. The senescence of plants is not discussed here: it has been reviewed in some detail by Crocker (1939), to whose paper there seems little to add.

Senescence is probably best regarded as a general title for the group of effects which, in various phyla, lead to a decreasing expectation of life with increasing age. It is not, in this sense, a 'fundamental', 'inherent', or otherwise generalizable process, and attempts to find one underlying cellular property which explains all instances of such a change are probably misplaced. It is important and desirable to recognize the origins of many such general theories, which owe much to folk-lore on one hand and to the emotional make-up of their authors on the other. The demoralizing effect of the subject of senescence, even upon biologists of the highest competence and critical intelligence, is well illustrated by the following passage from Pearl (1928), the father of animal actuarial studies:

'(Somatic death in metazoa) is simply the price they pay for the privilege of enjoying those higher specializations of structure and function which have been added on as a sideline to the 


\section{Introductory and Historical}

main business of living things, which is to pass on in unbroken continuity the never-dimmed fire of life itself.'

Warthin (1929), whose insistence upon the fundamental impossibility of modifying the tempo of human ageing, now or at any time in the future, has an orgiastic tone quite out of keeping with the rashness of such a prediction, writes:

'We live but to create a new machine of a little later model than our own, a new life-machine that in some ineffable way can help along the great process of evolution of the species somehow more efficiently than we could do were we immortal. The Universe, by its very nature, demands mortality for the individual if the life of the species is to attain immortality through the ability to cope with the changing environment of successive ages.... It is evident that involution is a biologic entity equally important with evolution in the broad scheme of the immortal process of life. Its processes are as physiologic as those of growth. It is therefore inherent in the cell itself, an intrinsic, inherited quality of the germ plasm and no slur or stigma of pathologic should be cast upon this process. What its exact chemicophysical mechanism is will be known only when we know the nature of the energy-charge and the energy-release of the cell. We may say, therefore, that age, the major involution, is due primarily to the gradually weakening energy-charge set in action by the moment of fertilization, and is dependent upon the potential fulfillment of function by the organism. The immortality of the germ plasm rests upon the renewal of this energy charge from generation to generation.'

This passage is highly typical of the literature of old age to the present day. There can be few branches of biology in which uplifting generalization of this kind has so long been treated as a respectable currency for scientific thought.

In general, the more elaborate the attempts to depict senescence in overall mathematical terms, the more intellectually disastrous they have proved. One of the most celebrated incursions of metaphysics into biology, that which postulates a separate 'biological time', is best expounded in the words of its sponsor, Lecomte du Noüy (1936): 


\section{The Biology of Senescence}

'When we refer to sidereal time as being the canvas on which the pattern of our existence is spread, we notice that the time needed to effectuate a certain unit of physiological work of repair is about four times greater at fifty than at ten years of age. Everything, therefore, occurs as if sidereal time flowed four times faster for a man of fifty than for a child of ten. It is evident, on the other hand, that from a psychological point of view many more things happen to a child in a year than to an old man. The year therefore seems much longer to the child.... Thus we find that when we take physiological time as a unit of comparison, physical time no longer flows uniformly. This affirmation revolts one if the words are taken in a literal sense. But ... the expression "flow of time" ... is entirely false and does not correspond to a reality. When ... . we say that physical time measured by means of a unit borrowed from our physiological time no longer flows uniformly, it simply means that it does not seem to flow uniformly ... Must one consider this fact as the indication of a difference of magnitude between our short individual period and the immense periods of the universe? Must we see a proof of the existence of such periods? Who knows? All that we can say at present is that our crude language, lacking appropriate words, translate this knowledge into improper, inadequate expressions such as "There are two species of time" or "Physiological time does not flow uniformly like physical time"... We must not let ourselves be duped by these words, etc. ...'

It is startling how many distinguished biologists have subsequently quoted the notion of a distinct 'biological' time with apparent sanction. The alcoholic who draws on his bottle irregularly will find that its progress towards emptiness follows an irregular scale, 'alcoholic time', so that judged by the rate of emptying of the bottle, 'sidereal' time appears to progress unevenly. But variation in rate is hardly an occult, or even an unfamiliar, phenomenon. Like others before him, du Noüy has gone down clutching a platitude and come up embracing a metaphysical system.

In almost any other important biological field than that of senescence, it is possible to present the main theories historic- 
ally, and to show a steady progression from a large number of speculative, to one or two highly probable, main hypotheses. In the case of senescence this cannot profitably be done. The general theories of its nature and cause which have been put forward from the time of Aristotle to the present day have fallen into a number of overall groups, and have been divided almost equally between fundamentalist theories which explain all senescence, or treat it as an inherent property of living matter or of metazoan cells, and epiphenomenalist theories which relate it to particular physiological systems or conditions. They are also fairly evenly divided between the various categories of Baconian idola. It is a striking feature of these theories that they show little or no historical development; they can much more readily be summarized as a catalogue than as a process of developing scientific awareness. To the fundamentalist group belong, in the first place, all theories which assume the existence of cellular 'wear and tear' (Abnutzungstheorie) without further particularization (Weismann, 1882; Pearl, 1928; Warthin, 1929); the mechanochemical deterioration of cell colloids (Bauer, Bergauer, 1924; Rủžícká, 1924; 1929; Dhar, 1932; Lepeschkin, 1931; Szabó, 1931; Marinesco, 1934; Kopaczewski, 1938; Georgiana, 1949); and pathological or histological elaborations of these, which attribute senescence to inherent changes in specified tissues, nervous (Muhlmann, 1900, 1910, 1914, 1927; Ribbert, 1908; Vogt and Vogt, 1946; Bab, 1948), endocrine (Lorand, 1904; Gley, 1922; Dunn, 1946; Findley, 1949; to cite only a few from an enormous literature in which the endocrine nature of mammalian senescence is discussed, stated or assumed), vascular (Demange, 1886), or even connective (Bogomolets, 1947). To the epiphenomenalist group belong toxic theories based on products of intestinal bacteria (Metchnikoff, 1904, 1907; Lorand, 1929; Metalnikov, 1937), accumulation of 'metaplasm' or of metabolites (Kassowitz, 1899; Jickeli, 1902; Montgomery, 1906; Muhlmann, 1910; Molisch, 1938; Heilbrunn, 1943; Lansing, 1942; etc.), the action of gravity (Darányi, 1930), the accumulation of heavy water (Hakh and Westling, 1934) and the deleterious effect of cosmic rays (Kunze, 1933). There are also general developmental theories which stress the continuity of senescence with 


\section{The Biology of Senescence}

morphogenesis (Baer, 1864; Cholodkowsky, 1882; Roux, 1881; Delage, 1903; Warthin, 1929) or the operation of an Aristotelean entelechy (Driesch, 1941; Bürger, 1954), metabolic theories introducing the concept of a fixed-quantity reaction or of a rate/quantity relationship in determining longevity (Rubner, 1908; Loeb, 1908; Pearl, 1928; Robertson, 1923), attainment of a critical volume-surface relationship (Muhlmann, 1910 etc.), depletive theories relating senescence to reproduction (Orton, 1929) and finally an important group of theories which relate senescence to the cessation of somatic growth (Minot, 1908; Carrel and Ebeling, 1921; Brody, 1924; Bidder, 1932; Lansing, 1947, 1951). Most of the older theories have been reviewed, against a background of Drieschian neovitalism, in the textbook of Bürger (1954).

The distribution of dates in this catalogue sufficiently indicates the state of the subject. When Francis Bacon examined the relationship between animal specific longevity, growth-rate, size and gestation period, he concluded that the available facts were unfortunately insufficient to support a general theory. That conclusion remains valid in practically all the instances quoted, but Bacon's self-denial failed to set a precedent for his successors. Almost all these theories, judging from the literature, continue at some point to influence biological thinking: some can be partially, or even largely, justified by the suitable selection of instances. Others did not bear critical inspection at the time they were first formulated, bearing in mind the known behaviour of cells, and the known discrepancies in longevity and in rate of ageing between animals of similar size, histological complexity, and physiological organization. Relatively few are supported by any body of fundamental experiment. The devising of general theories of senescence has employed able men, chiefly in their spare time from laboratory research, for many years. It seems reasonable to assume that almost all the mechanisms which might theoretically be involved have been considered, and if we are to understand what does in fact occur in a given ageing organism, we now need a combination of general observation with planned causal analysis in experimental animals.

The main theories of ageing will be discussed in the text. 


\section{Introduction and Historical}

There are, however, a few which should be outlined in greater detail here-either because they are still of importance, or because, though untenable, they have a considerable surviving influence.

The most influential nineteenth-century contribution to this second category was probably that of Weismann, whose theory sprang directly from his distinction between germ plasm and soma. Weismann regarded senescence as an inherent property of metazoa, though not of living matter, since he failed to find it in protozoans and other unicellular organisms. Its evolution had gone hand in hand with the evolution of the soma as a distinct entity, and it was the product of natural selection, arising like other mutants by chance, but perpetuated as a positively beneficial adaptation, because 'unlimited duration of life of the individual would be a senseless luxury'. 'Death', according to this view, 'takes place because a worn-out tissue cannot forever renew itself. ... Worn-out individuals are not only valueless to the species, but they are even harmful, for they take the place of those which are sound' (1882). This argument both assumes what it sets out to explain, that the survival value of an individual decreases with increasing age, and denies its own premise, by suggesting that worn-out individuals threaten the existence of the young. It had the advantage, however, of being an evolutionary theory, and we shall see later that this is the only type of theory which today seems likely to offer a general approach to the emergence of senescence in all the groups which exhibit it. The idea that all somatic cells must necessarily undergo irreversible senescence was challenged early in the century by the studies of Child (1915) upon planarians, and of Carrel (1912) upon tissue culture. The assumption that all higher metazoa must ex hypothesi exhibit senescence, however, dies hard, and the fallacious argument based on selection has been repeated as recently as 1937 (Metalnikov, 1936, 1937).

A considerable number of metabolic theories were based on the fact that an inverse relationship exists between length of life and 'rate of living'. On the basis of calorimetric experiments, Rubner (1908, 1909) calculated that the amount of energy required for the doubling of weight by body growth was approximately equal in a number of mammals. The energy 


\section{The Biology of Senescence}

requirement for the maintenance of metabolism, per unit adult body weight, was also approximately equal between species. Rubner inferred that senescence might, from these energy relationships, represent the completion of one particular system of chemical reactions, depending on a fixed total energy expenditure. He was obliged to erect a special category for man, whose energy requirement was found to be far higher than in laboratory or domestic animals. Loeb (1902, 1908) attempted to find out whether the temperature coefficient of this hypothetical reaction was identical with that of general rate of development. Working with echinoderm eggs at various temperatures, and using a hatchability criterion to determine 'senescence', if the word can be used in such a highlyspecialized instance, he concluded that the two coefficients were distinct. The importance of this work has been that its presuppositions have recurred in later studies, where some authors have based very similar inferences about the relationship of growth and senescence to a 'monomolecular, autocatalytic reaction' on the shape and supposed mathematical proportions of the growth curve. As d'Arcy Thompson pointed out, this might equally prove the 'autocatalytic' character of growth in a human population. In fact, with suitable adjustment, curves based on biological material can be made to provide support for almost any hypothesis of this kind.

Little need be said of the various toxic or pathological theories of mammalian senescence. We are really left with five historically important theories, or groups of observations: the suggestion of Weismann that senescence is evolved, not intrinsic in all cellular matter; the work of Pearl (1928) which leads to the conception of a 'rate of living', such that factors which retard development or reduce metabolism tend in many organisms to prevent or postpone senescence; the work of Minot (1913, 1908), of which the most important surviving parts are his relation of senescence to the decline of growth, and his insistence upon its continuous and gradual character and its continuity with morphogenesis; the experimental studies of Child (1915), which showed that cellular differentiation and 'senescence' in planarians is reversible, and of Carrel (1912), who demonstrated that some tissue cells derived from adult animals 


\section{Introductory and Historical}

could be propagated indefinitely in vitro, and finally the theories of Bidder (1932).

Minot considered that senescence was the direct outcome of cell differentiation, that differentiated cells, by reason of the changes undergone, chiefly by their cytoplasm, in the course of morphogenesis, had become largely incapable of growth or repair. He believed that the negative acceleration of specific growth, found in a very wide variety of organisms, and ultimate senescence, were products of this process, and that the first was a measure of the second. It followed from this that the rate of senescence, so defined, must actually be highest in embryonic life and in infancy, when the rate of differentiation is highest. Many of Minot's concepts, such as the rigid irreversibility of cell differentiation, echoed later by Warthin (1929), the incapacity of differentiated cells for growth, and the necessarily increasing liability to senescence of successive cell-generations, are now disproved or at least impugned. His work, however, leaves with us the two important concepts of a gradual process of senescence linked to morphogenesis, and of a relation between it and the decline of growth-potential. By using negative growth acceleration and rate of differentiation as a direct measure of senescence, Minot arrived at the conclusion that the rate of senescence is highest in foetal, and least in adult, life. This concept has been widely adopted. Its validity depends upon the acceptance of Minot's definition; if senescence be regarded, as we shall regard it, in terms of deteriorative change in the organism's power of resistance, the idea requires qualification.

A far more important question, which had been latent in the literature since Ray Lankester (1870) pointed to the apparent non-senescence of fish, was raised by Bidder (1932). With the exception of Metchnikoff $(1904,1907)$ who was attempting to relate longevity to the form of the digestive tract, very nearly all biological theorists had assumed that senescence occurs in all vertebrates. This may in fact be so, but if it is not, then manifestly the general theories of senescence based on degree of tissue differentiation, irreplaceability of neurones, and other such systems fall to the ground. Bidder pointed out that there were several lower vertebrates in which there was no ground for suspecting that the mortality ever increased with increasing 


\section{The Biology of Senescence}

age, beyond the inevitable increment from accumulation of evident injuries. He suggested that vertebrate senescence is a correlate of the evolution of determinate growth and of a final absolute size. Bidder regarded determinate size as a property which had evolved as a result of the migration of vertebrates to dry land. $\mathrm{He}$ pointed to a number of instances in fish where constant expectation of life, capacity for growth, and general vigour appeared to persist indefinitely (Bidder 1925). Bidder's argument is of importance, and is worth quoting in full.

'Giant trees, cultures of chick cells and of Paramecium, measurements of plaice and of sponges, all indicate that indefinite grow this natural. Galileo proved it fatal to swiftly moving land animals, therefore swiftly moving mammals and birds were impossible until their ancestors had evolved a mechanism for maintaining specific size within an error not impairing adequate efficiency. Even without evidence of evergrowing organisms, we could not suppose that the close correspondence to specific size, which we see in all swiftly moving creatures of earth or air, results from mere "senescent" fading-out of the zygotic impulse to cell division and cell increase. Specific size is probably most important to birds, with their aeroplane mechanics strictly enjoining conformity of scale to plan; but to men it is most noticeable in man. Only familiarity prevents marvel at the rarity of meeting a man more than 20 per cent taller or shorter than $5 \frac{1}{2} \mathrm{ft}$., or of discovering his remains in any place, or any race, or any epoch. Probably our erect posture enforces accurate proportions of length to weight, for running.

'Adequate efficiency could only be obtained by the evolution of some mechanism to stop natural growth so soon as specific size is reached. This mechanism may be called the regulator, avoiding the word "inhibitor" so as not to connote a physiological assumption. However ignorant we are of its nature, its action is traced in anthropometric statistics; a steady diminution in growth rate from a maximum at puberty to a vanishingpoint in the twenties. That the regulator works through change in the constitution of the blood is shown by the perpetual division of Carrell's chick cells in embryonic plasma, whereas cell division is ended in the heart of a hen. 


\section{Introductory and Historical}

'I have suggested that senescence is the result of the continued action of the regulator after growth is stopped. The regulator does efficiently all that concerns the welfare of the species. Man is within $2 \mathrm{~cm}$. of the same height between 18 and 60 , he gently rises $2 \mathrm{~cm}$. between 20 and 27, and still more gently loses $1 \mathrm{~cm}$. by 40 or thereabouts. If primitive man at 18 begat a son, the species had no more need of him by 37 , when his son could hunt for food for the grandchildren. Therefore the dwindling of cartilage, muscle and nerve cell, which we call senescence, did not affect the survival of the species, the checking of growth had secured that by ensuring a perfect physique between 20 and 40 . Effects of continued negative growth after 37 were of indifference to the race; probably no man ever reached 60 years old until language attained such importance in the equipment of the species that long experience became valuable in a man who could neither fight nor hunt. This negative growth is not the manifestation of a weakness inherent in protoplasm or characteristic of nucleated cells; it is the unimportant by-product of a regulating mechanism necessary to the survival of swiftly moving land animals, a mechanism evolved by selection and survival as have been evolved the jointing of mammalian limbs, and with similar perfection' (Bidder, 1932).

Bidder's theory, besides raising the question of senescence as an effect lying outside the 'programme' imposed by natural selection, poses the highly important suggestion that there may be two categories of vertebrates-those whose life span is fixed as in mammals, and those whose life-span is not fixed. From the theoretical point of view the establishment of the truth or falsity of this suggestion might be the key problem in the elucidation of mammalian ageing, since the disproof of almost all the major existing theories of senescence would follow from the demonstration that it is not universally present in vertebrates. This might appear a simple issue of fact, but for reasons which will appear later, no such demonstration one way or the other has yet been forthcoming.

Bidder's theory marks the last major attempt to produce a hypothesis of vertebrate senescence. No significant theory of 


\section{The Biology of Senescence}

the general biology of ageing has appeared since, although its evolutionary basis has been discussed (Haldane, 1941; Medawar, 1952). The decline in abstract speculation about old age is probably in itself a very good augury for research. Much of the previous published matter abundantly justified the view of Bacon that 'the method of discovery and proof whereby the most general principles are first established, and then intermediate axioms are tried and proved by them, is the parent of error and the curse of all science'.

In later work, the relation between growth-cessation and ageing has been generalized to cover the senescence of all kinds of organisms which have a fixed life span, such as the rotifers (Lansing, 1947a) in which the mechanism of ageing may be, and very probably is, quite unlike that which occurs in vertebrates. The real importance of Bidder's suggestions lies, however, in the possibility they indicate that mammalian senescence may be a close evolutionary correlate of certain investigable mechanisms, such as homoeothermy, which have evolved with it. The probing of this possibility belongs to the future. 


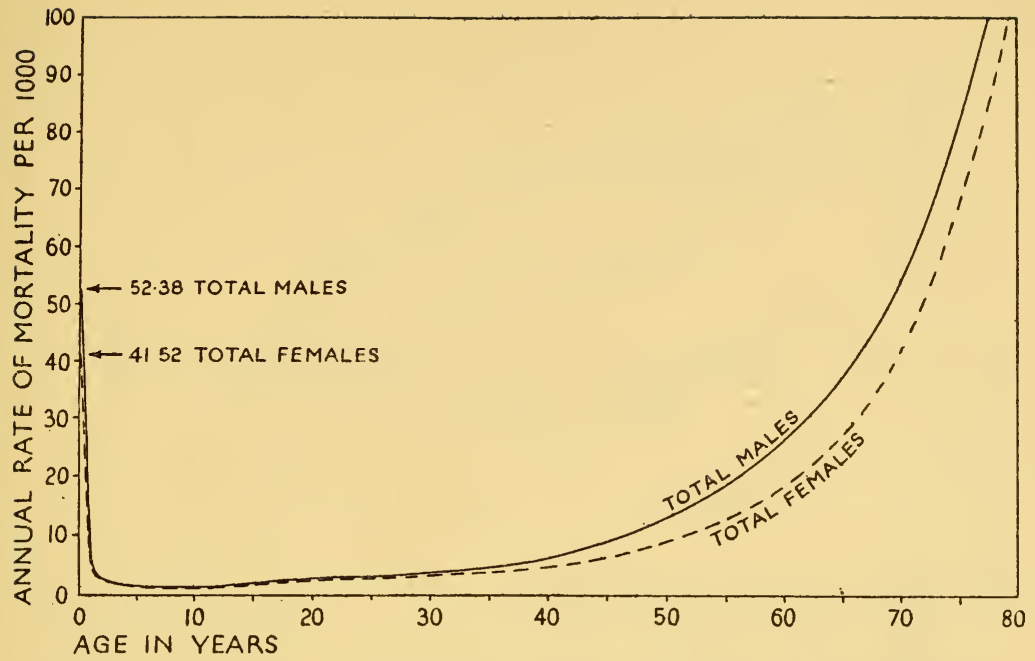

Fig. 1.-Annual rate of mortality per 1,000 by sex: United States, 1939-41.

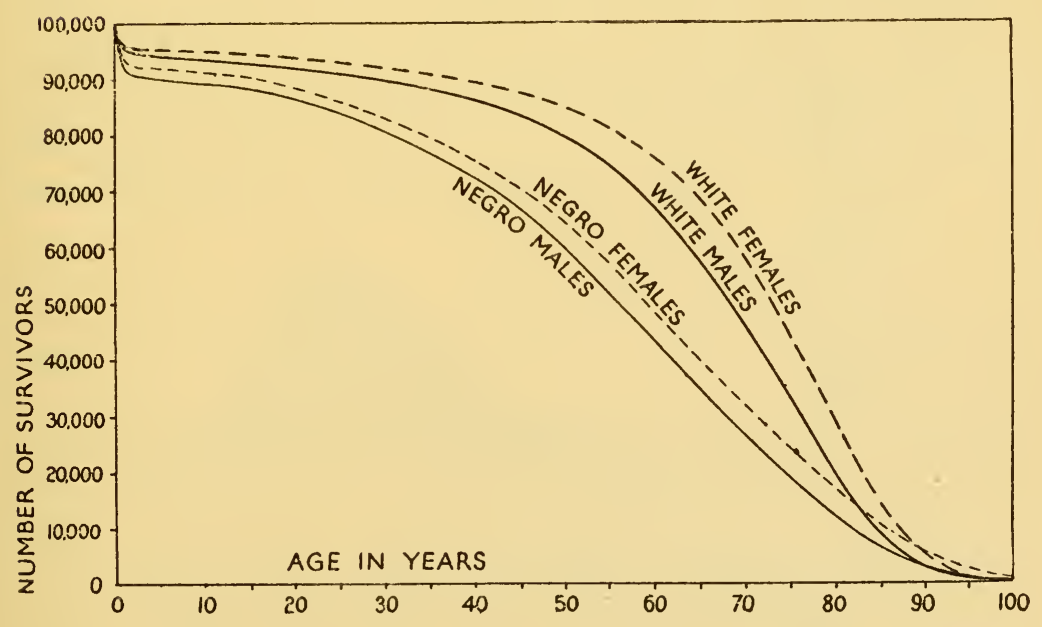

Fig. 2.-Number of survivors out of 100,000 born alive, for each race by sex: United States, 1939-41. 


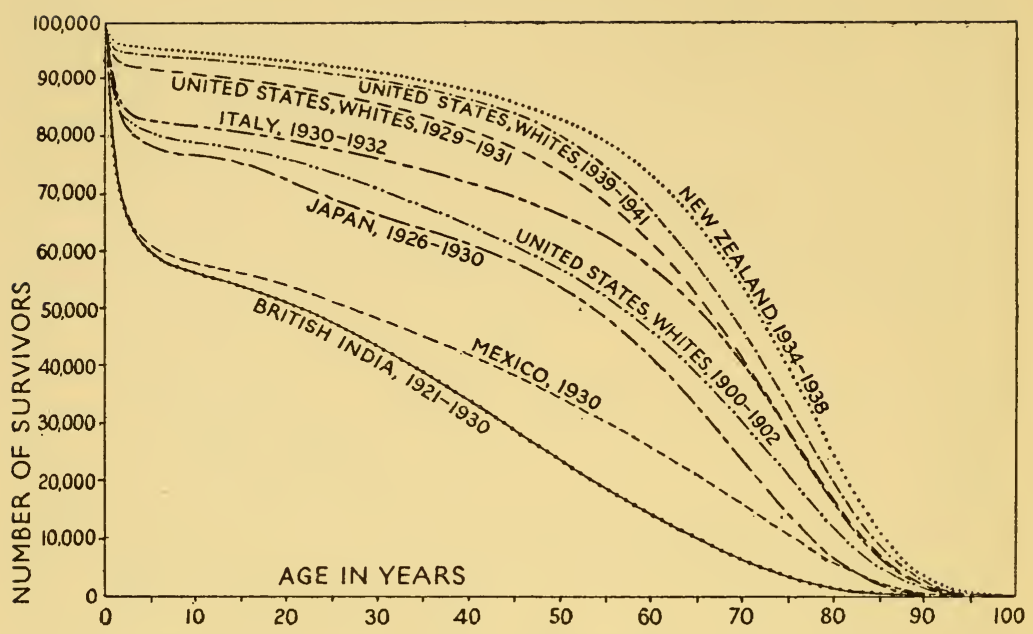

Fig. 3.-Number of Survivors out of 100,000 male live births, from recent life-tables for selected countries.

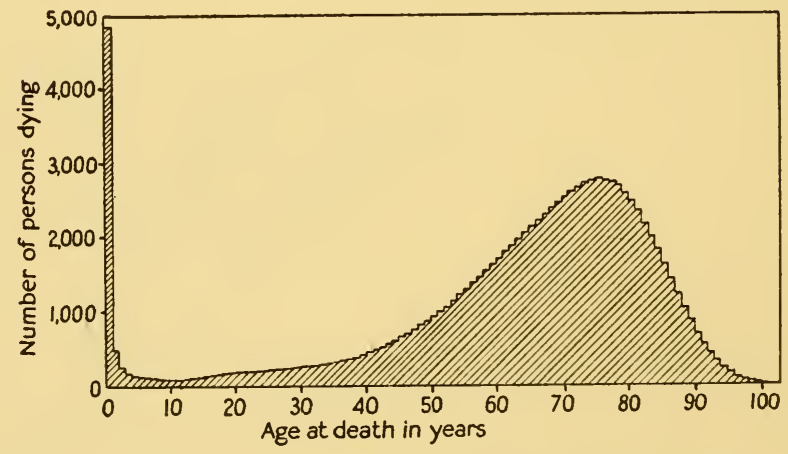

Fig. 4.-Frequency distribution of ages at death in a cohort starting with 100,000 live births, based on the mortality of white males: United States, 1939-41. 


\section{$\sim 1 \sim$}

\section{THE NATURE AND GRITERIA OF SENESGENGE}

\subsection{Measurement of Senescence}

Senescence is a deteriorative process. What is being measured, when we measure it, is a decrease in viability and an increase in vulnerability. Other definitions are possible, but they tend to ignore the raison d'etre of human and scientific concern with age processes. Senescence shows itself as an increasing probability of death with increasing chronological age: the study of senescence is the study of the group of processes, different in different organisms, which lead to this increase in vulnerability.

The probability that an individual organism which has survived to time $x$ will die before time $x+1$ depends on the rate of mortality $(q)$ per 1000 , meaning the number, out of 1000 individuals living at time $x$, who have died by time $x+1$. The force of mortality $(\mu)$ is given at any age $x$ by

$$
\mu_{x}=-n^{-1} \frac{d n}{d x}=\frac{-d}{d x} \ln . n
$$

where $n$ is the number of individuals which have survived to age $x$.

In most organisms, the likelihood of dying within a given period undergoes fluctuations, often large, throughout the life cycle. Senescence appears as a progressive increase throughout life, or after a given stadium, in the likelihood that a given individual will die, during the next succeeding unit of time, from randomly-distributed causes; the pressure of the environment, which it has successfully withstood in the past, it now ceases to be able to withstand, even though that pressure is not increased. It is rare that we can determine the vulnerability of 


\section{The Biology of Senescence}

an individual. Our estimate of it is determined statistically, upon a population. The demonstration of such an increase in vulnerability is a necessary condition for demonstrating senescence: it is, obviously, only a sufficient condition if selective mortality from age-distributed external causes is ruled out. Real populations are subject to mortality both from random and from age-distributed causes - the variation of exposure rate throughout life is familiar in man; grown men are subject to risks which do not affect children, and so on. Differences in 'risk' throughout life have been studied in some other animals, such as the locusts whose causes of death were analysed by Bodenheimer (1938) or the gall-fly Urophora (Varley, 1947). Pearson (1895), in his mathematical analysis of the curve of human survivorship into five components, attempted to limit the meaning of 'senile mortality' to one such component, reaching its maximum incidence between 70 and 75 years of age. This would be an ideal solution if it were practicable, but Pearson's analysis is artificial in the extreme, and his 'five separate Deaths' directing their fire at different age groups are not biologically identifiable. In general, however, a progressively increasing force of mortality and decreasing expectation of life in a population, if significant variation in exposure rate can be excluded, is evidence of the senescence of its individual members. The preliminary test for senescence in an animal species depends, therefore, on the life-table of an adequate population sample, studied with suitable precautions against selective causes of death.

The expected differences in behaviour, and form of life-table, between populations which age and which do not age are shown in Figs. $5 a, b$. In a population not subject to senescence and exposed only to random overall mortality, the decline of numbers is logarithmic, and animals die, ex hypothesi, from causes which would have killed them at any age. In a population exposed only to death from reduced resistance, due to senescence, the curve approaches a rectangular form: after a certain age, animals die from causes which would not have killed them in youth. In one case the force of mortality is constant, in the second it rises steadily with age. Thus in rats the force of mortality rises after the ninth month of life in a geo- 


\section{The Nature and Criteria of Senescence}

metrical progression (Wiesner and Sheard, 1934). Real survival graphs are commonly intermediate in form between the two ideal contours. Pearl and Miner (1935) distinguished three main types of observed death-curve, varying in skewness from the nearly rectangular in organisms with a low standing deathrate throughout life, but showing a tendency to die almost simultaneously in old age, to the logarithmic decline characteristic of populations which show no senescence, or which die out before it can become evident (Fig. 6). A fourth theoretical type, in which the curve is rectangular but inverse to that

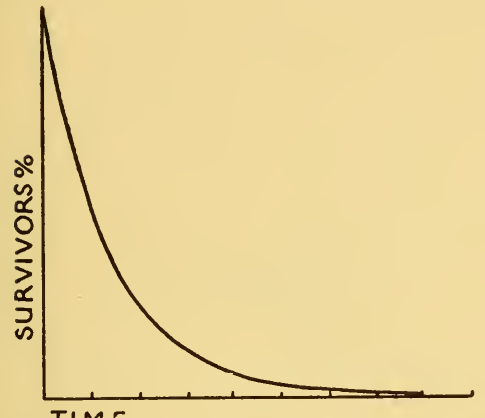

TIME

Fig. 5. (a)-Survival curve at a constant rate of mortality (50 per cent per unit time).

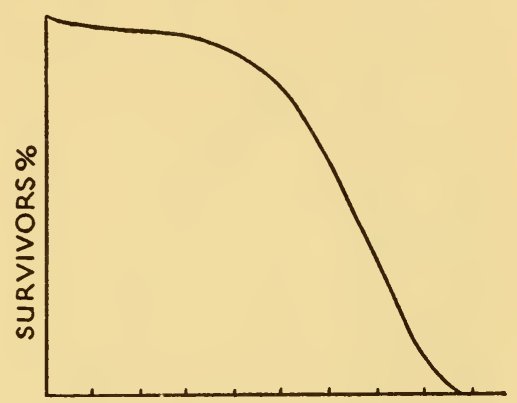

TIME

Fig. 5 (b).--Survival curve of a population which exhibits senescence.

found in the ideal senescent population, was recognized by Pearl (1940) as a theoretical possibility; it seems to be realized in nature among organisms which have a high infant mortality, but whose expectation of life increases over a long period with increasing age. This pattern of survival is characteristic of some trees (Szabó, 1931) but probably also occurs in animals. 'There may be animals in which the expectation of life increases continuously with age. This may be so for many fish under natural conditions. It certainly goes on increasing for a considerable time. Thus in a species where the expectation of life was equal to the age, or better, to the age plus one week, no members would live for ever, but a small fraction would live for a very long time. A centenarian aware of the facts would pity a child, with an expectation of life of only a few years, but would envy a bicentenarian' (Haldane, 1953). 


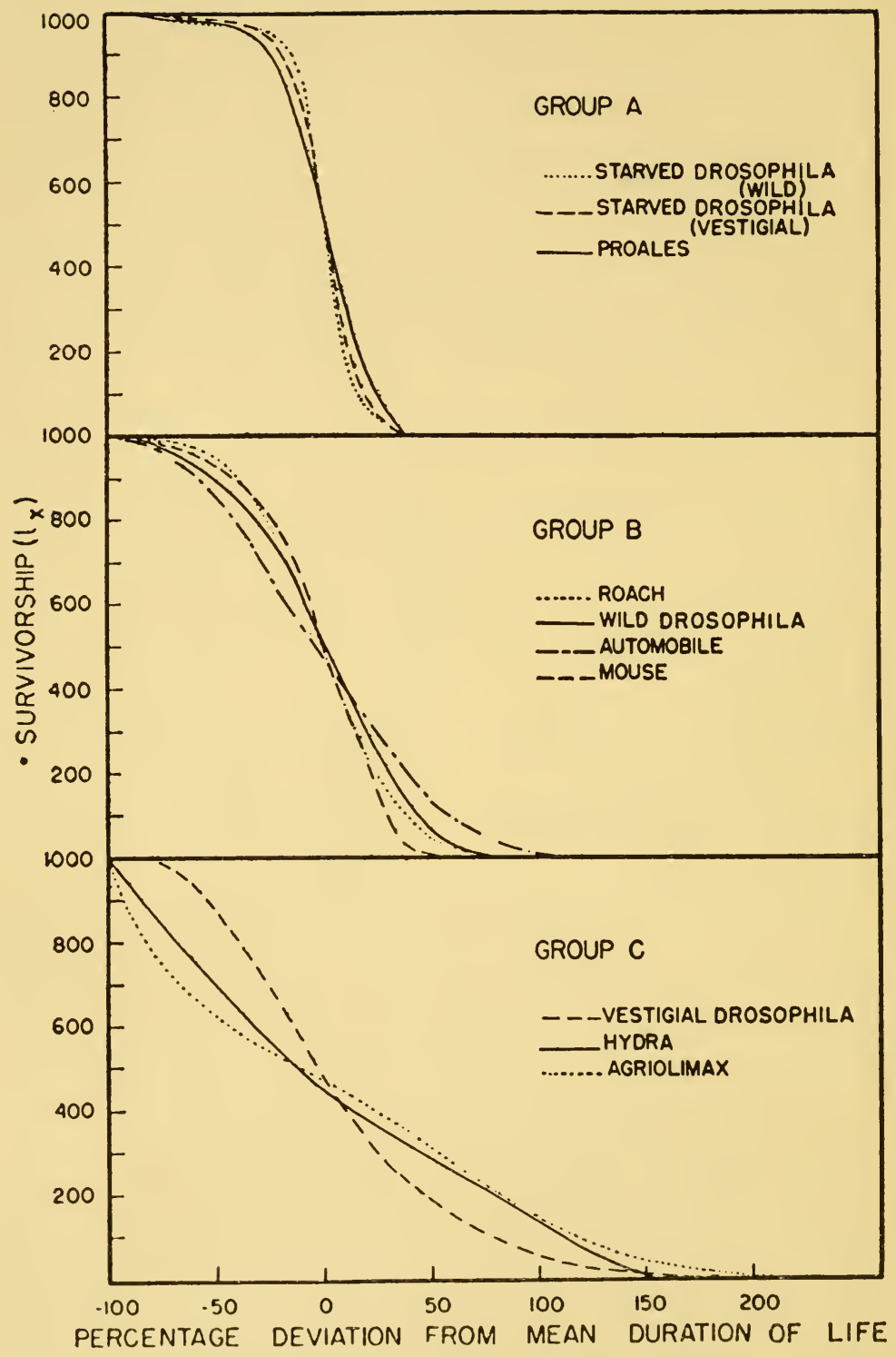

FIG. 6.-Types of survival curve (from Pearl, after Allee et al., 1949). 


\section{The Nature and Criteria of Senescence}

Some real animal populations decline in an approximately logarithmic manner. The 'potential immortality' of individuals in a population following such a path of decline, an entirely meaningless phrase which has caused much philosophical agitation in the past, is not more significant as a practical issue than the 'potential' meeting of any pair of railway metals at infinity. No population of organisms which is subject to a constant overall death-rate contains 'potentially' immortal individuals. The only advantage which a non-senescent orgarism possesses over senescent forms is that the odds in favour of its death within a fixed period remain constant instead of shortening with the passage of time.

The human survival curve, in societies possessing developed medical services and a high standard of living, is intermediate between the rectangular and log-linear contours, but approaches the rectangular, with an initial decline due to infant mortality. Figs. 1-3 and 7 show, first, the comparative curves of mortality for populations in the present century living under different conditions of economic and climatic advantage, and second, the change in form of the life-table for North German populations between 1787 and 1800. Many life-tables for populations before the advent of scientific medicine are given by Dublin (1949). The significance of technical and economic privilege is nowhere more evident than in the study of life-tables. The effects of public health upon the life-table are expressed rather in making it approach more closely to the rectangular shape than in prolonging the preinflectional part of the rectangle. In very many organisms, and in man under bad social and medical conditions, the infant mortality is so large as to obscure all subsequent trends, the curve coming to imitate Pearl's fourth, inverse rectangular, type (Fig. 6). The terminal increase in liability to die may also be masked by cyclical variations in mortality associated with breeding or wintering, but the presence of such an increase remains an essential requisite for the demonstration of senescence in an organism. In many senescent populations, such as the sheep and cavies in Figs. 11 and 12, the survival curve in adult life is not so much rectangular as arith-linear, a constant number of individuals dying during each unit of time, the mortality necessarily decreasing as the supply 


\section{The Biology of Senescence}

of animals decreases, like the companions of Odysseus of whom Polyphemus ate a fixed number daily.

The breakage rate of crockery or glasswear has sometimes been used to illustrate the decline of a non-senescent population (e.g. Medawar, 1952). A life-table for tumblers was actually

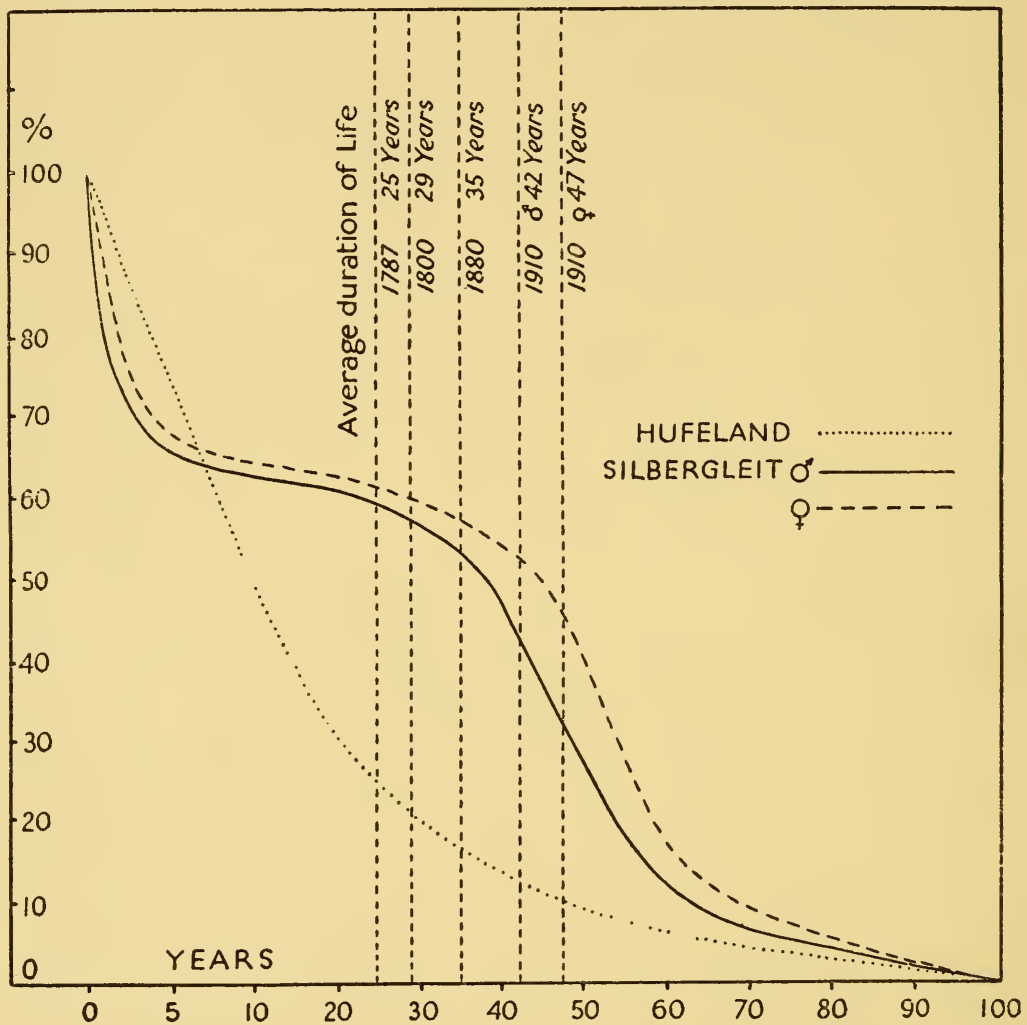

Fig. 7.- Survival curves of a German population. Hufeland's table (1798) is based on 'experience' and estimates. Silbergleit's data are based on official statistics as given in the Deutschen Statistischen Fahrbuch for 1915. Both sets of data relate to N. Germany (From Vischer, 1947)

constructed by Brown and Flood (1947) - that for annealed tumblers approaches the curve of constant mortality, though only roughly; while the decline of a smaller group of toughened glass tumblers was nearly arith-linear (Fig. 8). Senescence, however, does apparently occur in tumblers, since abrasions of 


\section{The Nature and Criteria of Senescence}

the lip make subsequent cracking more likely (Brown and Flood, 1947).

It is convenient to treat survival curves such as those of man
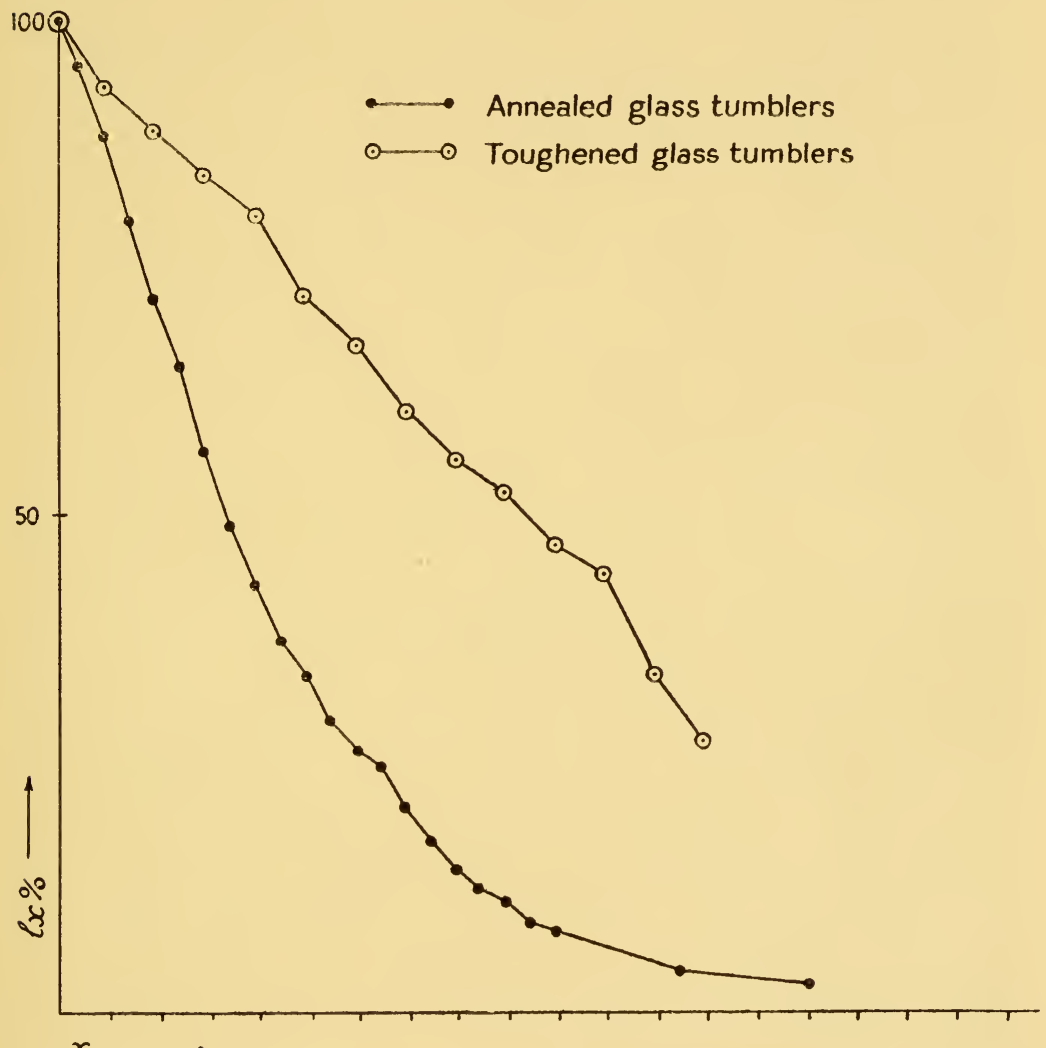

Frg. 8.-Survival curves for cafeteria tumblers.

$$
\begin{aligned}
& A=549 \text { annealed glass tumblers }- \\
& B=241 \text { toughened glass tumblers } \odot-\odot
\end{aligned}
$$

Time: 1 scale division $=2$ weeks for Curve A, 5 weeks for curve B.

(Drawn from the data of Brown and Flood, 1947)

or Drosophila as combinations of the log-linear 'environmental' curve, found where the standing death-rate is high, with a terminal rectangular decline due to senescence, since it is evident that not all those individuals who die in middle life 


\section{The Biology of Senescence}

owe any part of their misfortune to the senile increase in vulnerability, however early in life this is taken to begin.

Bodenheimer (1938) draws a useful distinction between the 'physiological' longevity of a species - that attained under optimal conditions in a genetically homogeneous population and approaching the longest recorded life-span within the species; and the 'ecological' longevity, which is the mean longevity observed empirically under given conditions. The ideal rectangular 'physiological' curve postulated by Bodenheimer is a convenient abstraction, at most, since the genetic and environmental conditions laid down for it cannot in practice be obtained in any real population. But in some forms the observed life-table in laboratory culture or domestication approximates to the ideal rectangular form, and this approximation is closest of all in some human societies. It is, however, pointless in terms of the actuarial definition of senescence to pursue a 'physiological' as opposed to a 'pathological' senescence in most laboratory animals. If senescence is measured as increased general vulnerability, Bodenheimer's 'physiological' longevity represents only the approximate region in which the rise in the curve of vulnerability to all assaults of the environment becomes so steep that even major protection against such assaults is insufficient to prolong life very greatly. The pattern can be modified and the apparent physiological longevity increased by removing specific causes of death-e.g. enteritis and ear disease in old rats (Korenchevsky, 1949) but the postponement of death obtainable in this way is itself limited, and argument about 'natural' death, apart from pathological processes, in mammals is quite otiose.

It is manifestly impossible to demonstrate senescence from life-tables unless the mortality in early and adult life is sufficiently low, and the number of animals reaching old age is therefore sufficiently high, for an endogenous increase in susceptibility to death-producing factors of random incidence to be evident. Thus wild mice die at a rate which precludes their reaching old age, but mice kept under laboratory conditions have a life-table similar to that of Western European human populations in the year 1900 (Leslie and Ranson, 1940, Fig. 30, p. 109 ; Haldane, 1953) : not even the most cherished labor- 
atory population can receive as detailed medical attention as civilized man, but if such were possible, the life-table of mice might then approach that for Western European man in 1953.

Organisms which undergo senescence, as judged by the lifetable, also exhibit specific age, meaning an age at death which is characteristic of the species when living under conditions approaching Bodenheimer's 'physiological' conditions.

Some of the limitations of the statistical definition of senescence have recently been re-stated by Medawar (1952). It is obvious that any survival curve can be simulated by judicious, or injudicious, choice of material. Tables based only on age at death, a single arbitrary event, are open to serious criticism if they are used as indices of a continuous process of declining vitality. The shape of such a curve is a measure of many things, including the genetic homogeneity of the sample. The incidence of various risks itself varies between age groups: the statistical appearance of senescence would, for example, be found in the life-table of any population of fish which was subject to frequent fishing with a net of fixed mesh size. Selective predation certainly produces effects of this kind of nature. The increased force of mortality among men of military age during a war is not a manifestation of senescence. On the other hand, some causes of mortality, such as cancer (Rutgers, 1953), have a curve of incidence which parallels the total curve of mortality. In employing the force of mortality as an index of senescence it is essential, as we have seen, to exclude so far as possible external factors which are not of random incidence in relation to age, yet this cannot be done with strict logical consistency. In the case of human life-tables, large secular changes in cause and incidence of death may occur within an individual life-span, while constitutional differences in rate of senescence between individuals ensure that the genetical composition of the survivors at, say, age 60 , is not representative of the whole cohort under study. These sources of error are, in fact, capable of avoidance or correction for most practical purposes, but they must always be recognized in inferring senescence from any life-table.

Since there is no direct way of measuring the liability of an 


\section{The Biology of Senescence}

individual to die without actually killing it, the statistical definition of senescence, although it reflects a real process in individuals, can only be tested upon a population.

It is evident that in applied biology, and especially in medicine, it is desirable to be able to infer not only the existence of senescence in a species but the degree of senile change in a given individual. This estimate must be based on secondary criteria, and can be made with accuracy only in forms whose life-cycle, like that of man or of Drosophila, has been subject to intensive study. The importance of the statistical definition of senescence is that it implies an obligatory recourse to adequate population studies. An over-common practice has been to keep a single specimen, a bird or a bullfrog, for ten or twenty years, and, when it is found dead, having been so for hours or possibly days, to describe histological appearances in its tissues in a note entitled 'Senile change in the nervous system of Passer (or Bufo)'. While senescence cannot be inferred from every life-table in which the force of mortality rises, neither can descriptions of 'senile' changes be properly based on single observations upon supposedly ageing organisms belonging to groups whose life-cycle, in relation to senescence, is not fully known.

In practice, other criteria than the life-table can be applied to organisms whose life-cycle is familiar, as secondary indices of senescence; these are distinct from mere measures of chronological age, based upon the morphology of scales, teeth or otoliths. Certain factors which are, in effect, direct measures of vigour or of vulnerability, such as the mortality from burns, (Ball and Squire, 1949), or even the annual absenteeism from sickness (Schlomka and Kersten, 1952) follow the general force of mortality in man. The supposed decline in the rate of wound healing proposed as a measure of senescence by du Noüy (1932) was based on grossly inadequate clinical material and is not supported by later work (Bourlière 1950). Less general criteria such as skin elasticity in man (Evans, Cowdry and Nielson, 1943; Kirk and Kvorning, 1949), organ weight and relative organ hyporplasia in rats (Korenchevsky, 1942; 1949), heart rate in Cladocerans (Ingle, Wood and Banta, 1937, Fig. 39, p. 146), milk yields in cattle (Brody, Ragsdale and Turner, 1923), egg production in fowls (Clark, 1940, Fig. 14, p. 63), 


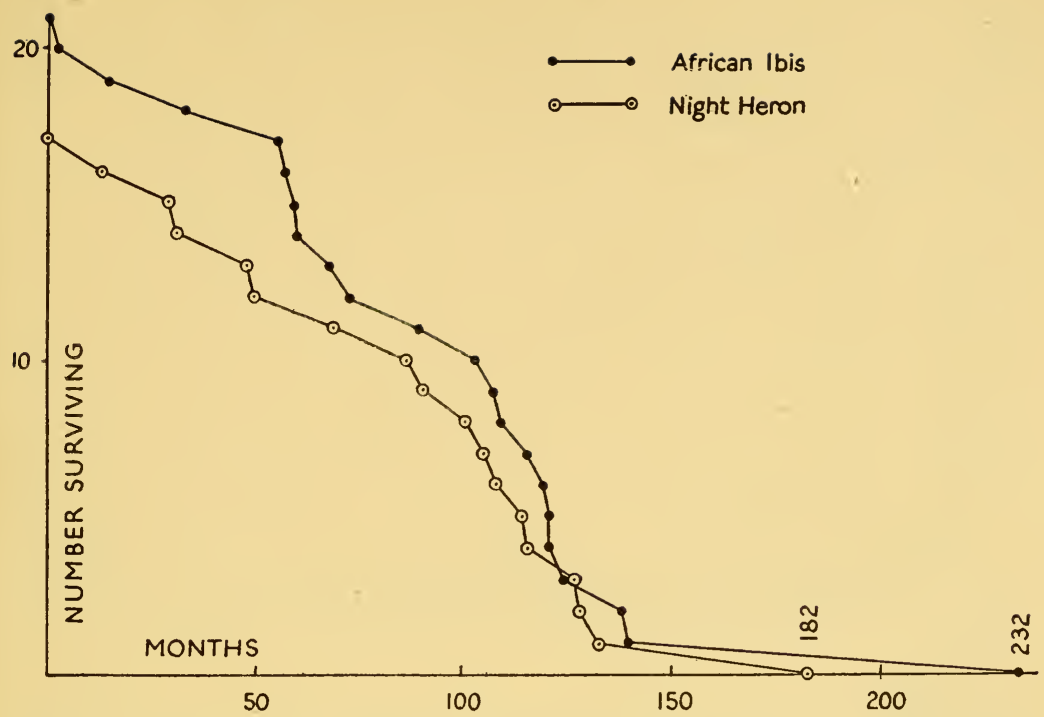

FIG. 9.-African Ibis (Threskiornis aethiopicus). Survival of 21 individualssexes combined (London Zoo)

Night Heron (Nycticorax nycticorax). Survival of 17 individuals-sexes combined (London Zoo) $\odot-\odot$.

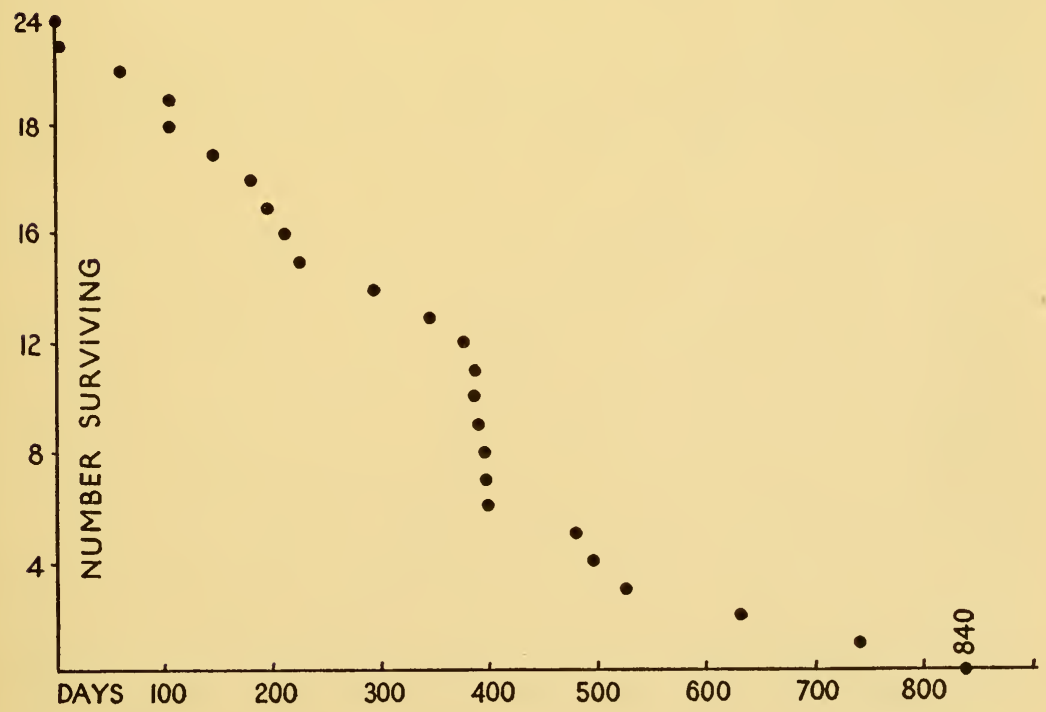

FIG. 10.-Orkney Vole (Microtus orcadensis). Survival of 24 individualssexes combined (London Zoo). 


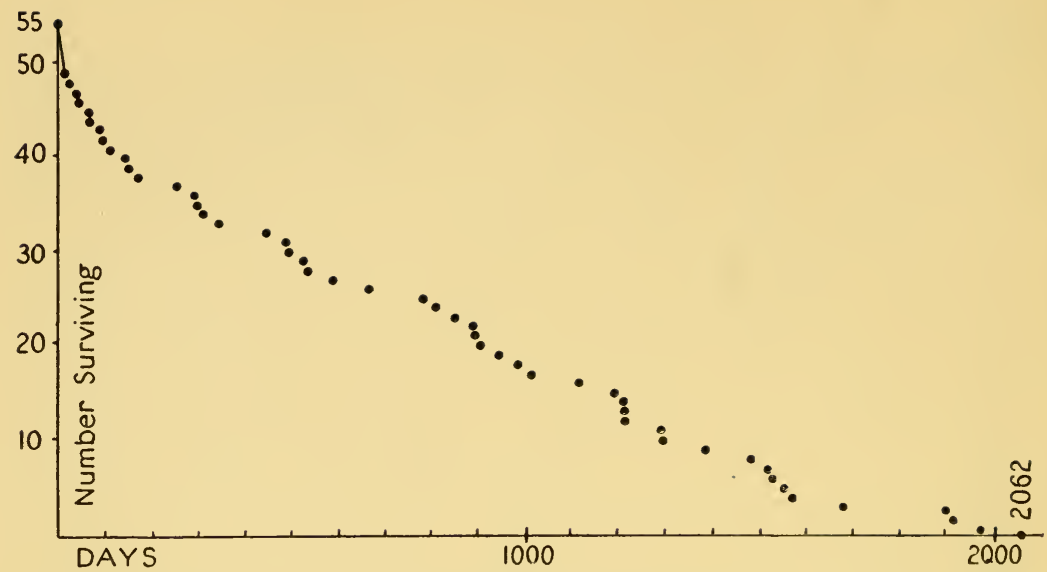

FIG. 11.-Patagonian Cavy (Dolichotis patagona). Survival of 55 individuals - sexes combined (London Zoo).

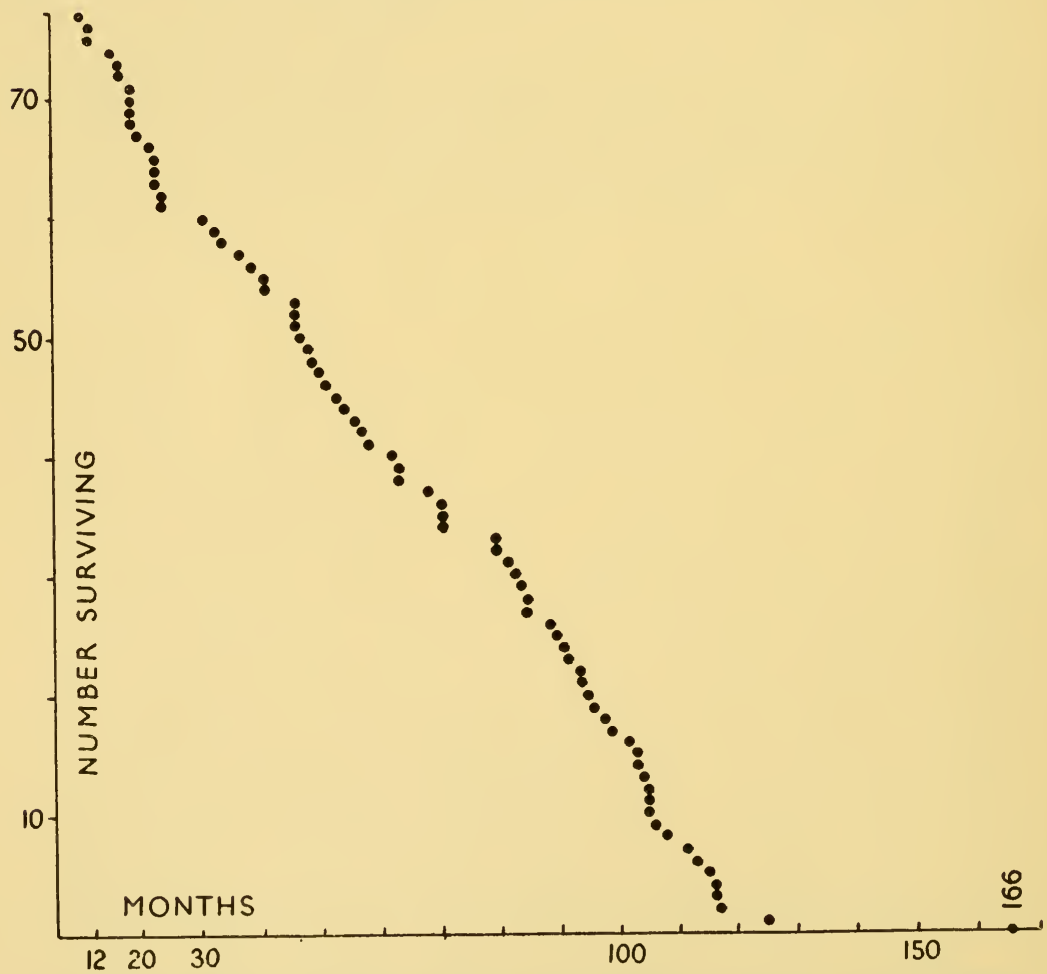

Fig. 12.-Mouflon Sheep (Ovis musimon). Survival of 77 individuals, beginning at 12 months-sexes combined (London Zoo). 


\section{The Nature and Criteria of Senescence}

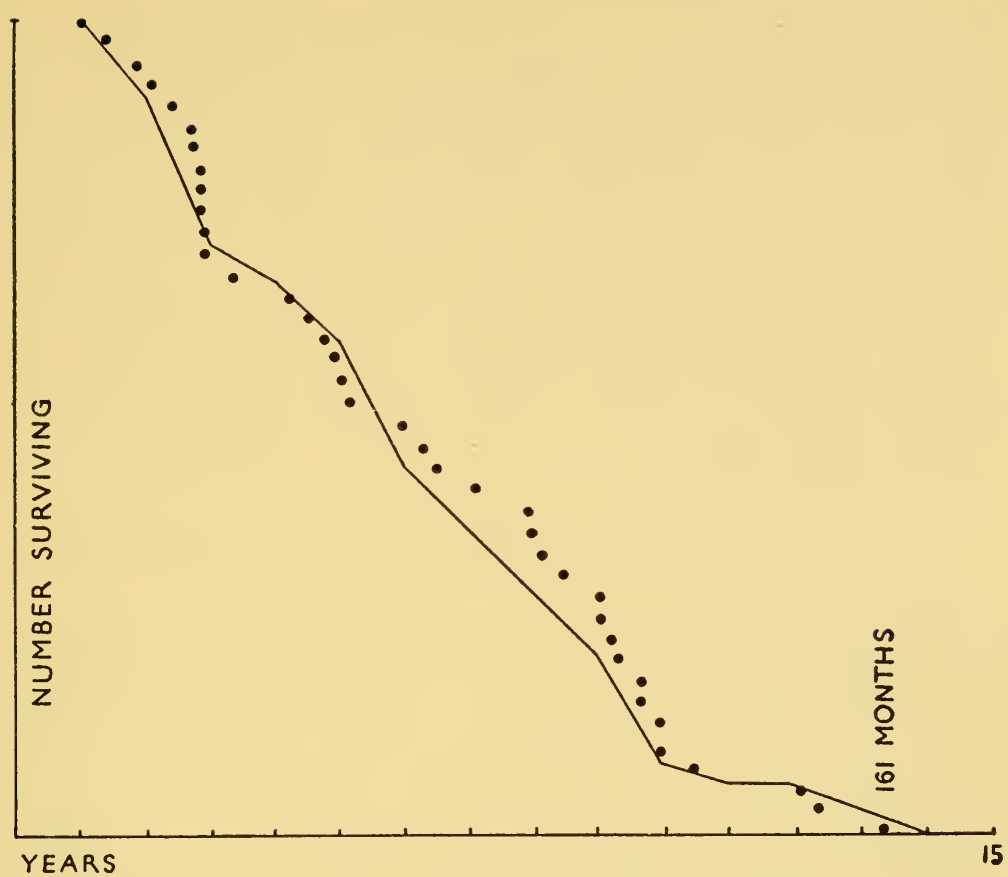

Frg. 13.--Irish Wolfhounds. Survival of 67 individuals from 12 months of age-sexes combined. Line-whole sample, annual totals. Points-38 individuals whose exact date of death was known, to scale (data from Miss D. Gardner).

histological appearances of many kinds, and estimations of general or special metabolism are of value within sharplydefined limits, but all are subject to considerable variation apart from the general senile process. In retarded Cladocera, for example, where mean life-span is artificially prolonged by postponing growth, the heart rate fails to decline before death to the low levels normally found in old age (Ingle, Wood and Banta, 1937). Minot (1908), Hertwig and others considered that a steady decrease in the nucleocytoplasmic ratio was a general feature of ageing in organisms, a suggestion which has not been upheld by later work, and which would today require translation into more precise biochemical terms. Dehydration was also formerly regarded as a general senile phenomenon. From a recalculation of older data, however, and from fresh material, 


\section{The Biology of Senescence}

Lowry and Hastings (1952) find that increased hydration, due perhaps to extracellular oedema, loss of cells, and even gross pathological causes such as heart failure, is the most consistent finding in senile mammalian tissue. There is at present no biochemical sign characteristic of 'oldness' in tissues or in cells, and the search for one may well reflect a fundamental misconception. It is in assessing the relevance of all such criteria to the main phenomenon of senescence, the decline in resistance to random stresses, that the statistical approach is essential. Ail assertions about senescence based upon pathological anatomy, or upon general theories which treat it as a single process, are open to question.

The decline of growth rate throughout life in some or all tissues appears to be a near-universal feature of metazoa.

'The specific growth rate always falls: living tissue progressively loses the power to reproduce itself at the rate at which it was formed. Minot arrived at this generalization, which should rightly be known as "Minot's Law", from the collation of his percentage growth-rate curves; and it was he who first recognized that the point of inflection of the integral curve of growth, and the division it makes between a period of positive and negative acceleration, is not of critical importance. The progressive dissipation of "growth energy" which this first law affirms was thought by Minot to be an expression of the phenomenon of senescence- "ageing" with its everyday implications. Senescence is not, in this view, a process which sets in after a preliminary period of maturation has run its course: senescence is development, looked at from the other end of life' (Medawar, 1945b).

The use of this criterion, which is a readily measurable one, and can be applied to smallish groups of animals with suitable precautions, as well as to single tissues or organs, implies the acceptance of Minot's definition of senescence. The definition is defensible. On the other hand, one of the important points at issue at the present moment is precisely whether all animals which show a decline in the specific growth rate-all vertebrates, and almost all invertebrates-display pari passu an ultimate increase in mortality either as a result of this process, or 


\section{The Nature and Criteria of Senescence}

as a result of some factor which also causes that decline. The decline is not a measure of senescence in its actuarial sense, since it does not run parallel with the force of mortality, and it would not be even an obligatory precursor of senescence if mortality only increased with age in those animals whose capacity for renewal or growth in some or all tissues has fallen to zero. It is with actuarial, deteriorative senescence that we are here concerned-if senility implied only the decline of growth rate in man, it would cause little public concern.

It is possible that future work will produce a workable and justifiable 'direct measure' of senescence in individuals, based on the time-lag in cell-division of tissue explants derived from old animals (Cohn and Murray, 1925; Suzuki, 1926; Medawar, 1940). No practical test of this kind has yet been developed, however-meanwhile the critical observations on the distribution of senescence in vertebrates have almost all to be made upon organisms (large fish, crocodiles, tortoises) where lifetable studies are out of the question. In these forms it is relatively easy to observe histologically or by a mating test, the degree of reproductive power persisting in individuals of known age. Inferences based on 'reproductive' senescence are therefore easy to draw, compared with the insuperable difficulties involved in measuring the force of mortality in such cases.

Reproductive decline is a very general feature of those vertebrates which undergo senescence as judged by the increasing force of mortality: its evidences in various forms include gonadal changes, loss of secondary sexual characters, cessation of ovarian cycles, and a fall in sperm production, fertilizing power, hatchability, litter size and viability. These changes follow a time scale which is different from that of the increase in force of mortality, however, and which bears no constant relation to that increase in different species. The gonad often appears to behave as an 'organism' having its own determinate life-span, but this is equally true of other structures, such as the thymus. The limited life of the gonad is in a special category only because, in terms of evolutionary teleology, the gonad is the significant part of the organism. Ageing of the whole organism after a prolonged post-reproductive period is a process which is realized only by human interference, at least so far as most 


\section{The Biology of Senescence}

species are concerned, and not 'envisaged' by evolutionary teleology. It could be argued that once gonadal senescence has become established in a species, eventual somatic senescence is a rule inevitable from the withdrawal in post-reproductive life of the selection-pressure towards homoeostasis. A clear physiological link between the activity of the gonad and the growth and survival of the animal has been demonstrated in a few forms (e.g. Daphnia, Edlén, 1937, 1938), although even in Daphnia, oogenesis continues until death (Schulze-Röbbecke 1951). In many vertebrates, however, even total castration has little or no adverse effect on longevity, and may increase it. Although senescence of the gonad is, in an evolutionary sense, the most important form of ageing, it is not self-evident that in the artificially-protected animal it must always be followed by generalized somatic senescence, unless the two processes are causally related. Such an identification reflects, once more, a human preoccupation. Reproductive function, because of its ease of measurement, remains at most a justifiable test of continuing vitality in old animals-fertility at least indicating the absence of irreversible organ changes in one important system.

Metabolic decline, either measured directly by calorimetry and manometry, or inferred from reduction in spontaneous activity, has also been regarded as an index of senescence-often on theoretical grounds, as representing the accumulation of inactive 'metaplasm' at the expense of active protoplasm (Kassowitz, 1899, etc.) or the completion of a 'monomolecular autocatalytic reaction' such as that postulated by Robertson (1923) or Bertalanffy (1941). The decline of heart rate in Cladocerans (Ingle, Wood and Banta, 1937) has already been mentioned. The mean resting heart rate in man also tends to decline throughout foetal and postnatal life. Child measured the age of hydromedusae by the decline in their rate of pulsation (Child, 1918). In some invertebrates (planarians, Child, 1915; hydromedusae, Child, 1918; molluscan adductor muscle, Hopkins, 1924, 1930) and in some isolated vertebrate tissues (articular cartilages, Rosenthal, Bowie and Wagoner, 1940, 1941, 1942; rat blood vessels, Lazovskaya, 1942, 1943; avian muscle, Glezina, 1939; rabbit muscle, Cheymol and Pelou, 1944; rat brain homogenate, Reiner, 1947; liver, kidney and heart homo- 


\section{The Nature and Criteria of Senescence}

genates, Pearce, 1936; mouse lymphoid tissue, Victor and Potter, 1935) $\mathrm{O}_{2}$ uptake has been reported to decline with age. Calorimetric experiments on the whole mammal indicate a general decline in heat production with increasing age (Sondén and Tigerstedt, 1895; Benedict and Root, 1934; Magnus-Levy and Falk, 1899; Shock, 1942, 1948; Benedict, 1935; Boothby et al., 1936; Kise and Ochi, 1934). This decline, however, like that of growth-energy, is greatest in early life, and relatively slight in man after the age of 50 (Shock, 1953). It does not parallel the senescent increase in mortality. There is also gross individual variation. Kunde and Norlund found (1927) no significant decrease in the basal metabolism of dogs up to 12 years of age. In rats, Benedict and Sherman (1937) found a slight decrease in heat production with increasing age, measured in the same individuals, but with the onset of senescence the body weight itself declined, so that the metabolism per unit body weight appeared to increase. In man $\mathrm{O}_{2}$ uptake per litre intracellular fluid shows no decrease with age (Shock, Watkin and Yiengst, 1954). A fuller bibliography is given by Shock (1951, 1953). It is not so far possible, in most organisms, to base intelligible estimates of individual senescence upon changes in metabolic rate.

\section{$1 \cdot 2$ Forms of senescence}

Increase in death-rate and decrease in resistance after a certain age might be expected in a number of model systems. The curve of failure rate for mechanical devices such as lamp bulbs, telephone switchboards (Kurtz and Winfrey, 1931), or radar units bears a superficial resemblance to the mortality curve of a senescent population, both in cases where all-or-none failure results from wear or from the passage of time (lamp filament failure, crystallization of metals, changes in condenser dielectrics) or where wear is cumulative and inefficiency increases to the point of failure (frictional wear, decline of cathode emission). The resemblance to biological senescence is closest in cases where several coincident processes ultimately become self-reinforcing. The 'death-rate' of motor-cars, plotted by Griffin (1928) and Pearl and Miner (1935) is closely similar to that of wild-type Drosophila (Fig. 6). 


\subsubsection{MECHANICAL SENESCENCE}

A few precise analogies to the failure of a non-replaceable part in a mechanical system are known to occur in organisms. Deterioration of the waxy epicuticle in insect imagines and of the teeth in the African elephant (Perry, 1953), the mongoose (Pearson and Baldwin, 1953), the shrew (Pearson, 1945; Pruitt, 1954) and some large carnivores are examples of strictly mechanical senescence. Such changes would ultimately kill the animal. Similar, though less obvious, mechanical changes may contribute to senescence in other forms. It is probable that the gradual loss of nephra in the mammalian kidney is an example of the incidental loss of essential structures, but one which rarely reaches the point of causing death per se. On the other hand, the differences between an old cart and an old horse are sufficiently striking to make the extensive acceptance of 'wear' as an explanation of senescence, and the resort to mechanical analogies based on the 'spontaneous slow decomposition' of explosives (Lepeschkin, 1931) or the behaviour of inanimate colloids (Rủžícká, 1924; Dhar, 1932) largely irrelevant. 'The old organism does not contain old colloids, it contains newlyformed colloids of an old character' (Lansing). The mean halflife of human protein is 80 days, of liver and serum proteins 10 days, and that of the carcase proteins 158 days (Bender, 1953). The continuation of high protein turnover in adult life has been demonstrated by isotope studies (Shemin and Rittenberg, 1944) though the turnover of materials such as collagen decreases almost to zero with increasing age (Perrone and Slack, 1952; Neuberger and Slack, 1953). The weakness of the 'colloidal' concept of ageing had been pointed out even before the discovery of colloids: 'Quoniam vero duplex est duratio corporum: altera in identitate simplici, altera per reparationem: quarum prima in inanimatis tantum obtinet, secunda in vegetabilibus et animalibus; et perficitur per alimentationem' (Hist. Vitae et Mortis). ${ }^{1}$

A chemical extension of the idea of 'mechanical' senescence

${ }^{1}$ Since there are in fact two ways in which bodies maintain their identity, the first, which applies only to inanimate objects, is simply by remaining the same. The second which applies to plants and animals, is by renewing themselves; and they do this by means of nourishment. 


\section{The Nature and Criteria of Senescence}

could be based more plausibly on the existence of expendable enzyme systems renewable only by cell division, to explain the ultimate death of some fixed postmitotic cells (Cowdry, 1952); this concept will be discussed later on. In all organisms except those which are capable of total regeneration, mechanical injury of a more general kind must accumulate with time, but this process will vary greatly in rate under different environmental conditions. The constancy of the specific age in forms which senesce is a strong argument against the primacy of 'mechanical' ageing.

\subsection{2 'ACCUMULATION' AND 'DEPLETION'}

In addition to a limited number of cases in which mechanical wear normally, or potentially, terminates an animal life-cycle, most of the other postulated 'causes' of senescence such as the accumulation of metabolites (Metchnikoff, 1915; Jickeli, 1902) and the exhaustion of stored irreplenishable reserves, do very probably contribute to senescence in specific instances. The very large literature of calcium and pigment accumulation in the cells of higher animals (reviewed by Lansing, 1951) deals with changes which are probably reversible consequences, rather than primary causes, of an underlying senile process. Lansing (1942) found, however, that reduction in the calcium content of the medium greatly increased the life-span of rotifers. A similar increase was produced by a single immersion in weak citrate solution. Accumulation of calcium with age was demonstrated in the same organisms by microincineration. Similar processes are described in plants (Molisch, 1938; Ahrens, 1938; Lansing, 1942). The 'life' of spermatozoa, though by no means analogous, has been shown to be prolonged by chelating agents which bind $\mathrm{Cu}^{++}$and $\mathrm{Zn}^{++}$(Tyler, 1953). In the case of the rotifer, at least, the evidence for an accumulative element in senescence is fairly strong.

Depletion certainly terminates the life-cycle of some non-feeding insect imagines, especially among Lepidoptera (Norris, 1934; Waloff, Norris and Broadhead, 1947), and possibly other types of imago (Krumbiegel, 1929a,b). Many animals die or become more vulnerable, as a result of the depletion or physiological derangement caused by spawning (Orton, 1929). The 


\section{The Biology of Senescence}

incidence of parental mortality in molluscs is reviewed by Pelseneer (1935). Attempts to explain the human menopause in terms of exhaustion of the supply of ova will be discussed later. There is no evidence of a 'depletive' senescence in mammals, unless the decline of growth rate be taken as evidence of the exhaustion of some hypothetical substance.

\subsubsection{MORPHOGENETIC SENESCENCE}

The accumulation of injuries presents no biological problem - it is readily observable in structures such as skin, and the only serious difficulty lies in assessing its contribution to ageing in particular structures or animal species.

But in addition to the processes of mechanical or metabolic senescence, and sometimes affecting the same organisms if they are protected from these, it is necessary to postulate a further, morphogenetic senescence to explain the sequence of events observed in many organisms. This senescence has been considered to arise directly from the operation of the processes of cell development which determine the shape and size characteristic of the species and of its organs either through changes in cell behaviour, or through the effects of divergent processes of heterogony; it expresses itself as a decline in the capacity to regenerate or maintain structures or conditions which, during growth and a post-growing period of variable duration, are normally regenerated and maintained. Morphogenetic senescence is a cumulative failure of homoeostasis, affecting the body as a whole, to which coincident or dependent mechanical failure or accumulative processes may contribute, but which appears to be continuous with the processes which control cell-differentiation and regulation. More accurately, it appears to represent the withdrawal of coordination between these processes, so that physiological homoeostasis 'falls apart'. It is this form of senescence which characterizes higher vertebrates and is particularly well seen in man. The chief evidence that this, morphogenetic, senescence is more that the 'sum of environmental insult' which was formerly invoked to explain it, is the existence in many organisms of specific age, analogous to specific size and possibly related to it, which displays little environmental, but marked inter-race and interspecific, variation. 


\section{The Nature and Criteria of Senescence}

Much information about the behaviour of self-restoring and self-regulating systems, and a number of important general concepts, are now available from the study of mechanical models. These analogies apply, strictly, only to the elucidation of single components of the process of maintaining physiological stability; the most important feature of 'cybernetics' and homoeostasis in the organism has no precise mechanical analogy. This is the fact that the homoeostatic process, the state of quantitative invariance, or self-restoration, in various physiological systems, is superimposed on qualitative and quantitative change in the nature of the systems themselves, their specificity, relative proportions, and function-in other words, upon developmental change. There is a strong inference that senescence occurs when these long-term changes, which are probably controlled or initiated largely by the same humoral mediators which function in day-to-day homoeostasis, pass out of control, or reach a point beyond which homoeostasis is no longer possible.

This argument ultimately stands or falls by the result of our study of the phylogeny of senescence. If mammalian senescence results from morphogenetic processes which ultimately escape from the homoeostatic mechanisms that operate during adult vigour, and if, on the other hand, some other vertebrates reach a state of growing, or self-replacing, equilibrium, even over limited periods, the problem of understanding mammalian senescence will be very greatly restricted in theoretical scope, though probably not very greatly simplified in experimental detail. Such an equilibrium would be most likely to be found in those forms where differential growth is least evident. The evidence on this point will be examined later.

\section{$1 \cdot 3$ Senescence in Evolution}

Senescence has frequently been regarded as an evolved adaptation, rather than as an inherent property of somatic organization. This view, which is reasonably well in accord with the existing, and very incomplete, evidence of its distribution in phylogeny, was held by Weismann in spite of his insistence on the contrast between germinal immortality and somatic mortality. Weismann, however, regarded senile change, 


\section{The Biology of Senescence}

and the limitation of the individual life-span, as a positively beneficial adaptation, and his argument is, as we have seen, of a circular kind.

The theoretical difficulties of devising a system in which short life is selected as a character of fitness are considerable though not insuperable. ${ }^{1}$ In any circumstances where a high number of generations in unit time has an adaptive value, the Weismannian argument against individual longevity might hold. The most conspicuous adaptive modifications of life-span in phylogeny seem, however, to be chiefly in the other direction. The development of social insects probably depended upon the evolution of long-lived sexual forms, and it is very likely that a similar process may have operated in human phylogeny, in connection with the development of social behaviour and the family unit. Not only was the evolution of neurones having a long potential life a condition for the development of elaborate learned behaviour and long parental dependence, but, with the development of rational power and social organization, the advantages of possessing the experience of even a few long-lived members was probably very high in any early hominid community. The social animals, especially man, provide one of the best examples where longevity depending on factors outside the reproductive period can theoretically be subject to positive selection in terms of fitness.

The chief objection to Weismann's idea of senescence as an adaptive effect is the rarity of its demonstrable occurrence in nature. In all but the few forms discussed on pp. 108-13, senescence is a potentiality, not a benefit or a handicap; it is realized only when we interfere artificially with the animal or its environment, and it is arguable whether evolution can select for such potentialities. Bidder, it will be recalled (p. 12), considered that senescence in mammals was an evolutionarily unimportant 'by-product' of an important positive adaptation, the limitation of size. It would indeed be possible to attribute senile change to the accumulation of such by-products outside the reproductive period. More recently it has been suggested that

1 Ribbands (1953) found an apparent example in worker bees, where the summer brood could increase its working life by consuming pollen, but uses it instead to rear additional larvae. 


\section{The Nature and Criteria of Senescence}

senescence is to be regarded not as the positively beneficial character which Weismann believed it to be, but as a potentiality lying outside the part of the life cycle which is relevant to evolution. It has certainly been 'evolved', in that the living system which senesces has evolved, but it has not evolved as a physiological mechanism. The line of argument which appears most plausible is that suggested by Medawar (1945, 1952). It seems probable, for a number of reasons, that except in certain social animals there can be little effective selection pressure against senescence as such. Normal population structure in wild communities of animals, even in the absence of senescence, leads to a continual preponderance of young reproducing over old reproducing individuals, sufficient to override the advantage in number of progeny which arises from a longer reproductive life. Death from senescence is itself in many species so rare an event in the wild state that failure to senesce early, or at all, has little value from the point of view of survival. In many forms the cessation or reduction of breeding capacity precedes senescence proper-with certain exceptions in social animals, events occurring in the post-reproductive period are theoretically outside the reach of selection, and irrelevant to it. A consequence even more important than the mere failure of evolutionary processes to operate in favour of the postponement of senescence follows from the same facts. In view of the constant reproductive preponderance of young individuals, the postponement of the action of a harmful genetic effect until late in the reproductive life is almost equivalent, in selective value, to its complete elimination: the longer the postponement, the closer the equivalence. The evolutionary 'demon' is concerned only to clear the part of the life-span in which he works, not the parts which might be reached if the environment were artificially made more favourable. This mechanism, by acting to move all adverse genetic effects which are capable of postponement and all the consequences of divergent but temporarily beneficial systems into the late reproductive or post-reproductive life, may itself provide a partial explanation of the evolution of senescence, as Haldane (1941) has already suggested. The selective equilibrium reached in man would be expected in this case to be such that the force of mortality is lowest when reproductive 


\section{The Biology of Senescence}

activity is potentially highest, though the observed lowest level falls rather earlier than this (10-12 years in males, Greville, 1946).

The selectionist argument which regards senescence as the decline of evolved survival-power through successive age groups is most convincing when we apply it to mammals and birds: among invertebrates, reservations require to be made. In those which are predominantly seasonal, with a total life-span less than one year, and which winter as fertilized adults, it is by no means true that at all times of the year young individuals must outnumber old in a free-running population. The autumn contingent of overwintering animals will consist of 'old' individuals. In such forms, the selective advantage of different genotypes will vary from season to season, and there will be an ultimate requirement that the adult be capable of living long enough to overwinter. Forms producing two broods annually will tend to select fertility in the spring brood and longevity in the autumn, but with a time-lag of one generation between selection and potential expression. The mechanism of selection in such a system must be very complicated.

In mammals some selective advantage would also presumably attach to longevity where older males are polygamous and younger males compete for the remaining females (deer, baboons). The solipsist model of selection operating on 'the individual' can obviously be upset by any selection pressures introduced into the system by interaction between individuals, and by community-patterns of ecological behaviour in the species; the idea of an 'individual' animal unsupported by the rest of the ecological community in which it lives is in fact unbiological, and large unpredictable selection pressures affecting the life-span may well arise from such hidden social relationships.

In spite of this criticism, the theory of senescence as a measure of declining selection-pressure is important. The declining evolutionary importance of the individual with age may be expressed in another way in the 'morphogenetic' senescence seen in mammals. At the point where a system of differential growth ceased to be regulated by forces which arose from natural selection, it would cease to be under effectively direc- 


\section{The Nature and Criteria of Senescence}

tional morphogenetic control, and would resemble an automatic control device which has run out of 'programme'. In any such system the equilibrium must be increasingly unstable. These two views of senescence, as accumulation of delayed lethal or sublethal genetic effects, and as a withdrawal of the evolutionary pressure towards homoeostasis with increasing age, are complementary, though probably only partial, pictures of its evolutionary significance. The concept of senescence as exhaustion of programme also restores a far greater unity to our definition of ageing, which includes a great many effects having little in common beyond their destructive effect on homoeostasis. All such effects fall within the idea of deterioration lying outside the 'terms of reference' of each species, as laid down by natural selection. The 'flying bomb' which failed to dive on its objective would ultimately 'die' either of fuel exhaustion, or through wear in its expendable engine. If its design had been produced by evolution, and its evolutionary relevance ceased at the moment of passing its objective, or decreased as a function of the distance flown, both these events would be outside the programme laid down by the selective equilibrium, as they were outside the calculation of the designing engineers. Death in such an expendable system may result from one of many factors, and even, as Bidder recognized, from the consequence of processes which contribute to fitness during earlier life, such as systems of differential growth. We shall find a good deal of gerontology is primarily the study of a living system's behaviour after its biological programme is exhausted. The various evolutionary explanations of ageing already combine to offer us some idea of the reasons why this may be so. 


\section{$\backsim 2 \backsim$}

\section{THE DISTRIBUTION OF SENESGENGE}

\subsection{Character of the Evidence}

To find out which animals exhibit an increasing mortality with increasing age, we should ideally keep large numbers of each species, or of representative species, from birth to death, under optimal conditions of captivity. In point of fact, apart from the impracticability of keeping any significant number of species in this way, the results would be both artificial and potentially misleading. It is possible to invent about animal senescence a paradox rather analogous to the principle of physical uncertainty: it is 'virtually unknowable' or, in other words, meaningless to ask, whether certain organisms are 'susceptible to senescence', because the organism is biologically dependent on its environment: in the wild state these forms never normally live long enough to reach senescence, while domestication or protective interference with the environment brings about changes in physiology and behaviour which produce effectively a different organism. The object of the paradox is to point out the fruitlessness of argument over 'potential' behaviour which is practically unrealizable. Almost all our detailed knowledge of senescence comes either from the observation of man, or of domestication-artefacts such as the laboratory mouse or the laboratory strains of Drosophila. In the wild state it is most unlikely that any species of Mus or of Drosophila reaches old age with sufficient regularity to be subject to study. In most cases we are creating for study a state which has no part in the life cycle as it has been shaped by evolution, but is at most a potentiality. This must be taken into account on every occasion when theories of the evolution of senescence are being based on the appearance of senescence in domestic animals. 


\section{The Distribution of Senescence}

In comparative studies of animal senescence we have three main types of information: single records of the extreme recorded longevity of different species under various conditions; observations on the composition of natural populations, ${ }^{1}$ and marking experiments, which give a measure of longevity and mortality under natural conditions; and life-tables and comparable material plotted for animals under domestic and laboratory conditions, which indicate the susceptibility of these species to eventual senescence, either by measuring the force of mortality, or by measuring subsidiary age-characters such as reproductive capacity. Studies of senescence in domestic animals are singularly deficient, since apart from individual pets of various phyla neither farmers nor laboratories are usually interested in maintaining their stocks throughout the whole lifecycle and on into senescence. While there are extensive data on the early development of almost all animals of economic importance, the senile period is a virtually unworked biometric field. The literature does not even contain life-tables for representative species of each class of vertebrate. There is only one published life-table for birds in captivity (domestic fowlsGardner and Hurst, 1933) and that is incomplete. No life-table appears to have been published for any reptile or fish, including common and short-lived aquarium species, or even for dogs or cats. Apart from man, adequate or partially adequate actuarial data exist in the literature for the following animals in captivity:

Mice (Kobozieff, 1931; Murray and Hoffman, 1941; Grüneberg, 1951, etc.) (Fig. 31).

Rats (Slonaker, 1912; Wiesner and Sheard, 1934).

Rattus natalensis (Oliff, 1953).

Voles (Leslie and Ranson, 1940) (Fig. 30).

Sheep (partial) (Kelley, 1939).

Fowls (Gardner and Hurst, 1933).

Limnaea (Gastropoda) (Winsor and Winsor, 1935; Baily, 1931) (Fig. 28).

Agriolimax (Gastropoda) (Pearl and Miner, 1935) (Fig. 5c).

1 Methods of age determination in fish, molluscs and mammals have been well reviewed (Trans. N.Y. Acad. Sci., 16, no. 6, 1954) and their value criticized. 


\section{The Biology of Senescence}

Drosophila (Diptera) (Pearl, 1928; Pearl and Parker, 1922, 1924; Gonzalez, 1923; Alpatov and Pearl, 1929; Alpatov, 1931; Pearl and Miner, 1935; Bilewicz, 1953).

Aëdes aegypti (Diptera) (Kershaw, Lavoipierre and Chalmers, 1953).

Acrobasis caryae (Lepidoptera) (Pearl and Miner, 1936).

Fumea crassiorella (Lepidoptera) (Mathes 1951) (Fig. 26).

Telea polyphemus (Lepidoptera) (Pearl and Miner, 1935).

Bombyx mori (Lepidoptera) (Alpatov and Gordeenko, 1932). Tribolium confusum, T. madens (Coleoptera) (Park, 1945;

Pearl, Park and Miner, 1941) (Fig. 36).

Cockroaches (Blatta orientalis, Periplaneta americana) (Rau, 1924; Griffiths and Tauber, 1942).

Bees (Ribbands, 1952, 1953).

Locusts (Bodenheimer, 1938).

Daphnia (Cladocera) (McArthur and Bailey, 1926; 1929a, 1929b; Ingle, Wood and Banta, 1937; Dunham, 1938; Anderson and Jenkins, 1942).

Latrodectes (Arachnida) (Deevey and Deevey, 1945) (Figs. 34, $35)$.

Rotifers (Jennings and Lynch, 1928; Lynch and Smith, 1931;

Miller, 1931; Edmondson, 1945a, b; Lansing, 1942 etc.), Figs. 20, 22, 23).

Hydra (Pearl and Miner, 1935) (Fig. 5c).

There must be others which have been overlooked, especially in the entomological literature. Some unpublished survival curves, mostly from populations too small for actuarial treatment, are given in the text figures:

Lebistes reticulatus (teleost) (Fig. 18a).

Night heron (Nycticorax nycticorax). (Fig. 9).

African Ibis (Threskiornis aethiopicus) (Fig. 9).

Orkney vole (Microtus orcadensis) (Fig. 10).

Patagonian cavy (Dolichotis patagona) (Fig. 11).

Mouflon sheep (Ovis musimon) (Fig. 12).

Irish wolfhounds (Fig. 13).

Figs. 9-12 are prepared from data in the records of the London 44 


\section{The Distribution of Senescence}

Zoo, by kind permission of the Director, and Fig. 13 from data sent me by Miss D. Gardner.

Maximum longevity records of animals species have a definite, but limited, use in giving a comparative picture of the possible longevity in different forms. They can give no direct evidence of the distribution of senescence, but they can provide an important test of a number of general theories-those based, for example, on the exhaustion of neurones (Vogt and Vogt, 1946; Bab, 1948) are difficult to reconcile with the variation in specific age and potential longevity between closely-related forms. A large scatter of maximum recorded ages is in itself suggestive, but not of course demonstrative, evidence of an indeterminate life-span, except in cases where it is evidence only of improving cultural methods and better understanding of the requirements of the animal under laboratory or domestic conditions. For a very large range of species we can readily infer a 'potential' age which is never attained, either in the wild, because of accident and predation, or in captivity, because the animals cannot be kept alive in captivity-the 'potential' longevity of snakes, chamaeleons (Flower, 1925, 1937) or mammals of little known habits (pangolins-Flower, 1931) are cases in point. 'Concerning the length and brevity of life in beasts, the knowledge which may be had is slender, the observation negligent, and tradition fabulous; in household beasts the idle life corrupts; in wild, the violence of the climate cuts them off' (Historia Vitae et Mortis). With most birds, fully domestic mammals, hardy reptiles such as tortoises, and man, however, maximum records can be taken to represent in some real degree the extreme length of time for which the species, or its hardier genotypes, can remain self-maintaining if protected from gross disease or accident. Theories of senescence must fit these data, or at least not contradict them, to be available as working hypotheses.

\subsection{Maximum Longevities in Animals}

Apart from the observations collected by Bacon, which were remarkably critical and accurate compared with the wildness of later estimates, the accurate study of animal life-spans virtually 


\section{The Biology of Senescence}

begins with the enormously painstaking studies of Chalmers Mitchell (1911) and Flower (1925, 1931, 1935, 1936, 1937, $1938^{1}$ ) in purging a vast body of legendary and anecdotal material which encumbered the subject. Much of this legendary material unfortunately persists in other books and papers (Tabulae Biologicae-Heilbrunn, 1943; Nagornyi, 1948; Hammond and Marshall, 1952; Schmidt, 1952; Wurmbach, 1951) deriving their data from Korschelt (1922). The scepticism of Flower's papers was very valuable, in view of the exorbitant claims made for parrots, elephants and so on, but it seems probable that birds, in particular, are in fact capable of living considerably longer than Flower's maximum figures suggest. Better data may, in time, become available, though the value of such records is still not sufficiently widely appreciated and many opportunities must have been lost through failure to keep track of individual specimens. No recent writer has dealt equally painstakingly with the longevity of invertebrates.

The data on vertebrate senescence which follow are those of Flower, except where otherwise stated. Some more recent records have been added, including a number derived from the series of longevity studies published by the Penrose Laboratory of the Philadelphia Zoo in the years prior to 1942 (Duetz, 1938, $1939,1940,1942)$.

\section{2・1 MAMMALS}

The longest-lived species is man. Elephas indicus is known to reach 60 years: a few individuals may reach or exceed 70 in captivity (77?-Mohr, 1951). The only other mammals which are known to approach or exceed 50 years are the horse, hippopotamus (49 years 6 months: 1953-Ann.Rep.N.Y.zool.Soc., 53, 12), Rhinoceros unicornis (49 years-Flower, 1931) and probably the ass (47 years?-Flower MS.). Many larger mammals, including baboons and other large primates, cats, bears, African elephant, equines, tapirs, can approach or exceed 30 years (Chimpanzee,

${ }^{1}$ Those references marked 'Flower MS.' refer to the card-index of data and letters from biological workers which Flower was preparing against a revision of his first mammalian list, and which was uncompleted at his death. This index is in the library of the Zoological Society of London, and includes also bird and reptilian records and the skeleton of a list of invertebrate longevities. 


\section{The Distribution of Senescence}

39, Tomilin, 1936; Baboon, Papio papio, 27-Duetz, 1938; P. anubis $30+-$ Krohn, in press; Gibbon, Hylobates lar, $32+-$ Duetz, 1938; domestic cat, 31-Mellen, 1939, 1940; 27, Comfort, 1955: Chapman's zebra, 40-Weber, 1942: Echidna, nearly 40 years-Duetz, 1942). A large group, including almost all ruminants, many medium-sized herbivores and carnivores, large bats and the larger rodents (beaver, capybara, the domestic rabbit) have recorded maximum ages between 12 and 20 years (Golden agouti, 15-Duetz, 1938). The maximum ages of very many rodents and small carnivores are not accurately established, since few specimens have been kept, but it is likely that a very large group among these forms has a potential lifespan approaching ten years. The small Chiroptera certainly have a much longer life than most mammals of comparable size -ringed horseshoe bats have been recovered after at least 7 years (Bourlière, 1947). This agrees with their slow rate of reproduction.

The shortest-lived mammalian group ( $<5$ years) includes rats, mice, voles, and other small rodents, and the small insectivores. (Rat-4 years 8 months in a white rat probably already 1 year old-Donaldson, 1924; laboratory mouse, 3 years 3 months-Kobozieff, 1931; Micromys minutus, nearly 4 years-Pitt, 1945; golden hamster (Cricetus auratus), usually 2-3 years maximum-Bruce and Hindle, 1934; Deansley, 1938; one specimen in London Zoo, 3 years 11 months-Flower MS; guinea pig, 7 years 7 months-Rogers, 1950; Blarina, 18 months -Pearson, 1945; Sorex fumeus, 13-14 months-Hamilton, 1940.) The real life-span of whales has never been established, but it is almost certainly not more than $30-50$ years at the most, and probably less. The age of maturity of whales has been placed as low as 2 years (John, 1937). Ruud et al. (1950) found that blue whales reach sexual maturity in about 5 years-no individual in their very large sample was apparently older than 12 years, judged by the baleen pattern. The life-span of dolphins in the wild appears to be of the same order (15 years-Sleptzov, 1940; $30+$, one specimen-Parker, 1933).

Detailed records of many other mammalian species are given by Flower.

Recent data on the longevity of seals were reviewed by Laws 


\section{The Biology of Senescence}

(1953), upon the basis of tooth sections. Captive records include Otaria byronia, 23 years, Eumetopias stelleri, 19 (Flower, 1931); Zalophus californianus, 23; Arctocephalus pusillus, 20 (Bourlière, 1951); Phoca vitulina, 19 (Sivertsen, 1941); Halichoerus grypus, 41-2 (Matheson, 1950). In the wild, Callorhinus ursinus has reached $21+$ years (Schaffer, 1950); Mirounga leonina ơ 20; ㅇ 18 (Laws, 1953).

The maximum age records of horses and domestic pets are of importance because these animals are the only mammals kept throughout life in sufficient numbers to give any estimate of the extreme age for the species. In spite of the likelihood of exaggeration and mistake, records of domestic pets kept singly, throughout life, by intelligent witnesses, provide evidence as good as that from laboratory stocks and sometimes better than that from zoos, since reliable mnemonic evidence is better than unreliable documents.

The known range of maximum ages for some domestic species is given below. The figures in brackets represent unauthenticated claims within the range of possibility, based as a rule on evidence which can be neither assessed nor dismissed.

Horses certainly exceed 40, may perhaps exceed 50 yearsmost higher claims refer to ponies. Smyth (1937) reported a 46-year-old brood mare which foaled for the 34th time at 42 -this case appears authentic. (Horse, 62-Flower, 1931; jennet, reputed 60-Wright, 1936; pony, 54-Rothschild fide Flower, 1931; Shetland pony, 58-The Times, $3 / 5 / 44$; roan pony, 52 The Times, 12/4/44; Iceland pony, 47-The Times, 7/8/34; many records between 40 and 45.) A zebra has reached 40 in captivity (Weber, 1942). Asses-probably exceed 40 (47Flower MS. from a press report; but an 86-year-old ass in The Times, 29/11/37, can hardly be taken seriously). A 48-year-old mule is reported (Galea, 1936).

Domestic goats, 15 and probably up to 20 years (20 years 9 months - female wild goat, London Zoo).

Carnivora: cats are the longest lived of the small domestic mammals. Mellen (1940) from questionnaires sent out in Canada and the U.S.A. obtained these records: gelt males, 21, 21, 22, 23, 24, 24, 25, 28, 31 years; entire males, 23, 24, 26; females, $21,21,22,31$. These were owners' estimates, but at 


\section{The Distribution of Senescence}

least one 31-year record was well supported. 33 years has been claimed (Mellen, 1940). Figures for cats in England in recent years included at least ten apparently authentic cases over 20, and one gelt male alive at 28 (Comfort, 1955).

Dogs very seldom exceed 18 years, and only exceptionally reach twenty. In many breeds the limit is far lower. There are remarkably few claims of greater longevity in the literature (34 years, Lankester, 1870).

Rodents: the rabbit can almost certainly exceed 15 years. (10 years 3 months in the laboratory-Tegge 1936; buck 13 years-Barrett-Hamilton 1911; buck, chinchilla $\times$ Belgian hare, 11 years two cases; English buck 14 years, both authenticated -Comfort 1955.) Flower MS. contains a plausible correspondence with the owner of a rabbit (doe) which was said to have exceeded 18 years and was still alive.

\section{$2 \cdot 2 \cdot 2$ BIRDS}

Flower's longest 'incontestable' record in captivity (Flower, 1925,1938 ) was 68 years in Bubo bubo. This is probably too low. Records exceeding 70 years in parrots, swans, and several large predators given by Gurney (1899), though less fully proven, are probably substantially correct.

The maximum life-span in birds is not proportional to size. It is materially longer than in mammals of comparable size and activity. Many species can live 30-40 years, including small and active birds such as pigeons (Flower 1938, Fitzinger 1853: Streptopelia risoria 40 years, Columba livia 30 years, Goura cristata ot 49 , o 53 years), while even the smaller passerines have a potential life of $10-15$ or more years in captivity (29 years in a chaffinch-Moltoni, 1947) and ages of this order are occasionally reached even in the wild state (Perry, R. 1953). It has been properly remarked that

\section{$A$ robin redbreast in a cage \\ Lives to a tremendous age.}

Extensive aviary records are given by Chalmers Mitchell (1911). 


\title{
The Biology of Senescence
}

\author{
TABLE I \\ MAXIMUM REGORDED LONGEVITIES IN 45 SPEGIES OF BIRD \\ (Flower, 1938)
}

\begin{tabular}{|c|c|c|}
\hline & & Years \\
\hline agle owl (Bubo bubo) & $\begin{array}{c}\text { Proven } \\
68\end{array}$ & Reported \\
\hline Greater sulphur-crested Cockatoo (Cacatua galerita) & 56 & $69,80,120$ \\
\hline Bateleur Eagle (Terathopsius ecaudatus) & 55 & \\
\hline Vasa Parrot (Coracopsis vasa) & 54 & \\
\hline Condor (Vultur gryphus) & 52 & \\
\hline White Pelican (Pelicanus onocrotalus) & 51 & \\
\hline Grey Parrot (Psittacus erythacus) & 49 & 73 \\
\hline Golden-naped Parrot (Amazona auropalliata) & 49 & \\
\hline Australian Crane (Megalornis rubicunda) & 47 & \\
\hline Golden Eagle (Aquila chrysaëtos) & 46 & 80 \\
\hline Adalbert's Eagle (Aquila adalberti) & 44 & \\
\hline Blue-and-yellow Macaw (Ara ararauna) & 43 & \\
\hline Grey Crane (Megalornis grus) & 43 & \\
\hline Leadbeater's Cockatoo (Cacatua leadbeateri) & 42 & 60 \\
\hline Caracara (Polyborus tharus) & 42 & \\
\hline Chilean Eagle (Geranoaëtus melanoleucus) & 42 & \\
\hline White-tailed Eagle (Haliaetus albicillus) & 42 & \\
\hline Sarus Crane (Megalornis antigone) & 42 & \\
\hline Rough-billed Pelican (Pelicanus erythrorhynchos) & 41 & \\
\hline Manchurian Crane (Megalornis japonensis) & 41 & \\
\hline Asiatic White Crane (M. leucogeranus) & 41 & \\
\hline Herring gull (Larus argentatus) & 41 & 44,49 \\
\hline Banksian Cockatoo (Calyptorrhynchus banksii) & 40 & \\
\hline Bare-eyed Cockatoo (Cacatua gymnopis) & 40 & \\
\hline Western slender-billed Cockatoo (Licmetis pastinator) & 40 & \\
\hline Tawny Eagle (Aquila rapax) & 40 & \\
\hline King Vulture (Sarcorhamphus papa) & 40 & \\
\hline Ceylon Fish Owl (Ketupa zeylonensis) & 39 & \\
\hline Cinereous Vulture (Aegypius monachus) & 39 & \\
\hline Red-and-blue Macaw (Ara macao) & 38 & 64 \\
\hline Griffon Vulture (Gyps fulvus) & 38 & 117 \\
\hline American Crane (Megalornis americana) & 38 & \\
\hline Californian Condor (Pseudogryphus californianus) & 37 & \\
\hline Shoebill (Balaeniceps rex) & 36 & \\
\hline Domestic goose (Anser anser domesticus) & 35 & 80 \\
\hline Slender-billed Cockatoo (Licmetis tenuirostris) & 34 & 85 \\
\hline Canadian Goose (Branta canadensis) & 33 & 47 \\
\hline Orange-winged Parrot (Amazona amazonica) & 30 & 71 \\
\hline Roseate Cockatoo (Cacatua roseicapilla) & 30 & 47 \\
\hline Domestic Pigeon (Columba livia domestica) & 30 & 35 \\
\hline Domestic Dove (Streptopelia risoria) & 30 & 42 \\
\hline Emu (Dromiceius novae-hollandiae) & 28 & 40 \\
\hline Ostrich (Struthio camelus) & 27 & 40 \\
\hline Egyptian Vulture (Neophron percnopterus) & 23 & 101 \\
\hline Growned Pigeon (Goura cristata) & 16 & 49,53 \\
\hline
\end{tabular}




\section{The Distribution of Senescence}

\section{$2 \cdot 2 \cdot 3$ REPTILES}

The longevity of tortoises is one of the few popular beliefs about animal life-span which is correct, though it has been exaggerated. There is no clear evidence that the larger species

\section{TABLE II}

MAXIMUM REGORDED LONGEVITIES OF GHELONIANS

(Data from Flower, 1937, except where otherwise stated)

Testudo sumeiri
elephantopus
graeca
daudini
hermanni
radiata
gigantea
sulcata
marginata

Terrapene carolina

Marion's Tortoise 152

rears

Galapagos Tortoise $100+$

Greek Tortoise 102, 105

Daudin's Tortoise $100+$

Hermann's Tortoise $90+$

Radiated Tortoise $\quad 85+$

Giant Tortoise $\quad 68-180$

Spurred Tortoise 42

Margined Tortoise 28

Carolina Boxtortoise

$123+$

$118+$ Dittmars, 1934

129* Oliver 1953

88+* Deck, 1927

65* Edney and Allen, 1951

Emys orbicularis

European Pondtortoise

70-120 Rollinat, 1934

Macroclemmys temminckii

Clemmys guttata

Pelusios derbianus subniger

Snapping Turtle

Speckled Terrapin $42+$

$58+, 47$ Conant and Hudson, 1949

Derby's Terrapin

$41+$

29+ Conant and Hudson, 1949

Sternotherus odoratus Stinkpot Terrapin

Kinosternon subrubrum Pennsylvania

Chelodina longicollis $\begin{gathered}\text { Terrapin } \\ \text { Longnecked }\end{gathered}$

Terrapin

Caretta caretta

Loggerhead Turtle

Malaclemmys centrata

Diamond-backed Terrapin

Cuora trifasciata

Three-banded

Geoclemmys reevesi

$53+$ Conant and Hudson, 1949

$38+$

$37+$

$31+$ Conant and Hudson, 1949

\section{3}

?40 Hildebrand, 1932

$26+$

24+ Conant and Hudson, 1949

* Marked individual recovered in the wild. 


\section{The Biology of Senescence}

are potentially very much longer-lived than some small forms. The maximum authenticated records include Testudo sumeirii, $152+$ (years); T. elephantopus $100+;$ T. graeca, 102, 105; T. daudini, 100 +; T. hermanni, 90+; Emys orbicularis, 70-120 (Flower, 1925, 1937; Rollinat, 1934; Korschelt, 1931); Terrapene carolina, 118+ (Ditmars, 1934), 88+ (Deck, 1926), 64 (Edney and Allen, 1951), the last two in the wild. The age of the royal tortoise of Tonga, said to have belonged to Capt. Cook, and still living, is unsupported by documents, but may well be authentic.

The longevity of turtles and luths (Parker, 1926, 1929) and of crocodiles has been assumed, upon a basis of recorded sizes, to be very great, though the longest captive record of a crocodile is $56+$ years (Flower, 1937). Alligator sinensis has been kept 52 years (Lederer, 1941), and $A$. mississippiensis 41 years in the London Zoo (1912-53). The records of snakes are limited by their poor survival in zoos. (Eunectes murinus, 29 years (Flower, 1937), 28 (Perkins, 1948); Epicrates cenchris 27 (Perkins, 1948).) Lizards: Anguis fragilis, 33 years (Hvass, 1938), 32 (Flower, 1937), 27 (Thummel, 1938); Sphenodon punctatus, $28+$ (Flower, 1937); Heloderma suspectum, 20 (Conant and Hudson, 1949); Ophisaurus apodus, 11 years 7 months (Conant and Hudson, 1949), 24 years (Perkins, 1948). The maximum life-span appears to be relatively brief in chamaeleons, but this may simply be due to failure to thrive in captivity.

\section{$2 \cdot 2 \cdot 4$ AMPHIBIANS}

Here again the figures in relation to size and growth give no very clear evidence that the life-span is sharply determined. The maximum records are in Megalobatrachus $(52+$ yearsFlower, 1936; 65 + years-Schneider, 1932) but many small species are capable of very long life (Triton spp., 35 yearsSmith, 1951; Triturus pyrrhogaster, 25-Walterstorff, 1928; Amphiuma punctatum, 25-Koch, 1952; Triton marmoratus, 24, 21 Wendt, 1934; Pleurodeles waltl, 20-Noble, 1931). Siren, 25 years, Amphiuma, 26-Noble, 1931; Salamandra salamandra, 24, Bufo bufo, 36, Hyla coerulea, 16, Rana catesbiana, 15, Xenopus laevis, 15 (Flower 1925; 1936), Rana temporaria $12+$ years (Wilson 1950), 


\section{The Distribution of Senescence}

$R$. esculenta $14+, 16+, R$. temporaria $9+$ (Sebesta 1935), Leptodactylus pentadactylus 15 years 9 months (Conant and Hudson, 1949).

\subsubsection{FISH}

Seriously acceptable records of longevity in the larger fish are very few. The longest accepted by Flower are Silurus glanis, $60+$ years, Anguilla anguilla, 55, A. chrisypa, 50 (Flower 1935). Some of the more celebrated legends of fish longevity (up to $170,200,300$, or 400 years in carp, and 250 years in pike) are revived by Backmann (1938) and by Wurmbach (1951). 'Wenn auch diese Angaben hier und da übertreiben sein sollten', remarks Wurmbach, 'so kann doch gar kein Zweifel daran herrschen, dass der Karpfen wirklich ausserordentlich alt wird, und das Alter des Menschen weitaus übertrifft'-this is quite possibly true. Many exaggerated estimates have been based upon size, as extrapolations of the normal mean growth rate for the species-upon this basis, a $720 \mathrm{~kg}$. sturgeon should be about 200 years old, and occasional examples weighing 1200 to 1600 $\mathrm{kg}$. would be of fantastic antiquity. In no case, however, are any of these estimates supported by otolith or comparable studies, and the extrapolation is almost certainly unjustified. It is a matter of considerable biological importance to get proper age determination upon exceptionally large specimens of this kind.

The life-span of small fish is certainly limited in captivity (Aphya pellucida, 1 year; Lebistes, 1-2; Xiphophorus, 2-3; Molliensia latipinna, 3-4; Betta pugnax, 1 $\frac{1}{2}-2$-Wurmbach, 1951). A few species of Gobius and Latrunculus must be regarded as annuals, even in captivity (Bourlière, 1946, Meyers 1952). In this field there is little new information since the seventeenth century. 'The life of fishes is more doubtful than that of land beasts, since, living below the waters, they are less observed. Dolphins are said to live about thirty years; this is obtained by experiment upon some of them, the tail being marked by cutting; they grow for ten years. In Caesar's fishponds were certain Muraenae found to have lived to the sixtieth year. Indeed, they were grown with long use so familiar, that Crassus the orator mourned for the death of one. The pike, of freshwater fish, is 


\section{The Biology of Senescence}

found to live the longest, sometimes to the fortieth year. But the carp, bream, tench, eel and the like are not held to live above ten years. Salmon grow quickly and live not long, as do also trout; but the perch grows slowly and lives longer. How long the breath governs the vast bulk of whales and orcae, we have no certain knowledge; neither for seals, nor for innumerable other fish' ${ }^{1}$ (Hist. Vitae et Mortis). Most of these figures are reasonably congruent with Flower's list.

\subsubsection{INVERTEBRATES}

Previous lists of invertebrate longevities (Tabulae Biologicae; Heilbrunn, 1943; Nagornyi, 1948, etc.), apart from the excellent data collected by Weismann (1891), almost all spring directly from the opinions of Korschelt (1922). These are based on data from the older literature, largely unsupported by exact references, some accurate, but others highly speculative. The type of evidence which has got into such lists is well exemplified by the 15-20 year life-span of the crayfish. This, though probably correct, appears to owe its origin to an aside by T. H. Huxley (1880) to the effect that it seems probable that the life of these animals may be prolonged to as much as fifteen or twenty years' (The Crayfish, p. 32). The large Tridacna may in fact be the longest-lived invertebrate, in view of high records of age in much smaller pelecypods, but the literature contains no information of any description about its life-span, and the relationship between great size and great age is perpetually being disproved in other animals. Of a supposedly 18-year-old Helix pomatia Korschelt writes elsewhere: 'Gewiss hat diese Angabe von vornherein wenig Wahrscheinlichkeit für sich, aber als

1 'Piscium vita magis incerta est, quam terrestrium, quum sub aquis degentes minus observantur.... Delphini traduntur vivere annos circa triginta; capta experimento in aliquibus a cauda precisa; grandescunt autem ad annos decem. Deprehensae sunt aliquando in piscinis Caesarianis muraenae vixisse ad annum sexagesimum. Certe redditae sunt longo usu tam familiares, ut Crassus orator unam ex illis defleverit. Lucius, ex piscibus aquae dulcis, longissime vivere reperitur; ad annum quandoque quadragesimum .... at carpio, abramis, tinca, anguilla et huiusmodi non putantur vivere ultra annos decem. Salmones cito grandescunt, brevi vivunt, quod etiam faciunt trutae; at perca tarde crescit, et vivit diutius. Vasta illa moles balaenarum et orcarum, quamdiu spiritu regatur, nil certi habemus; neque etiam de phocis. . . . et aliis piscibus innumeris.' 


\section{The Distribution of Senescence}

unmöglich wird man dieser Langlebigkeit nach dem, was man von anderen Tieren weiss, nicht bezeichnen dürfen' 1 (1922, p. 36, footnote).

A proper survey of the longevity of invertebrates can hardly yet be undertaken - the information is mostly lacking. It seemed wisest in compiling Table III, which includes a few of the longest and most interesting invertebrate records, to give not only the record and source, but the type of evidence upon which the record is based. In invertebrates which metamorphose, length of larval life often depends entirely upon environment and food, while in other forms adult life can be punctuated by very long spells of diapause. Figures for these forms should therefore when possible indicate the circumstances of life. Larval life-spans have in general been omitted from Table III. The most reliable records are in all cases those of animals kept, like Labitte's (1916) beetles or the Edinburgh sea anemones (Ashworth and Annandale, 1904) under close observation in captivity. Evidence from growth rings requires very careful scrutiny. Some purely inferential evidence, as of the age of termite primaries, is probably reliable. There are also some surprisingly high records in the wild, especially for pelecypods, where the method of ageing by rings of growth has been well upheld by other evidence. The life-span of common invertebrates certainly remains a wide-open field for those with facilities and an unlimited capacity for taking pains, and one where any reliably-attested information is worth putting on record.

1 'No doubt these findings have little probability in themselves, but one cannot dismiss such longevity records as impossible, in view of what is known of other animals.' 


\section{The Biology of Senescence}

\section{TABLE III}

\section{MAXIMUM RECORDED LONGEVITIES OF VARIOUS INVERTEBRATE SPECIES BY PHYLA}

(Ages in years unless specified)

$\mathrm{c}=$ information based on specimens in culture or captivity

$\mathrm{w}=$ information based on specimens in the wild

$\mathrm{g}=$ age estimated by examination of growth rings

$\mathrm{h}=$ case history (in parasitic forms)

\section{Porifera}

Suberites carnosus

Adocia alba

\section{Coelenterata}

Actinia mesembryanthemum

Cereus pedunculatus
15

9

$65-70$

85-90 c Arndt, 1941

c Arndt, 1941

Dalyell, 1848

c Korschelt, 1922

c Ashworth and Annandale, 1904 Stephenson, 1935 Warwick, 1954 (personal commn.)

\section{Platyhelminths}

Schistosoma haematobium

\section{5}

28

25

Clonorchis sinensis

Gastrodiscus aegyptiacus

Taeniorrhynchus saginatus

Diphyllobothrium latum

'Echinococcus cysts'

Dugesia tigrina (= Planaria maculata)

Dendrocoelum lacteum

\section{Nematoda}

Loa loa

Wuchereria bancrofti

Necator americanus

Rotifera-see Table IV

Annelida

Eisenia foetida

Lumbricus terrestris

Allolobophora longa

Sabella pavonina

Arthropoda

(Arạchnida)

'Tarantula' (aviculariid)오

Avicularia avicularia 우

Tegenaria derhami 우

Filistata insidiatrix 우 h Kirkland, 1928

h Christopherson, 1924

h Moore, 1924

h Christopherson, 1924

h Penfold, Penfold and Phillips, 1936

h Riley, 1919

h Lawson, 1939*

c Goldsmith, 1942

? Bresslau, 1928-33

h Coutelen, 1935

h Knabe, 1932

h Sandground, 1936

* See also Coutelen et al., 1950, Davaine, 1877, Wardle and McLeod, 1952, pp. 116-17. 


\section{The Distribution of Senescence}

\section{Arthropoda}

Physocyclus simoni

Teutana grossa 우

4

6

Psalmopoeus cambridgii

Lasiodera curtior

(Crustacea)

Astacus

Homarus

Leander serratus $q$

Oniscus asellus

Philoscia muscorum

Porcellio scaber dilatatus

Platyarthrus hoffmanseggi

Armadillium vulgare

Balanus balanoides
50

5-6

$4 \frac{1}{4}$

$3 \frac{3}{4}$

$3 \frac{1}{2}$

$5+$

$4+$

$>5$ c Bonnet, 1935

c Bacelar and Frade, 1933

c London Zoo, Flower MS.

c London Zoo, Flower MS.

inference Friedel, 1880 inference Herrick, 1898, 1911

inference Solland, 1916

$\left.\begin{array}{l}\text { c } \\ \text { c } \\ \text { c } \\ \text { c }\end{array}\right\}$ Collinge, 1944

w Moore, 1934

(Insecta)

Thysanura

Ctenolepisma longicaudata

total 7

w Lindsay, 1940

Ephemeroptera

Cloëon dipterum

imago 4 wks

c Vane, 1946

\section{Isoptera}

Neotermes castaneus $q$ o $\hat{\delta}$ imago $>25 \mathrm{yrs}$

Nasutitermes-physogastric $q \quad 20-40$

'Termite primaries' 60-?

w Snyder, fide Howard, 1939

w v. Hagen, 1938

w Richards, 1953

\section{Lepidoptera}

Nymphalis antiopa

Calliophrys rubi

Maniola jurtina

imago 12 wks imago 6 wks imago 44 days

$\left.\begin{array}{l}\text { c } \\ \text { c }\end{array}\right\}$ Frohawk, 1935

Coleoptera*

Blaps gigas

Timarcha sp.

Carabus auratus

Dytiscus marginalis

Prionotheca coronata

Akis bacarozzo

Cybister laterimarginalis

imago $>10$ yrs

imago $>5$

imago 3-1

imago $<3$

imago $6,7+$

imago $>4$

imago $5 \frac{1}{2}$

Hymenoptera

\begin{tabular}{|c|c|}
\hline Apis mellifica $q$ & imago \\
\hline Lasius niger $ㅇ$ & imago $>19$ \\
\hline Stenamma westwoodi 우 & imago $16-18$ \\
\hline Formica fusca 우 & $\begin{array}{l}\text { imago } \\
\text { imago }\end{array}$ \\
\hline sanguinea 웅 & imago \\
\hline $\begin{array}{l}\text { Lasius niger } \not{\phi} \\
\text { Formica fusca } \not\end{array}$ & $\left.\begin{array}{l}\text { imago } \\
\text { imago }\end{array}\right\}$ \\
\hline
\end{tabular}

*For a discussion of the longevity of beetle larvae, see Howard 1939; also Latter 1935 (Cossus) Linsley 1938 (Stromatium). c) Labitte, 1916

c Blunck, 1924

c) London Zoo, Flower

c) MS.

c Sharp, 1883

c Pflugfelder, 1948

c Goetsch, 1940

c Donisthorpe, 1936

c Janet, 1904

c Lubbock fide Weismann, 1882

c Lubbock fide Weismann, 1882

c Lubbock fide Weismann, 1882 


\section{The Biology of Senescence}

Echinodermata

Echinus esculentus

Psammechinus miliaris

Asterias rubens

(reaches sexual maturity)

Marthasterias glacialis

Ophiothrix fragilis

$>8$
$>6$
$5-6$
$>7$
$>5$

w Moore, 1935

c Bull, 1938

c Bull, 1934

c Wilson, 1954 (personal comm.)

c Zool. Gart., 1930

\section{Mollusca}

Patella vulgata

Acmaea dorsuosa

Gibbula umbilicalis

Trochus niloticus

Viviparus contectus

Hydrobia ulvae

$$
\text { viviparus }
$$

Pila sp.

Haminea hydatis

Planorbis corneus

Limnaea luteola

Physa gyrina

Abida secale

Helix pomatia aspersa

(Cepaea) nemoralis hortensis nem $\times$ hort hybrid

(Arianta) arbustorum

'Helix spiriplana'

Eulota fruticum

Hyalinia villae

Limax cinereoniger

Geomalacus maculosus

Achatina zebra

Rumina decollata

Oxystyla capax (aestivating)

Ostrea edulis

Pecten jessoensis

Megalonaias gigantea

Quadrula sp.

12-13 months

14-15 months

$<3$

6-7

5-6

c) Oldham, 1931

c Geyer, 1909

c Quick, 1924

c Flower, 1922

w Berrill, 1931

c Oldham, 1930

w Seshaiya, 1927

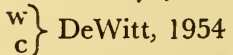

c fide Flower MS.

c Künkel, 1916

c Welch, 1901

c Brockmeier, 1896

c Lang, 1896

c Cuenot, 1911

c Künkel, 1916

c Vignal, 1923

w c Künkel, 1928

c van der Horst, 1929

c) Oldham, 1942a, b

c Longstaff, 1921

c Vignal, 1919

c Baker, 1934

wg Orton and Amirthalingam, 1930

w g Bazykalova, 1934

w Chamberlain, 1933

w $g$ Lefevre and Curtis, 1912

Margaritana margaritifera

$>60$ inference Geyer, 1909 (see also Israel, 1913, Cuenot, 1911)

Cardium corbis

Tivela stultorum

Venus mercenaria

Siliqua patula

Mya arenaria

wg Weymouth and Thompson, 1930

w g Weymouth, 1923

w g Hopkins, 1930

w g Weymouth, 1931

wg Newcombe, 1935, 1936 


\section{The Distribution of Senescence}

TABLE IV

MAXIMUM RECORDED LONGEVITIES OF ROTIFERS

(Bibliography from Hyman, 1951)

Asplanchna sieboldii

Proales decipiens sordida

Cupelopagis vorax

Euchlanis triquetra

Epiphanes senta

Brachionus pala

Euchlanis dilatata

Keratella aculeata

Epiphanes brachionus

Floscularia conifera

Lecane inermis

Philodina roseola citrina megalotrocha

Rotaria macrura rotatoria

Callidina sp.

Adineta vaga barbata

Habrotrocha constricta

Macrotrachela quadricornifera

Mniobia russeola
2-3 weeks c Tannreuther, 1919

12 days c Liebers, 1937

22 days c Jennings and Lynch, 1928

Lynch and Smith, 1931

40 days c Cori, 1925

21 days c Lehmensick, 1926

8 days c Ferris, 1932

12-19 days c Chu, 1934

23 days c Liebers, 1937

29 days c Kolisko, 1938

17 days c Kolisko, 1938

18 days c Edmondson, 1945

14 days c Miller, 1931

10 days

21 days

17 days $\} \quad$ Spemann, 1924

58 days

20-50 days

5 months c Zelinka, 1891

15-22 days

21 days

34 days

2 months $\}$ c Dobers, 1915

\subsection{Maximum Life-span in Man}

Human longevity records are even more notorious than those of animals. They depend largely on unsupported memory and tradition in a field where the emotional premiums of exaggeration are high. 'Furthermore, even though this satisfaction and vanity, of which we have spoken, were absent, yet such is the peculiar and perpetual wandering of the human Intellect, that it is more moved and roused by affirmatives than by negatives, whereas properly it ought to be just to both, nay even, in the forming of any axiom, the force of the negative instance is the greater.' (Novum Organum). King (1911) found in the 1911 census a discrepancy between the size of the 85-90 year-old age group and that of the next higher group, which was almost certainly due to exaggeration. William Thoms (1873), founder 


\section{The Biology of Senescence}

of Notes and Queries, and Young (1899) devoted much time to exposing the pretensions of past supercentenarians. In some of the 'documented' cases, the life-span of father, son, and grandson of the same names were apparently conjoined in one record. Young's greatest authenticated record was a few weeks short of 111 years.

The actuarial probability of an individual's exceeding the age of 150 years, on the life-data of 1939, has been estimated at $\left(\frac{1}{2}\right)^{50}$ (Greenwood and Irwin, 1939). Pütter (1921) calculated on a basis of German vital statistics for the years 1871-91 that ages over 105 were effectively impossible, and that for every million persons reaching 20 years, the number reaching 109 would be $4.8 \times 10^{-10}$ : 'danach wäre es nunmehr wohl an der Zeit, die Berichte über 120, 130, 140, 150 usw.-jährige dahin zu verweisen, wohin sie gehören: ins Reich der Fabel'. This scepticism has proved excessive, especially as regards the population-frequency of centenarians (see Freudenberg, 1949). The existence of supercentenarians cannot be disproved by statistical means unless the distribution of ages is really continuous, since ordinary life-tables have no defence against, say, a rare genotype with double the normal potential life-span. The number of persons reaching 100 years is in any event too small for statistically significant estimates of the rate of increase in the force of mortality after about 90 years of age. Pütter's estimate was based on the assumption that this increase continued at the same rate as in earlier life. The relation between observation and calculation in this part of the life-table is fully discussed by Greenwood and Irwin (1939).

Subsequent writers have been content to rely on direct observation, provided that only records supported by proper documentary evidence are taken seriously (Forster, 1945; Tomilin, 1938). The minimum requirements are these laid down by Thoms (1873)-documentary evidence of birth (or baptism), of death or present age, and of identity. The third of these, as Pearl (1928) points out, is commonly the key to false records of extreme age. The best of such evidence, from compulsory birth certification, has been available in England since 1837, and would now be available for records up to 118 years (1955). By critical standards of comparable severity the greatest 


\section{The Distribution of Senescence}

human age to be authenticated with reasonable certainty has been said to be 120 years (Fisher, 1923). A considerable number of cases between 110 and 115 years have also stood up to examination (e.g. Bowerman, 1939; Backman, 1945; Korenchevsky, 1947). The greatest age to be authenticated in England and Wales by actual birth certificate, however, is 109 years, while in one case the absence of a birth certificate indicated an age in excess of 111 years.

Glaims of extreme longevity in particular districts abound. Metchnikoff investigated statements of this kind in Bulgaria and the Caucasus. Bazilievitch (1938a, b) led an expedition to investigate the celebrated longevity of Abkhasians, and examined several claimants in detail. Two of these were reputed to be over 130 years old. The evidence (identity papers and memory of events in the Caucasus during the early nineteenth century) is given by Bazilievitch in careful detail; much of it is extremely entertaining, but far from conclusive, although the subjects were certainly very old men (Bazilievitch, 1938b). ${ }^{1}$ In recent years very large numbers of claims to extreme longevity have been made in Russia (e.g. Rokhlina, 1951; Nagornyi, 1948; Lukyanov, 1952; Nikitin, 1954). Dealing with the figures in the 1926 census of the U.S.S.R., which showed proportions of 3.5 and 3.8 centenarians per thousand gross population in Daghestan and Abkhasia respectively, as to 1.8 per million among Volga Germans, Tomilin (1938) says 'We must doubt the factual truth of these figures, since no documentary evidence of the age of persons who had passed the century mark was produced.' The analysed distribution of age-groups in the Abkhasian census shows exactly the same deficiency in the 85-89 and 95-99 year groups, compared with the 90-94 and $100+$ groups, which was observed by King (1911) in England. 'Without special documentary evidence of the accuracy of these age-data, we cannot conclude definitely that the relative number of persons reaching the age of 100 and over in the general

1 Prof. G. Z. Pitshelaouri, of Tbilisi University, who very kindly showed me his unpublished data on the longevity of Abkhasians, has found several subjects whose reputed age exceeds I 30 years and is colourably supported by baptismal registers-one man still living took part in, and accurately describes, the Crimean war of $1854-56$. I have failed to obtain a paper by Mishaikov (1929) giving statistics for centenarians in Bulgaria. 
The Biology of Senescence

\section{TABLE V}

NUMBER AND MAXIMUM AGES OF GENTENARIANS DYING IN ENGLAND AND WALES

(Registrar-General's statistics)

\begin{tabular}{ccc} 
Year & \multicolumn{2}{c}{$\begin{array}{c}\text { Number and probable maximum age } \\
\text { Men }\end{array}$} \\
1940 & $20(105)$ & $102(108)$ \\
1941 & $18(112)$ & $91(108)$ \\
1942 & $12(107)$ & $79(108)$ \\
1943 & $21(108)$ & $92(106)^{*}$ \\
1044 & $21(109)$ & $85(105)^{*}$ \\
1045 & $19(105)^{*}$ & $71(106)^{*}$ \\
1946 & $22(105)^{*}$ & $94(108)^{*}$ \\
1947 & $19(106)^{*}$ & $97(108)^{*}$ \\
1948 & $19(103)^{*}$ & $107(115)$ \\
1949 & $27(104)^{*}$ & $133(106)^{*}$ \\
1950 & $22(102)^{*}$ & $131(107)^{*}$ \\
1951 & $33(104)^{*}$ & $142(109)^{*}$ \\
1952 & $24(105)^{*}$ & $147(107)^{*}$ \\
& $*$ verifiable by birth certificate.
\end{tabular}

mass of the population of Abkhasia is really higher than in the population of Russia' (Tomilin 1938). In America, Nascher's investigation of John Shell, reputed to be 131, showed him to be in fact about 100 years old (Nascher 1920). In England and Wales, the oldest persons dying between 1930 and 1945 appear to have reached ages of 112 and 109 years (Korenchevsky, 1947). A woman who died at St. Asaph, Flintshire, in 1948 may have reached 115 years, and had certainly reached 111 .

Sporadic records of supercentenarians such as Old Parr, whose tomb in Westminster Abbey credits him with an age of 152 years, whose body was examined by Harvey, and whose complete lack of documentation was exposed by Thoms (1873), occur in almost all cultures: a long series of similar anecdotes is given by Gould and Pyle (1898). The best recent summary of these often-paraded examples is that of $R$. T. Gould (1945). Though in most cases the stories conform closely to the childhood fantasy of 'going on living for almost always', they may also indicate that authenticated records do not yet represent the extreme of human longevity under all conditions. There is some ground, apart from the absence of critical record in backward countries, to associate extreme individual longevity 


\section{The Distribution of Senescence}

with a low rather than a very high standard of living throughout life (Gumbel, 1938), an argument which fortunately has not so far been advanced to justify starvation as a social policy. Extreme records in man, occurring in excess of statistical probability, are chiefly of interest in suggesting that after a certain age the rate of increase in the force of mortality is not maintained, either by reason of selection or from other causes.

\subsection{Distribution of Senescence in Vertebrates}

Actuarial senescence is known, or reasonably assumed, to occur in all mammals, provided they live long enough. It is less easily recognized, but apparently equally universal, in birds. There are apparently no satisfactory life-table studies of birds under domestic conditions apart from a single paper on fowls (Gardner and Hurst, 1933), but individuals kept as pets certainly become increasingly enfeebled after an age which is fairly constant for the species, and the reproductive senescence of poultry, marked by a steep decline in egg production, is wellknown to farmers (Clark, 1940; Brody, 1945; Fig. 14). This

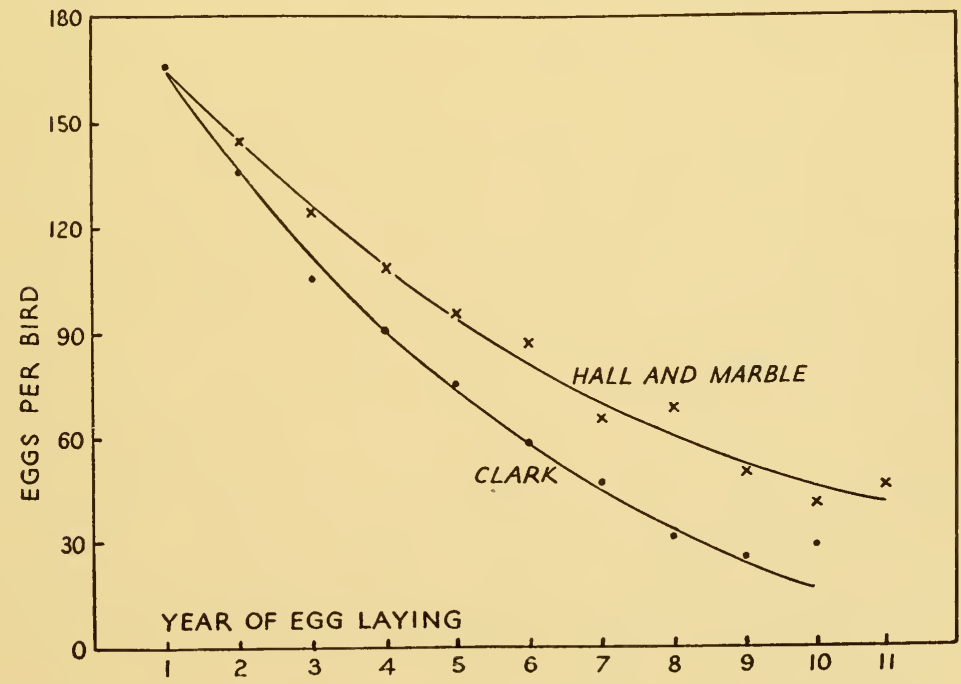

FIG. 14.-The decline in egg production in successive years of laying (drawn from the data of Clark and of Hall and Marble). 


\section{The Biology of Senescence}

decline can be reduced by mild hypothyroidism (Turner and Kempster, 1948) The pair of crowned pigeons which lived, according to Fitzinger (1853) for over 40 years, mated and laid throughout life, but hatched no offspring after the age of 18 or 20 years (Flower, 1938). Spermatogenesis likewise appears to decline (Payne, 1952). The life-span of birds is longer in proportion to size and metabolic rate than that of mammals, and the scatter of age in senescence as shown by aviary records appears, superficially at least, to be rather greater within a species.

We are familiar with the ageing of warm-blooded animals because we keep them. It is among the 'cold-blooded' vertebrates that the real uncertainty begins. We keep fish, but only the smaller forms-we do not, apart from zoological gardens and occasional pet tortoises, keep reptiles; as for amphibia, Hilaire Belloc wrote uncontrovertibly concerning lonely people who keep frogs that

\section{by the way}

\section{They are extremely rare.}

The general assumption that all vertebrates must necessarily undergo a senescence at least superficially similar to that of mammals has prejudiced even those biologists who have kept frogs for long periods, with the result that very little real information unbiassed by this assumption has been published. Very possibly the assumption may prove to be correct, but it cannot be lightly made. It is evident that some senile change, in the form of an accumulation of injuries, must occur in all vertebrates with the passage of time, and be reflected in the force of mortality. But this effect is certainly small and inconstant compared with the 'morphogenetic' senescence which determines the life-span of mammals. It is this morphogenetic component which we are concerned to detect and estimate in lower vertebrates. Unfortunately for such a study, the life of many of these creatures, whether it ends in senescence or not, is, as we have seen, long enough to make ordinary short-term laboratory observation useless.

Bidder's opinions on the relation between perpetual youth and continuing growth have already been quoted (p. 12). 64 


\section{The Distribution of Senescence}

Three types of growth-pattern are theoretically possible in vertebrates-growth to a maximum size, ceasing when this is reached: growth toward a limiting size which is approached asymptotically: and growth without a limiting size. In the third of these cases, the specific growth-acceleration can be negative -i.e. the growth rate continually declines-but it could theoretically do so in such a way that, given a sufficiently long life, any final size could be reached. These last two modes of growth correspond to convergent and divergent series. Thus in the series

$$
\text { (1) } 1+\frac{1}{2}+\frac{1}{4}+\frac{1}{8} \ldots \lim 2 \text {, }
$$

and the series

$$
\text { (2) } 1+\frac{1}{2}+\frac{1}{3}+\frac{1}{4}+\frac{1}{5} \ldots \text {, }
$$

the increment at each term decreases (the specific growth rate falls), but whereas in (1) the series tends to a limiting size (specific size), in (2) it does not, and can be indefinitely continued so that any sum is ultimately attained. The terms 'indeterminate growth' and 'indeterminate size' have been differently used by different writers. D'Arcy Thompson wrote, 'It is the rule in fishes and other cold-blooded vertebrates that growth is asymptotic and size indeterminate' (1942). If the growth of an animal is in fact asymptotic, its size is limited by the sum of the asymptotic series. 'Indeterminate' growth without limit, but with a decline in the specific growth-rate, strictly follows the pattern of the divergent series. For this reason it would be desirable, but it is not empirically possible, given real biological material, to distinguish between 'asymptotic' and 'indeterminate' growth. In both cases the rate of growth declines with advancing age; but in the second case the potential size is unlimited.

Distinctions of this kind, however, are based upon the fitting of equations to points derived by averaging observations upon populations of animals, and in spite of the real value of such biometric applications, in the study of growth-curves they have tended to lose contact with the real behaviour of observable material. It is possible in practice to distinguish only between species, or particular populations of a given species, which 


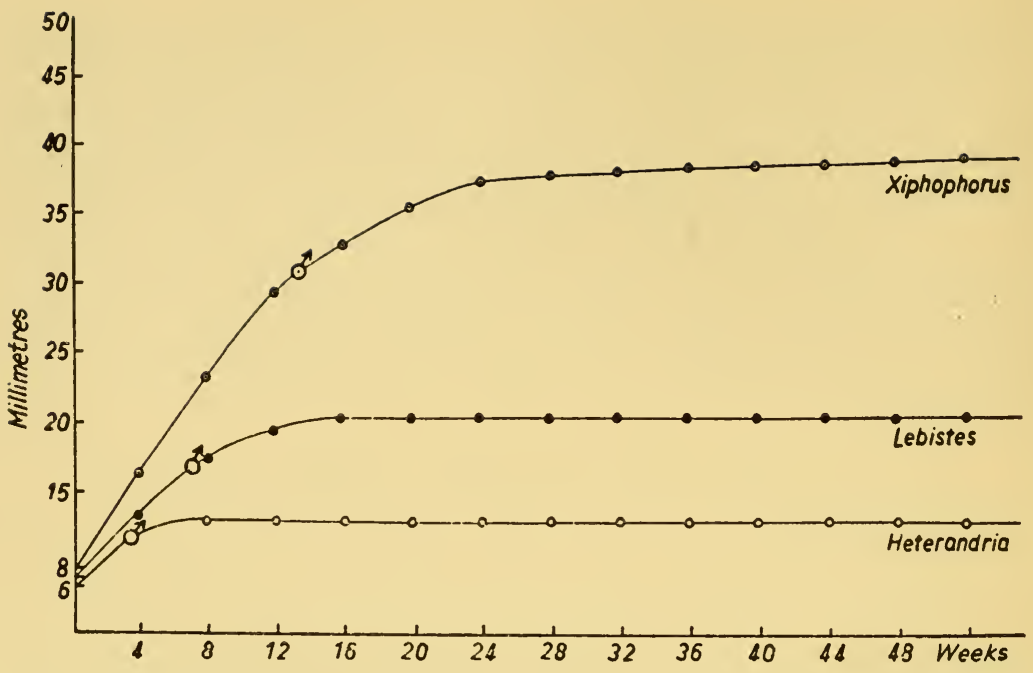

FIG. $15(a)$.- Growth in length (mm.) of male fish of the genera Xiphophorus, Lebistes and Heterandria during the first year of life. Sexual maturity is indicated by $\hat{o}$ (from Wellensieck, 1953).

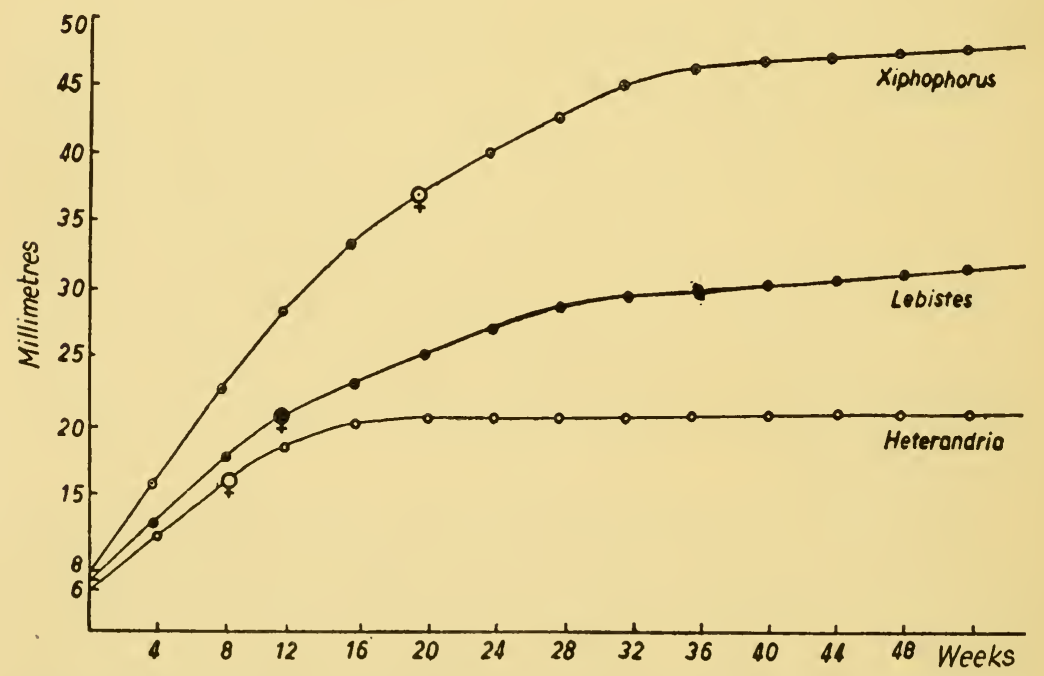

FIG. $15(b)$.-Growth in length of female fish of the genera Xiphophorus, Lebistes and Heterandria during the first year of life. Sexual maturity is indicated by $q$ (Wellensieck, 1953). 


\section{The Distribution of Senescence}

continue throughout life to increase tangibly in size, given suitable conditions, and forms where the maximum size is reached relatively early in life, is fixed for the species, and does not increase further with increasing age even under the most favourable conditions. The chief obstacle to wide generalization about the determinacy or indeterminacy of growth in lower vertebrates, and in other forms such as pelecypods, lies in the fact that arrest of growth at an apparent specific size can be brought about by environmental conditions. In some cases growth can be resumed after such an arrest-in others, apparently, it cannot. Even less is known of the effect of these phenomena on the life-span than is known of the normal ageing of such forms. Differences are also substantial within each of the main groups of poikilothermic vertebrates. In many reptiles and small fish, continued growth after a relatively early age is no more evident than in the male rat. In amphibia, 'many species, particularly some tropical forms, seem to have an absolute size, which the males soon attain, but this does not hold for many salamanders, nor for some Northern frogs' (Noble, 1931). In many cases the male has an absolute size and the female has not. If enough data were available, the variety of growthpatterns is more than sufficient to test Bidder's hypothesisunfortunately, corresponding data upon age/mortality relations are almost entirely lacking.

The idea of a 'self-maintaining' vertebrate is not impossible ex hypothesi. It is in fact what we should expect if growthcessation is an equilibrium process, if there is no important process of differential growth at work, and if there is no qualitative change in the regenerative power of cells throughout adult life. It is not self-evident, though it might be true, that an animal should be obliged to increase in size in order to retain the power of carrying out running replacements. It seems reasonable for our purposes to regard an animal of 'indeterminate' growth as one in which the probability of nursing an individual to the point at which increase in somatic size has ceased is infinitely small, and an animal of 'indeterminate' life-span as one in which the survival rate under favourable conditions is substantially independent of age, however long a population of that animal is observed from birth. 


\section{The Biology of Senescence}

In all the groups whose susceptibility to senescence is doubtful, there is wide variation in life-cycle and growth-pattern, which is very probably reflected in differences of their capacity for age changes. Some aquarium species of fish certainly 'age' as judged by their declining reproductive powers: in the larger sea fish this has not been clearly demonstrated. The contradictory views of fish senescence given to Flower (1935) by two acknowledged authorities, one on aquarium and the other on marine ichthyology, and based on small and large teleosts respectively, are possibly both correct. In other forms there is an obvious sex difference in growth-maintenance, in longevity, or in both. The specific age might also be indefinite in animals which nevertheless became more liable to die, as individuals, with increasing age. It was implied by Ricker (1945) that fish might senesce individually, i.e. undergo a waning of vitality and resistance with age, but that there is no sharp specific age- the life-span of each individual would be limited by senescence, but the senile process would reach its critical point at a much more variable age than in mammals: as if the menopause in human beings were to occur with approximately equal probability in any year after the menarche. Such senescence would be real, but could not readily be detected actuarially.

Very nearly all these problems require abundant new data to settle them finally. The general evidence of the distribution of vertebrate senescence which will be given here is both fragmentary and equivocal. It does, however, contain some facts which suggest that Bidder's hypothesis is too simple and that the manner of growth-cessation, rather than the fact of it, is the main determinant of the mammalian pattern of senescence.

\subsubsection{FISH}

The 'indeterminate' growth of fish, on which Bidder based his hypothesis, has often been discussed (Hecht, 1916; Keys, 1928; Huxley, 1932; Vaznetzov, 1934; Thompson, 1942; Wellensieck, 1953). Many large species of teleosts can continue to grow throughout life, and the rate of decline of their growthrate is considerably slower than e.g. in most reptiles. The locus classicus of continued growth without evidence of senescence, actuarial or reproductive, is the female plaice. Here the evi68 


\section{The Distribution of Senescence}

dence supports Bidder in that growth in the male plaice ceases relatively early, and there is evidence that it has a shorter lifespan than the female (Wimpenny, 1953). On the other hand, in many small teleosts reproductive senescence is known to occur, and both the sexes appear to exhibit specific age, in spite of the fact that growth in the female may continue throughout life. The reproductive failure of many teleosts with increasing age is familiar to aquarists. So is the tendency of particular species to have a limiting age, although there have previously been no published life-tables for any teleost in captivity by which this impression could be confirmed. The growth of some small teleosts has been studied (Felin, 1951; Wellensieck, 1953).

There is a good deal of evidence that small teleosts, and perhaps teleost species generally, undergo both reproductive and actuarial senescence comparable to that of mammals. The most dogmatic assertions on this score are those of pathological anatomists. On the basis of concretions occurring in the testis of a single teleost species (Astyanax americanus), Rasquin and Hafter (1951) hold that the 'appearance of senility changes shows that the teleosts conform to the common vertebrate pattern of ageing despite a widespread misconception to the contrary'. The decline of fertility in some aquarium species provides more solid evidence in support of this view. Many species of fish are in any case exposed to a specialized series of fluctuations in mortality associated with reproduction - the difficulties of treating these fluctuations as a form of senescence in those species which always die after breeding, such as the male of Callionymus (Chang, 1951) and the lamprey, are indicated by observations upon other fish in which there are a limited number of survivors from each breeding season, and these thereafter acquire a new lease of life. It is doubtful if any cyclical or potentially cyclical change in mortality can properly be called senile. In Callionymus lyra in the wild, the male appears to live 5 and the female up to 7 years. The males disappear, probably through death, but possibly by migration to deeper water, after breeding once. Females may first breed in their third, fourth, or fifth year of life, depending on their rate of growth, and probably breed more than once (Chang, 1951). In such a case, 


\section{The Biology of Senescence}

the late-developing females would very probably have a longer total life-cycle.

Studies of wild populations are almost always conducted under conditions where the standing force of mortality throughout life is very high, and they therefore give little information about mortality trends in the latter part of the life-cycle of the longer-lived forms. Excluding the very high larval mortality, populations of many species of fish, studied in the wild, show an age structure and a pattern of death similar to that found in birds, i.e. a high constant mortality unrelated to age and a virtually constant expectation of life (Frost and Smyly, 1952 (Fig. 16); Deevey, 1947). Substantial differences in life-span may be dictated by availability of food organisms of a size suited to adult feeding, and by competition between the fry of the observed species and adults of other species. Some populations of minnows show apparent specific age which is exceeded in other populations of a closely-related species by a very large factor (Frost, 1943; Tack, 1940). In Pimephales promelas, Markus (1934) observed apparent specific size and specific age in all but a few exceptionally large individuals. This was apparently due to the fact that there was an overall mortality of 80 per cent following spawning; the survivors, and individuals which took no part in breeding during their first year of maturity, continued growth until the next breeding season. If reproduction is avoided, life may be prolonged-Bidder (1932) points out that eels, which, it is believed, normally die after spawning, live many years in captivity (Flower, 1925). Frost and Smyly (1952) found considerable differences in growth rates and in the form of the growth curve between brown trout inhabiting tarns and those inhabiting Windermere (Fig. 16). The age structure of the tarn population agreed well with a steady annual survival rate of 35 per cent between the second and eighth year of life. In these fish growth had become very slow, whereas in the Windermere population individual fish were still growing at 7 years upon an approximately linear scale. The ability to continue growth may depend on attaining a size which makes it possible to prey on smaller fish. Long-lived fish such as pike certainly continue to grow measurably for very long periods (Schloemer, 1936) but the increase in size is associated with an 


\section{The Distribution of Senescence}

increase in the size of the prey taken (Frost,1954). Ricker (1945) comments that 'senile death is an everyday occurrence' in population-studies of the Indiana sun fish. This conclusion is, how-

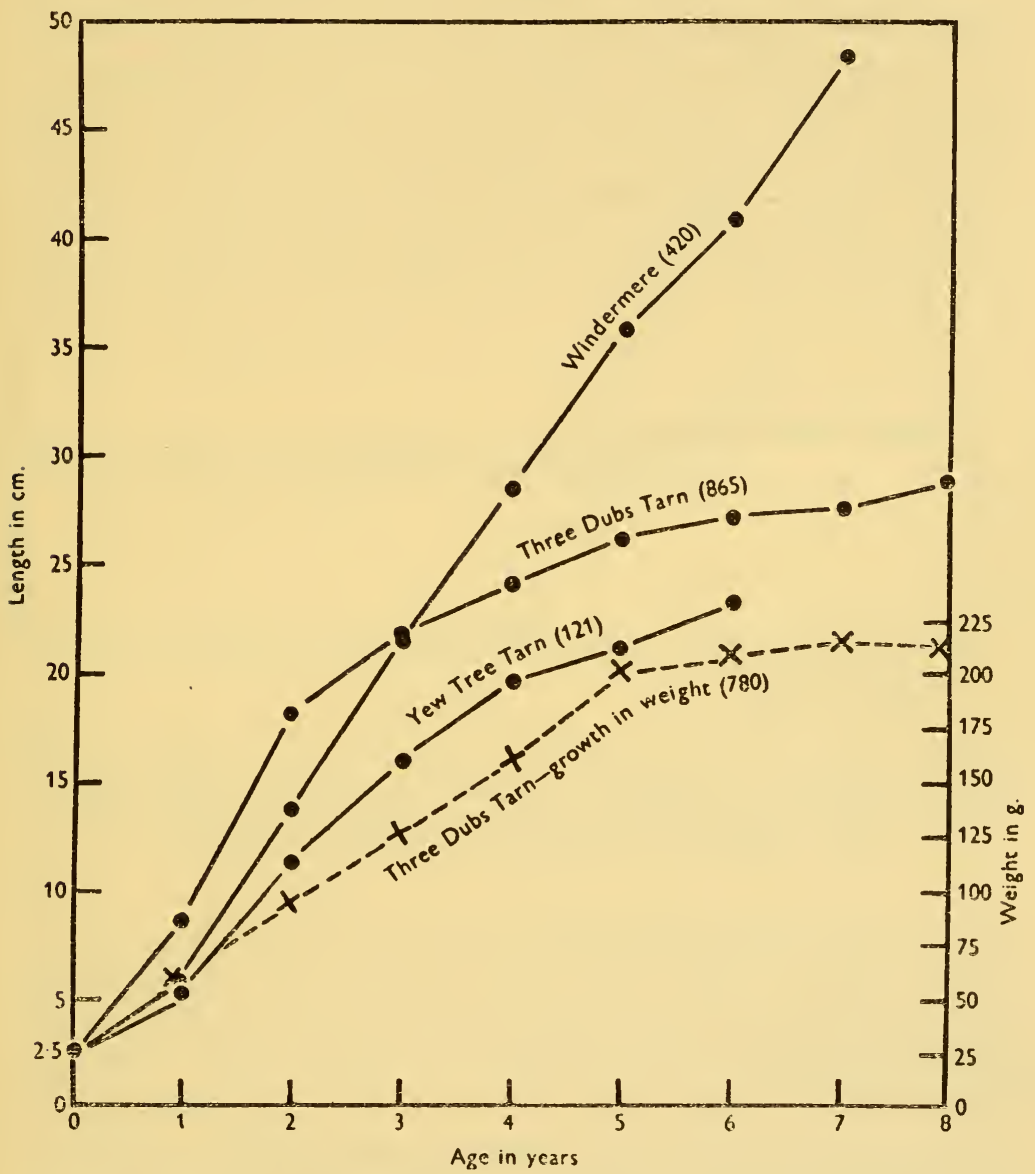

Fig. 16.-Growth of trout in Windermere and the small tarns (Frost and Smyly, 1952)

ever, based upon the failure of known sources of death (disease and predation) to account for the disappearance of fish. The overall mortality rates actually found in marking experiments were 56 per cent for small and 58 per cent for older specimens. 


\section{The Biology of Senescence}

But in many unfished populations of other species there is a steady increase in mortality with increasing age and size (Ricker, 1948).

A great deal of important information upon fish growth was collected by Schmalhausen (1928) from the data of a number of Russian workers (e.g. Tereschenko, 1917). In the sturgeon, growth continues actively throughout at least 30 years of life, with little decline in rate at sexual maturity (about 15 years). In the bream, on the other hand, the growth constant shows a more regular and progressive decline. These fish were found to mature at about 3 years, and degenerative changes in the

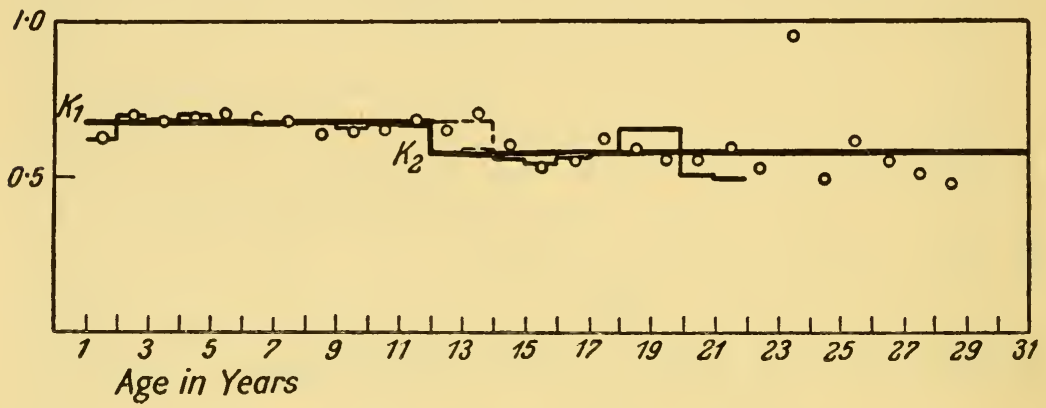

Fig. $17(a)$.-Growth-constant for growth in length of the sturgeon, Acipenser stellatus, at various ages. Broken line-females: single pointsmales: thick line, mean value for males; dashes, mean value for females. $\mathrm{K}_{1}=0.67, \mathrm{~K}_{2}=0.58$ (from Schmalhausen, 1928).

gonad were usually evident from the sixth year on-two definite stadia could be observed in the growth curve, one following puberty, and the other following this gonadal senescence, the growth coefficient settling down to a steady value thereafter without further decline up to 13 years of age (Fig. 17a,b,c). This rather closely resembles the pattern reported in the goldfish.

In Xiphophorus and Lebistes the male exhibits sharp specific size, but the female may continue to grow measurably throughout life, the pattern of growth differing little from that of the plaice (Wellensieck, 1953). Yet in these forms previous experience suggests that there is no striking difference between the survivals of the two sexes in captivity (Bellamy, 1934). In Heterandria both sexes reach a virtual limiting size (Wellensieck, 


\section{The Distribution of Senescence}

1953), Fig. 15a, $b$. In the goldfish, according to exhibition breeders, fertility reaches a maximum under aquarium conditions in the third year of life, declining thereafter, and almost all fish are sterile by the seventh year. Breeding at 10 years is recorded (Hervey and Hems, 1948). When the reproductive

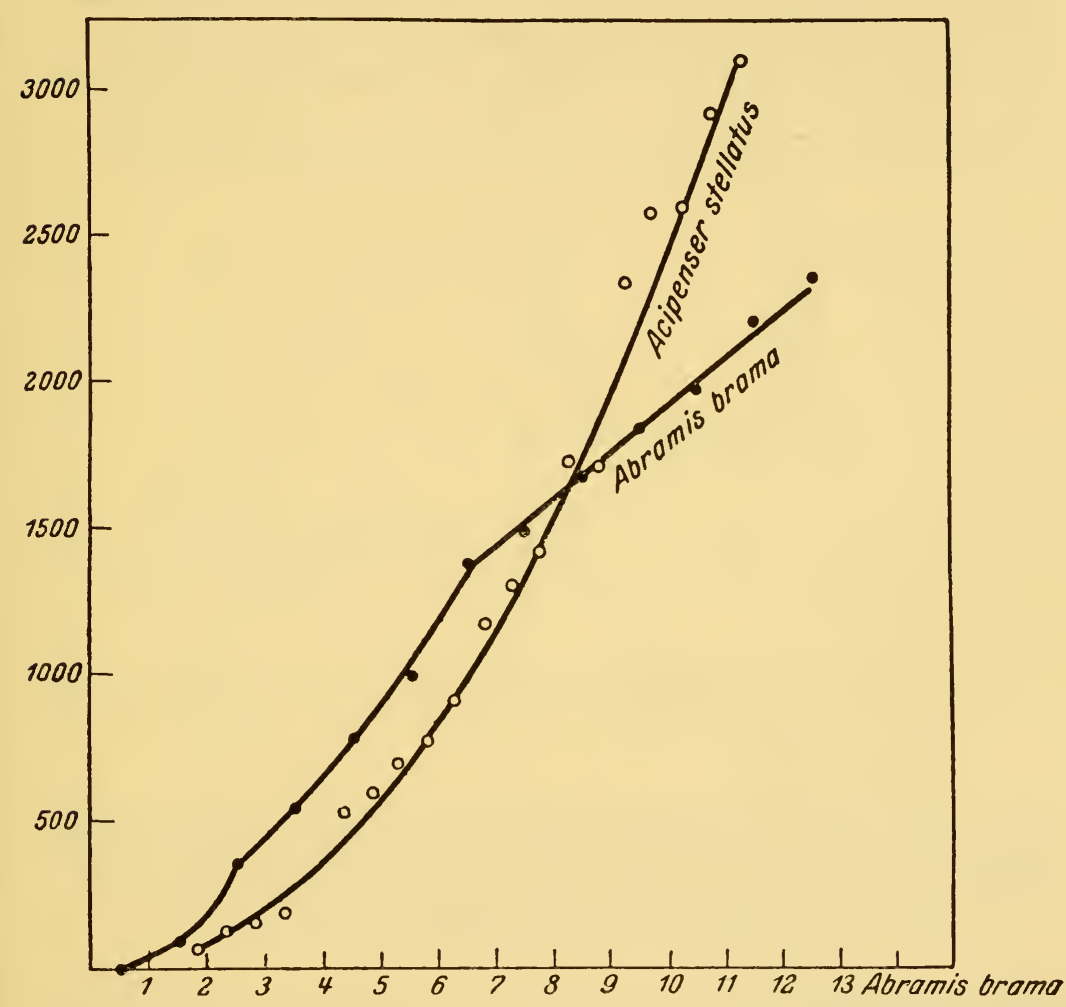
Age in Years

Fig. $17(b)$.- Growth in weight of the sturgeon (Acipenser stellatus) and the bream (Abramis brama). Scale for A. stellatus 1 Russian $\mathrm{lb}=100$. Scale for A. brama $1 \mathrm{~g} .=1$ (after Schmalhausen, 1928).

life is over, however, the fish may improve greatly in condition, and appear much less sensitive to environmental damage than before. In exhibition fish the life-span appears to be about 17 years, though much older examples are known. The extreme 


\section{The Biology of Senescence}

record of longevity appears to be between 30 and 40 years. Rate of growth is extremely variable. One specimen, kept in a six-gallon tank, reached a length of only 4 inches in 25 years (Hervey and Hems, 1948).

In none of these cases is it clear how large a part of the potential life-cycle is actually covered by the observed growth curve. In most fish the rate of growth does in fact decline with age, though in many the effective reproductive life appears to

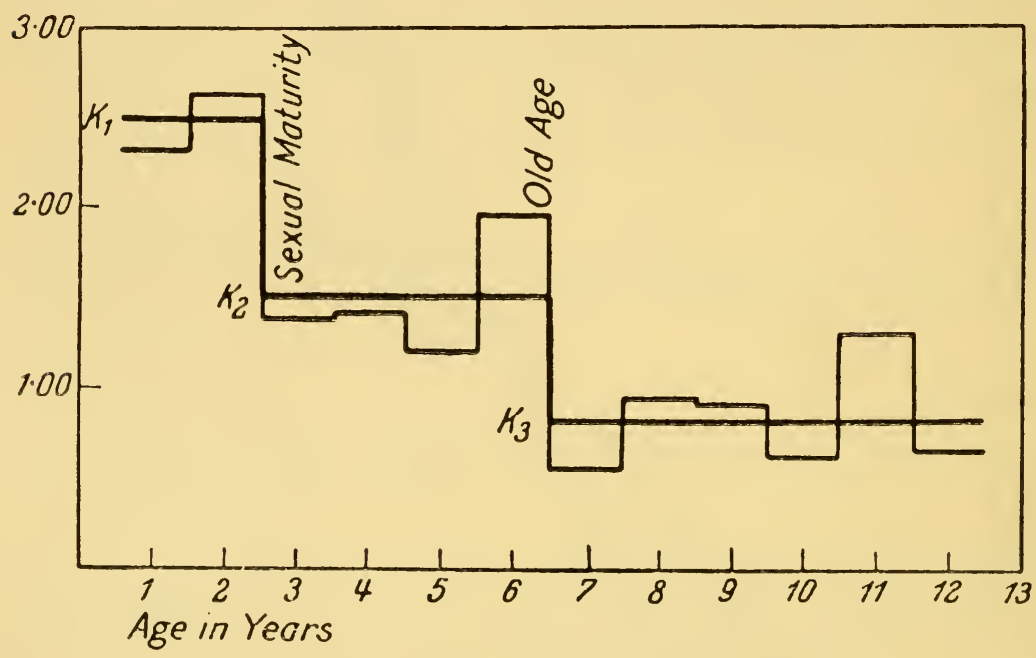

Frg. $17(c)$.- Growth in weight of the Bream (Abramis brama)-annual increments. The mean growth-coefficients at various stadia (youth, maturity, postreproductive life) are indicated by transverse lines $K_{1,2,3}$ (from Schmalhausen, 1928).

have ceased long before this decline has produced an almost stationary body-size. The reproductive decline, moreover, does not appear to involve any decrease in vigour, and may actually imply the reverse, in view of the hazards which reproduction involves for many fish.

In the small teleosts, it ought to be possible to answer most of these questions by direct experiment. For this purpose the guppy (Lebistes) is proving a particularly suitable experimental animal, both because of the ease with which it can be reared and handled for purposes of measurement, and because of the 


\section{The Distribution of Senescence}

neatness with which its growth can be controlled by varying the food intake and living space.

A large population of Lebistes has been kept at University College under conditions in which each individual was isolated throughout life, and the dates of birth and death were accurately known. Dr. H. Spurway has kindly allowed me to use her data on this population; from these, and from fish which I have kept myself, it has been possible to construct a number of lifetables for Lebistes under different conditions. These are consistent, and all show a progressive increase in mortality with

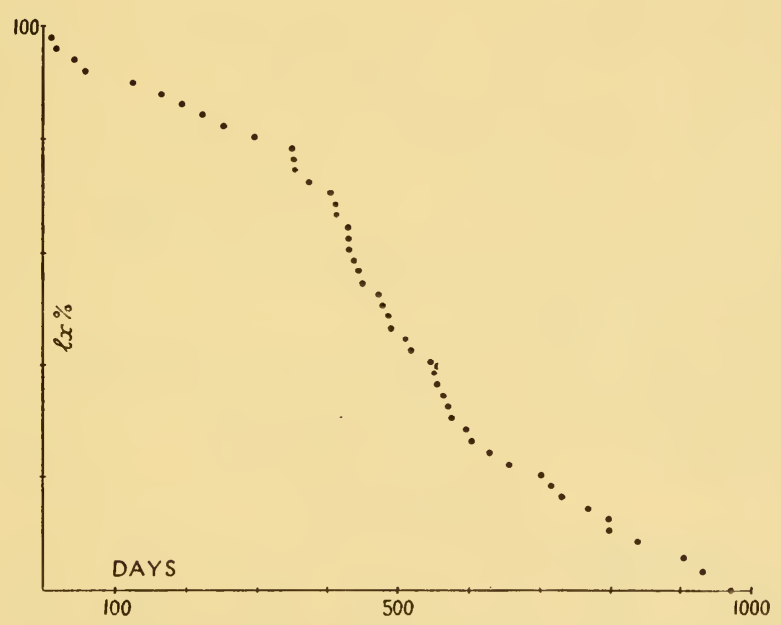

Fig. 18a.-Survival of 12 male and 40 female guppies (Lebistes reticulatus) kept individually at $25^{\circ}$ C.: sexes combined. (From data provided by Dr. H. Spurway.)

advancing age very similar to that found in mammalian lifetables (Fig. 18a). The fish in this sample were not measured during life, but had certainly reached or exceeded the usual 'specific size'. The growth rate of female Lebistes and the size at which the growth curve reaches a plateau can very easily be altered. Spurway has found that these fish could be kept in individual half-pint milk bottles-by combining restricted space with restricted diet, I have kept female Lebistes at a length of about $2 \mathrm{~cm}$. for as long as 600 days. In this state they are 


\section{The Biology of Senescence}

reproductively mature (unlike the rats subjected to retardation by McCay-p. 149) and capable of resuming growth. There are 'specific sizes' characteristic of each size of container and each level of nutrition-or, alternatively, of each population-density in a tank, when a fish is promoted from one such container to a larger, or when fish are removed from a tank population, a new plateau is rapidly reached. The curve given by Wellensieck represents only one such equilibrium, The growth capacity also appears to decline somewhat throughout life, and there is a

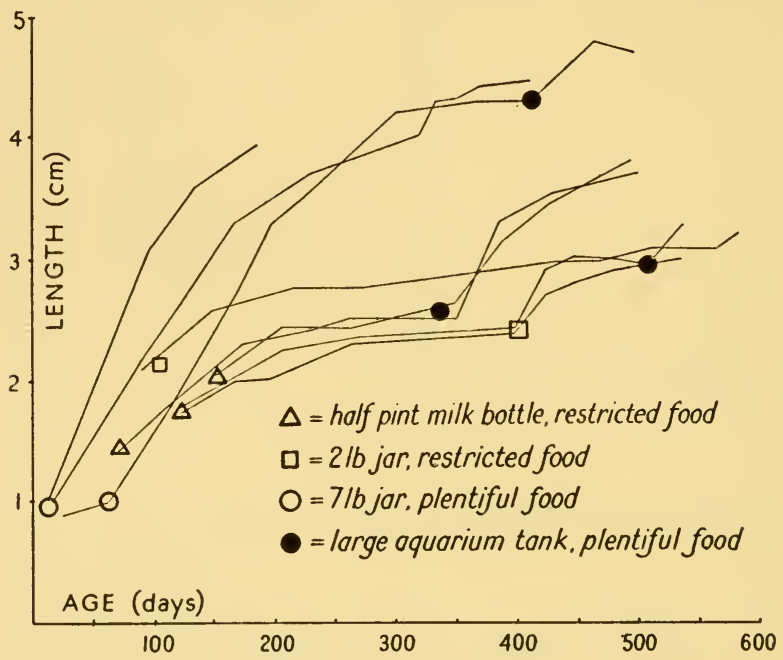

FIG. 18b.-Growth of female guppies (Lebistes reticulatus) in different conditions of feeding and living-space. The symbols indicate the time of transference to new conditions. All the fish were alive at the time of drawing. The growth pattern of the fish whose life-table is given in Fig. $18 a$ approximated to that of the fastest group shown in this figure.

practical limit, as might be expected, to the size of guppy which can be produced at maximum food intake and maximum living space. The combination of variables in Lebistes, and the fact that the life-span of the non-growing males is not, upon present data, grossly different from that of the growing females, suggest that a great deal about growth and senescence in fish can be 


\section{The Distribution of Senescence}

learned by the collection of actuarial data for guppies subjected to different programmes of growth: this work is in hand, but it is in the nature of the subject that life-table making cannot be hurried, and life-tables under various conditions of growth were not ready for inclusion here. The growth curves shown in Fig. $18 b$ are instructive, however, when we compare them with the closely similar growth-behaviour and pseudospecific size of wild trout.

It seems probable that there is as much variation in 'senescence' as in growth-patterns among teleosts. Some forms apparently resemble monocarpic plants, mortality being linked to reproduction. Some, in captivity, have a life-span determined by senescence, their mortality increasing with age on a curve closely similar to that of mammals. Some forms, however, may conceivably have an effectively indeterminate life-span, and are not at present known to undergo any form of senescence, reproductive or general, other than the accumulation of injuries, though this may well mean only that their 'determinate' maximum, as in wild birds, comes so late in relation to mortality as never to be reached in practice. The effect of variation in the growth-rate upon the development of senescence has yet to be determined.

\section{2·4·2 REPTILES}

There are no published reptilian life-tables, but a number of careful studies of reptilian growth have been made (Sergeev, 1937; Townsend, 1931, 1937; Cagle, 1946). By collating these with maximum age records, a good deal of significant information can be obtained. Sergeev found that while, in all reptiles, early growth depends on environmental conditions, being sometimes very rapid, and growth rate declines with increasing age, there are a number of forms where both sexes have an effective specific size which is reached early in life, and after the attainment of which no further growth occurs. The cessation of growth in these forms is apparently as definitive as that in mammals, and its timing does not appear to depend on the arrival of sexual maturity. There appears to be no close correlation between either of these two patterns of growth and the length of the life-span. 


\section{The Biology of Senescence}

Among chelonians, both patterns of growth are known to occur. Continuous growth as a decreasing rate appears to be general in tortoises, the large species having inherently higher growth rates throughout. Townsend $(1931,1937)$ found that early growth in 100 specimens of the large $T$. vicina, kept in captivity, was potentially very rapid, and continued after the age of sexual maturity (about 20 years of age). Flower (1945) observed continuing growth in a 39-year old specimen of T. graeca. The age of sexual maturity in the male Terrapene carolina appears to lie between 12 and 15 years (Nichols, 1939). All these are known to be long-lived forms. On the other hand, the majority of terrapins exhibit specific size. In Emys Sergeev

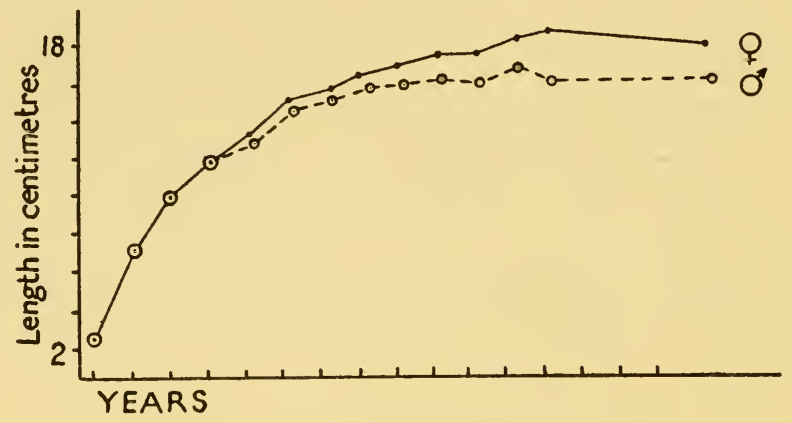

Fig. 19.-Growth of Emys (Sergeev, 1937).

(1937) found that growth-cessation by the fifteenth year of life was as complete as in the adult mammal (Fig. 19) although $E$. orbicularis, like $\mathcal{T}$. graeca, is apparently capable of living 70-120 years and probably of breeding throughout life (Flower, 1937). Rollinat, however, on whose observations Flower's records were based, considered that growth in this form might continue for 30-40 years (Rollinat, 1934). Hildebrand (1932) studied the longevity and growth of over 1,000 specimens of Malaclemmys centrata in captivity - an investigation which is the nearest published approach to a chelonian life-table, but which was unfortunately continued in detail for only 10 years. He found the age of maturity much more variable than in mammals, some individuals being full-grown in 8-9 years, others requiring 12-15. The oldest specimens in captivity were 21 years old, and 


\section{The Distribution of Senescence}

'showed every appearance of being young animals', but other wild specimens taken when full-grown had been kept for 20 years without decline of vitality or reproductive power. Hildebrand placed the maximum life-span for this species at 40 years or more, but evidence from other small terrapins suggests that this may be a considerable underestimate. Although the only aquatic species which is known to have reached an age comparable with that of the land tortoises is Emys orbicularis, it would be very difficult to argue upon the existing evidence that specific size and determinate age are correlated in chelonians. Contrary to Bidder's hypothesis, specific size here seems to be an adaptation to carnivorous life in small pools, while continuing growth is found in land tortoises and marine turtles (Parker, 1926, 1929).

Crocodiles have also been credited with indeterminate growth - 'Crocodili perhibentur esse admodum vivaces, atque grandescendi periodem itidem habere insignem; adeo ut hos solos ex animalibus perpetuo, dum vivunt, grandescere opinio fit. ... At de aliquo testaceo genere, nihil certi, quod ad vitam ipsorum attinet, reperimus' 1 (Hist. Vitae et Mortis). Claims of longevity are based on the exceptional size of some specimens. Large alligators have been observed in captivity to remain for 25 years in a non-growing state, e.g. Alligator sinensis (Dathe, 1935), though the difficulties of accurate length-measurement are evident.

\subsection{Distribution of Senescence in Invertebrates}

Among invertebrates not only is there a demonstrable variety, greater than in vertebrates, in the nature of the preponderant senile process, but we have also the full range, from indeterminacy to very sharply defined determinacy of life-span. The gaps in our knowledge of life-cycles are so large that we cannot yet picture the distribution of senescence in invertebrate phylogeny: papers entitled 'The life-history of ...' only very exceptionally include reference to the senescence of the species

1 'Crocodiles are held to be very lively, and to have a notable span of growth-so that they alone of beasts, so opinion runs, grow so long as they live. ... But of any hard-skinned beast, as pertaining to their length of life, we find nothing certain.' 


\section{The Biology of Senescence}

under study - an extraordinary deficiency, which is a measure of the equally extraordinary lack of interest in age processes. It is fairly evident, however, that the distribution both of senescence in general and of any one process of senescence, such as depletion or mechanical deterioration, is quite discontinuous in phylogeny. This evolutionary discontinuity is what we should expect if 'exhaustion of programme' is the common basis of adverse age changes.

Senescence in some shape or form probably occurs in every group where the power of regeneration or fissile reproduction is less than total, or where body-cells are not continuously and 'indeterminately' replaced. Some forms which 'degrow' under adverse conditions appear to be capable, in all probability, of unlimited alternate growth and degrowth, at least in the laboratory, while in a few, such as actinians, the adult can remain indefinitely in statu quo, though with a changing population of cells. Senescence is most striking in forms such as rotifers where determinacy of cell number is very highly-developed and the power of regeneration is usually negligible. There do not appear to be any invertebrate cells (except possibly pelecypod neurones, of whose longevity and renewability we know little) which are called upon to remain for 100 or more years in active function, like a human neurone, or for still longer, like the neurones of the tortoise. The distribution of senescence in invertebrates suggests that in spite of the general argument against the selection of long-lived forms, relatively great longevity is sometimes an evolved adaptation, and that if some coldblooded vertebrates are in fact immune to senile change, that, too, is likewise a specialized mechanism and not a primitive or an 'inherent' mechanism which has been lost with increasing somatic complexity.

\subsubsection{PORIFERA}

Bidder infelicitously cited 'the sea anemone, the bath sponge and the water-vole' as three organisms insusceptible to senescence. The only serious study of senescence in Porifera appears to be that of Arndt (1928) who concludes that it does not occur, although some sponges are fatally disrupted by their own larvae. Aquarium specimens have an effectively limited life, as in so 


\section{The Distribution of Senescence}

many other groups, but sponges seem ideally able to conform to Bidder's expectations of them.

\subsubsection{COELENTERATES}

In hydromedusae, Child (1918) observed a progressive decrease in metabolism and pulsation rate with increasing size, which he regarded as evidence of senescence. His work on the processes of ageing and rejuvenation in hydroids (1915) depends on the criterion of resistance to cyanide as evidence of 'physiological age'-one which is hardly acceptable in this context. Child's results with Pennaria, using this test of age, were in any case less consistent than those he obtained with planarians, where cyanide resistance rose steadily throughout life (Child, 1915).

Evidence that the life-span of sea anemones is 'indeterminate' is probably stronger than for any other metazoan group. Dalyell's (1848) celebrated specimens of Actinia lived for 70 years in captivity without any sign of deterioration. An even more famous batch of sea anemones were collected 'some years prior to 1862', and were first identified as Sagartia troglodytes by Ashworth and Annandale (1904), later by Stephenson as Cereus pedunculatus (1935). They remained in the aquarium of Edinburgh University Department of Zoology until 1940 or 1942, when they were all simultaneously found dead. Budding continued freely throughout life, and the animals underwent no obvious change during eighty to ninety years of continuous observation (Warwick, 1954, personal communication). Whether gametogenesis likewise continued throughout life is not known.

Hydra. The long-standing controversy over the senescence of Hydra illustrates some of the difficulties of placing a gerontological interpretation on life-tables and histological appearances. Hydra was a favourite organism, earlier in the century, in the argument over the 'potentielle Unsterblichkeit' of metazoa. Differences in culture conditions almost certainly account for the very irregular results obtained.

Early workers (Hertwig, 1906; Boecker, 1914; Berninger, 1910) on this question found it impossible to keep Hydra for long periods without the onset of 'depression', evidenced by cloudy 


\section{The Biology of Senescence}

swelling and cytolysis. With better cultural methods Goetsch (1922, 1925) kept individuals of Pelmatohydra oligactis, Hydra attenuata, and Chlorohydra viridissima alive for 27 months. Goetsch considered that like the actinians Hydra was capable of remaining indefinitely in statu quo. Gross (1925) working with $P$. oligactis failed to keep any individual alive for more than 349 days, 'senescence' being evidenced by irregular and hypertrophic budding or by the animal becoming smaller and smaller in the presence of abundant food. 'Senile' changes in Gross's material began after the fourth month of life. A life-table, drawn from Hase's (1909) data by Pearl and Miner (1935), extending over only 148 days, indicates some increase in mortality with age, but is closer to the log-linear than to the rectangular contour (see Fig. 6c, p. 20). Hartlaub (1916) had already described experiments on Syncorinae in which he concluded that the power of producing gametes was lost relatively early in life, while that of budding persisted.

David (1925) kept isolation records in cultures of $P$. oligactis and satisfied himself that in this form the individual animals tended to die between 20 and 28 months in approximate order of individual age-an important observation which has not been repeated. According to Schlottke, however (Schlottke, 1930), the material in David's histological sections was heavily parasitized. Schlottke's own observations suggested that all the tissues of Hydra are continuously replaced throughout life, from a subjacent reserve of interstitial cells. This view is supported by the work of Brien (1953), who showed by marking experiments that there is continuous growth in Hydra from before backward, the marked zone travelling down the animal and being ultimately rejected at the base: a case, in other words, of 'indeterminate growth' coexisting with a final specific size.

In colonial hydroids, however, it seems to have been shown beyond reasonable doubt that the life-span of each hydranth is physiologically determinate. The resorption and involution of hydranths was described in full by Huxley and de Beer (1923); the hydranth shrinks, the gut becomes filled with cellular debris, and the degenerating material is returned to the colony by the contraction of the hydranth itself. In Obelia and Campanularia Crowell (1953) has now shown that regression takes 


\section{The Distribution of Senescence}

place strictly in order of age, each hydranth having a life of 4 days at $21^{\circ} \mathrm{C}$. and 7 at $17^{\circ} \mathrm{C}$. When regression is accelerated by starvation or adverse culture conditions, the age order is still preserved.

\subsubsection{SUNDRY INVERTEBRATES}

Existing observations are scattered rather thinly over a number of groups. Child $(1911,1913,1914,1915,1918)$ carried out exhaustive studies upon the regeneration of planarians, and upon their capacity for de-differentiation, to which subsequent research has been able to add little or nothing. Here again, as in Pennaria, he employed the increase in resistance to dilute cyanide solutions as a criterion of senescence, on the assumption that this change reflected a decrease in metabolic rate. While susceptibility decreased as a function of age in the growing animal, planarians kept for several months at a constant size showed no such increase, and planarians undergoing shrinkage under adverse food conditions showed a decrease in susceptibility. Child also demonstrated the 'rejuvenation', partial or entire, of regenerating fragments of planarians. This further observation, using the same criterion of resistance to toxicity (1915), that a gradient of 'rejuvenation' exists in Stenostomum (Rhabdocoela) during the production of new zooids has been confirmed by Sonneborn (1930) using direct life-table studies. Sonneborn's experiments showed that the regenerative effects of fission were markedly unequal in the two halves, since the head portions, which required only to regenerate tails, underwent typical senescence, and died after a limited number of divisions, while tails, which required to regenerate most of the body and nervous system, could be propagated indefinitely.

In Aeolosoma (Oligochaeta), Haemmerling (1924) found that the anterior end of the body appeared to undergo eventual senescence, new worms being produced from the posterior end. Stolč (1902) had already given a circumstantial histopathological account of 'senile' death in Aeolosoma as a whole, but the appearances observed might have resulted from almost any environmental cause. In Nais (Annelida), Stolte $(1924,1927)$ found extensive histological changes with age, with disappearance of the normal zones, degeneration of the visceral ganglia, G 


\section{The Biology of Senescence}

and the cessation of reserve-cell production from the embryonic tissue persisting in the posterior end. The significance of these changes is again obscure, and no attempt was made to determine actuarially the mortality rates at different ages. Rhabdocoelians have (Bresslau, 1928-33) been observed to be increasingly susceptible to protozoan parasites the longer they live.

How far the capacity for 'degrowth', which is found in planarians, is evidence of a potentially indeterminate life-span is not evident, but it seems likely that forms such as Lineus (Nemertinea), which revert on starvation over a period of years to a mass of cells resembling an embryo (Dawidoff, 1924), might be maintained indefinitely in alternate growth and degrowth until the patience of the investigator was exhausted.

The evidence in fissile worms at present suggests that nonsenescence depends upon fairly active replacement of cells, and that any organ which fails to take part in the regenerative process is liable to undergo senile change. Harms (1949) considered that the senescence of Serpulids was due primarily to changes in the nervous system, and rejuvenated old specimens of Protula by grafting young heads. Some further work on this subject as careful as that of Child and Sonneborn would probably be well worth undertaking.

Morphogenetic loss throughout life of the power of regeneration in a nematode of determinate cell-number was actually demonstrated by Pai (1928) in Anguillula aceti. Amputation of the tail with nuclear removal kills the animal at any age. In young individuals, provided the nucleus is left intact, wound healing and cytoplasmic regeneration can take place. In mature animals there is wound closure but no cytoplasmic regeneration, while in senile animals amputation is fatal. In Anguillula senescence follows a pattern very similar to that of rotifers (see below) and occurs at about 44 days. The degenerative cellular changes in ovaries, gut and nerve cells have been described: these appear in the two or three days preceding death Pai, 1928; Bürger, 1954).

\subsubsection{ROTIFERS}

The ageing of rotifers is one of the most spectacular examples of endogenous senescence in animals. It is also one of the most 


\section{The Distribution of Senescence}

thoroughly-studied, at least from the descriptive point of view. The life-span varies in different species from a few days to several months, and each species tends to exhibit very sharp specific age. After a period of growth, which takes place by increase in cell size, the nuclear number being fixed, and adult vigour, rotifers enter a period of senescence, with conspicuous loss of activity, degeneration of cells, deposition of pigment, and ultimate death in extension. In some forms the senescent phase is genuinely post-reproductive, but in the majority it occurs while egg-laying is still occurring at a diminished rate, and may be accompanied by the production of malformed eggs, or eggs of varying size.

The external appearances of rotifer senescence have been vividly described in several forms (Callidina, Plate 1886; Pleurotrocha, Metchnikoff, 1907; Proales, Noyes, 1922; Jennings and Lynch, 1928; Hydatina, Plate, 1886; Lecane, Szabó, 1935; Miller, 1931; Rotifer vulgaris, Spemann, 1924). The animal becomes sluggish in behaviour and reaction to jarring, the tissues and cuticle shrink and become opaque or granular in appearance, swimming is replaced by creeping, pigment accumulates in the gut, digestive gland and mastax. The movements of the pharyngeal cilia are the last signs of life to persist.

It seems clear that this is an endogenous process of degeneration. A number of attempts have been made to correlate it with other features of rotifer organization. Plate (1886) considered that senescence in Hydatina occurred typically when the activity of the ovary, and the supply of germ cells, failed. This is not the case in all rotifers, however. In Lecane inermis Miller (1931) found that the mictic females cease egg laying early in life and have a relatively prolonged post-reproductive period, while amictic females show signs of age before the last egg is produced, and all are dead within two days thereafter; the life-span of males is even shorter (Fig. 20). In this species, fertilization of the mictic females does not appear to influence longevity. Miller attributes the difference in life-span between mictic and amictic females directly to the difference in fertility, but this is not fully borne out by her life-tables, the chief difference being in the longer post-reproductive period of the mictic females. In Hydatina senta it is the amictic females which are the longer 


\section{The Biology of Senescence}

lived (Ferris, 1932). In both these species, however, the form having the higher reproductive rate in early life dies younger, an observation which supports Miller's suggestion that death results from 'exhaustion'. Egg laying in Apsilus vorax continues until death (Cori, 1925) and in Proales, appears itself to be adversely affected by somatic senescence, the egg-substance failing to enter the eggshell, and eggs of bizarre size and shape and of low hatchability being produced (Jennings and Lynch, 1928). Old populations of $P$. sordida consist of two types of

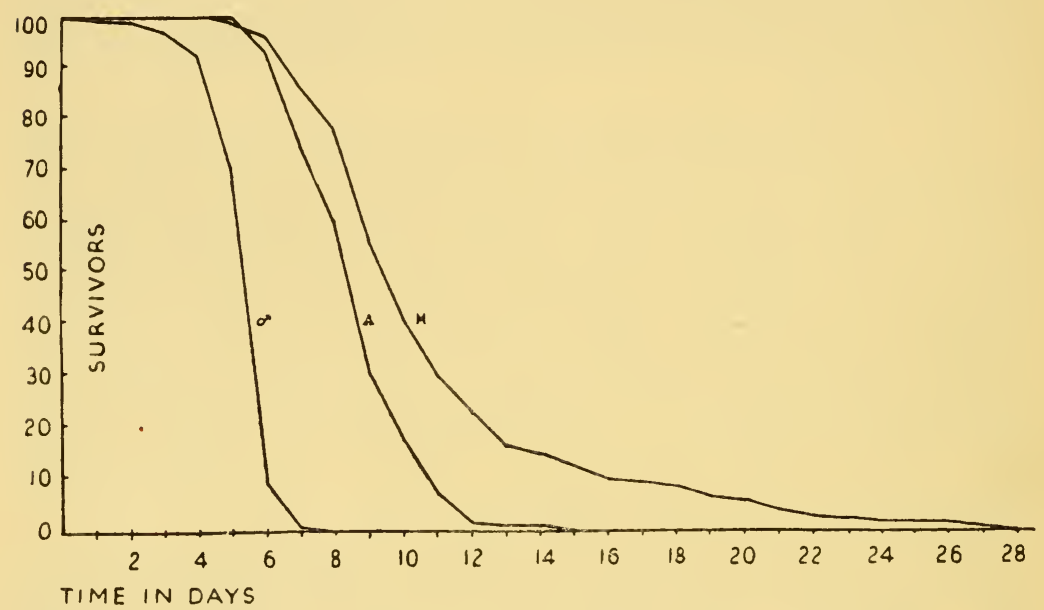

FIG. 20.-Survival curves for males, mictic (M) and amictic (A) females of Lecane inermis (from Miller, 1931).

senile individuals, some thick and opaque, and others abnormally transparent, with pigmentation of the gastric glands. There is considerable individual variation in the length of survival once senescence is established.

Impairment of function in all the species which have been studied is so general during senescence that it is not possible to identify a pace-maker organ in the process, though in some cases it appears to be the digestive system which first deteriorates. The pattern is fully consistent with some or all of the somatic cells having a fixed survival-time under normal metabolic conditions- a highly important precedent for the study of other types of metazoan senescence. The senescent change 


\section{The Distribution of Senescence}

depends directly upon metabolism-encysted rotifers can survive for very long periods (59 years-Rahm, 1923) and display enhanced reproductive performance on emergence from diapause (Dobers, 1915).

It is particularly interesting that this dramatic senesence in rotifers accompanies a very strict determinacy of cell number, a lack of regenerative capacity, and in most species a very

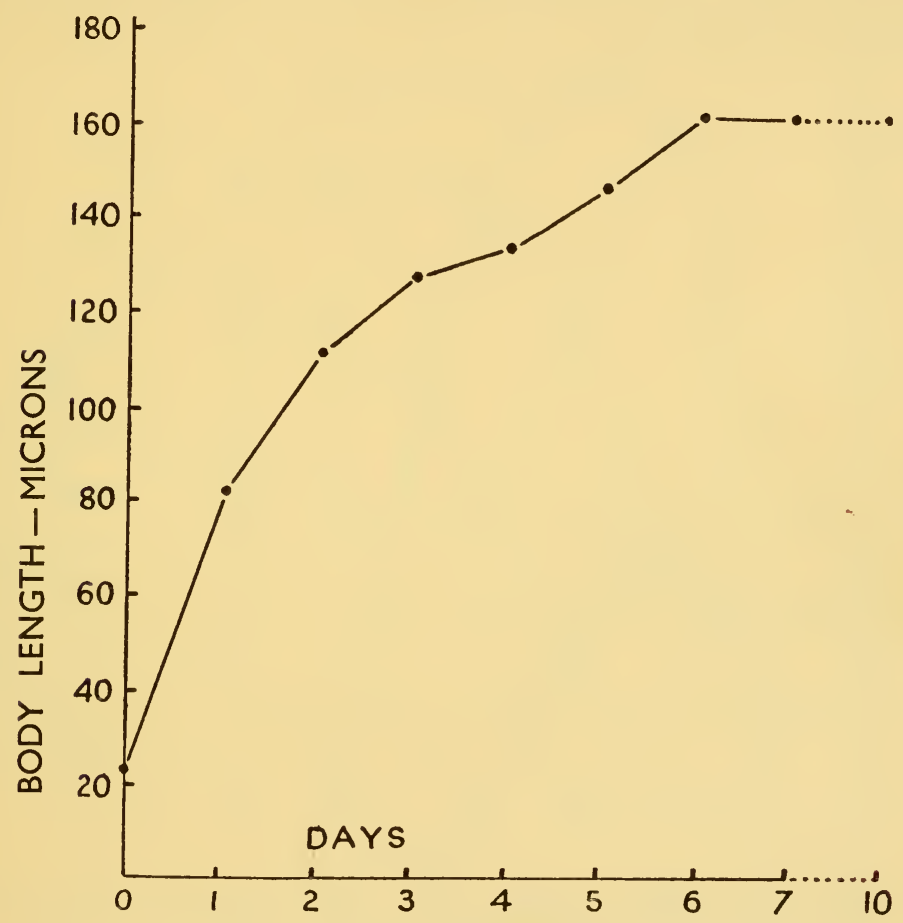

Fig. 21.-Growth in length of Philodina citrina (Lansing, 1948).

limited power of repair. Nuclear division after hatching has not been described in any rotifer. In many forms wound healing is confined to young animals-older animals die after amputation (Pai, 1934) but in young Asplanchna brightwelli (Pai, 1934) and Stephanoceros (Jurszýk, 1926, 1927; Ubisch, 1926) the cytoplasm of the coronal lobes can be regenerated, as can parts of the coronal funnel in Cupelopagis (Huhnerhoff, 1931; references from Hyman, 1951). 


\section{The Biology of Senescence}

The somatic growth of rotifers has been studied by several workers. Rotifer vulgaris shows little or no change in size throughout life (Spemann, 1924). The growth curve of Apsilus vorax is a parabola, with shrinkage before death (Cori, 1925) while in Philodina citrina growth ceases by the sixth day (Lansing, 1948). (See Fig. 21.) Lansing also made the striking observation that

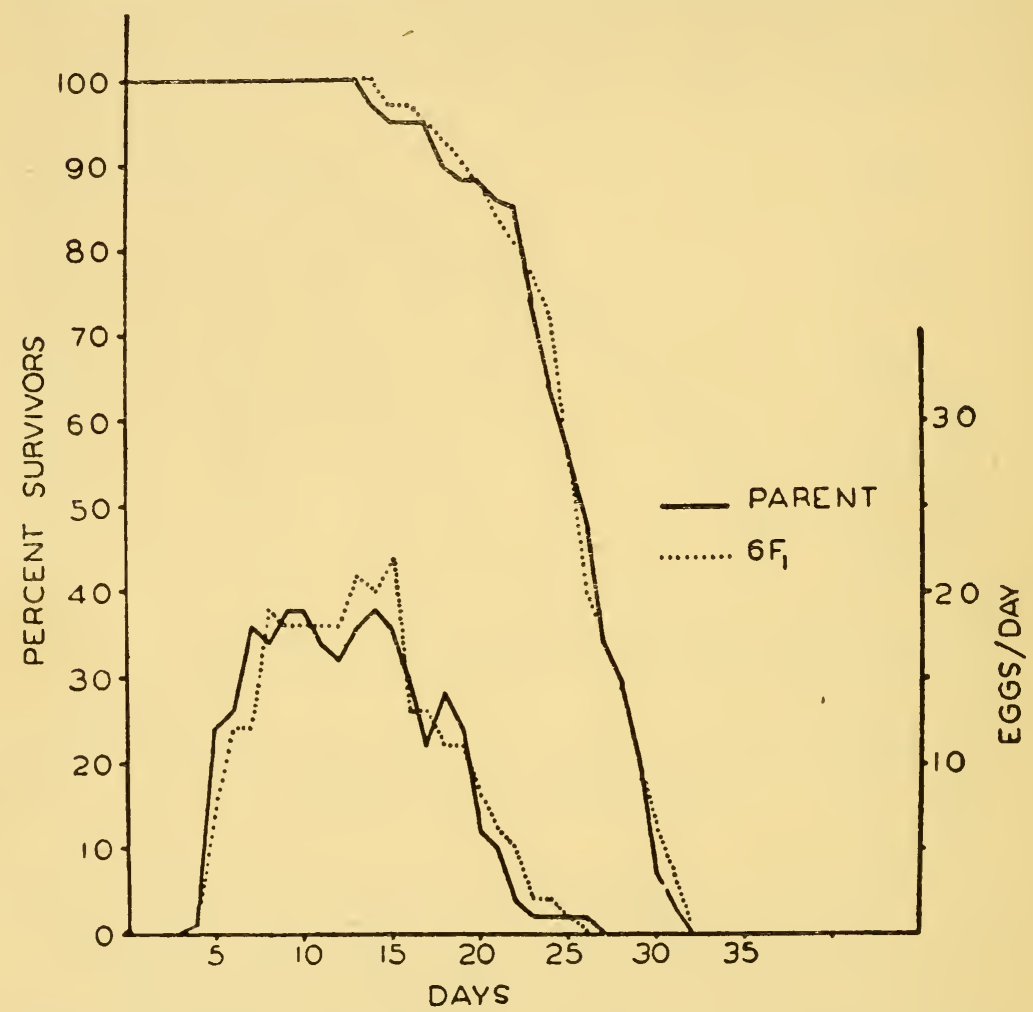

FIG. 22.-Life-span and egglaying of Philodina citrina (Rotifera) over 6 generations in normal culture (from Lansing, 1952).

if these rotifers are propagated in each generation from eggs laid at or after the fifth day of maternal life, the rate of development becomes progressively greater and greater from generation to generation, and the longevity of the individual less and less, so that clones propagated in each generation from old mothers invariable become extinct (Figs. 22, 23, 24). Jennings 88 


\section{The Distribution of Senescence}

and Lynch (1928) had already noted that the offspring of very old rotifers are less viable than those of vigorous adults. Lansing's results suggested that the effects of maternal age are cumulative from generation to generation: they were also reversible, the eggs laid by young members of such a clone being capable of giving rise to normally long-lived individuals. Lansing also found that clones propagated in each generation from the eggs of very young mothers showed an increase in

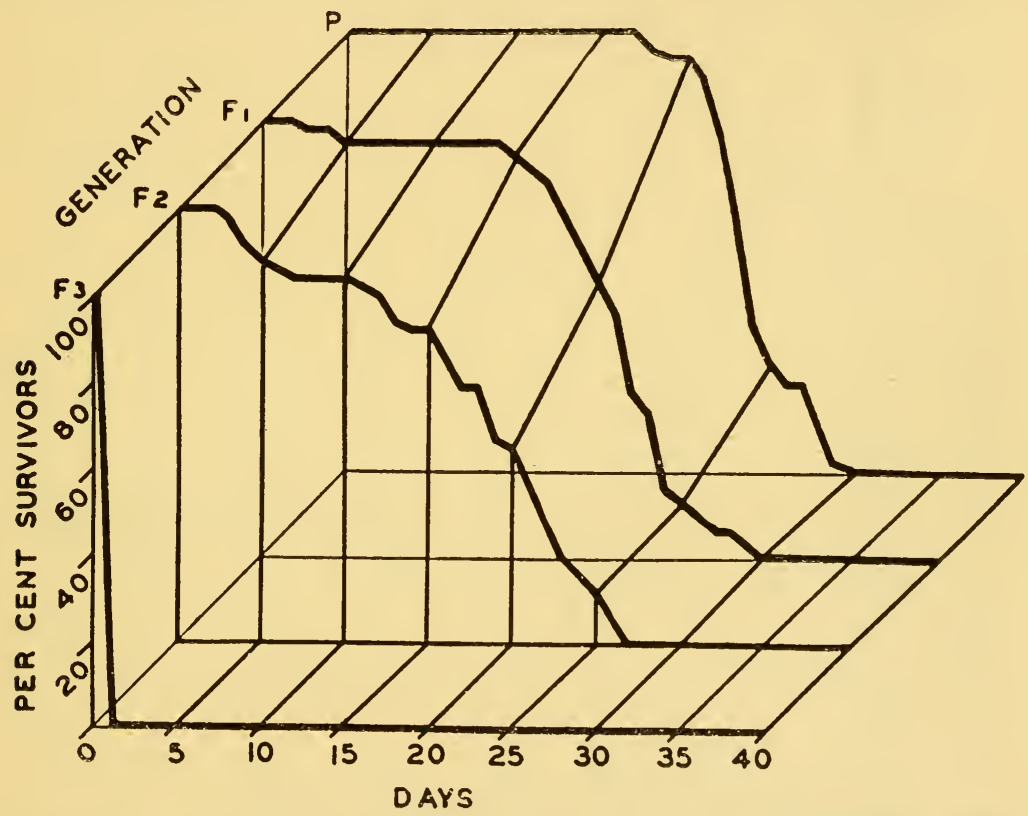

Fig. 23.-Progressive decline in life-span of a strain of Philodina citrina (Rotifera) raised in each generation from eggs laid by old mothers (from Lansing, 1952).

longevity over the control stock. In Euchlanis triquetra, the 'young' orthoclone could not be maintained, however, because within a few generations it gave rise largely to male-producing eggs. Lansing regards his ageing-factor as a product of growthcessation, since it appears in the individual animal at the point where the negative specific acceleration of growth is greatest.

The susceptibility of rotifer eggs to external influences affecting the life-cycle of the progeny has been much studied in forms 


\section{The Biology of Senescence}

which give rise periodically to mictic generations. The literature on sex-determination in rotifers is reviewed by Hyman (1951). The longevity of the two types of female differs considerably; 'somewhere in the ontogeny of the females, it must be determined which kind of egg they are destined to lay. The determination occurs during the maturation of the egg from which

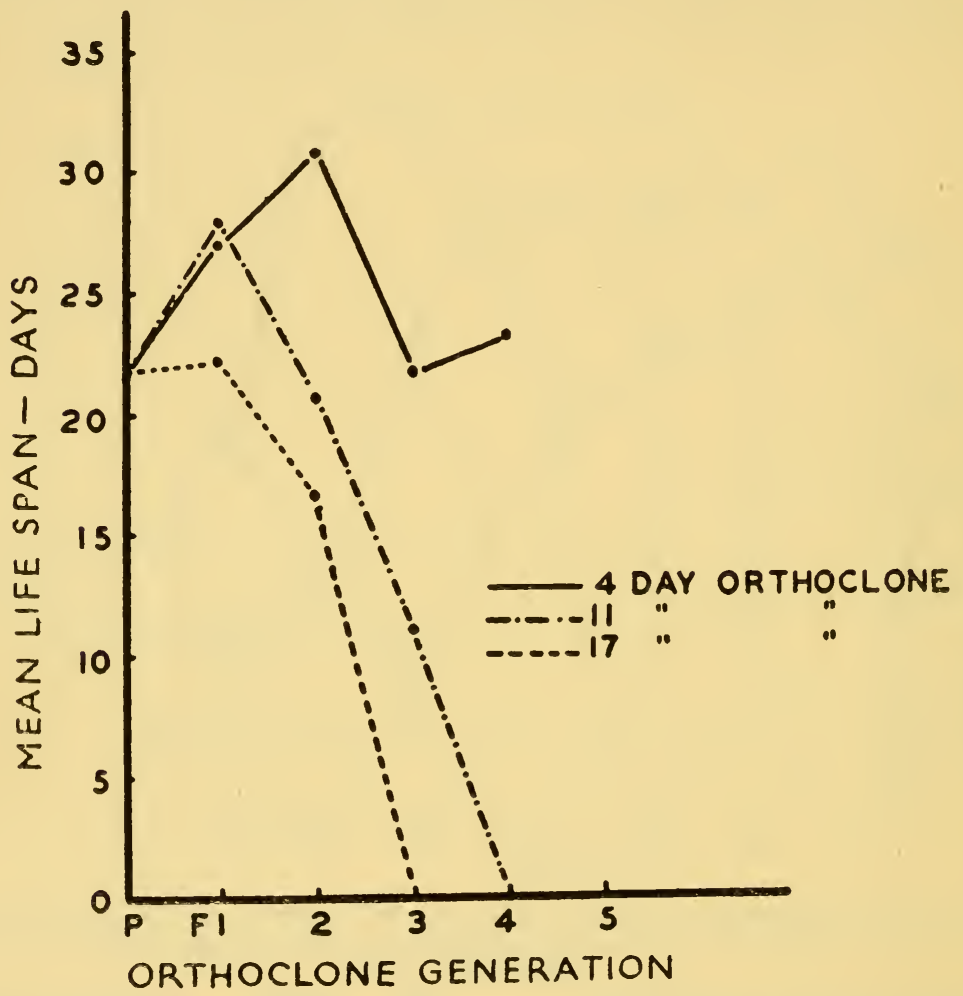

FIG. 24.-Life-span of successive generations of Philodina reared in each generation from the eggs of 4-11- and 17- day-old mothers (Lansing, 1948).

the female comes, that is, during the last few hours before the egg is laid' (Hyman, 1951). Both internal and environmental factors of great complexity appear to operate in different forms. 'The conclusion from numerous researches seems to be that, in addition to an inherent rhythm as regards male production, monotony of conditions suppresses mictic females, whereas any 


\section{The Distribution of Senescence}

sudden change, especially of diet and of physiochemical composition of the water, induces the appearance of mictic females' (Hyman, 1951). The reason for the difference in longevity between Lansing's old and young orthoclones is not, it should be noted, entirely comparable to that between mictic and amictic females. It does not seem to represent a difference in specific age due to a shortening of that part of the survivalcurves which, owing to the low early mortality in rotifers, is usually horizontal, but rather a 'breaking away' of this plateau by the introduction of a higher and higher early mortality, the curve becoming less and less rectangular and more and more oblique. If conclusions are to be drawn upon the effect of maternal age upon senescence, this difference is important.

It is possible that the uniform specific age of rotifer populations is due to depletion. Reproductive exhaustion has already been discussed. It is also known that the limited regeneration observed in Stephanoceros takes place at the expense of reproduction and of somatic growth. Little is known of the metabolic capacity of rotifers - they apparently store glycogen, but may be incapable of assimilating carbohydrate (Hyman, 1951). Sudden senescence might well represent the exhaustion of a metabolic substrate, or of a non-renewable system. Accumulation has also been suggested: pigment certainly does accumulate, probably secondarily to the ageing process. Lansing (1942) demonstrated the accumulation of calcium in old rotifers, and succeeded in prolonging their life by immersion in dilute citrate solution-it is not clear how often this process can be repeated. A more curious factor influencing the life-span was observed by Edmondson (1945) in Floscularia conifera, where individuals growing in aggregation reach twice the length, twice the age, and a higher level of fertility than solitary specimens.

The peculiarities of rotifer organization are so numerous that some, if not all, of the mechanisms controlling their longevity are likely to be peculiar to the group. On the other hand, their short life-span makes them a suitable object for study, and they provide an unequivocal example of senescence coupled with cellular non-renewal which calls for further investigation. 


\section{The Biology of Senescence}

\subsubsection{ARTHROPODS}

Senescence in arthropods is widespread and probably universal. Those forms which have wings, jaws, bristles, and other chitinous tegumentary structures not renewed by moulting are particularly liable to genuinely 'mechanical' senescence. In the forms which moult as adults, the time of ecdysis is a particularly arduous one, judged by the mortality, and many of these, such as Daphnia and large spiders, appear very often to die in the attempt to carry out a final moult.

'Physiological' senescence, in the sense in which nineteenthcentury biology used the term, also appears in a convincing form for the first time in arthropods, since, as Metchnikoff first pointed out $(1907,1915)$, a non-feeding imago must be regarded as expendable from the evolutionary point of view. The evolution of short sexual life as a modification in some groups is balanced by the evolution of a very long sexual life in specialized individuals of other, social, species, as part of the adaptive development of a group-existence-the longest life-span being reached in one or both sexual forms among true ants and termites.

There is no known case of arthropod indeterminacy comparable with that of actinians. Growth in most insect imagines is more or less rigidly limited, although the capacity for continued cell division persists in varying degrees. According to Harms (1949), somatic mitosis in many arthropod imagines is virtually confined to the mid-gut. Mitotic capacity has not'been shown to bear any relationship to longevity, except perhaps in forms producing queens, where the relation of continued reproduction to long life might be either a direct example of cause and effect, or the result of two parallel adaptations. Some solitary arthropods are capable of very long life (20 years in tarantulas, Baerg 1945, possibly 50 years in lobsters, Herrick, 1896).

Crustacea. The small crustacea (Cladocerans, Copepods, Isopods) generally show very sharp specific age. In Daphnia ${ }^{1}$ this

${ }^{1}$ There is a striking lack of unanimity in the literature over the 'normal' life-span of various species of Daphnia, even when grown in apparently similar media. Fritsch (1953) has shown that this variation depends to some extent upon the amount of available pantothenic acid. Where Daphnids are 


\section{The Distribution of Senescence}

appears to be definable in terms of instars, $D$. longispina living for 19-22 instars, the duration of which depend upon the conditions of culture (Ingle, Wood and Banta, 1937) and D. magna for 17 instars (Anderson and Jenkins, 1942). Detailed studies upon factors which retard or accelerate the rate of development and life-span in Daphnia have been carried out. (McArthur and Baillie, 1926 seq.; Ingle, Wood and Banta, 1937; Anderson and Jenkins 1942, etc., see pp. 143 seq.). In view of the availability of life-tables for Daphnia, the pattern of its normal growth is of

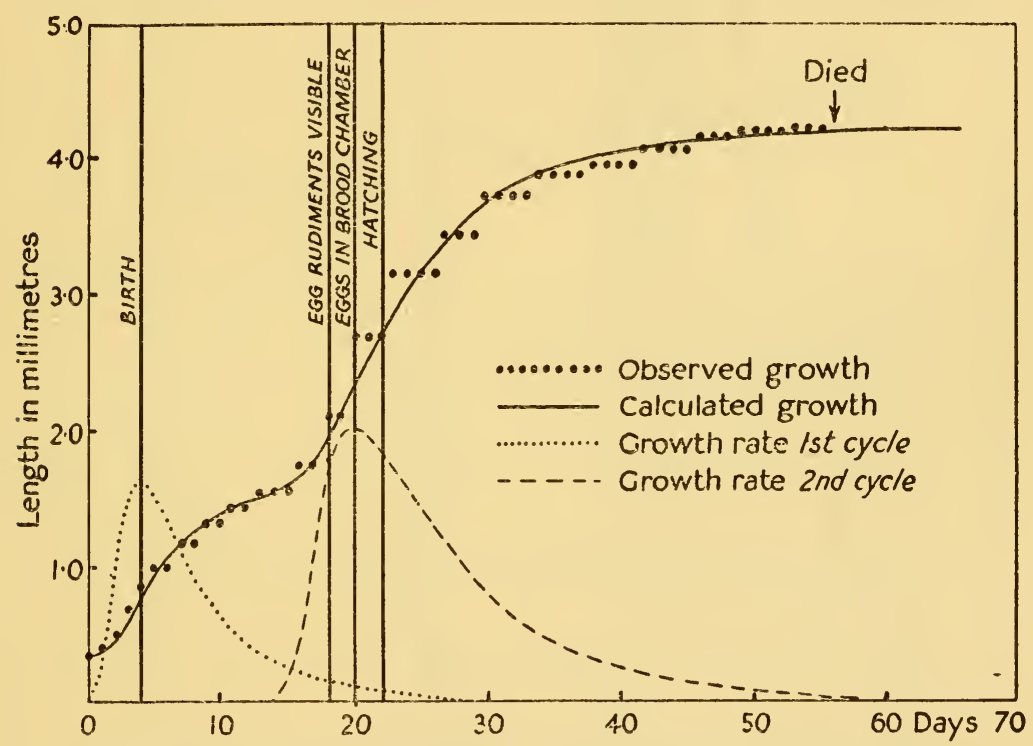

Frg. 25 (a).—Growth of Daphnia magna-first type (Edlén, 1938).

particular interest. Edlén (1938) showed that the growth of normal daphnids takes place in two cycles, the first levelling off after three or four instars, and the second coinciding with the development of the gonad. He found three types of pattern in

fed upon living cultures of protozoans or algae, the food organism itself may metabolize and remove pantothenic acid. It is highly questionable in view of Fritsch's findings how far the life-tables obtained by workers using different culture techniques, or even by one worker at different times, are comparable. This is unfortunate, as Cladocerans are most useful organisms to gerontologists-further standardization of culture techniques seems essential if they are to be used in this way, however. 


\section{The Biology of Senescence}

the growth of individual $D$. magna. In the majority of specimens (Fig. 25a) the two cycles of growth followed one another, the growth-potential in the second cycle falling almost to zero with increasing age; this fall is accompanied by a decrease in egg size and number, and the animal finally dies after a short period in which growth has almost ceased. In individuals of the second

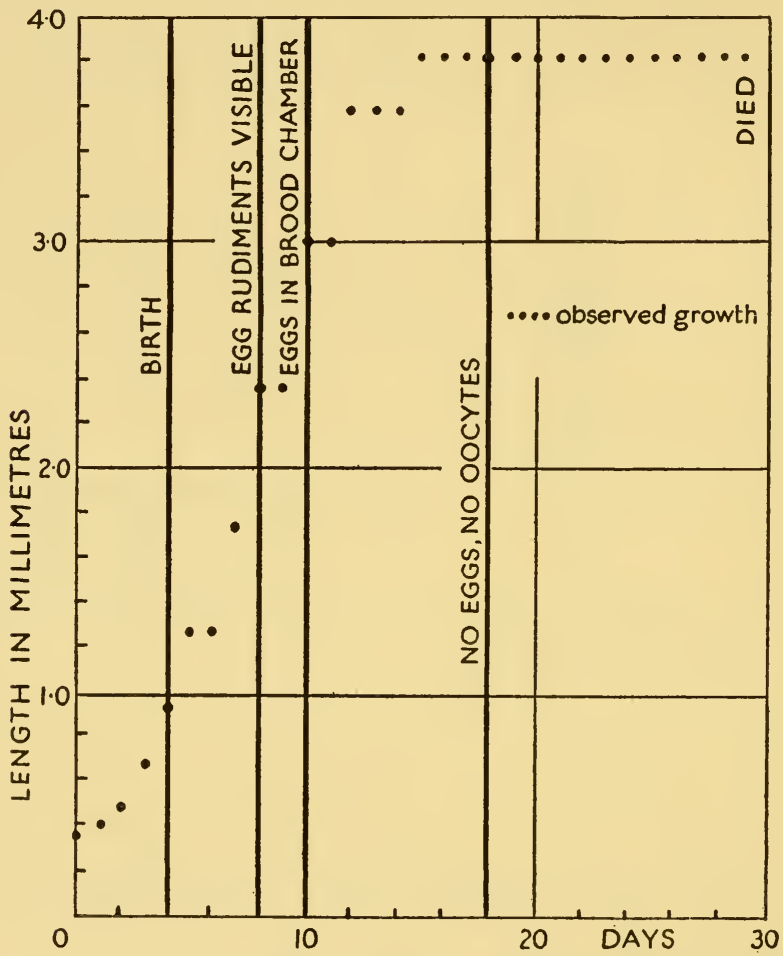

Fig. $25(b)$.- Growth of D. magna-second type: growth-phases superimposed (Edlén, 1938).

type (Fig. 25b) the two growth cycles were superimposed-in these growth was very rapid, there was no prepubertal 'shelf' in the curve of body size, and fertility was lost early, although the life-span appeared to be normal. The third type (Fig. 25c) showed only the first cycle of growth, but no gonadal function developed, and adult size was not attained. These forms died early. Edlén considered that the developing ovary exerts a 


\section{The Distrioution of Senescence}

hormonal control over growth, and possibly over the maintenance of life-processes generally.

The chief senile changes in Daphnia appear to be in the fat body, intestinal epithelium and musculature (Schulze-Röbbecke, 1951). This author found no evidence of the 'cerebral death' which was once widely accepted as the general cause of invertebrate senescence (Harms, 1926; Muhlmann, 1900, 1911), and which was described by Walter (1922) in Cyclops. Withdrawal

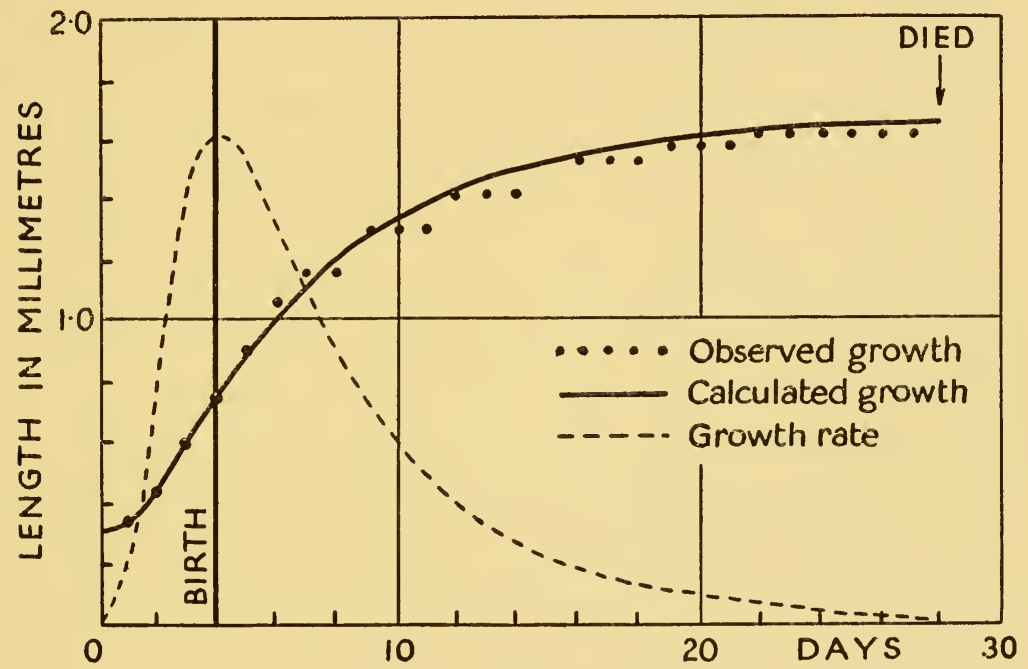

Fig. $25(c)$.-Growth of $D$. magna-third type. One growth-cycle only (Edlén, 1938).

of ovarian activity does not seem to be the direct cause of senescence in Daphnia. Schulze-Röbbecke's oldest specimens still showed considerable ovarian activity, and continued to lay eggs, though in reduced numbers, up to the time of death. Oocytes at all stages of maturation remained in the ovary to the last. Schulze-Röbbecke attributed the death of Daphnia in old age to failure of nutrition following degenerative changes in the gut.

Walter's work on Cyclops (1922) dealt with C. viridis, which has a life-span of about 9 months, 'senile' change in gut epithelium and in the cerebral ganglia being evident from the 


\section{The Biology of Senescence}

fifth month. Somatic mitosis in adult life occurs only in the mid-gut of Cyclops, and in this region 'senile' changes were not found (Harms, 1949). The most striking degenerative changes in Cyclops were found in the chromatin of the ganglion cells, with the appearance of large inclusion bodies suspiciously reminiscent of virus inclusions or fixation artefacts, and in the antennules. Gut degeneration occurred later in life, about the eighth month, and was confined to the anterior gut, mitosis continuing in other parts of the gut epithelium until the end. It is difficult to know what connection, if any, these changes have with the process of senescence.

Needham (A. E. Needham, 1950) has studied the growth rate of limb regeneration in Asellus aquaticus; growth in crustacea, on Needham's figures for Asellus and Carcinus, is determinate and the curve sigmoid, the arithmetic rate of growth rising to a maximum and declining asymptotically thereafter to zero. The geometric rate of growth declines monotonically with age from the outset, and the rate of decline itself declines with increasing age. The specific regeneration rate decreases progressively with age, owing to the progressive increase in the duration of each instar; the rate of decline is much less than that of the normal growth rate, and itself declines with age. 'In some crustacea the limiting size is attained at an age beyond the mean expected life-span. Growth is indeterminate in Crustacea only in this sense. They are not potentially immortal.' This investigation illustrates once again the difficulty of characterizing the growth-behaviour of real organisms mathematically: the decline of arithmetic growth may be asymptotic, or tangible size increase may continue; in crustacea there is the additional difficulty that growth is discontinuous, being interrupted by stadia, which superimpose a 'quantal' effect on the smooth ideal curve. The conclusion of Needham's studies is that the growth of crustacea follows a convergent series, and must cease, presumably, for practical purposes in any form which lives long enough. But the relation between such cessation and determinacy of life-span is still entirely conjectural.

Insects. It has long been recognized that several separate types of senile change may occur in insects. Mechanical damage 


\section{The Distribution of Senescence}

to the cuticle (Blunck, 1924; Wigglesworth, 1945), depletion of reserves both in feeding and non-feeding imagines, accelerated in some cases by reproduction (Krumbiegel, 1929a, b; Bilewicz, 1953), accumulation of urates (Metchnikoff, 1915), deterioration of the nervous system (Hodge, 1894-95; Pixell-Goodrich, 1920; Schmidt, 1923; Weyer, 1931, etc.) and 'general senile decay' have all been demonstrated by more or less satisfactory evidence. The vast majority of holometabolous imagines give every evidence of having a sharp specific age, and this is a group in which we are unusually well-equipped with lifetables. The nature of the processes which limits imaginal life seems, however, to vary widely, but they have the common property of being processes operating in a cellular system where little or no renewal, and no further morphogenetic development, are occurring.

One of the best general descriptions of insect senescence is given by Blunck (1924) for Dytiscus marginalis: he describes the main signs of advancing age as diminution in activity and deterioration of the epicuticle, with the growth of colonial protozoa on the dorsal shield, legs and mouth parts, which the animal cannot any longer clean effectively. The cleaning secretions seem to be reduced, and the chitin appears brittle, whole legs or antennae being occasionally snapped off in swimming. If pygidial gland secretion fails, air enters the subalar air chamber and the beetle drowns. In the beetles dissected by Blunck, the gonads had almost disappeared during the third year of life, the fat-body was increased in size, almost filling the body cavity, but chalky and full of concretions. In some individuals there was almost complete atrophy of the wing muscles. The extreme life-span is under 3 years, females living longer than males: sexual activity usually ceases in the second year but may persist in individuals into the third. A number of senile processes, which may not be mutually dependent, can be detected in this description. The balance between mechanical, depletive and 'morphogenetic' senescence must vary considerably from species to species, and even from individual to individual. Blunck's description is of interest in providing not only an account of such a mixed senescence, but one of the very few instances where the 'change in inert structures', so popular with colloid 


\section{The Biology of Senescence}

chemists investigating senescence, really seems to occur-in the progressive hardening and weakening of the chitin of Dytiscus elytra, which Blunck found to be a reliable rough measure of the age of specimens taken in the wild. On the other hand, a considerable part of this change, as Blunck himself suspected, may represent failure to secrete the normal lubricant coat-a cellular rather than a mechanical deterioration.

In many insects, especially lepidoptera, there is evidence that the fat-body contains a definite reserve of materials, which are not replaceable during imaginal life. In females of the moth Ephestia elutella, longevity and fecundity are both functions of body weight at eclosion (Waloff, Norris and Broadhead, 1947). Longevity is also greater in virgin females, possibly owing to the sparing of reserves through egg-rudiment resorption (Norris, 1933, 1934). Exhaustion of the fat-body is characteristically found in Ephestia which appear to have died of old age. Norris (1934) found evidence that the fat-body contains two types of store, one needed for the maintenance of the ovaries and the other for the maintenance of life. The second appears to be supplemented by feeding the imago, but not the first (Norris, 1933). Similar deterioration of the fat-body has been described as a sign of senescence in Carabus and Drosophila (Krumbiegel, 1929) and Sitodrepa panicea (Janisch, 1924) in which the period of depletion is apparently hastened by exposure to $\mathrm{CO}_{2}$. This type of 'depletion senescence' is, in fact, in one sense an extension of morphogenetic senescence, if in the transition from larva to imago the organism loses the power of synthesis or assimilation of some material which it is able to store during larval and pupal life. How far depletion of larval reserves is a general feature of insect senescence it is difficult to say. The non-feeding or the starved imago is necessarily dependent upon what stores it has, although Metchnikoff (1915) from a careful study of Bombyx, favoured an 'accumulative' rather than a 'depletive' mechanism to account for imaginal death. Other imagines probably vary a great deal in their biochemical accomplishments. Some lepidopteran imagines feed on nectar and are known to absorb water and sugars. Frohawk (1935) kept $\mathcal{N} y$ mphalis antiopa alive for three months from eclosion by feeding sugar solution. On the other hand, robust Coleoptera, such as Blaps, are fully 


\section{The Distribution of Senescence}

capable of living on their intake and stores for ten years, while the mole cricket has been thought able to live much longer. Activity reduces the life-span: Camboué (1926) greatly prolonged the life of butterflies by decapitating them.

The influence of reproduction on life-span is equally variable, but it often seems to involve inroads upon stored and irreplaceable reserves. Unmated females of Periplaneta lay fewer eggs than mated females and live longer (Griffiths and Tauber, 1942). The life-span in both male and female Drosophila is substantially decreased by mating (Bilewicz 1953). Krumbiegel

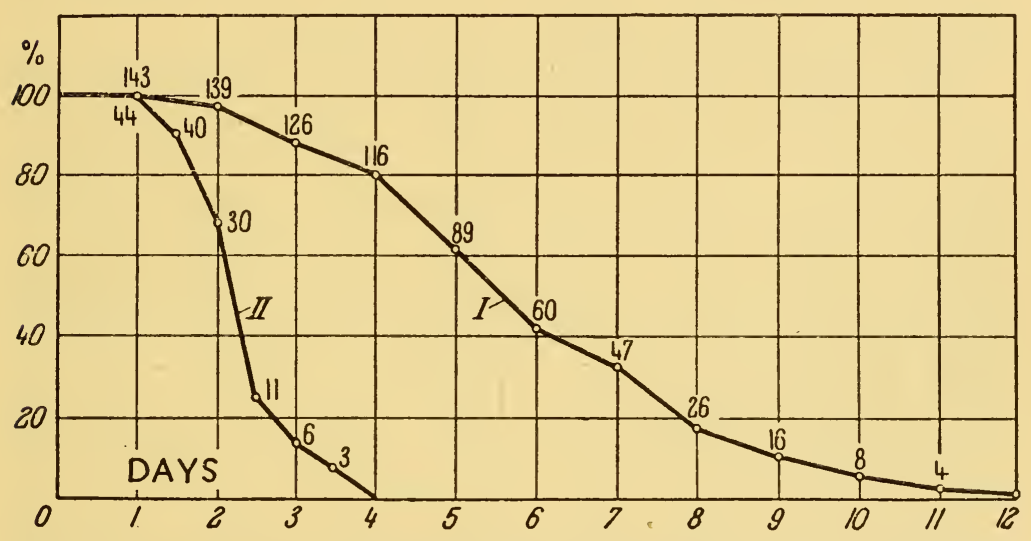

Fig. 26.-Survival curves of 145 isolated virgin females (I) and 44 isolated, fertilized females (II) of the moth Fumea crassiorella (from Matthes, 1951).

found that the reserves in the fat-body of Carabids decreases after first copulation, but increases again with feeding (1929). In the moth Fumea crassiorella Matthes (1951) found that the longevity of the female was halved by copulation if egg-laying was allowed, and slightly reduced by it if egg-laying was prevented (Fig. 26).

The theory of 'cerebral death' (Gehirntod) in insects arises chiefly from some long-standing work on bees. Hodge (1894, 1895), Pixell-Goodrich (1920) and Schmidt (1923) all described cerebral degeneration, reduction of cerebral cell-number, and disorganization of the nervous system as characteristic and probably causal mechanisms in the senescence of worker bees. 


\section{The Biology of Senescence}

According to Hodge, the cell-number in the brain of old workers was reduced by three quarters. Pixell-Goodrich found that in diseased, and therefore inactive, workers, the cerebral architecture was more normal than in healthy workers. Schmidt attributed the reduction in cell size and cell-number to direct 'wear by use', the amount of work done by the insect being a fixed quantity. Holmgren (1909) found a similar deterioration in the supraoesophageal ganglia of old termite primaries: the brain of old physogastric queens of Eutermes was reduced to two thirds of the volume usually found in virgin queens. Another instance of 'Gehirntod' in insects was described by Hansemann (1914) in Bacillus rossi (Phasmidae).

Quite apart from the fact that they have been indiscriminately transferred to mammals, these findings themselves have been open to intermittent criticism. ${ }^{1}$ Smallwood and Phillips (1916) were by no means satisfied that the changes in relative nuclear size described by Hodge in worker bees resulted from ageing or were in any way pathological. Weyer (1930) regarded the cerebral ganglion changes as secondary, since the supposedly senile degeneration appears remarkably suddenly, and only after evident deterioration in other organs. In a 5-year-old queen, Pflugfelder (1948) found some disturbances of cerebral histology especially in the corpora pedunculata, but no significant cerebral change in old drones and workers. Rockstein (1950), however, found a decline in cell-number in the brain of worker bees from a mean 522 at eclosion to 369 at 6 weeks. The complex behaviour of worker bees deteriorates suddenly just before death, moreover.

Schulze-Röbbecke (1951) made a careful search for evidence of 'cerebral death' in Dixippus and Melolontha and found no signs of it whatsoever, the primary senile deterioration being most evident in gut and musculature. 'Vielleicht hat v. Hansemann bereits töte Tiere untersucht, was sehr leicht vorkommen kann, da bei den Stabheuschrecken infolge ihrer Reaktionsträgheit der Übergang von den letzten Lebensaüsserungen zum Tode nicht ohne weiteres festzustellen ist.' The amount of senile change described either as a result of fixation-artefacts or the

1 The large literature of neurone loss with increasing age in mammals, especially in the cerebellum, is reviewed by Andrew (1955). 


\section{The Distribution of Senescence}

sectioning of 'that which dies of itself' has yet to be assessed in the literature.

A considerable amount of work has been done upon the physiological factors which influence longevity in worker bees. Winter bees are known to be considerably longer-lived than the summer brood even when they are kept under similar conditions of temperature and activity. Maurizio (1946) found that caged winter bees had a mean survival of 36 days from eclosion compared with 24 days in caged summer bees. The life-span of summer bees can be prolonged in two ways-by feeding pollen to caged bees (Maurizio, 1946), or by removing all the sealed brood regularly from the colony, so that the same bees continue with brood-rearing throughout life-under these conditions bees may live as long as 72 days (Moskovljević, 1939; Maurizio, 1950).

Two factors appear to influence the longevity of workers. One of these is certainly activity. Ribbands (1950) found that anaesthesia with $\mathrm{CO}_{2}$ had the effect of causing young bees to begin foraging earlier than usual: in bees which forage early, expectation of imaginal life is less (30.1 $\pm 1 \cdot 2$ days), but expectation of foraging-life is greater $(15.0 \pm 1.2$ days $)$ than in late starters (37.1 \pm 0.6 and $10.8 \pm 0.8$ days). The second appears to be dietary. 'Winter bees differ from summer bees in the greater development of their pharyngeal glands and their fat-bodies. This development results from autumn consumption of pollen, in excess of the requirements for immediate brood-rearing. In queen-right colonies in summer, prevention of brood-rearing can produce similar consequences, and in pre-swarming colonies temporary interruption of brood-rearing produces conditions different only in degree.' In all these cases the increased expectation of life is associated both with enhanced development of the pharyngeal glands and fat-body, and with decreased activity (Ribbands, 1953). It appears that worker bees have a life-span which is partially expressible in 'flying-hours', and that this life-span, and the total output of work per life, can be increased by increasing pollen consumption (Maurizio, 1950), but summer bees only increase their life-span in this way if they are deprived of brood. There is also ground for believing that the activity of worker bees is reduced by the possession of internal food 


\section{The Biology of Senescence}

reserves. In winter bees, then, absence of brood leads to repletion, which in turn induces both quiescence and inherently greater longevity at a time when both are beneficial to survival. The expectation of foraging life decreases in proportion to the age of the bee when it begins to forage-endogenous senescence therefore appears to play a part in limiting the life of workers, and they do not all die from accident alone (Ribbands, 1952). Whatever the facts concerning 'Gehirntod', this process of senescence appears to contain a major depletive element, combined, in all probability, with an element of mechanical damage. In this respect the senescence of worker bees conforms to a pattern which seems to be widespread in insects.

\subsubsection{MOLLUSCS}

Pelseneer (1934) divides molluscs in the wild into annual species, pluriennial species with a short reproductive life, and pluriennial species with a long reproductive life. In some members of this last group, indeterminacy of life-span cannot be excluded. Most of the evidence is obtained from wild material. The combination of patterns appears analogous to that found in fish. Like fish, molluscs include short-lived forms, forms with a longer but apparently determinate life, and forms, expecially among the larger pelecypods, which appear to have no maximum size.

The annual forms include many nudibranchs (Pelseneer, $1934,1935)$ and probably most of the smaller freshwater species (Paludestrina jenkinsi-Boycott, 1936; Ancylus-Hunter, 1953). According to Boycott (1936) Planorbis corneus is the only British fresh water pulmonate which is not normally an annual. Many of these annual forms die immediately after reproduction. In Viviparus contectoides (van Cleave and Lederer, 1932) and $V$. bengalensis (Annandale and Sewell, 1921) the wild males live one, and the females up to three years. In captivity Oldham kept male $V$. contectus for $4 \frac{1}{2}$ and female for 5 years (Oldham, 1931), and living embryos were present at the time of death. Growth, judged by length, ceased in the second or third year of life. A number of other forms live for a maximum of 2 or 3 years in the wild, breeding during one or two seasons (Lioplax -van Cleave and Chambers, 1935; Bithynia-Boycott, 1936; 


\section{The Distribution of Senescence}

Lilly, 1953; Fossaria-van Gleave, 1935; Sphaerium-Foster, 1932; Teredo navalis-Grave, 1928). Specimens of Limnaea columella kept in captivity under good conditions give a lifetable showing a typical senile increase in force of mortality similar to that in Drosophila (Winsor and Winsor 1935; Baily 1931). The growth of Limnaea has been studied by Baily (1931) and Crabb (1929). Among rather longer-lived forms, Pelseneer (1934) found a complete cessation of shell growth and a decline

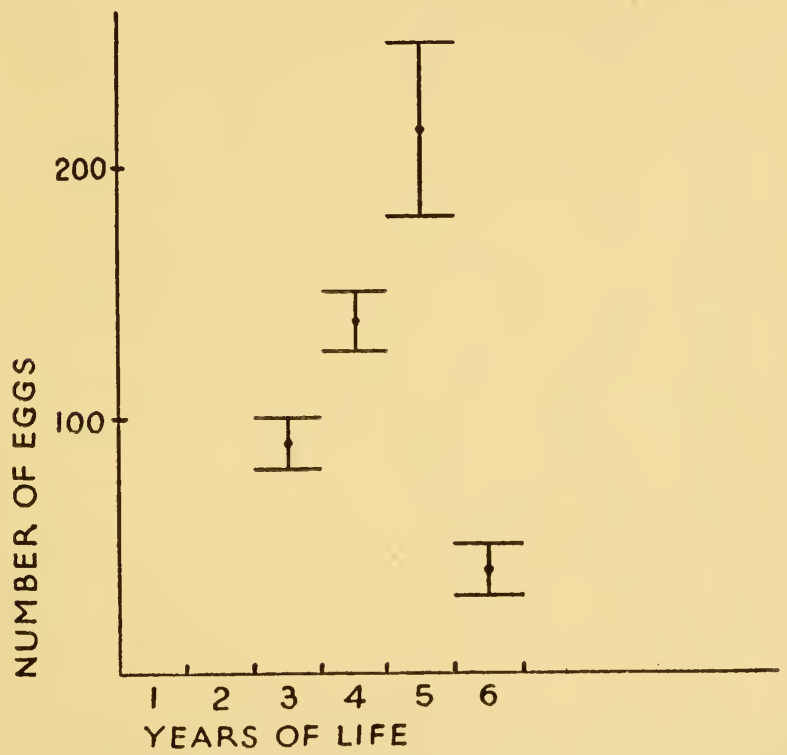

FIG. 27.-Egg production of Eulota fruticum (after Künkel, 1928).

in fertility with age in Gibbula umbilicalis, complete infertility being general at about 54 months, and the extreme life-span $4 \frac{1}{2}-5$ years. In Eulota fruticum, the relation of egg-laying to age has been determined. According to Künkel, death takes place in captivity 'when the germinal glands are exhausted' (Künkel, 1928). (Fig. 27.) In Physa gyrina DeWitt (1954) found a distinct post-reproductive period, amounting to as much as 49 per cent of the total life-span in mass culture, or 36 per cent in isolation culture, the overall mean life-spans being 211 and 143 days respectively. Szabó and Szabó (1929-36 passim) published a 103 


\section{The Biology of Senescence}

number of studies upon the 'senescent' changes observable in the digestive gland and nervous system of Agriolimax: these, however, were inconstant from species to species, and a lifetable (Fig. 6c, p. 20) constructed from their data by Pearl \& Miner (1935) shows a steady high mortality: it is probable that none of these slugs reached their maximum potential age.

Very little evidence exists to relate the apparent senescence of short-lived molluscs in the wild to their growth pattern, or to their potential life-span in isolation. Van Cleave (1935) and Hoff (1937) considered that the snails Fossaria and Viviparus continue to grow throughout life; in these forms, according to van Cleave, the maximum size which is characteristic of the facies of any colony is secured by a combination of environmental effects on the growth rate and an endogenous process of senescence which kills the animal after the completion of its lifecycle, irrespective of its general somatic growth. In the large Trochus niloticus Rao (1937) found no evidence of senile mortality, the upper limit of age being about 12 years in a wild population, and growth continuing at a decreasing rate throughout life. On the other hand, in spiral gastropods with an elaborate lip armature, growth must be effectively determinate so far as shell size is concerned. It has been suggested that in Polygyra growth in size ceases at lip-formation, but body weight and shell thickness continue to increase (Foster, 1936). Przibram (1909) quoted observations by Taylor and de Villepoix that the gland-cells of the mantle disappear in fully-grown specimens of Helix aspersa, H. nemoralis and Clausilia perversa. The growth of molluscs is seasonal, and the development of the gonad appears in some forms to compete with, or inhibit, body growth-in oysters, the periods of shell growth occur in each year before and after spawning (Orton, 1928) while in Hydrobia ulvae parasitic castration leads to gigantism (Rothschild, 1935). The life-span of such giants was unfortunately not recorded. On a small series of Limnaea columella Baily (1931) found that shell growth ceased at or soon after sexual maturity, and that the shortest-lived individuals were those with the highest growth rates. A life-table was constructed for this species by Winsor and Winsor (1935) (Fig. 28). Species whose life-cycle rarely exceeds two years may be capable of much 104 


\section{The Distribution of Senescence}

longer life in captivity. Oldham (1930) kept Planorbis corneus in active reproduction up to 6 years of age. Many Helicidae, especially the smaller forms, have been regarded as annuals in the wild (Lamy, 1933; Pelseneer, 1935): the potential life of helicids and medium-sized land snails in captivity (excluding diapause, aestivation and so on), may, however, reach or exceed 10 years (Rumina decollata, 12 years, 'Helix spiriplana', 15 years-Vignal 1919; Helix pomatia, 6-7 years-Künkel 1916;

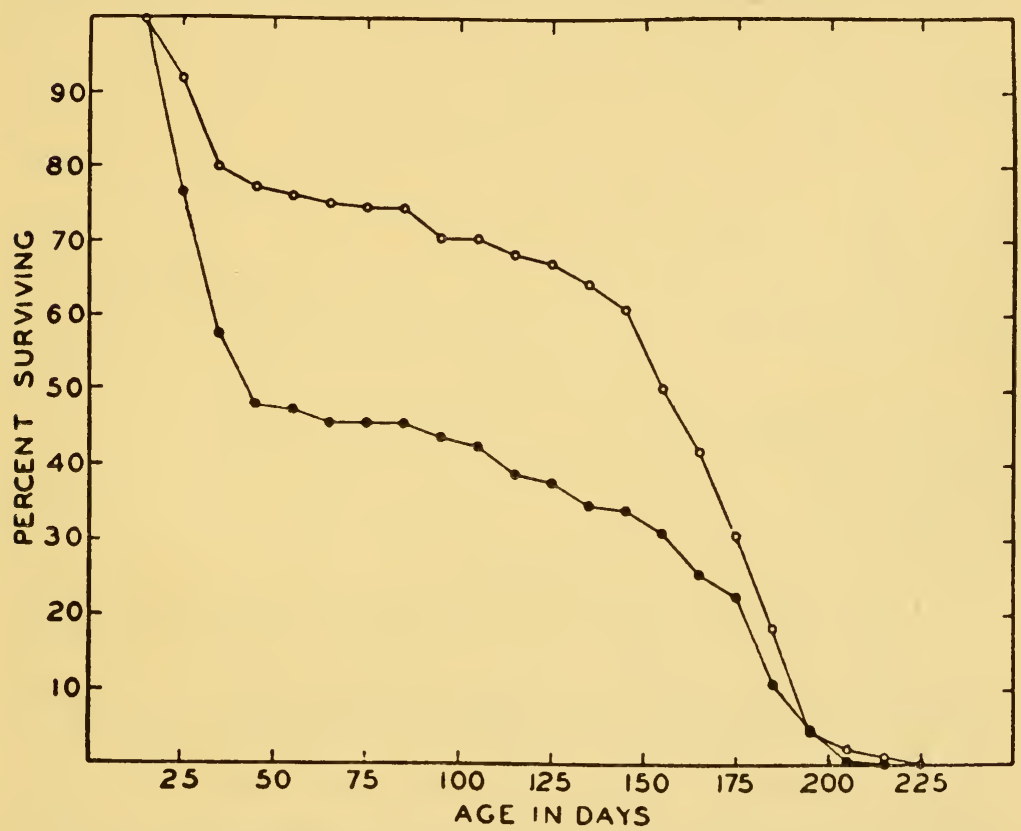

Fig. 28.--Life-span of the pulmonate Limnaea columella at two different population densities (from Winsor and Winsor, 1935).

6-8 years-Cuénot, 1911; H. hortensis, 6 years, hybrid $H$. hortensis $\times$ nemoralis 10 years-Cuénot, 1911) while Oxystyla capax has been revived from diapause after 23 years (Baker, 1934).

Even less is known about the longevity and liability to senescence of most marine gastropods. In Acmaea dorsuosa Abe (1932) found that growth continued in 15-year-old specimens from some localities, while in other localities an apparent specific size was reached at 5 years. Apparent specific size in certain 105 
colonies was also found by Hamai (1937) in Patelloida grata. The most suggestive evidence of a determinate life-span in limpets comes from Fischer-Piette's (1939) observations which showed a definite inverse relationship between longevity, judged by growth rings, and rate of growth in different stations (Fig. 29). This strongly suggests that a process of morphogenetic ageing is occurring at different rates depending on the rate of growth.

In some pelecypods, there might be ground for regarding growth as genuinely indeterminate. It continues in the oldest

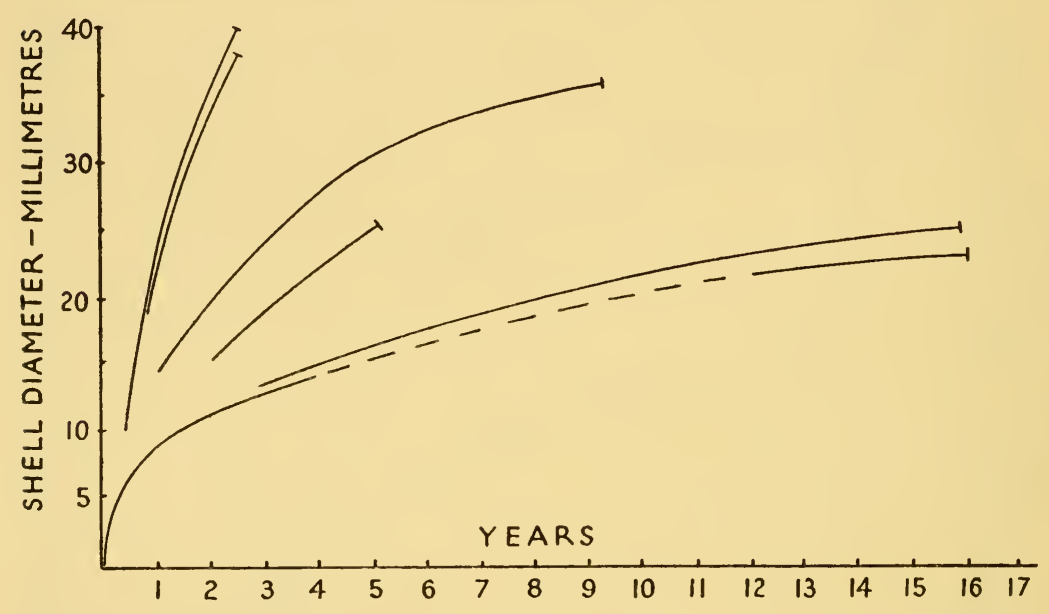

FIG. 29.-Growth and longevity of Patella vulgata in various stations, showing the short life of rapidly-growing populations (from Fischer-Piette, 1939).

recorded specimens, and the occurrence of abnormally large individuals of species whose age can be estimated by growth rings makes it possible also to estimate the rate of decline of growth rate by measurement of the intervals between the rings. Growth continuing actively to the maximum recorded age has becn found in many forms (Cardium, 16 years-Weymouth and Thompson, 1930; Venus mercenaria, 40 years-Hopkins, 1930; Siliqua, 14-16 years-Weymouth, 1931; Pecten jessoensis, 8 years-Bazykalova, 1934; Mya, 7-8 years-Newcombe, 1935, 1936). The larger fresh-water pelecypods, which have fewer enemies and are not subject to tidal disturbances, reach even greater ages. Huge specimens of the washboard mussel, Mega106 


\section{The Distribution of Senescence}

lonaias gigantea (Unionidae) showing 54 and 36 annual rings are recorded (Chamberlain, 1933) - these molluscs were still growing, and even larger examples exist. Longevity of this order is not, however, confined to large species-marking experiments have enabled some Unionidae (Quadrula) already over 20 years old to be followed for a further 15 years, and the correspondence of adult growth rings to years confirmed (Isely, 1931). (See also Coker, Shira, Clark and Howard, 1919-20.) In the small Margaritana margaritifera no important decline in the growth rate has occurred at 13 years (Saldau, 1939.) Geyer (1909) gave this species a life-span of at least 60 years. The estimate of 100 years quoted by Korschelt from Israel (1914) is unlikely but not impossible.

The supposed longevity of Tridacna has already been mentioned, together with the fact that nothing whatever is known about its real life-span. The same applies to many large marine pelecypods, whose probable age can only be discussed when we know something of their growth rate.

The pelecypods also illustrate the risks of purely ideal and mathematical representations of growth-pattern. Pseudo-specific size from environmental causes is common. In Siliqua (Weymouth, 1931), some populations reach an apparent limiting size, cease altogether to grow thereafter, and die early: this, like Fischer-Piette's observation on limpets (1939) might suggest that a senile process is at work. Wild limpets apparently die while in active growth, but those which grow fastest die earliest (Fig. 29). Other molluscan populations have growth records which, though fitted for practical purposes to an asymptotic curve, actually give observed readings in the highest age groups which lie well above such a curve, and indicate that in these groups growth is continuing (Weymouth, 1931). There is an obvious objection to the use of growth rings to measure age, however, if conclusions are then to be drawn about continuing growth-arrest of growth lasting for years would leave no record of itself in this system of notation. The results obtained by the use of the ring method in pelecypods have so far been reasonably consistent (see Newcombe, 1936). The validity of growth rings as annual markers requires careful confirmation in each population examined, however (Haskings, 1954). 


\section{The Biology of Senescence}

Hopkins (1930) found that in Venus mercenaria growth was continuing actively at 20 years. The oldest specimens aged by growth rings were in general not the largest shells. Some small examples had reached an estimated age of 40 years, and appeared to have grown abnormally slowly. This observation, like Fischer-Piette's (1939) and Weymouth's (1931) findings, should lead to a great deal of caution in regarding the life-span of any mollusc as indeterminate in the same sense as that of actinians.

\section{$2 \cdot 6$ Senescence in Wild Populations}

Senescence as a potential part of the individual life-cycle is, as we have seen, widespread: in discussing the evolution of senile processes, however, it is important to know how far it really occurs in wild animals. The weight of evidence suggests that senescence in the wild is rare but not unknown. Its commonest form is undoubtedly the pseudo-senescence which follows reproduction, but genuine senescence analogous to that of man is occasionally reached, at least by individuals, while there are probably some forms in which it is normally reached. If our observation of animal life-cycles were confined to small birds and mammals in the wild, however, we should probably not recognize senescence as an entity except in ourselves.

\subsubsection{VERTEBRATES}

Although data from bird and small mammal populations have perhaps led to an overstatement of the case against 'natural' senescence, old age is undoubtedly a relatively rare or very rare termination to the life-cycle of vertebrates studied in the field-as it is for man in societies where medical and economic conditions are bad. For large numbers of animal species, the typical curve is one in which a high or very high infant mortality rate is succeeded by a high adult mortality rate which does not increase with age. These species, even when they are capable of senescence, never reach it. This type of curve has been repeatedly demonstrated in population studies, (see Lack, 1954). Whereas in voles kept in the laboratory the survival curve approximates to that of man (Leslie and Ranson, 


\section{The Distribution of Senescence}

1940, Fig. 30), in wild voles (Hinton, 1925, 1926; Elton, 1942) and in Peromyscus (Burt, 1940) senescence is never observed, judging from the state of the teeth and bones of recent and fossil animals. In some populations the vole must be regarded as an annual (Elton, 1942). Tooth wear is a reliable index of age in short-tailed shrews, those over 2 years of age being edentulous,

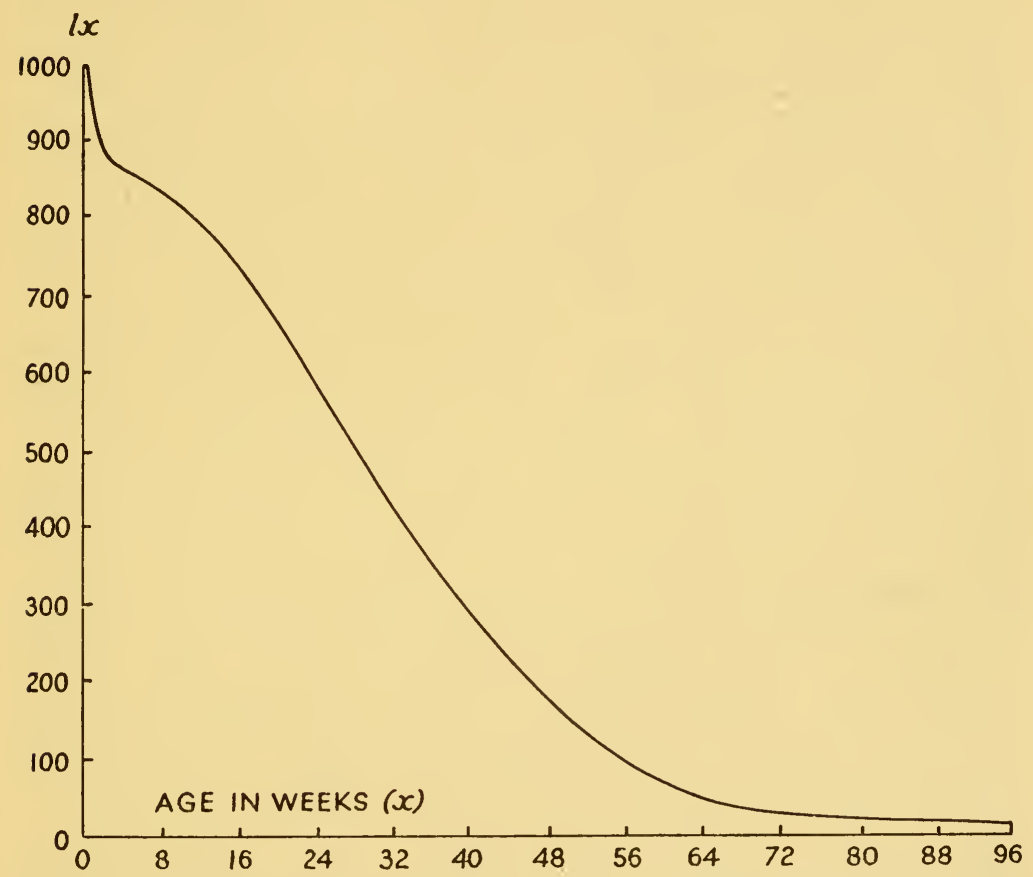

Fig. 30.-Smoothed survival curve for the vole, Microtus agrestis in captivity (from Leslie and Ranson, 1940).

but age limitation by this mechanical form of senescence is more potential than actual since few survive to exhibit it. They may survive in captivity up to 33 months (Pearson, 1945).

The log-linear pattern of decline in survivorship is highly characteristic of birds. It has been demonstrated in the blackbird, song-thrush, robin, starling and lapwing (Lack, 1943a, b, c), redstart (Buxton, 1950), American robin (Farner, 1945) and herring gull (Marshall, 1947). In a series of robins ringed by Lack (1943a), 111 out of 144 leaving the nest (77 per cent) died 109 


\section{The Biology of Senescence}

in the first year. This compares with a maximum recorded age of 11 years, which is occasionally reached in the wild state. The succeeding annual mortality was at a steady rate approaching 50 per cent. A survivorship curve for lapwings (Vanellus vanellus) calculated from 1333 birds is closely fitted by a line corresponding to a constant mortality of 40 per cent per annum (Kraak, Rinkel and Hoogerheide, 1940; Lack, 1950). The rates of mortality for most birds which have been studied appear to fall between 30 and 60 per cent per annum. Very much lower figures have been recorded for large sea birds such as cormorants (Kortlandt, 1942) in which the mortality was found to decline from 17 per cent before fledging to an annual rate of 4 per cent between the third and twelfth years. The annual mortality in one species of albatross (Diomedea epomophora) is only 3 per cent. Such birds may well live to reach senescence, if their life-span is 50 years. But considerable evidence has accumulated, chiefly from ringing studies, to show that the expectation of life of some wild birds actually increases with age. Although the total of ringed birds recovered in Europe does not exceed 10,000 per year, a few individuals are known to have survived for longer than could be expected if the early mortality were maintained. R. Perry (1953) gives records of this kind (Redwing - Turdus musicus, 17 + years; goldfinch-Carduelis carduelis, 16 + years; meadow pipit-Anthus pratensis, 13 years) all of them in species which have mean annual survivals of the order of 50 per cent (Lack, 1950). A ringed starling (Sturnus vulgaris) has been retaken after 18 years. The probability of such records being obtained as a result of chance, bearing in mind how few birds are ringed, is very low indeed. An almost exactly similar situation has been observed in the human population of the Punjab, where, in spite of a very heavy early and adult mortality, very old individuals are not uncommon, and those who survive beyond middle life have an expectation of life comparable to that in Western Europe (Yacob and Swaroop, 1945).

In lizards, the wild mortality rate declines with increasing age (Sergeev, 1939): this result agrees with the ecological studies of Stebbings (Stebbings and Robinson, 1946; Stebbings, 1948) on Sceleporus graciosus in the wild. A very high proportion of the population was found to consist of lizards 6 to 9 years 


\section{The Distribution of Senescence}

old (30 per cent), and there were signs of a decreasing force of mortality with age. In some cases the decrease may be even steeper. In some vertebrates the enormous infant mortality would completely overshadow subsequent trends in any lifetable based upon a cohort at birth: in the mackerel, for instance (Sette, 1943), survival to the $50 \mathrm{~mm}$. stage is less than 0.0004 per cent.

There are a certain number of apparent instances where senescence occurs as a regular phenomenon in wild populations of animals, both vertebrate and invertebrate, quite apart from occasional records of 'old' individuals. Murie (1944), from the examination of the skulls of 608 mountain sheep (Ovis dalli), constructed a life-table in which the death-rate was minimal between $1 \frac{1}{2}$ and 5 years of age, and climbed thereafter. The main deaths in old and young sheep appear to have been due to predation by wolves. The Arctic fin whales studied by Wheeler (1934) appeared to undergo an increase in mortality after the fifteenth year of age (in females); the apparent increase may however have been the result of the failure of the older specimens to return from their winter quarters to the regions where they can be caught and recorded. A good many larger carnivores and herding animals probably survive occasionally into old age in the wild state, though death must as a rule occur very early in the process of declining resistance. It is evidently impossible, in population studies, to assume either a constant mortality with age or a mortality increasing with increasing age, without some prior evidence of the behaviour of similar forms.

The 'normal' or 'wild' pattern of mortality in man is, of course, an abstraction, since even man in modern urban society is, biologically speaking, living 'in the wild', albeit after much social and behavioural adaptation. Early and primitive human societies almost certainly resembled in their ageing behaviour those populations of animals which occasionally reach old age, and in which the force of mortality shows some decrease during middle adult life. This is the pattern one would expect in social animals, where the survival of certain experienced individuals has probably a positive survival-value for the group, although in man the adaptation has been expressed in increasing capacity for abstract thought and social organization, rather than in 


\section{The Biology of Senescence}

increasing longevity per se. Although one may guess that early man occasionally reached the point at which his powers of homoeostasis began to fail through age, he must have died through environmental pressure, like Murie's sheep, very early in the process. Out of 173 palaeolithic and mesolithic individuals whose age could be determined, only 3 (all males) appeared to have been older than 50 years, and none much older (Vallois, 1937). Palaeolithic man in the Chinese deposits normally died from violence at a presenile age (Wiedenreich, 1939). In rather more civilized societies, the fall in mortality with increasing age becomes more evident: according to Lack (1943a, 1954) the curve of mortality based on the ages given in Roman funerary inscriptions (Macdonnell, 1913) is much like that for birds. Hufeland's (1798) and Silbergleit's (Vischer, 1947) figures (Fig. 7) illustrate further stages in the transition to the rectangular survival curve of modern societies in privileged countries: many other examples have been collected by Dublin and his fellow actuaries (1949).

\subsubsection{INVERTEBRATES}

Senescence also occurs in the wild in some invertebrates, though it is often probably of the type of the 'parental' deaths of shotten eels. Senescence in one form or another has been invoked to account for the fixity of size and life-span in some fresh-water gastropods (Sewell, 1924; Van Cleave, 1934, 1935). The figures of Fischer-Piette (1939), relating longevity inversely to growth rate in Patella, also suggest the operation of senescence. It very probably occurs in the long-lived sexual forms of social insects, such as termite primaries, and has been found to contribute to the mortality of worker bees (Ribbands, 1952). Among other insects, Jackson (1940) observed a factor of senescence in tsetse flies (Glossina) occurring only during the rainy season, when the life-span of the flies is longer. Dowdeswell, Fisher and Ford (1940) infer the possibility of a decline in the viability of butterflies (Polyommatus icarus) throughout imaginal life. The position in insects is considerably complicated by the existence of specialized overwintering forms. Overwintering Gerrids show changes in the muscles which appear to precede natural death-mechanical wear of the rostrum, which occurs 


\section{The Distribution of Senescence}

in old insects, is never far enough advanced to explain their decease (Guthrie, 1953). Cladocera and Amphipoda, together with other small crustaceans, tend to exhibit constant specific age in the laboratory, and may also do so in the wild state. In a natural population of Corophium volutator (Watkin, 1941) the mortality in females rose sharply after maturity.

Several genera of rotifers also exhibit well-defined specific age in culture (Pearl and Doering, 1923; Pearl and Miner, 1935; Lansing, 1942, 1947a, b, 1948) and almost certainly undergo senescence with significant frequency in the wild state. A population of the tube-building Floscularia marked in the wild with carmine underwent a linear decline, followed by a steep increase in mortality in the final survivors (Edmonson, 1945): the curve obtained in this marking experiment was not far different from those obtained in laboratory populations of rotifers. 


\section{a3a \\ SENESGENGE IN PROTOZOA}

\section{3·1 Individual Cells}

Much theoretical study was devoted during the last century to the 'immortality' of protozoans, and their insusceptibility to senescence, following the concepts put forward by Weismann. It was considered that in unicellular organisms generally, and in populations of metazoan cells undergoing division without differentiation, the product of a cell's division is always a pair of daughter cells having the same age status, and destined each to lose its identity in another division. This theory makes very important assumptions about the nature of the copying processes which underlie cell division. In the majority of cases to which it was applied, the assumptions are probably correct, although there seem to have been no direct experiments designed to show whether, in a given protozoan population, the diagram of lineages shows any tendency to segregate the deaths of individual cells towards its edges, as in a metazoan genealogy.

Weismann had been impressed (1882) that in protozoa there is no death because there is no corpse. 'Natural death' of individuals (often apparently from strictly endogenous causes) does occur in protozoa, as Jennings (1945) has shown (see below); and the assumption that there is no unrenewable matter at cell division is not universally true; in many forms, especially those producing swarm spores, there may be a substantial corpse, at least as tangible as the rejected parental shell of the dividing radiolarian. This is less often demonstrably the case in somatic cells, and the analogy between strictly acellular organisms and tissue cells cannot now be whole-heartedly maintained: it is still generally held, however, that the outcome of a protozoan 


\section{Senescence in Protozoa}

cell division is a pair of rejuvenated and infant cells rather than a mother and a daughter of different seniority.

The indeterminacy of cell lineages has lately been attacked with some ferocity, though on grounds of political philosophy rather than experimental evidence (Lyepeschinskaya, 1950). The question legitimately arises, however, particularly in ciliates, how far the renewal of structures at mitosis is evenly distributed between the resulting cells. Child (1915) noticed that in Stentor one of the progeny retains the old, while the other forms a new, peristome. From experiments he concluded that this made no difference to the age status of the inheritors, both being equally 'young'. The criterion of 'youth', however, was high susceptibility to cyanide poisoning. The critical experiment of making a genealogical table to determine the order of death of the fission products over several generations on the pattern of Sonneborn's (1930) Stenostomum experiments does not appear to have been carried out.

True senescence, and a marked difference in age status between mother and progeny, certainly appears to occur in suctorians. Korschelt (1922) noticed this in several forms (Acanthocystis, Spirochona, Podophrya, etc.), while in Tokophrya the parent organism's life-span can be measured, and is increased by underfeeding (Rudzinska, 1952). In a far greater number of cases, there are signs that the copying process at division only produces a new structure additional to one which already exists, not two new, or one new and one manifestly renovated, structure. The theoretical interest of this process (in Euglypha) and its bearing on protozoan 'age' has been noticed before (Severtsov, 1934). In such cases, either the structure does not deteriorate with time, or it is maintained continuously during life, or its possession must ultimately confer a disadvantage on one or other of the division products.

Whereas in some protozoa organelles, axostyles, flagella and cilia are visibly resorbed or shed at fission, and new ones produced for each fission product, in others, especially in ciliates, maternal organelles, flagella and other structures are shared between the progeny, being taken over by one daughter cell while copies are developed in the other. Of two closely-related species of Spirotrichonympha infesting termites, for example, one 


\section{The Biology of Senescence}

divides longitudinally in the normal flagellate manner, while in the other division is transverse, the anterior daughter receiving all the extranuclear organelles of the parent cell except the axostyle, while new organs are formed for the posterior daughter. The axostyle is resorbed (Cleveland, 1938). The possibility that the 'inheritance' of organelles may modify the age status of the inheritor certainly merits re-investigation.

\subsection{The 'Senescence' of Clones}

A large part of the literature included in the bibliographies of senescence deals with the presence or absence of 'ageing' in protozoan clones. Maupas (1886) appears to have been the first to draw an analogy between somatic ageing in metazoa and the behaviour of protozoan populations. He predicted that such populations would display a life-cycle including a phase analogous to metazoan senescence, and ending in the death of the population, unless nuclear reorganization by conjugation, or some similar mechanism, brought about the 'rejuvenation' of the stock. For many years a vigorous competition was conducted between proto-zoologists in seeing how many asexual generations of Paramecium, Eudorina, and similar creatures they could rear. In the course of this process much nonsense was written about 'potential immortality', but a great deal was learnt about protozoan reproduction and culture methods. It became evident that some clones deteriorate and others, including somatic cells such as fibroblasts in tissue-culture, do not. Calkins (1919) in a classical study showed that strains of Uroleptus mobilis kept in isolation culture without conjugation underwent senescence characterized by falling-off of growth-potential, degeneration of nuclei, and ultimate loss of micro-nucleus. These strains ultimately became extinct. Conjugation at any stage of the process, and probably also endomixis, produced an immediate reversion to normal, regardless of whether the conjugates came from old or young isolation strains. Sonneborn (1938) succeeded, by selection of strains of Paramecium in which endomixis was long delayed, in breeding a race which no longer exhibited any kind of nuclear reorganization. These strains invariably died after 4 or 5 months. Rizet (1953) has recently reported similar results 
with an Ascomycete kept in continuous vegetative reproduction. On the other hand, Bélár (1924) maintained Actinophrys sol in isolation culture, without the occurrence of paedogamy, for 1244 generations over 32 months, and observed no decline in the rate of cell division. Beers (1929) kept Didinium nasutum for 1384 generations without conjugation or endomixis. Hartman (1921) kept Eudorina elegans in active asexual reproduction for 8 years. Woodruff's oldest culture of Paramecium aurelia persisted for over 15,000 generations but was undergoing autogamy. The conclusion must be that some clones are stable while others are not.

More light is thrown on this problem by the work of Jennings (1945) upon clones of Paramecium bursaria. He found that in this species the life-cycle fell into well-defined phases of growth, sexual reproduction by conjugation with other clones, and decline. The length and character of these phases differed substantially from clone to clone. In the decline phase the death of individual cells, and especially of the progeny of conjugation between old clones, becomes very common. The vitality and viability of the progeny of conjugation, even when the conjugant clones are young, varies greatly, and a very high proportion of ex-conjugants normally die. This mortality is highest among the progeny of conjugation between related clones. Of 20,478 ex-conjugants, 10,800 (52.7 per cent) died before undergoing their fifth successive cell division, while 29.7 per cent died without dividing at all. Most conjugations produced some nonviable clones, some weakly clones capable of limited survival, and a few exceptionally strong clones, some of which appeared capable of unlimited asexual reproduction. It is from these strong races that the population of laboratory cultures is normally obtained.

Jennings concluded as follows: 'Death did not take origin in consequence of organisms becoming multicellular ... it occurs on a vast scale in the Protozoa, and it results from causes which are intrinsic to the organism. Most if not all clones ultimately die if they do not undergo some form of sexual reproduction. ... Rejuvenation through sexual reproduction is a fact... yet conjugation produces, in addition to rejuvenated clones, vast numbers of weak, pathological or abnormal clones whose 


\section{The Biology of Senescence}

pre-destined fate is early death. The rejuvenating function of conjugation is distinct from, and in addition to, its function as a producer of variation by redistribution of genes. Among the clones produced (by conjugation) there are seemingly, in some species, some clones of such vigour that they may continue vegetatively for an indefinite period, without decline or death' (Jennings, 1945).

Some authors have regarded the increased proportion of weak and non-viable conjugants of old clones as the outcome of an accumulation of unfavourable mutations. Comparable effects (Banta, 1914; Banta and Wood, 1937) have been described in clones of Daphnia. This was long since suggested by Raffel (1932) on the basis of Paramecium experiments. The type of lineal 'senescence' which occurs in Paramecium is in some respects analogous to the processes which are familiar in inbred stocks reproducing sexually, from Drosophila to domestic cattle (Regan, Mead and Gregory, 1947), and described under the general title of inbreeding depression, but differs from it in that in clones the accumulation of mutations, rather than the segregation of existing genes and the loss of the advantages of heterozygy, have been held to be involved. The mortality among the progeny of autogamy in Paramecium is directly related to the length of time during which autogamy has been previously suppressed (Pierson, 1938). The time scale of the group 'life-cycle' is modified by a great many physical and chemical agents-on the other hand, methylcholanthrene, normally a mutagenic agent, delays the decline of Paramecium clones (Spenser and Melroy, 1949).

The real mechanism of clonal senescence in Paramecium, however, has now been brilliantly elucidated by Sonneborn and his co-workers (in press). It depends, as other workers have foreseen (Fauré-Frémiet, 1953) on the peculiar mechanism in ciliates whereby the germinal and vegetative functions of the nucleus are divided between two separate structures. When Paramecium divides after a sexual process, the new nucleus of each daughter cell again divides into two. One of these products, the micronucleus, which reaches the anterior end of the cell, has the normal diploid number of chromosomes, and is apparently concerned solely with conveying the genotype: it is, in 
other words, the 'germ-plasm'. The other portion, the macronucleus, controls the metabolism of the cell. It becomes highly polyploid, and at subsequent cell divisions, while the micronucleus divides evenly in the normal manner of nuclei, the macronucleus distributes its chromosomes at random to the daughter macronucleus arising from it. Because of the enormous number of sets which it contains, every cell in the earlier divisions has a fair chance of getting its quota, but with the passage of time more and more daughters receive an unbalanced set and a reduced physiological repertoire, and a chromosome once lost cannot be restored from the micronucleus except by sexual division-conjugation or autogamy. In the later stages of clonal senescence even sexual division is affected and abnormal or non-viable products increase. Sonneborn has shown that this is not due to the accumulation of mutations, since it can be prevented by periodic autogamy, even though this does not alter the genotype: it appears to be due to injury inflicted upon the micronucleus itself through the abnormal intracellular conditions produced by the defective macronucleus. In ciliates the germ-plasm has to live in the cell where the processes of somatic maintenance are carried out, and it is therefore unusually exposed. This is probably a unique situation-it does not even apply in other ciliates-and the division of function between vegetative and germinal nuclei is confined to this group. The existence of presumed cytoplasmic mutations, although there is no evidence to relate them to metazoan senescence as such, might be far more relevant to it than studies of protozoan clones. A kindred subject, that of somatic aneuploidy, is discussed in $6 \cdot 1 \cdot 3$ (p. 168). It is in any case probably misleading to identify the decline of protozoan cultures with the metazoan senescence which it superficially resembles; it is doubtful if analogies can properly be drawn between acellular organisms and metazoan cells, and the only relevance of the whole question of 'ageing' in protozoan clones to ageing in the metazoan body lies in the the light which it might possibly throw upon the effects of cell division in renewing expendable enzyme systems. There is no special reason, upon the present evidence, why the 'senescence' of Paramecium should continue to figure as extensively as it has done in treatises devoted to gerontology. 


\section{The Biology of Senescence}

The 'senescence' of some lines of plants in vegetative propagation apparently depend on the accumulation of exogenous viruses which hamper vigour (Crocker, 1939) - other agriculturally important varieties have been propagated vegetatively for years or centuries without deterioration. The accumulation of exogenous viruses itself raises interesting questions in regard to the possible accumulation of other, endogenous, intra- or extranuclear self-propagating materials.

Not all senescence or degeneration in clones, however, can be put down to the peculiarities of protozoa or to the action of viruses. A striking example of such a degeneration has been studied at Oxford by K. G. McWhirter, to whom I am much indebted for his unpublished observations on it. This is the condition called 'June Yellows', which affects strawberry plants propagated by runners, and impairs the formation of chloroplasts. It appears simultaneously in all plantations of a clone, even when they are geographically separated, and progresses in jumps, all the plants of the same clonal (but not individual) age passing synchronously from stage to stage. Usually in the end the clone dies out. The condition cannot be transmitted to adult plants by grafting. Transmission to seedlings is ambilinear through both egg-cell and pollen. In the progeny of crosses between clones at different stages of degeneration it is matroclinous: seedlings of very degenerate 'mothers' deteriorate most rapidly. As a clone degenerates, the tendency to transmit 'yellows' to its offspring increases. The factor or factors remain latent in some clones, but 'yellows' may appear after varying intervals in some of the selfed or crossed seedlings obtained from these clones, thus showing a latency reminiscent of that of the presumed oncogenic plasmagenes. This similarity has been pointed out before (Darlington, 1948; Darlington and Mather, 1949).

The behaviour of this degeneration is like that of a mutation which is in part cytoplasmically controlled. Such conditions are characterized by a lag-phase, by simultaneous appearance in all the members of a clone, non-infectivity, passage through a series of stable phenotypic stages, and interaction with growth and reproductive hormones. In some of McWhirter's material, 'yellows' appeared to be aggravated during the flowering period, although it may occur in seedlings long before flowering. 


\section{$-4 \cdot$}

\section{THE INFLUENGE OF GENETIC CONSTITUTION ON SENESGENGE AND LONGEVITY}

\section{4·1 Inheritance of life-span}

4.1.1 GENERAL

IT is evident in any comparison of laboratory stocks that differences of specific age are to some degree 'inherited' (Pearl and Parker, 1922; Gonzales, 1923, Gruneberg, 1951, Fig. 31), but detailed genetic knowledge of the manner of their inheritance is not plentiful. Much variation in life-span occurs between inbred lines. This variation is often related to a single heritable predisposition to die of cancer, renal disease, or some other single cause: in these cases it is often short life, not long life, which is capable of genetic selection in the homozygote. Bittner (1937) showed that in some cases it is possible to transpose the longevities of strains of mice by cross-suckling. In other cases, secondary causes, such as restricted capacity for activity in deformed stocks, affect the life-span. In a stock of mice bred by Strong (Strong, 1936; Strong and Smith, 1936) longevity increased the apparent incidence of disease by allowing animals to reach the cancer age. Two factors appear at first sight to be involved in inherited longevity-absence of genetic predisposition to specific causes of death, and a less definite quantity ('vigour') which contributes to Darwinian fitness because it is usually expressed both in fertility and in longevity. It is by no means certain that these factors are distinct. 'Vigour' itself may in fact represent either the covering-up of deleterious recessives by heterozygosis, or a state of over-dominance, in which the heterozygote is inherently more vigorous than either homozygote. 


\section{The Biology of Senescence}

Hereditary factors in human longevity have often been sought. Pearl and Pearl (1934a, b) found, for instance, that the summed ages at death of the six immediate ancestors of centenarians and nonagenarians were significantly greater than in a control series of the relatives of individuals not selected for longevity. 86.6 per cent of long-lived $(>70)$ subjects had at least one long-lived parent, while 48.5 per cent of nonagenarians

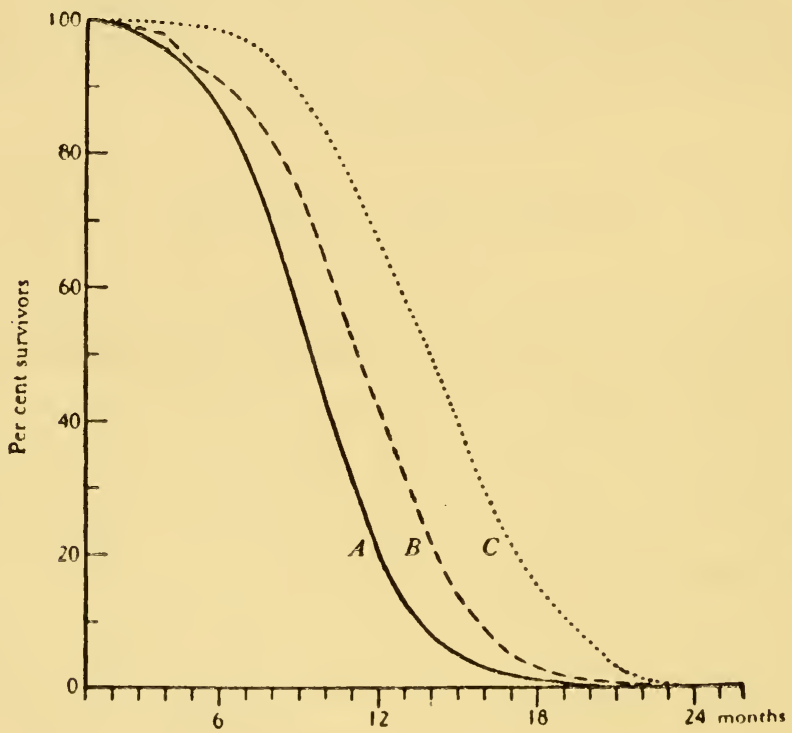

Fig. 31.-Survival curves of mice in laboratory culture-breeding females. Curve A based on $241 d b a$ females, curve B on 730 Bittner albinos, curve C, on 1350 Marsh albinos (from Gruneberg, 1951).

and 53.4 per cent of centenarians had two such parents, all these figures being significantly higher than in the control series. Kallman and Sander $(1948,1949)$ found that in 1062 pairs of twins the mean difference in longevity between dizygotic twin individuals was twice as great as in monozygotics. These and other studies indicate that longevity is 'hereditary', but unfortunately give little light on its genetics. Beeton and Pearson (1901) studied the longevity records of Quaker families, and found that the sib-sib correlation of longevity was nearly twice the parent-offspring correlation, in those individuals who died 


\section{The Influence of Genetic Constitution}

at 21 years of age or later, but that there was a far lower sib-sib correlation between those dying as minors. Haldane (1949) has pointed out that this is the type of correlation which would be expected where the heterozygote is fitter in the Darwinian sense than either homozygote: insofar as natural selection operates to elimate homozygosis, not to promote it, such fitness must imply a higher correlation between sibs in an equilibrium population than between parent and child. In any case, the degree of parent-child correlation observed by Beeton and Pearson is only a quarter that between parental and filial statures in comparable studies.

Dublin and his colleagues (1949) have summarized most of the historic studies on the inheritance of longevity in man. They conclude that the popular idea of inheritance as a factor in longevity is probably correct, that the evidence from actuarial studies is heavily vitiated by all kinds of environmental influences, and that the order of advantage to the sons of long-lived fathers is small compared with the secular increase in life-span during recent generations. The difference in life expectation at 25 years between those with better and poorer parental longevity records is between 2 and 4 years - this compares with a gain of 6.7 years in the general expectation of life at 25 years in the U.S.A. between 1900 and 1946. 'It may be well, as has been suggested, to seek advantages in longevity by being careful in the choice of one's grandparents, but the method is not very practicable. It is simpler and more effective to adapt the environment more closely to man, (Dublin, 1949, p. 118).

It does not follow from these considerations that longer life cannot be obtained in a given population by selective breeding, and in mice this has, in fact, been done (Strong and Smith, 1936). There may well be single-gene characters where the homozygote is significantly longer-lived. 'Vigour', on the other hand, which is a correlate of both longevity and fertility, and hence of Darwinian fitness, is likely in most cases to be an expression of heterozygosis, and one would not expect to be able necessarily to produce abnormally long-lived animals by inbreeding long-lived parents.

Agricultural genetics, like natural selection, has for the most part attempted to increase lifetime production averages by 123 


\section{The Biology of Senescence}

increasing early output of eggs or offspring. Greenwood (1932) found that the fertility and hatchability of hens' eggs decline with age of the parent to such an extent that attempts to improve the stock by breeding from long-lived birds were economically impracticable. Apart from the obvious difficulty

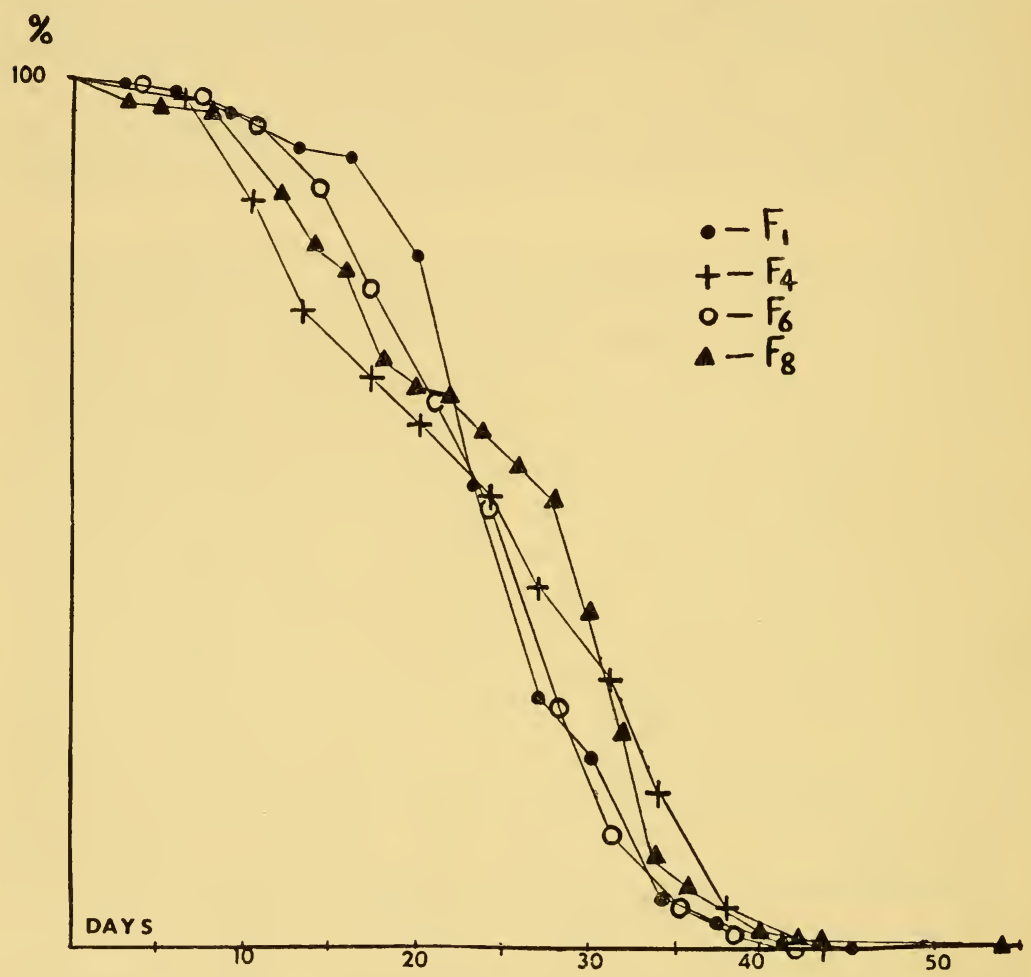

FIG. 32.-Drosophila subobscura. Strain K. Survival curves of flies raised in each generation from eggs laid by adults which had passed the thirtieth day of imaginal life. Compare Fig. 33.

of breeding for long life in any animal with a substantial post-reproductive period, which involves rearing all the progeny of large numbers of animals throughout life, the consequence of inbreeding per se, and the tendency of inbred laboratory stocks to reach a very stable equilibrium life-span (Pearl and Parker, 1922) militate against any such experiment. In Pearl's own experiments (Pearl, 1928) the long- and short-lived 


\section{The Influence of Genetic Constitution}

Drosophila segregates were identified in the $F_{1}$ by subsidiary, anatomical characters known to be associated with the desired lines. In Drosophila subobscura of the structurally homozygous Küssnacht strain, which had been in culture for about three years, and had reached an equilibrium life-span considerably shorter than that of wild-caught flies, breeding for 8 generations over 1 year exclusively from eggs laid after the thirtieth day of parental life produced no significant alteration in mean imaginal longevity (Comfort, 1953) (Fig. 32).

The inheritance of long life in man is presumably bound up with the inheritance of 'general health' (Pearson and Elderton, 1913; Pearl, 1927) an element which is not more susceptible to analysis than 'vigour', though it has been partially described in terms of response to stress (Selye, 1946). Robertson and Ray (1920) found that in a population of mice the relatively longlived individuals formed a stable sub-group, displaying the least variation and the highest resistance to disturbing factors. In such a group the growth-rate tends to be a measure of 'general health', and rapid rather than retarded growth correlates with longevity. In other studies on groups of animals living under standardized conditions, rate of growth and length of life have been found to vary independently (Sherman and Campbell, 1935). The relation between growth-rate and vigour in a mixed population requires to be distinguished from the effect of growth retardation by dietary means in a homogeneous population, when the retarded growers live longer. As McCay (1952) points out, much early work on the relation between growth-rate and longevity was vitiated by this confusion in experimental planning.

\section{$4 \cdot 1 \cdot 2$ PARENTAL AGE}

The age of the mother is known in certain cases to modify the longevity of her offspring. This influence apparently include a wide range of dissimilar effects, some strictly 'genetic', and others operating at various stages in the process of embryogenesis, or, in mammals, on into lactation. Certain of these effects appear only in the $F_{1}$, while others, like the factor described by Lansing in rotifers, which leads to a decreasing life-span in successive generations of clones propagated 


\section{The Biology of Senescence}

exclusively from old individuals, appear to be cumulative and reversible (p. 88).

The general question of maternal age effects in genetics is beyond the scope of this book. It has recently been reviewed (Miner, 1954) in a valuable symposium. In mammals the age of the mother exerts an influence on the vigour of the progeny which appears to vary greatly in direction and extent, even within a species. Sawin (in Miner, 1954) found that in one strain of rabbits, the early ( $<6$ months) mortality was lowest in the progeny of young mothers, and increased throughout maternal life, while in another, larger, strain it reached a minimum in the progeny of mothers 18 months old. These changes were not correlated with any differences in lactation or maternal weight. Jalavisto (1950) found evidence that in man the expectation of life decreases with increasing maternal, but not paternal, age. The percentage of abnormal offspring is greatest in litters born to young guinea pigs (Wright, 1926) and elderly women (Murphy in Miner, 1954). It is possible that the association of mongolism with high parental age is a reflection not of increasing foetal abnormality, but a decrease to the point of viability in an abnormality which, at younger maternal ages, is lethal (Penrose in Miner, 1954). In some celebrated experiments upon mouse leukaemia, McDowell and his co-workers have shown that when susceptible males are crossed with resistant females, the age of onset of leukaemia in the hybrid $F_{1}$ is significantly retarded in mice born to, or suckled by, old as compared with young mothers. At the same time, the mean longevity of mice which die of causes other than leukaemia is also greatest in the progeny and nurslings of old mothers (McDowell, Taylor and Broadfort, 1951). Strong (in Miner, 1954) has described a factor influencing the latent period of sarcoma production after injection of methylcholanthrene into mice, which appears, like Lansing's rotifer longevity factor, to be cumulative - a line derived from seventh to ninth litters in each generation had a significantly increased and increasing latent period compared with a line derived from first and second litters. Unlike Lansing's effect, this increase has not been shown to be reversible in the progeny of young members of the 'old' line. There is at present no evidence in mammals of any 


\section{The Influence of Genetic Constitution}

cumulative disadvantage in longevity accruing to 'youngest sons of youngest daughters'. In this connection Strong has however stressed, on a number of occasions, the need for further information on the relation between longevity and cumulative parental age in human genealogies. Such information is unfortunately hard to come by, and no large-scale study has yet been published. Lansing's effect might well be sought in the parthenogenetic Cladocera. The age of the mother affects the rate of development, and probably the longevity, of young Daphnia. Green (1954) recently found that the size of Daphnia at birth determines the instar in which maturity occurs, the largest becoming mature earliest. The birth size itself depends upon maternal age, being highest (in D. magna) in the third brood. Since the pre-mature phase is the part of the life-cycle in which most variation occurs, the mature phase being usually of fixed length, early developers might be expected to be significantly shorter-lived than late. But R. H. Fritsch, at the Justus Liebig School in Giessen (unpublished) has compared the longevity under carefully standardized conditions of successive generations of Daphnia raised wholly from first, third, and sixth hatchings, and finds no significant trend in any of the orthoclones, the mean life-span in all remaining at about 30 days.

\subsection{Heterosis or Hybrid V'igour}

Abnormally long-lived animals can regularly be produced by crossing certain pure lines, not themselves unusually long-lived, the effect being greatest in the hybrid $F_{1}$ and their offspring and declining rapidly on subsequent inbreeding. This is, in fact, the simplest method of increasing the specific age in many already inbred laboratory and domestic animals. Striking examples of this effect (heterosis) in increasing longevity have been recorded in mice. Gates (1926) by crossing Japanese waltzing with 'dilute brown' strains produced a generation which was still actively breeding at 2 years of age. Comparative life-tables for crosses exhibiting extreme hybrid vigour do not seem to have been published. 'Super-mice' produced by heterosis develop precociously, reach a large size, and remain in active reproduction much longer than their parents, thereby exhibiting a 


\section{The Biology of Senescence}

combination of rapid growth with increased longevity analogous to that of the rapid-growers described by Robertson and Ray (1920). An example of the same effect in Drosophila is shown in Fig. 33. The greater longevity of goldfinch-canary mules compared with the parent species is apparently well known to aviarists, and such techniques of crossing are of widespread

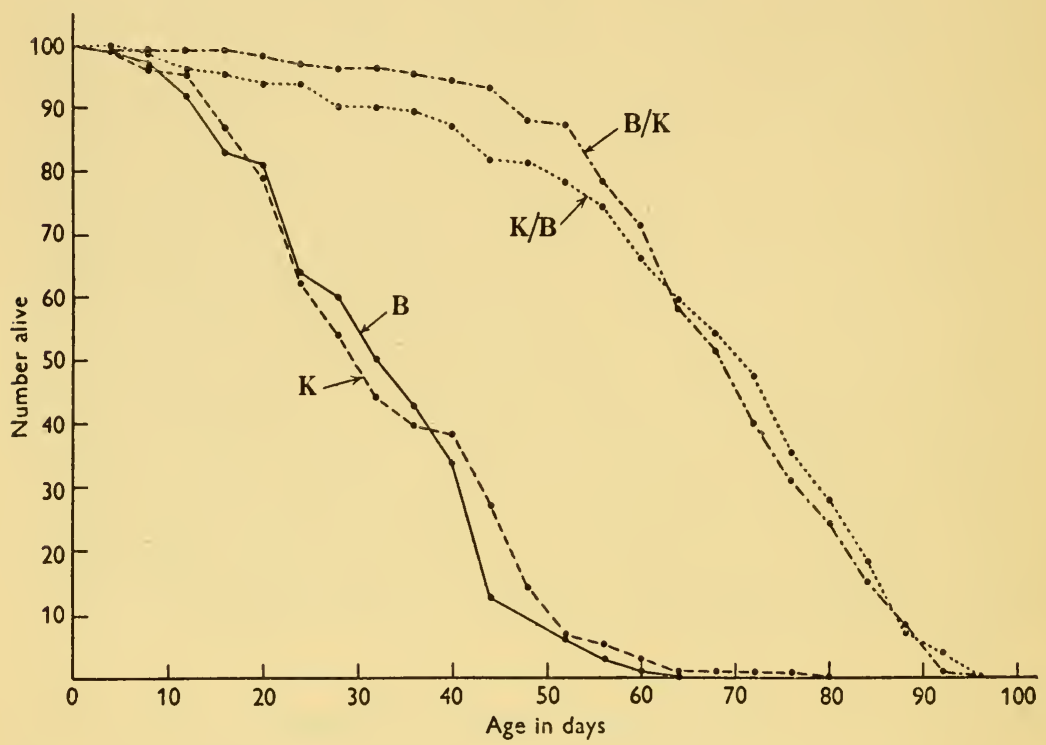

Fig. 33.-Drosophila subobscura-hybrid vigour and longevity. Survival curves for the inbred lines B and $\mathrm{K}$, and for the reciprocal hybrids between them (sexes combined) (from Clarke and Maynard Smith, 1955).

agricultural and economic importance when applied to sheep or to plants.

The existence and magnitude of this effect should always be borne in mind in the planning of experiments on the life-span of animals drawn from closed laboratory stocks-such work can produce very seriously misleading results if unrecognized heterosis takes place. If an experiment in which the longevity of generations is compared begins with hybrid progeny, marked inbreeding depression can shorten the life-span of the succeeding generations if genetical precautions are not taken.

A fuller study of longevity in hybrids might provide useful 


\section{The Influence of Genetic Constitution}

information on the nature of 'constitutional vigour' in relation to growth-rate. The effect is variously explained. Some of the possible complications of heterosis in relation to the criteria of vigour are indicated by the findings of Rutman (1950, 1951), who compared the rates of methionine uptake in liver slices from a fast- and a slow-growing strain of rats. The methionine replacement rate in slices derived from the fastgrowing strain was almost double that in the slow, but the growth-rate of the slow strain could be made to approach that of the fast by transposing the litters during suckling, and appeared to be controlled by a milk-borne factor. Interstrain hybrids at first showed a growth pattern like that of the mother, but later followed that of the faster-growing strain.

Although by a very elegant experiment J. and S. Maynard Smith (1954) have shown that in certain cases at least heterosis appears to result from orthodox heterozygy, the number of instances in which cytoplasmic and environmental factors also appear able to evoke vigour is increasing. This is largely a reflection of the very heterogeneous character of 'vigour'. Some years ago Borisenko $(1939,1941)$ reported an increase in vigour in the progeny of Drosophila matings where the inbred parents were reared under different environmental conditions. This observation does not appear to have been repeated. The question of the induction of vigour by non-genic means has since been most actively investigated by avowed anti-Mendelians (Kurbatov, 1951; Hašek, 1953, etc.) but by no means all the positive results come from this school. As far back as 1928, Parkes observed that mice suckled by rats exhibited an extraordinary overgrowth, which results simply from excessive nutrition. Marshak (1936) found evidence of a maternal cytoplasmic factor influencing the increase of growth-rate due to heterosis in mice. The increased vigour in progeny of pure-line ova transplanted to hybrid mothers (Kurbatov, 1951) is also found in transplanted foetuses (Venge, 1953). Hašek has claimed (1953) that when parabiosis is carried out between Rhode Island and Leghorn embryos in the egg, by an ingenious technique, the pullets occasionally show even greater vigour than the progeny of R.I.R. $\times$ Leghorn crosses. Without endorsing the sweeping theoretical claims based by the Russian school upon 


\section{The Biology of Senescence}

'vegetative hybridization' of this type, it seems clear that the last word has yet to be said upon the nature of induced vigour. The whole problem is one which might be of considerable interest to gerontology, since in some cases 'vigour' appears capable of induction post-conceptually, or even post-natally. It is important to notice, however, that there is no clear evidence at present to show that the vigour and longevity obtainable by true heterosis are greater than those existing in wild strains. Heterosis should be regarded, in all probability, as the restoration of 'wild' vigour, whether by restoring heterozygy or by other processes, in lines which have lost that vigour through inbreeding. Whether the results of heterosis can be superior to those of wildness, in longevity or otherwise, remains to be demonstrated.

\section{$4 \cdot 3$ Sex Differences}

In most animals which have been studied, the male sex is the shorter lived. This is true in organisms as dissimilar as fish (Bidder, 1932; Wimpenny, 1953), spiders (Deevey and Deevey, 1945, Figs. 34, 35), Drosophila (Alpatov and Pearl, 1929; Bilewicz, 1953), Habrobracon (Georgiana, 1949), Tribolium (Park, 1945, Fig. 36); water-beetles (Blunck, 1924) and man. In exceptional cases the preponderance of male mortality can be reversed. Thus Woolley (1946) found that in crosses between $\mathrm{dba}$ female and c57 male mice, the virgin females of the $\mathrm{F}_{1}$ had a mean life of 27 and the males 29 months: in the reciprocal cross, the females lived 30 and the males 33 months. Males of Rattus natalensis outlive the females (Oliff, 1953). Darwin (1874) regarded the shorter life of the male as 'a natural and constitutional peculiarity due to sex alone'. Attempts have also been made to explain it in genetic terms (Geiser, 1924; Gowen, 1931, 1934). Gowen constructed life-tables for Drosophila intersexes and triploids, and concluded from his results that chromosome imbalance in itself exerted an adverse effect on life-span. In most of the forms where full life-tables have been made, the bias of mortality against the male follows the rule of greater vigour in the homogametic sex. McArthur and Baillie (1932) pointed out that if the lowered vitality of the male was due to 


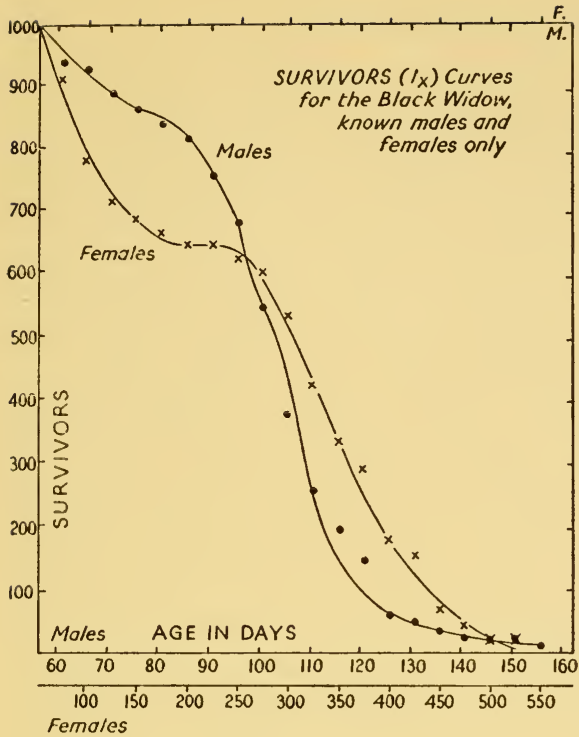

Frg. 34.

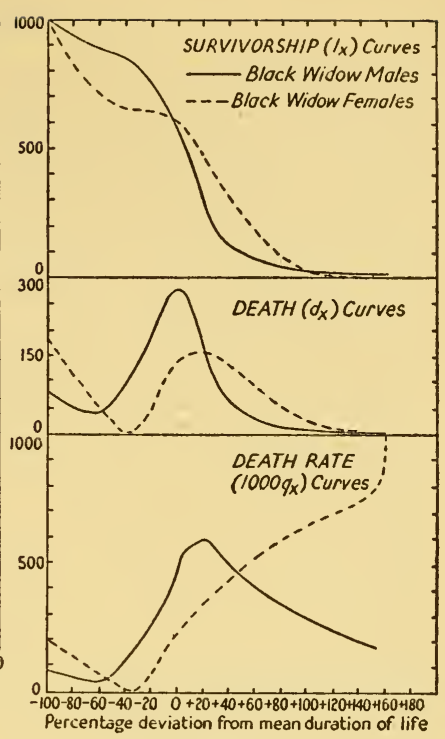

FIG. 35.

Fig. 34.-Survivorship curves for 82 males and 45 females of the black widow spider Latrodecte smactans (Fabr). Note that the male curve is shown to five times the time scale of the female curve (from Deevey and Deevey, 1945). FIG. 35.--Survivorship, death and death-rate curves for the black widow. Note that the death curves are shown to twice the ordinate scale of the others (from Deevey and Deevey, 1945).

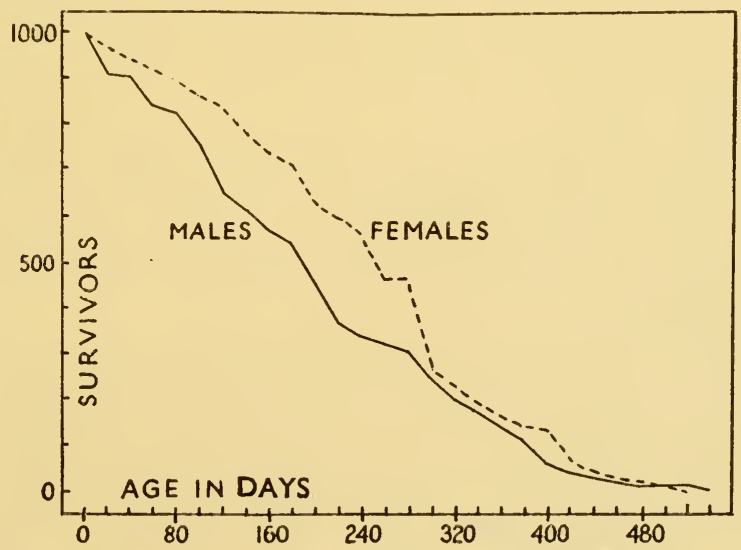

FIG. 36.-Survivorship curves for male and female Tribolium madens (radix of 1,000 images) (from Park, 1945). 


\section{The Biology of Senescence}

greater homozygosis for adverse genes, the effect should be reversed in those forms where the female is heterogameticnotably lepidoptera and birds. From the studies of Landauer and Landauer on fowls (1931) and of Rau and Rau (1914) on saturnid moths, they could find no evidence of such a reversal. Adequate life-table studies are still very scarce in these groups. In crosses, the difference in vigour between homogametic and heterogametic sexes may certainly be so great that only the homogametic reaches maturity-thus Federley (1929) found that in certain interspecific crosses in hawk moths, only the males survived pupation, though in reciprocal crosses both sexes survived. Beside these studies, that of Pearl and Miner (1936) upon Acrobasis caryae, which is one of the few actuariallyconstructed lepidopteran life-tables which have been published, and an extensive study by Woodruffe (1951) on the survival of the moth Hofmanophila pseudospretella under different environmental conditions both show a significantly higher female lifespan. Alpatov and Gordeenko (1932) working on Bombyx mori, found no difference in longevity between unmated males and females, but a significantly longer male life in mated moths. Reexamining the results of Rau and Rau (1914) they concluded that in both Samia cecropia and Calosamia promethea the mated female had a shorter life-span than the male. This difference, however, might be due at least in part to the exhaustion of reserves by more frequent egg-laying in mated females. The life-span of the female Aglia tau is said to be the shorter (Metchnikoff, 1907).

Rey (1936) working on the non-feeding imago of the moth Galleria mellonella, found that the males lived up to twice as long as the females, the difference being unaffected by humidity but exaggerated at low temperatures. He assumes this to be 'the rule for lepidoptera'.

In poultry, it seems to be established that the female is the more viable and has the longer reproductive life (Pease, 1947) and observations such as those of McIlhenny on wild ducks (1940), which indicate an increase in the proportion of males with increasing age, are probably the result of differential risks. Longer life-span in males is also found in some other birds in the wild (Lack, 1954). In cyprinodont fishes, some of which have 


\section{The Influence of Genetic Constitution}

an atypical mechanism of sex-determination, evidence is inadequate, but Bellamy (1934) found no conspicuous sex difference in longevity in a small series. An example of longer life in the male teleost occurs in minnows (van Cleave and Markus, 1929) but this refers to a wild population. It seems altogether likely that where a sex difference in longevity is observed it arises from the sum of differences in metabolic rate and behavioural pattern-in other words, from physiological sexual dimorphism. A number of invertebrate metabolic studies support such a view (Daphnia, McArthur and Baillie, 1929a, b; Drosophila, Alpatov and Pearl, 1929), by indicating that the 'rate of living' in the male is in fact higher. The degree to which the inferior vitality of the male mammal results directly from the action of androgens has been discussed, and the whole question of male mortality reviewed at length, by Hamilton (1948). In man, the higher male mortality is present both in utero and in infancy. At later ages the question is, of course, complicated by social and occupational factors (Herdan, 1952). There are as yet no fully satisfactory human data upon the relative longevity of castrates, though their life-span is certainly not grossly inferior to that of normals. Many of the highest recorded ages in cats have occurred in gelt males (p. 48). The finding of Slonaker (1930) that castration produces a slight decrease in rat longevity was based on too few animals to be significant.

In some instances (Drosophila, Bilewicz, 1953) the life of the male is still further shortened by copulation. In others (Latrodectes, Shulov, 1939-40) the male dies after a determinate short life-span, whether mated or not. While the mortality of Anglican clergy in England during the 1930's was only 69 per cent of the general male mortality, and that of other Protestant clergy 74 per cent, the mortality of Roman Catholic clergy was 105 per cent (Registrar-General's statistics, 1938). This observation is complicated by a variety of factors: in rats, however, regular mating improves the condition and longevity of the male (Agduhr, 1939; Agduhr and Barron, 1938). This might tend to support the view that the virtues of 'continence' in man, vis-à-vis longevity, have been over-praised by interested parties. After citing the opinion given by the Dutch physician Boerhave 


\section{The Biology of Senescence}

(1668-1738), who 'recommended an old Burgomaster of Amsterdam to lie between two young girls, assuring him that he would thus recover strength and spirits', Hufeland (1798) remarks 'We cannot refuse our approval to the method.' It would seem by tradition to be applicable only to the male.

\subsection{Progeria}

Although the rate of senile deterioration varies between individuals, the specific age of genetically homogeneous animal lines is very stable; even in human populations the range of apparent variation is not very great, and the few descriptions of racially-distributed 'premature senility', as in Eskimos (Brown, Sinclair, Cronk and Clark, 1948) are not actuarially supported, though such variation, genetic or environmental, may occur.

Sporadic cases of syndromes having some of the general characters of premature old age occasionally occur in man. It is not clear how far any of these syndromes can be regarded as genuine accelerations of the timing mechanisms which determines senescence. They are apparently pleiotropic genetic defects, occurring commonly in sibs, and are most conveniently mentioned here. They have been regarded as pluriglandular endocrine disturbances, but they affect many ectodermal structures and have the rather generalized character more typical of an inborn error of metabolism-possibly the deficiency of an enzyme system.

Infantile progeria (Hutchinson-Gilford syndrome) (Thomson and Forfar, 1950; Manschot, 1940, 1950) occurs in childhood. After an apparently normal infancy, the child begins to show retarded growth, with dwarfism and progressively increasing physical abnormality. The appearance becomes senile, the skin atrophic, and there is hypertension with extensive atheroma and calcification. Death usually occurs from coronary disease before the thirtieth year. The mental development of these children may be retarded, but is more typically precocious. Cataract may occur. The endocrine appearances at necropsy are inconstant, but pituitary eosinophiles are reported to be reduced (Manschot, 1940). 


\section{The Influence of Genetic Constitution}

Adult progeria (Werner's syndrome) was first described by Werner (1904) in four sibs. It bears some resemblance to a delayed infantile progeria, occurring after growth has been wholly or partially completed. The subjects are short and of unusual appearance. The symptoms begin in the third or fourth decade, with the development of baldness, greying, skin changes, cataract, calcification of vessels and occasionally of tissues, osteoporosis, hypogonadism, and a tendency to diabetes (Thannhauser, 1945). This seems in general a more promising source of analogy with normal senescence than does the infantile progeric syndrome. Extensive bibliographies of progeria are given by Thannhauser (1945) and by Thomson and Forfar (1950).

Other less generalized conditions with rather similar symptomatology have been described. 'Senile' change may be limited to the extremities (acrogeria). The main interest of these conditions is in providing examples of mechanisms which may mimic the deteriorative changes of human old age. The conditions are all rare, and no parallels have been described in laboratory animals. In infant progeria, pituitary growth-hormone deficiency appears to play some part, though the condition differs markedly from straightforward dwarfism. The deficiency of oxyphil cells in some reported cases bears a resemblance to that which follows castration (Wolfe, 1941, 1943).

Sudden 'senescence' in adults, a great standby of the nineteenthcentury dramatist, is an uncommon endocrine, or possibly hypothalamic, reaction to severe emotional shock or accident, which, although not genetic, can conveniently be considered here because of its superficial affinity with progeria. In the interest of literary effect, the preliminary phase of sudden baldness is usually not stressed. The hair may fall out within twentyfour hours, to be replaced when it grows again after an interval, by white or structurally defective hair-impotence, depression and cachexia are described as concomitants. The condition is recoverable, and appears to have more connection with Simmonds' disease than with senescence. A case was reported by Greene and Paterson (1943) in a railwayman who fell from a locomotive and suffered head injury and severe shock. A few cases are alleged to have followed intense fear, as in battle. The pituitary may well be the endocrine chiefly responsible. 


\subsection{Choice of Material for Experimental Study of Age Effects}

Research on the senescence of man and most large mammals necessarily involves work on genetically diverse populations. Where closed laboratory stocks are used, or the subject is a 'genetical' domestic animal such as the mouse or Drosophila, genetic precautions are essential in ageing experiments, especially if comparisons are to be made between the life-spans of different groups or different generations. The size of the effect which can be produced in such stocks by heterosis has already been mentioned. The presence or absence of uniformity in the experimental population is also particularly important in research involving life-tables, since in many inbred lines the form of the life-table depends entirely on one cause of death which is not typical of the species, or even the phylum.

In non-genetical experiments (nutrition, biochemistry, growthrate and so on) the choice lies between inbred, hybrid and randombred material. Inbred lines commonly have a life-span which is rather low for the species, and this may be advantageous. Their vigour is often low, though inbreeding depression is more evident in some species than others. Inbred lines are often chosen by non-genetical workers for bioassay, in the belief that they have the advantage of uniformity. This, however, is not so. Grüneberg (1954) has stressed two important characters of such lines: they cannot be relied upon to remain constant in their heritable properties with the passage of time, and may diverge rapidly when split into separate colonies; and they do not constitute phenotypically uniform material, but may, on the contrary, be strikingly more variable than $F_{1}$ hybrids between strains, and even than random-bred material (McLaren and Michie, 1954).

Hybrid material, bred in each generation by crossing inbred lines, suitably chosen, has a number of important advantages for general work upon ageing. In such crosses the life-span approaches the maximum for the species under the experimental conditions. Vigour is high, so that 'background' losses due to temperature change, infection, operative mortality and accident is much reduced, and variation between individuals is minimal. This uniformity is itself probably a reflection of 
vigour, in the form of better homoeostasis (Robertson and Reeve, 1952). Hybrids can, like inbreds, be employed for transplantation experiments. Like inbreds, too, they may all die of a single cause, and will do so as a rule with greater unanimity in regard to age.

Random-mated material, when mating is genuinely random, and not occurring within an already highly-inbred colony or between such colonies, produces animals, the strongest of which exhibit a vigour and life-span approaching that of hybrids, more variable than hybrids, unsuitable for transplantation experiments, showing a variety of causes of death more closely resembling that in human populations, and, in general, resembling such populations more closely than hybrid or inbred lines.

The choice of inbred, hybrid, or random-bred material, when it is not dictated by the fact that no pure lines are available, will depend upon which of these attributes are most useful. The type of material must, however, be correctly stated, since it greatly affects the interpretation of results. Probably the most valuable approach to the comparative study of ageing, though not always a practicable one, would be a scheme of research carried out in parallel upon all three types of strain, in an animal which is already genetically familiar. 


\section{$-5=$}

\section{GROWTH AND SENESGENCE}

\section{5·1 'Rate of Living'}

ThE idea of the life-span as a fixed quantity is an old one. In a great many organisms it has long been recognized that the contrast, perhaps originally moralistic, between a long life and a high 'rate of living' had valid biological applications. The phrase 'rate of living' we owe to Pearl, and it conveys the concept very satisfactorily without making too many assumptions. In many organisms the life-span, like the rate of development, is a function of the temperature over a considerable range. In such forms it appears that a fixcd quantity of something, which, for want of a better term, we have called 'programme', must run out and be succeeded by senescence. The organism must pass through a fixed sequence of operations, metabolic or developmental, the rate of its passage determining the observed life-span.

The period in which the kinetics of metabolism were being discovered expressed this 'programme' in directly chemical terms. Life had an observable temperature-coefficient. Growth, in the classical conception of Robertson (1923), followed the same course as a monomolecular autocatalytic reaction. Loeb (1908) attempted to answer by the determination of temperature coefficients a fundamental question about the 'rate of living' in relation to ageing-what is the nature of the 'programme' which has to be fulfilled before senescence begins? Is it a programme of differentiation, or growth, or maintenance metabolism, or of all three? Loeb's experiments showed that the temperature coefficient of the rate of 'ageing' in echinoderm ova differed greatly from that of their respiration. Later work has shown the relationship between development and tempera- 


\section{Growth and Senescence}

ture to be too complex for simple estimation of coefficients. Morphogenesis depends upon a large number of simultaneous and occasionally contrary processes. We should almost certainly now be inclined to interpret the programme fulfilled by an animal during its life-cycle in terms drawn from experimental morphology and from the study of control systems, rather than directly from physical chemistry.

The postulation that senescence always accompanies, or follows, the cessation of growth, which certainly appears to fit many of the observed facts, we owe originally to the work of Minot (1908). It is, in fact, no more than a postulation, since, as we have seen, there may be organisms in which senescence occurs hand-in-hand with growth, and there are certainly organisms, such as terrapins, which have a virtual maximum size but are not known to exhibit senescence. Senescence in man, judged by the life-table, commences while active growth is in progress: Minot himself considered that the rate of senescence was actually greatest when growth rate was at its maximum. If the relationship between senescence and growthcessation is real, it might mean (1) that that which 'causes' the cessation of growth also causes senescence-implying that growth-cessation results from an active and inhibitory principle, (2) that that which no longer grows, senesces, (3) that growthcessation and senescence are parallel phenomena, both arising from the process of differentiation.

The dissociability of growth from development was first shown by Gudernatsch's researches upon the action of thyroid in the developing tadpole (1912). Metabolism, measured by respiration, is dissociable from both. 'The fundamental mechanisms are not separable only in thought: on the contrary, they can be dissociated experimentally or thrown out of gear with one another' (Needham). The fundamental problem in relation to the 'rate of living' lies, therefore, in determining which of these processes, and in what proportions, make up the essential sequence of operations through which the organism must pass before senescence makes its appearance. In its crudest form the question is: given that these processes, though dissociable, are normally interdependent, does this organism undergo senescence (1) when it reaches a particular stage of cellular 


\section{The Biology of Senescence}

differentiation, (2) when it has exhausted a particular store of 'growth energy', whatever the nature of such a store, or (3) when it has carried out a certain stint of metabolism-a lifespan measurable in calories or in litres of oxygen consumed? It is immediately evident that the programme in real organisms is complex, that since senescence is a diverse process the pacemaker differs in different forms. In some cases, when (1) above has been satisfied, the further life-span of the differentiated cells may depend upon their metabolism, as in (3). All concepts based on 'wear and tear' in neurones or other cells postulate a similar sequence: loss of regenerative power followed by mechanical or chemical exhaustion. In the rotifer the normal sequence of differentiation produces an organism which is almost incapable of cellular repair, and quite incapable of nuclear regeneration. The life-span of the adult, once this point in the programme has been reached, is inversely proportional to temperature and metabolic rate over a certain range. How this effect operates we do not know. The encysted adult, although unable to survive in the complete absence of oxygen (Rahm, 1923) may pass years in diapause. The life-span of many larvae can be enormously prolonged by underfeeding or accelerated by heating: once metamorphosis has taken place the programme is resumed but still responds to changes in temperature by a change in pace. The longest-lived imagines, termite queens, do in fact increase in size after eclosion (Harvey, 1934). In mammals it has been postulated that, since the metabolic rate is held steady by various homoeostatic devices, the essential ingredients of the programme leading to senescence are growth and differentiation; that growth ceases as a result of some process or processes of differentiation, and that the absence of growth is a proximate cause of senescence.

We have already suggested that this is not wholly in accordance with the evidence. The observational test, that no vertebrate which continues to grow undergoes 'morphogenetic' senescence, and that all vertebrates which cease to grow are subject to it, does not appear to be satisfied, while the experimental test, the demonstration that the life-span of an adult vertebrate can be prolonged by keeping it artificially in continued growth, beginning after normal size and development have been at- 


\section{Growth and Senescence}

tained, has not been carried out, although there is some evidence that it may be experimentally feasible. We cannot yet identify any single process which, by its failure, produces the senile decline of homoeostasis in mammals. It is however possible to treat the developmental sequence leading to senescence, in its relation to growth and to differentiation, as an 'integrating system', of the type employed in various calculating and timing devices.

The most familiar example of such a system, functioning as a calculating device, is the taxi-meter. This machine records time when the taxi is stationary, and distance, or time and distance, when it is moving. The real taxi-meter does so upon an 'openended' scale, the amount of the fare which can be rung up on the the dial being theoretically unlimited, since the dials after reaching $\AA^{99} 19$ s. $11 \frac{1}{2} d$. return to zero. For the purpose of our argument, the biological taxi-meter has been adapted by an anarchist to produce an undesirable result when a particular fare is reached-say $£ 10$; or, more correctly, an increasing probability of this result as $\mathcal{E} 10$ is approached and passed: an increasing impairment of the brakes and steering would be a suitable device. The meter records one shilling per minute, so long as the taxi is stationary, and half a crown per mile plus one shilling per minute so long as it is moving. In this case, if the journey never begins, the impairment will take place eventually, though not for a very long time. For an extended biological analogy it is probably better to take the case in which the conditions of the impairment reaching a disastrous stage are, first, that the fare shall reach $£ 10$, and second that the taxi shall have travelled at least a short distance from its starting point.

The question we have to ask is this: does mammalian senescence effectively resemble such an integrating system, in which differentiation is the higher-scoring and the essential component, but in which retardation leading to continuance of growth directly or indirectly delays the point at which senescence appears; or does cessation of growth itself, whether it arises from some active mechanism of size limitation or through the attainment of an equilibrium state, directly cause the senile deterioration? The crude application of the calculating-machine or the time-fuse analogy has many objections, the chief of them 


\section{The Biology of Senescence}

being that the senile decline in resistance in mammals is not a sudden process, as it is in the rotifer, but a smooth rise in the force of mortality beginning at an early stage. Mechanical timing devices produce as a rule a single event after a fixed programme, not an increasing probability throughout the programme, though this objection does not hold good for analogue computing systems: it is relatively simple to devise an electronic taximeter-bomb in which the probability of an explosion increases with the increase of time and distance, or a system in which the steering of the taxi becomes increasingly impaired as the 'programme' continues. A far more serious objection is that in ordinary taxi-meters time and distance are not normally interlocked, as growth and differentiation, though experimentally separable, are interlocked in the developing animal. It has been suggested that the two processes are in some degree mutually exclusive (Bertalanffy, 1933, 1941) - a conception which goes back to Minot. It seems probable that in most organisms it is the component of differentiation, not that of mere growth, which is responsible for senescence.

Analogies, in any case, are mostly of use as teaching-illustrations. In the final analysis, senescence, even if it never reaches the ideal state of being expressed as a sequence of chemical reactions and equilibria, must presumably be reducible to a series of definite processes-such-and-such a mechanism leads to the loss of dividing-power in such-and-such cells, which then have a life-span limited by the non-renewability of their enzymes to so many chemical operations, after which they deteriorate with the following consequences. We are nowhere near such a picture of any one senile or developmental process in any organism, let alone of mammalian senescence or morphogenesis in general. A certain amount of experimental evidence has, however, accumulated-enough to indicate the directions in which further research might profitably be directed. 


\subsection{Experimental Alteration of the Growth Rate}

\section{5·2·1 INVERTEBRATES}

In many invertebrates, the specific age is easily altered, either in response to temperature changes, to which it bears a simple relation, or by retardation of growth through the restriction of food. The total longevity of insects can be increased either by underfeeding the larvae, or by keeping any or all of the stages, from egg to imago, at low temperatures. The same applies to ticks-starvation will increase the life-span of some species from a few weeks to 2 years (Bishopp and Smith, 1938). Northrop (Northrop, 1917; Loeb and Northrop, 1917) kept Drosophila larvae for varying periods on a yeastless medium to delay growth and induce stunting: by this means the total life-span from hatching to death was increased. There is disagreement whether delayed growth of larvae leads to an increase in the life-span from eclosion. Northrop found no such increase in imagines reared from retarded larvae. Intermittent starvation of the imago of Drosophila shortens its life; retardation of the larvae of Lymantria also fails to increase the life-span of the imago, which cannot feed (Kopeć, 1924, 1928). Alpatov and Pearl (Alpatov and Pearl, 1929; Alpatov, 1930) found a slight increase in imaginal life-span in Drosophila when the larvae were retarded by development at $18^{\circ}$. This effect was less evident in males, and appeared to be reversed in some experiments: where the imagines were kept at $25-28^{\circ}$ larvae reared at $28^{\circ}$ gave longer-lived flies than those reared at $18^{\circ}$. The statistical significance of the differences was in any case small.

The life-span and final size of Daphnia (McArthur and Baillie, 1926) and Moina (Ingle, 1933; Terao, 1932 etc.) vary inversely with the temperature over a considerable range. Like Drosophila, Daphnia can be markedly retarded either by cooling or by underfeeding. A detailed study on the effect of retardation upon specific age and growth in Daphnia was carried out by Ingle, Wood and Banta (1937). By diluting the medium, it was shown that starvation of Daphnia for varying numbers of instars resulted in an increase of life-span approximately equal 


\section{The Biology of Senescence}

to the period of starvation, but that individuals starved only until the 11 th or 17 th instar lived longer than individuals starved throughout life. This prolongation of life was achieved

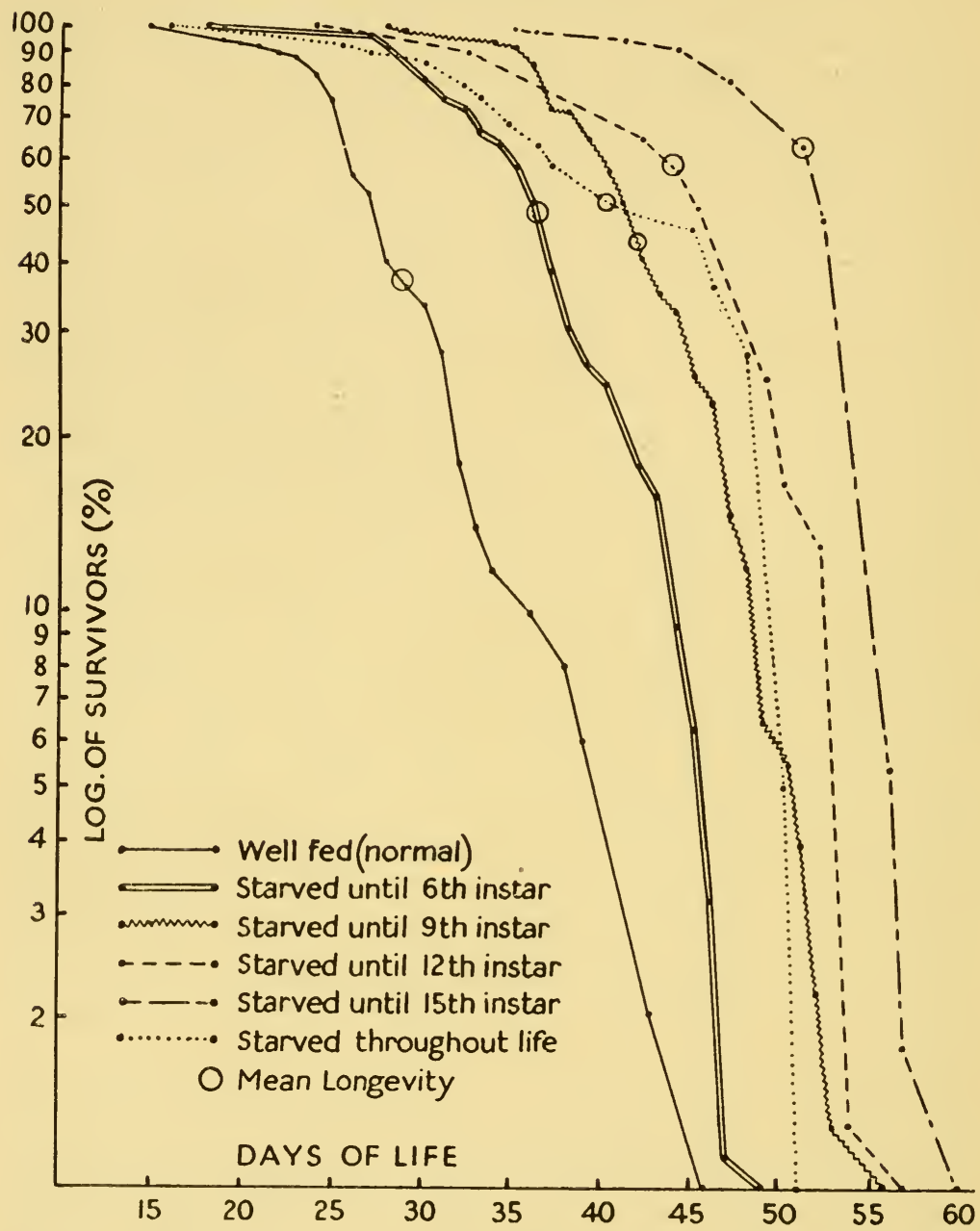

Fig. 37.-Effect of restricted food upon the longevity of Daphnia longispina (from Ingle, Wood and Banta, 1937).

by lengthening the duration of each retarded instar, the total number of instars remaining constant. In this species ( $D$. longispina) the specific age appeared to lie between the 19th and 144 


\section{Growth and Senescence}

22nd instars, without reference to the chronological age which these may represent. (Figs. 37, 38, 39.) In D. magna, Anderson and Jenkins (1942) found a mean life-span of 960 hours or 17 instars - the number of pre-adult instars varied from 4 to 6 and

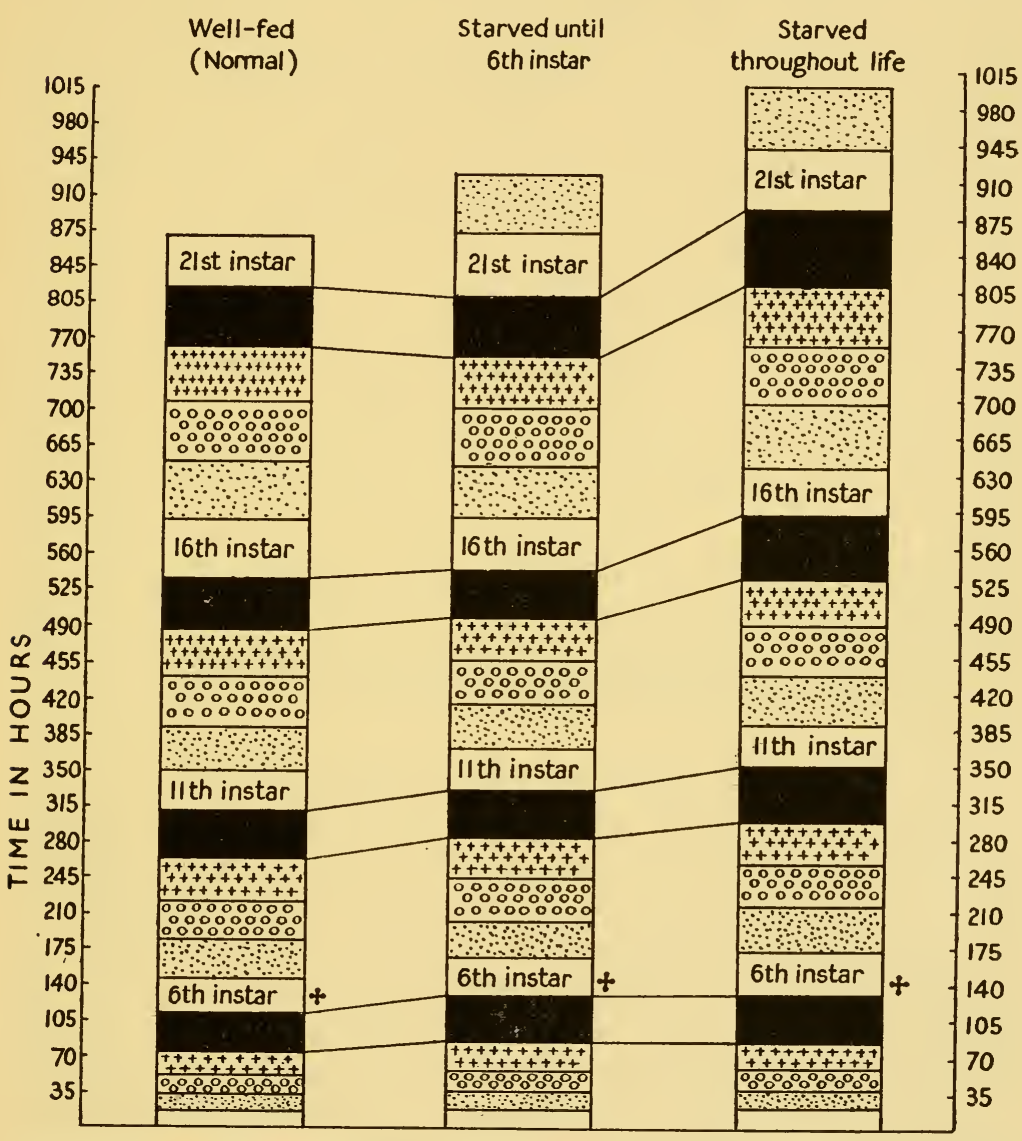

Fig. 38.-Effect of restricted food upon the duration of instars in Daphnia longispina (from Ingle et al., 1937).

the differences in longevity between individuals represented differences in the length of the pre-adult period. (See also Dunham, 1938.) The finding of Fritsch (1953) that the pantothenic acid content of the medium is a major factor in 


\section{The Biology of Senescence}

determining the life-span of Daphnia complicates the interpretation of some of these studies of dietary retardation, however.

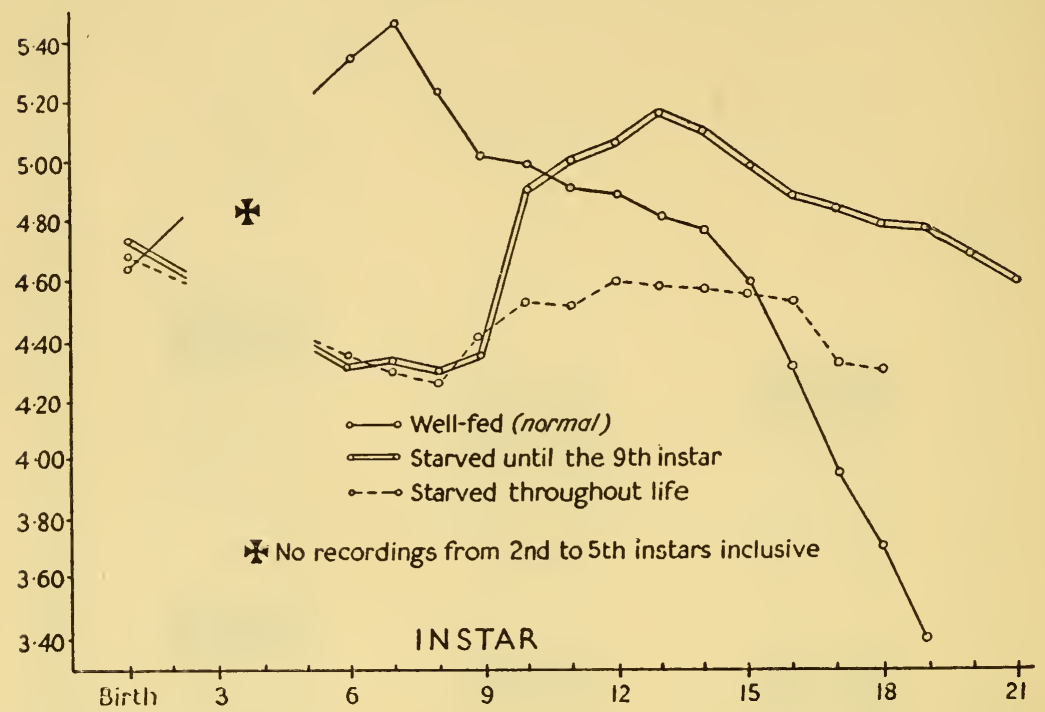

FIG. 39.-Effect of restricted food upon the rate of senile change in the heart rate of Daphnia longispina (from Ingle et al., 1937).

\subsubsection{INSECT METAMORPHOSIS AND SENESCENCE}

A great many insects are capable of very long pre-imaginal life, the duration of which is largely determined by food supply. The 'rate of living', as a simple quantity treated apart from morphogenetic processes, does not give an entirely satisfactory picture of insect development. We might possibly make an experimental approach to the study of insect senescence on the following lines. Senescence, of course, occurs in the ordinary course of events only in the imago. The larval or nymphal stages must be regarded as a system which is self-maintaining but which tends towards ultimate metamorphosis. They are analogous to the young growing period of non-metabolous metazoa. The question arises how long, if metamorphosis could be indefinitely prevented, the metathetelic larva would remain self-maintaining as an equilibrium system. It might presumably do so indefinitely, or it might ultimately undergo a specialized 


\section{Growth and Senescence}

type of senescence due to the suppression of development or to imbalance between continued, divergent growth processes; or it might nevertheless undergo senescence from the same cause, whatever that cause may be, which limits the life of the imago.

To ask whether a larva or a nymph would senesce if it did not metamorphose is not entirely idle speculation. The data which we have on the developmental physiology of Rhodnius, chiefly from the work of Wigglesworth, make it possible to contemplate interfering with the development of nymphs. The pre-imaginal phase of Rhodnius, during which growth takes place, is maintained by the so-called juvenile hormone. 'During larval life, imaginal differentiation is suppressed because in the presence of the juvenile hormone secreted by the corpus allatum the intracellular system which leads to the production of larval structures takes precedence over the system which leads to the formation of adult structures' (Wigglesworth, 1953b). The influence of temperature on larval development appears to act through this system, high temperatures or low $\mathrm{O}_{2}$ tensions depressing the juvenile hormone and producing prothetely, low temperatures enhancing its effect and producing metathetely. This system lends itself particularly well to analysis in terms of control-mechanisms. The tendency of the cellular system in its 'free-running' state appears to be towards the imaginal form. Moulting hormone from a fifth-stage larva will cause a firststage larva of Rhodnius to metamorphose (Wigglesworth, 1934). Second-instar moth larvae will metamorphose to minute pupae and adults if the corpora allata are removed (Bounhiol, 1938) and isolated fragments from the integument of newly-hatched moth larvae tend to pupate (Piepho, 1938). The function of the juvenile hormone appears to be to moderate or prevent this free-running tendency, though as a standing bias, not as a negative feedback. The point to which the free-running system tends, moreover, is an unstable one, ending in eventual senescence. In the fifth stage Rhodnius nymph the thoracic gland undergoes very rapid disintegration as soon as metamorphosis takes place, and the possibility of moulting and cuticular renewal is thereby lost, from lack of evocator, although the power of the dermal cells to respond to injected moulting hormone remains (Wigglesworth, 1953a). Long-term change 


\section{The Biology of Senescence}

in this system causes the bias to be overcome at the correct moment. The homoeostasis achieved by the juvenile hormone is not absolute, otherwise metamorphosis would never take place; the metamorphosis-producing hormone ultimately carries the day. But occasional nymphs of Rhodnius devoid of the thoracic gland cannot metamorphose, and appear to live for long periods without senescence. This mechanism offers an opportunity for the dissection of just such a system of partial homoeostasis, directed to act as a delay-mechanism, as appears to underlie so many life-cycles which end in senescence. Work on insect senescence is in many respects unpromising as a source of principles which can be extended to the biology of vertebrate old age; such research is frequently confined to the very special circumstances which exist in the imago-in other words, to a system which is already in a time-limited equilibrium. For measures of interference with the growing organism, however, and attempts to stabilize the system in its earlier stages, insect material may prove the most manageable. Any example of indefinite stabilisation at an immature stage, in any organism, would be of great biological interest. The degree of drift towards the unstable state probably varies throughout development in different insects-Bodenstein has shown (1943a, b) that in Drosophila eariy salivary glands implanted in late larvae are not immediately capable of metamorphosis: 'Whether the organ discs respond with growth or differentiation depends on a definite relationship between hormone concentration and organ responsiveness' (Bodenstein, 1943b).

\section{$5 \cdot 2 \cdot 3$ VERTEBRATES}

The possibility of producing a long-lasting but recoverable delay in mammalian growth and development by underfeeding first arose from the studies of Osborne and Mendel, (1915, 1916). The work of McCay on rats, which extended the results obtained by underfeeding upon arthropod growth directly to mammals, is well known, but still very remarkable. It also still represents the only successful assault which has ever been made on the problem of mammalian specific age, which is itself the key problem of medical gerontology; and the rather exceptional growth-pattern of rats in no way diminishes its interest. The 148 


\section{Growth and Senescence}

experiments, first described in 1934 (McCay and Crowell, 1934) extended over years, and are fully reviewed in retrospect by McCay (1952). Groups of rats were reared on a diet sufficient in all other constituents but deficient in calories, and their growth thereby retarded. After periods of retardation up to 1000 days, the calorie intake was raised to permit growth. The animals then grew rapidly to adult size, even though the longest-retarded group had already exceeded the normal life

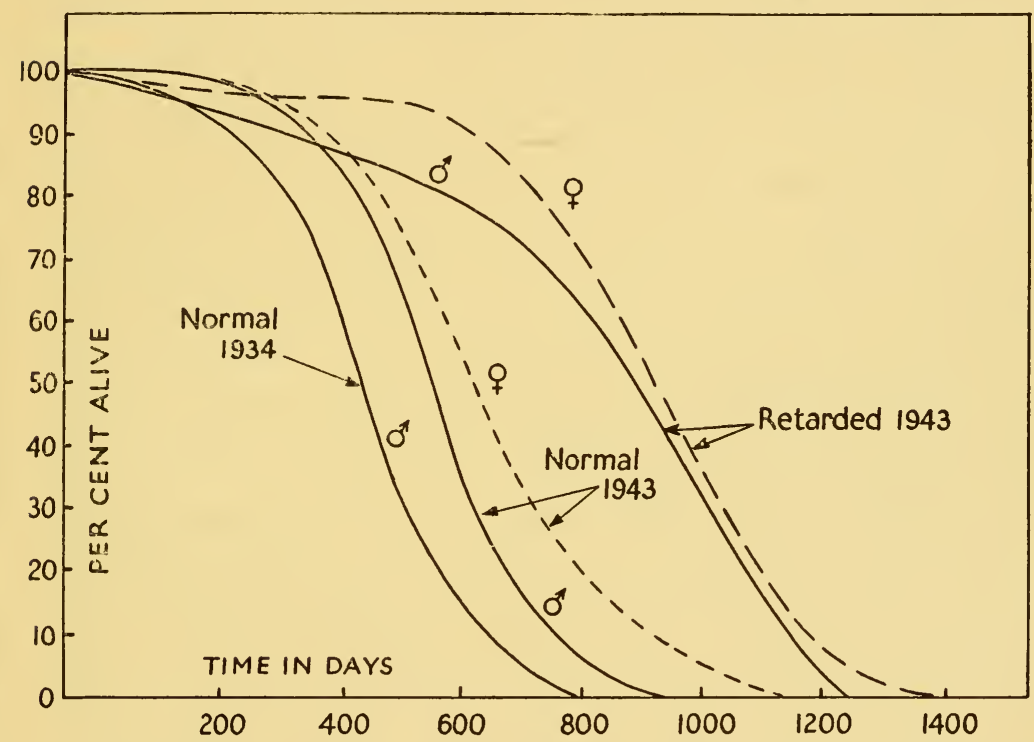

Fig. 40.-Survival curves of normal and retarded male and female rats, showing the effect of dietary restriction (from McCay, Sperling and Barnes, 1943).

span for the strain, and continued to live to approximately twice the maximum age reached by unretarded controls (Fig. 40.) This long survival was accompanied by a decreased incidence of many chronic diseases, which appeared to represent a true diminution in senile liability to death from random causes. The chief specific diminution was in death-rate from pulmonary diseases and from tumours. 'In general, the retarded rat remains active and appears young whatever its chronological age. It is very alert. It tends to go blind in the second 


\section{The Biology of Senescence}

and third year of life. Its pulse rate of 340 beats per minute is about 100 below normal' (McCay, 1952). The basal metabolic rate of rats so retarded lay between that of normal young and normal old animals (Horst et al., 1934). In rats retarded for 850 days, heat production per unit surface area was lower, but heat production per unit weight higher, than in normal controls (Will and McGay, 1943). The aorta and kidneys of retarded rats showed in general a higher level of calcification than those of controls (Hummel and Barnes, 1938) perhaps on account of the relatively higher mineral concentrations in the restricted diet (Barnes, 1942). A further series of experiments in the dietary restriction of animals which had already reached maturity was unfortunately complicated by the introduction of many groups of variables (exercise, casein intake, liver supplements, etc.) -in these experiments, underfeeding produced a significant increase in life-span compared with fully-fed controls, but the difference was far less conspicuous than in the retardation of young growing rats, and the factors which were most important in determining life-span were those which determined the degree of body fatness (McGay, Maynard, Sperling and Osgood, 1941: Silberberg and Silberberg, 1954). This difference was largely accounted for by the higher incidence of renal disease on a high protein diet and in obese animals (Saxton and Kimball, 1941); in contrast to the findings in animals retarded while young, the incidence of chronic pneumonitis and of tumours was not reduced by underfeeding in mature animals (McCay, Sperling and Barnes, 1943; Saxon, 1945). A 33 per cent restriction of calories, other elements in the diet being unaltered, produces a significant prolongation of life in male $\mathrm{C} 3 \mathrm{H}$ mice (King and Visscher 1950).

The results of these experiments indicate that at least some mammals are capable while immature of undergoing prolonged suspension of growth without any acceleration of senescence. The suspension is not complete, since deaths occur unless some increase in weight is allowed. The most important inference to be drawn from the work, would appear to be that senescence itself is the direct consequence not so much of growth-cessation as that of the attainment of a developmental stage, the timing of which is partially, but not wholly, linked to the growth-rate 


\section{Growth and Senescence}

- there being no evidence that starved rats remain 'young' indefinitely. By 1150 days, moreover, only about half the retarded individuals were capable of resuming growth (McCay, Sperling and Barnes, 1943). There is some evidence from later work that prolongation of the life-span, though in a smaller degree, can be produced by intermittent dietary restriction without any evident effect on the growth-rate (Carlson and Hoelzel, 1946). Moreover most of the changes which ultimately fix the specific age appear to have occurred at the time of maturity, since the increase in longevity obtained by underfeeding, adult rats is far less (McCay, Maynard, Sperling and Osgood, 1941).

The mechanism of retardation by dietary restriction in growing mammals is partially known from other studies. Inanition lowers the gonadotrophic activity of the pituitary: this was clearly shown by the transplantation studies of Mason and Wolfe (1930) on female rats, and again in male rats by Moore and Samuels (1931). In rats, reduction of the protein content of the diet below 7 per cent produces anoestrus from gonadotrophin deficiency (Guilbert and Goss, 1932). In the 'pseudohypophysectomy' of malnutrition, pituitary growth hormone will re-initiate growth of the skeleton and decrease the rate of weight loss even without increase of food intake (Mulinos and Pomerantz, 1941). The subject was reviewed by Samuels (1946). The relationship between this 'pseudohypophysectomy' and McCay's results is not yet clear, but the effects of restricted food intake on the pituitary probably play a major part in the alteration of apparent specific age.

In C3H mice, Carr, King and Visscher (1949) produced anoestrus by reducing the standard calorie intake by half: at 14 months of age, single cycles were readily induced by administering dextrose, though the dose necessary to bring this about varied from 0.15 to $1.0 \mathrm{gm}$. When the mice were permitted at the age of 21 months to feed at will, and mated, all became pregnant, and 10 out of an initial total of 17 were alive and sexually active at the age of 23 months.

We have no comparable observations in man. Malnutrition can produce gross retardation of puberty (as can disease or 'indirect' malnutrition - the effects of bilharzia are particularly striking) but such malnutrition is always total, and shortens life. 


\section{The Biology of Senescence}

In McCay's experiments the dietary restriction was confined to reduction of calories. The undernourished majority in the world at the present time derive no benefit in longevity from their circumstances. But it is not impossible, as Edmonds suggested in 1832, and as Sinclair (1955) and McGance and Widdowson (1955) have repeated, that adult life may be shortened by the pursuit of excessively rapid growth during childhood. Human puberty can be accelerated by overfeeding (Bruch 1941), and there is already evidence that while the maximum mean height of Englishmen has not increased during the last century, it is now reached no less than five years earlier (Morant 1950), and the loss of height with increasing age shows a parallel advance.

In 1948, Evans, Simpson and Li confirmed with pure growth hormone Wiesner's (1932) original finding that rats could be kept in continuous growth throughout life by injections of pituitary growth hormone. Wiesner had reported some improvement in the condition of old male rats under the influence of growth hormone. The experiment of Evans, Simpson and Li was not designed to study the effect of growth on longevity, and they found that continued growth from hormone administration in rats itself leads to death from an increased incidence of tumours. The 12 animals in the original experiment of Evans, Simpson and $\mathrm{Li}$ were killed at 647 days for histological purposes. With small doses of the purified hormone, 'drug-resistance' to the growth-promoting and nitrogen-retaining effects develops (Whitney, Bennett, Li and Evans, 1948). In dogs, and cats, continued administration of growth hormone after growth cessation produces not growth but diabetes, while in others (man) epiphyseal fusion prevents continued body growth after sexual maturity. Although the response of rats both to retardation and to growth hormone is apparently atypical, and certainly differs from that which might be expected in man, the possibility exists of comparing in a mammal the effects on rate of senescence of (1) retarded growth to the full specific size, (2) of accelerated growth up to, and beyond, the specific size, and (3) of growth beyond the specific size, but beginning in old age. Apart from the complication of tumour production, the general endocrine effects of growth hormone are likely to be 


\section{Growth and Senescence}

too extensive for simple life-table experiments, but its use as a tool in work on the specific size-specific age relationship deserves further thought. The difficulty of such a direct application may be less than it appears. Moon and his co-workers (Moon et al., 1952) found that massive administration of growth hormone (2 mg./day) to mice evoked tumours in only one of the tested strains. It appears, moreover, that growth hormone alone fails to induce tumours in hypophysectomized animals (Asling et al., 1952a, b). The resistance which develops to the heterologous (ox) hormone used in such experiments may perhaps be surmountable. The idea underlying this kind of investigation was already present in the work of Robertson (Robertson and Ray, 1919; Robertson, 1923) at a time when endocrinology was insufficiently advanced to enable it to be realized. The results they obtained in retarding growth with 'tethelin' were almost certainly non-specific. Work upon growth hormone in mammals whose epiphyses do not unite would appear to be one of the critical experiments in finding out how far growth and development are an integrating system tending to senescence at a fixed point, and how far mere growth, induced by one of many anabolism-stimulating factors, is capable of reversing or preventing senile change.

Attempts to accelerate mammalian senescence have been surprisingly unsuccessful. While laboratory animals can be prematurely killed by a number of drugs or deficiencies, these do not in general affect the process of senescence. Experimental efforts to accelerate ageing in rats with dinitrophenol (Tainter, 1936, 1938) and thyroid (Robertson et al. 1933) or retard it with thiouracil (Hartzell, 1945) have been uniformly unsuccessful in bringing about any change in the specific age. Petrova (1946) obtained evidence that induced neurosis at least shortens the life, if it does not affect the specific age, in dogs: it is significant that in man the most effective means of reducing the apparent rate of senile change, ceteris paribus, are psychological, social and occupational.

\subsection{Growth-cessation and Mammalian Senescence}

Mammals in captivity under 'optimal' conditions exhibit both specific size and specific age, and these vary widely 


\section{The Biology of Senescence}

between related species, and between genetic races of the same species. The mechanism which determines specific size has long been believed by some workers to intervene more actively in mammalian development and to be more selective in its action on tissues, than the mechanism which leads to the more gradual decline of growth in some reptiles and fish. In these forms, according to this view, the die-away curve of growth, which is generally exponential in relation to body weight, suggests a far more general process of size-limitation affecting all the tissues approximately equally, and reaching the virtual limiting size without much alteration in the general physiology of the animal. 'It is the rule in fishes and other cold-blooded vertebrates that growth is asymptotic and size indeterminate, while in warmblooded animals, growth comes, sooner or later, to an end. But the characteristic form is established earlier in the former case, and changes less, save for . . . minor fluctuations. In the higher animals, such as ourselves, the whole course of life is attended by constant alteration and modification of form' (D'Arcy Thompson, 1942). The form of the mammalian, and especially the human, cycle both of growth and of senescence has frequently been interpreted as an active process of negative feedback, which operates unequally, which may contribute to the relatively sharp arrest of growth at the level represented by the specific size, but which results in a 'morphogenetic' senescence depending in turn upon a rather limited number of key physiological changes.

With the hypothetical relationship between growth-cessation and senescence in mind, a number of attempts have been made in the past to interpret senile changes in terms of endogenous 'growth inhibitors', whether these are regarded as substances or as physico-chemical conditions (Baker and Carrel, 1926; Carrel and Ebeling, 1921; Simms and Stillman, 1936). The case for such an inhibiting system was stated by Bidder (1932) in the passage already quoted (p. 12). The nature of influences determining mammalian organ size is virtually unknown. Some of these appear to be extra-cellular and inhibitory. In cultures, e.g. of diatoms, growth may be arrested by the accumulation of a metabolite (Denffer, 1948). The most primitive types of morphogenesis, such as that found in hydroids, depend on the 154 


\section{Growth and Senescence}

acquisition by certain zooids of inhibitory powers over the development of others (Summers, 1938), although the inhibited cells retain the potentiaiity of growth. It is also known that some 'old' tissue cells are capable of indefinite growth in cultivation.

The suggestions implicit in this type of reasoning are tempting, but there are evidential grounds for caution in postulating a simple, 'toxic' senescence due to the existence of a growthinhibiting senile principle. Such a principle is not readily demonstrated. Bidder once rashly located it in the pineal gland. Kotsovsky (1931) attempted successfully to retard the growth of tadpoles by feeding senile heart muscle-an improbable tissue for such a purpose-and Grimm (1949) obtained similar results with senile plasma. Picado (1930) cnhanced the growth of young rats by transfusions of adult plasma. More serious data, however, exist.

The best experimental evidence concerning growth-limitation is probably that obtained from studies of mammalian liver. Although mitotic figures and binucleate cells decrease in mammalian liver throughout life, regeneration after hepatectomy occurs in senile rats, apparently at a rate not much lower, so far as replacement of cell number of concerned, than in young adults, though much less than in growing animals (Bucher and Glinos, 1950). As Minot pointed out (1908) the adult differs more from the infant than the old from the adult. The time lag between hepatectomy and maximum mitotic count increases with age (Marshak and Byron, 1945), thereby paralleling the difference between the behaviour of tissues from young immature and young adult donors in tissue culture (Hoffman, Goldschmidt and Doljanski, 1937), and confirming the universal finding of increased growth-inertia, rather than decreased growth capacity, as the most conspicuous character of cellular explants with increasing donor age (Cohn and Murray, 1925; Suzuki, 1926; Medawar, 1940). In regenerating rat liver at all ages, however, the lag reverts to the value characteristic of young animals (Glinos and Bartlett, 1951). In young, actively growing rats the restoration of liver mass after hepatectomy shows a considerable rebound phenomenon, reaching 145 per cent of the original weight in 7 days (Norris, Blanchard and 


\section{The Biology of Senescence}

Polovny, 1942). All the general characters of tissue behaviour during the attainment of specific size appear to be exemplified in liver. These include (1) negative specific acceleration of growth, (2) retention of growth capacity after the limiting size has been attained, as demonstrated either by explants, or, in this case, following partial removal of the organ, (3) increased growth inertia with increasing age and (4) 'post-inhibition growth rebound'. Medawar (1942) stresses the surprisingly wide distribution of this last effect, which is shown by tissue cultures (Spear, 1928) and Amblystoma larvae (Buchanan, 1938) retarded by cooling, and in rats or mice following brief restriction of diet (Osborne and Mendel, 1916; Clarke and Smith, 1938; Jackson, 1936).

Much has been made of the decline in rate of wound healing with age proposed by du Noüy $(1916,1932)$ as a criterion of senescence. This entire theory was based on less than a dozen uncontrolled cases. Experimental studies suggest that while the mitotic rate in wounded skin is highest in infancy, little difference in cell multiplication exists between adult and senile animals, though here again the time-lag in reaching the peak mitotic rate increases with age (Howes and Harvey, 1932; Bourlière, 1950. Delayed healing of skin wounds is not clinically very evident in old people (Elman, 1953). In male mice the mitosis curve for skin in situ is bimodal, with peaks in infancy and again in middle age (Bullough, 1949). One easily-measured growth-system which shows a steady decline throughout later life is that controlling fingernail growth (Knobloch, 1951; Bürger, 1954).

Attempts have been made in the specific case of liver tissues to relate organ size to the existence of a mitotic inhibitor or inhibitors. Studies on plasmapheresis (Glinos and Gey, 1952) and parabiosis (Bucher, Scott and Aub, 1950) after partial hepatectomy have yielded some evidence that a humoral inhibitor, of the kind envisaged by Carrel and Ebeling (1921) disappears from circulation after hepatectomy. These observations, though interesting, could provide a suspiciously simple picture of the dynamics of growth limitation, and of consequent senescence.

An opposing view to the humoral school has been suggested 156 
by Medawar (1942). Both in whole animals and in specific organs and tissues the rate of growth declines throughout life. Medawar points out that it is not self-evident that this decline is the result of active growth inhibition. 'We are so deeply influenced by the spirit of Newton's First Law that we tend to think that whenever a rate falls off, something is actively suppressing it. This is true of rates of motion, but it is not true in quite the same sense of the rates of a type of change which we may call changes in probability states. The rate at which heat is lost from a cooling body is initially high, and falls off as its temperature approaches that of the environment. The rate at which the distribution of molecules in a closed diffusion system tends towards uniformity is likewise rapid at first, and slower and slower thereafter. In these cases, and in others similar to them, we are dealing with rates that fall off "of their own accord", with systems that tend to a certain, most-probable state at a rate which depends upon how far they have yet to go to reach it. We may look in vain for inhibitors and controllers: they are not there. I do not know whether what I have called the "kinetic picture" of growth will be found to fall within the domain of statistical mechanics. . . . It is simply a picture which we should keep in mind when thinking of growth processes, lest we should come to regard the doctrine of growth-controlling factors as self-evident; which it certainly is not.'

This argument is graphical rather than explanatory, and the analogy which it contains must be approached with caution. It is evident that organ size has certain properties of an equilibrium state, in approaching which the cell number and growth energy vary after the manner of potential energy in the process of redistribution. The equilibrating forces, however, manifestly arise, on the evidence of explanation, from the organ's and the cell's surroundings. Mathematically similar systems involving real energy loss, such as cooling, are in no real sense analogous, since they are examples of a process not subject to further analysis. The decline in human population-growth is as fair a comparison. Although morphogenesis is no doubt ultimately expressible as a redistribution of energy, 'inherent' decline of rate in approaching a most-probable state is only explanatory, in the sense of providing a satisfactory regression of causes to the 


\section{The Biology of Senescence}

limit of useful experiment, if 'growth energy' is itself a form of energy in the physical sense, analogous to heat in a kettle or electro-chemical energy in a battery-in the hypothetical case where a population of cells was restricted in growth by exhausting a particular energy source, employed only for growth and not for maintenance metabolism, such a system would apply, and would not only depict but 'explain' the course of events.

The great value of the approach from probability, as Medawar points out, is in preventing a facile assumption that if a growth-rate declines, this decline must result from the action of a specific toxin or inhibitor. This does not mean, however, that in a complex biological system we can avoid asking specifically what declines, since a decline in rate implies real quantitative and qualitative change in terms of chemical structure, and the investigation of these changes is practicable. It appears manifest that the reversion of explanted tissues to active growth is in fact caused by removal from their previous environment. It seems at least arguable whether the time lag in multiplication which characterizes aged explants is inherent in the cell at all. Simms found that the lag in cell-division of aortic explants from old fowls can be reduced by a number of non-specific procedures such as papain digestion, or washing with an ultrafiltrate of serum (Simms, 1936; Simms and Stillman, 1937). Such effects might even be purely mechanical. For most purposes it is probably also desirable to regard growth energy less as a 'store', since, to maintain the analogy, such a 'store' must be almost immediately 'replenished' after hepatectomy or explanation, than as a 'space', with walls defined by the continuously-varying properties of any individual cell in the growing tissue, and by the continuously-varying properties of the 'environment', in which are included all the adjacent cells of the same tissue. Such a concept, and, in fact, any concept of limiting size as an equilibrium process, would seem incidentally to imply the continuous replacement of any deciduous cells. The chief criticism of the humoral theories of growth limitation is their readiness to assume that the limiting factors derived from the 'environment' can (a) be treated in isolation and (b) necessarily correspond to substances rather than to physico- 


\section{Growth and Senescence}

chemical states and gradients. That adjacent-cell effects need not depend upon molecular hormones is well shown by Whitaker's work on the mutual orientation of Fucus egg cells through a simple pH gradient (see J. Needham, 1942). The search for hormonal substances which can be isolated is abundantly justifiable, but the failure to find them should not be astonishing or discouraging. There is much evidence (reviewed by Stewart and Kirk, 1954) to suggest that the 'inhibitors' detected in old serum by Carrel and his associates were nonspecific materials, probably including the serum lipoproteins. This is not to say that such materials do not exert a growth-inhibiting effect in vivo, or that such an effect is without physiological significance, but most existing studies certainly support Medawar's conclusion (1942) that there is no simply extractable contact hormone in adult tissue which directly restrains the growth of cells. The 'inflection' in the curve of absolute growth (weight/time) is still occasionally quoted as evidence of active growth-inhibition, but this is a mathematical fallacy which has been repeatedly exposed (Minot, 1908; Schmalhäusen, 1929; Weymouth, 1931; Medawar, 1945).

The most interesting aspect of this question, in relation to senescence rather than morphogenesis, turns once again on the supposed absence of age changes in some reptiles and fish, though speculation is vain so long as we do not know whether this absence is real. The growth of the body, and of the individual organs, in some of these forms follows much the same pattern of decline as that described by Medawar in the growth energy of isolated tissues. If reptiles whose growth declines in this way, and whose degree of histological complexity is in any case similar to that found in mammals, do not exhibit senescence, then this general pattern of growth-decline with age, although it occurs in many mammalian tissues treated individually, is not the 'cause' of mammalian senescence. Equilibrium cessation of growth implies the probability of one-for-one replacement in tissues which are capable of continuing division, so that unless some other process intervenes, an organism in the equilibrium state as regards growth should remain indefinitely self-maintaining, except for tissues whose degree of differentiation precludes mitotic renewal. This seems a reasonable 


\section{The Biology of Senescence}

depiction of the state of affairs in long-lived cold-blooded vertebrates (at least there seems to be no good evidence to the contrary), but it does not appear to obtain in mammals.

We have already suggested that while we might have reason to expect senescence, or one form of it, in the total absence of cell division, either in the whole animal or in certain organs, it is not self-evident why, in order to avoid senescence, an animal should be obliged to increase constantly its total cell number or its overall body size. If this were the case, it would suggest, perhaps, not that growth prevents senescence, but that the capacity for continued growth reflects a type of morphogenetic physiology which does not produce senescence.

The possibility exists, then, that vertebrate growth-cessation might be of two kinds: that some cold-blooded vertebrates may cease to grow visibly when a cell-population of a particular size and composition is reached, and that this population thereafter remains substantially static, with replacement of all except such mechanically irreplaceable cells as neurones, while mammalian growth is arrested by a more active process-probably of differentiation rather than mere mitotic inhibition-affecting a few key points. This would resemble in its effects the difference between the behaviour of a society which voluntarily limited its reproduction to replacement level, and one which, when a predetermined figure was reached, summarily castrated a vital and hereditary profession. Such a difference, if real, would explain the apparently less catastrophic effects of growth cessation upon those reptiles which exhibit virtual specific size, compared with the rapid post-mature decline in most mammals. Birds, significantly, occupy a midway position, since it is virtually certain that all species are subject to senescence in captivity, though at specific ages considerably higher than those of mammals of comparable size and activity: their period of growth, however, is proportionately much shorter. A serious investigation of the phylogeny of senescence is badly needed. The hypothesis put forward here would regard it, so far as mammals are concerned, not as the consequence of general growth cessation, but of a particular manner of growth cessation, involving, perhaps, selective non-renewal of certain important structures and changes in the specificity of the response in 
others; a genuinely morphogenetic senescence depending upon alteration of cell-responses, and having evolved, or re-evolved, within the phylogeny of vertebrates. The mammalian pattern of ageing, if it differs from that of other vertebrates, would in this case have evolved as a correlate, though not necessarily a consequence, of several fundamentally important physiological processes-homoeothermy, the development of a complex endocrine regulation centred in the pituitary, the avian-mammalian pattern of determinate growth, which is lirked with this development, and the system of immune response and tissue specificity characteristic of higher vertebrates. The possible association between size-limitation and homoeothermy is interesting in view of the different relationships between pituitary and thyroid hormones in the determination of growth which have been found in mammals and in amphibians (Evans, Simpson and Pencharz, 1939; Scow and Marx, 1945; Steinmetz, 1954); at some point in vertebrate evolution, a balancemechanism between thyroid and growth-hormone, which leads to gigantism in the thiouracil-treated tadpole, has become converted into a synergism such as normally operates in the rat or in man. Unfortunately for any phylogenetic theory, the pattern in fish appears to resemble that in mammals (Goldsmith et al., 1944; Hopper, 1950). This subject will be further considered in a subsequent chapter. 


\section{$-6-$}

\section{THE MEGHANISMS OF SENESGENGE}

All theories of senescence are at present based on unwarrantable assumptions, in the absence of concrete answers to the essential questions of fact. The formulation which would receive, perhaps, the widest assent, at least in the matter of human senescence, is that morphogenetic processes lead to the differentiation of cells which have lost the capacity for division, such as neurones and skeletal muscle fibres, and to a suspension of division in others, and that processes of 'wear and tear', chemical, mechanical, or of a degree of biophysical subtlety depending on the taste of the investigator, thereafter bring about the decline of some or all of the tissues thus deprived of the power of self-renewal. This is plausible and probably true. On the other hand (1) it has been shown already that we do not know whether all vertebrates, in spite of their apparently similar degree of histological complexity, are susceptible to senescence, and there is some ground to suspect that they are not; (2) no satisfactory technique has been devised for the study of cell populations in situ, apart from the search for mitotic figures in sections: we do not, therefore, know the life-span of any tissue cell in its natural situation; (3) many of the descriptions of senile change in fixed postmitotics, especially neurones, are based upon the assumption that the life-span of cells specialized to this extent is limited by their incapacity for division, as appears to be the case in rotifer and Anguillula cells. The striking differences in specific age between related species do not disprove the contribution of cell ageing to general senescence, but they cast a great deal of doubt on any assumption that the effect of wear and tear upon neurones (Bab, 1948; Vogt and Vogt, 1946) or any similar process is the prime mover 


\section{The Mechanisms of Senescence}

in determining the senile decline. The powers of self-renewal possessed by neurones apart from cell division have almost certainly been under- rather than over-estimated. Neurone regeneration in adult fish and amphibia can involve actual cell replacement from a reserve of neuroblasts: ${ }^{1}$ in adult birds and mammals it is usually held to be limited to axon growth (see Clemente and Windle 1955 for a review of the large literature). Cell division, however, may not be the only means of nuclear renewal - the appearance of 'binucleate' neurones in some old animals has been taken as evidence of a process of reconstitution (Andrew 1955). Apart from this it is evident from observation that some neurones are capable of living and remaining in function for 100-150 years, unless we postulate a system of 'reserve circuits' which has so far no evidence to support it. The distinction drawn by Weismann between immortal germ cells and mortal soma still persists in many of these assumptions, in spite of the growing number of instances where differentiated somatic cells in invertebrates are thought to give rise to germ cells, or to structures having the potentialities of germ cells (Brien, 1953).

\section{$6 \cdot 1$ Senescence in Cells}

\section{6•1·1 'IRREPLAGEABLE' ENZYMES}

There is no self-evident reason why morphogenetic forces acting upon cells, and inhibiting their free division, should lead to their senescence. Mechanical and 'colloidal' interpretations will not do-they fail to treat postmitotic cells as the dynamic systems which they certainly are. A theory of 'mechanical ageing' in postmitotic cells could, however, be based upon the exhaustion of specific cell constituents. It is reasonable to ask how much of the senescence of such cells, if they necessarily undergo senescence, is due to the existence of 'expendable' enzymic or other intracellular structures which can be replaced only at cell division.

${ }^{1}$ It has even been claimed that the Purkinje cells of the mammalian cerebellum, the least likely of all such cells to do so, undergo a cycle of periodic replacement from such a reserve (Baffoni, 1954). This is surely either a fundamental discovery or an egregious error. 


\section{The Biology of Senescence}

The concept of an expendable 'life ferment' appears to have originated with Bütschli (1882), although he probably regarded it simply as a material undergoing distribution from the germ cells, where it is highly concentrated, to the somatic cells in which it is increasingly diluted by subdivision. There are two essentials for our acceptance today of a system in which senescence depends on enzyme exhaustion in postmitotics-we have to postulate (1) a fixed quantity of enzyme present in the cell and exhaustible by use, and (2) the existence of an essential enzyme replaceable only at cell division. The first proviso appears already to be largely met, since it is known that the effective life-span of enzyme molecules is finite in terms of molecule-turnover (McIlwain, 1946, 1949; Theorell et al., 1951).

The existence of enzyme systems renewed only at cell division has not, it seems, been demonstrated as such, but with the single general and large exception of 'hereditary materials', nuclear and extranuclear, it has not been sought. Some direct evidence might be derived from the action of known selective blocking agents upon bacteria of protozoa. It will be evident, however, that the idea of an 'enzyme replaced only by mitosis' falls very close to some biochemical models of the gene, which has been invested, either directly or at one remove, with direct catalytic properties. McIlwain (1946) has shown that in some catalytic systems the number of enzyme molecules per cell is of the order of unity. The inference from his figures is that if genes are not themselves molecules acting as catalysts, each gene during its 'lifetime' (i.e. between one cell division and the next) produces one such molecule. McIlwain (1949) also calculated the life-span per molecule of the nicotinic acid co-enzyme component of Lactobacillus arabinosus as representing the production of $5.8 \times 10^{7} \mathrm{~mol}$. lactic acid. Theorell (1951) in tracer experiments demonstrated a very slow turnover of haemoprotein enzymes, the exception being liver catalase which has a molecule/life of only 4-5 days. The wastage of such systems is due, presumably, in part to side reactions and non-specific inactivation, and in part to competitive inhibition or blocking by metabolites partially resembling the correct substrate. If the determination of such a single-molecule system were a cause of cell senescence, and if the catalyst itself were to be identified 


\section{The Mechanisms of Senescence}

with the gene, we would evidently need to postulate a copying mechanism at mitosis in which inactivation of the catalytic portion of the system (1) does not interfere with the production of a copy, and (2) is itself reversible: or, alternatively, one in which the products of division are two copies, not an original and a copy. It can, of course, be argued that when a differentiated cell in fact undergoes senescence, we cannot infer whether any system in it would be renewed by further division. Its failure to divide, even if that failure is a physiological one, leading to final differentiation, may be due to the loss of a copying mechanism. This type of problem has been encountered already, however, by workers attempting to explain some of the results of research on adaptive variation in Neurospora and yeasts. 'Unless gene reproduction and gene action are totally independent of each other, we have to reconcile the uniformity in the reproduction of genes with the enormous variation in what we believe to be their primary products' (Pontecorvo, 1946).

Classical genetics, although they allocate an equal proportion of nuclear genic material to every cell, have so far given little direct information about the activity of this material in cells of different kinds at any time except during mitosis, and a new category of study ('epigenetics') has had to be coined to cover this activity. Of the large number of subsidiary copying processes which have been inferred from adaptation experiments and work on anuclear portions of cells some apparently continue undiminished throughout the intermitotic period. The power of adaptive enzyme production persists in yeasts rendered non-viable by X-rays (Spiegelman, Baron and Quastler, 1951). In a neurone which may remain functioning in man for over a century, either the enzymic mechanism which maintains cell metabolism is continuously kept in repair, or it is of a kind which is almost invulnerable to incidental spoilage by use. The survival-time of non-dividing cells varies greatly, even between closely related organisms: thus in Rotifers, the life-span reaches 5 months in Callidina (Zelinka, 1891) and even, perhaps, several years in certain bdelloids (Murray, 1910). If 'wear' is to be invoked in these cases where senescence occurs in the presence of cellular determinancy, then the susceptibility to it must vary enormously. Other cells-squamous epithelium, for example- 


\section{The Biology of Senescence}

have a function which depends on the progressive change in their structure and metabolism from formation to complete cornification. This implies a process of chemical heterauxesis within the cell, and all such 'open-ended' systems, if they continue, must eventually destroy homoeostasis. The development of histochemical methods of detecting enzymes in cells, and of selective blocking agents which irreversibly inactivate particular enzymes, already suggest experiments by which we might learn something of the limits of the postmitotic cell's power to regenerate its enzymic complement, and detect long-term changes in this power.

A special case of limited survival in the non-dividing cell is provided by the mammalian erythrocyte. This is one of the few cell-types for which a life-table can be constructed. The form of the curves obtained by a variety of methods indicates that the decay of circulating erythrocytes is a true 'senescence', i.e. that the probability of the destruction of a given cell increases markedly after it reaches a certain age. There is also, apparently, an 'infant mortality' among newly-formed red cells to make the mimicry of a metazoan survival curve even closer.

The cause of erythrocyte 'senescence' has been the subject of a good deal of study. Although it is probable that the proximate cause of erythrocyte destruction is a change in the physical properties of the stroma or the envelope of the cell, there is considerable evidence that the timing mechanism in this instance is the deleterious effect on other intracellular systems of the products of one particular oxidation-reduction system, in which methaemoglobin is formed from haemoglobin. The evidence for this view has been reviewed by Lemberg and Legge (1949). In this case we are dealing with a specialized, anuclear cell-in the nucleated avian erythrocyte, haemoglobin synthesis, and possibly other processes of renewal, continue in the circulation, but the life-span is, curiously enough, very much shorter (Hevesy and Ottesen, 1945; Hevesy, 1947) than that of the mammalian red cell.

\section{6·1·2 CELL TURNOVER}

It is necessary to point to a widespread impression among medical writers on senescence that cell turnover in the organs 


\section{The Mechanisms of Senescence}

of the adult animal is virtually confined to such tissues as skin, and that the 'cause' of senescence resides in the exhaustion of endocrine cells which have accompanied the individual throughout life. This may be true of some invertebrates, many of which have a wholly determinate cell-number throughout, or in certain organs, such as the corpus allatum of bees (Pflugfelder, 1948) and the suggestion cannot be refuted in terms of individual cells in man and other mammals. Such irreplaceables may exist, but the idea is in many ways open to the same criticism as that which attributes ageing to changes in biologically inert colloids, and the body of evidence suggests that it is equally erroneous. Although the rate of turnover in liver cells decreases with age, and mitotic figures become few, the mean mitosis rate in adult rats is such as to double the volume of the organ in the animal's lifetime, if there were no incidental wastage. ${ }^{1}$ This figure suggests that some liver cells may accompany the animals from cradle to grave, but that the majority do not. Adrenal cortical cells are continuously replaced in the adult cat (Lobban, 1952). Mitotic activity does, however, appear to decrease with advancing age (Blumenthal, 1945; Townsend, 1946; Korenchevsky, Paris and Benjamin, 1950). The adrenals of old rats show various degenerative changes (Jayne, 1953). Mitosis varying in frequency with the sexual cycle occurs in the anterior pituitary (Hunt, 1942, 1943, 1947) though it may not affect all cell types equally, since the population changes in composition with advancing age (Parsons, 1936). There is no direct evidence that the power of cell replacement is lost in any endocrine gland with age, though there may be more general involutional changes at both cellular and tissue levels. The pattern of mammalian endocrine cell behaviour is predominantly one of continual division and replacement, regulated in level by hormonal influences, and often occurring in cycles. It is impossible to say at present whether there is a single key exception to this pattern, but ageing is unlikely to be so simple a matter as the defection of one type of cell. It is significant that the syndrome of senescence cannot be produced experimentally by extirpating any one gland.

The morphological changes in endocrine cells with age have

${ }^{1}$ I am indebted to Mr. M. Abercrombie for this figure. 


\section{The Biology of Senescence}

been widely studied, though here, as in all pathological studies on ageing, no line can be drawn between cause and effect. Such morphological changes in pituitary cells have recently been reexamined by Weiss and Lansing (1953) and by Shanklin (1953), but without any new findings on the rate of cellular replacement. In some glandular organs, such as rat salivary glands, mitosis becomes both rare and abnormal in pattern after the end of active body growth, while in senile rats numerous imperfect mitoses occur (Andrew, 1953).

\subsubsection{SOMATIC MUTATION}

If the copying-mechanisms of somatic cells could be shown to deteriorate, like those of the Paramecium macronucleus, the further they travel from the germ line, senescence might result from the fact of cell turnover, not from its cessation. A possible mechanism for this has been suggested to me by Dr. Helen Spurway. She suggests that as a result of somatic mutation the constituent cells of some mammalian tissues may lose their autarky and become a 'community', in which both function and the capacity for replacement have undergone distribution. Such a community would contain both irreplaceable and indispensable members, and would therefore ultimately undergo senescence.

It is clear that if mammalian tissues exhibit increasingly imperfect mitosis with increasing age, resulting in the accumulation of aneuploid cells, this would lead to steady deterioration of equilibrium. Any difference in liability to senescence between mammals and lower vertebrates would be explicable, in terms of this theory, on the ground that mutation rate would be higher, in all probability, with higher temperatures and chromosome numbers.

This is a highly ingenious but unproven suggestion. The contentious issue of mammalian aneuploidy generally has been reviewed recently by Hsu and Pomerat (1953): a large and even more contentious body of data is reviewed by Sorokina (1950). Variation in chromosome number has been reported in human (Andres and Jiv, 1936; Timonen and Therman, 1950; Therman and Timonen 1951) and pig embryos (Sorokina, 1950). In adult rat liver, Tanaka $(1951,1953)$ recently des- 


\section{The Mechanisms of Senescence}

cribed wide variation in chromosome number. He found that cells with 42 chromosomes (diploids) contribute primarily to the growth of embryonic liver and to regeneration after hepatectomy in adults, and that growth and restoration were apparently confined to diploids and subdiploids. The idea of increasingly faulty copying with increasing age, or of an accumulation of faulty copies, is one best left for verification and assessment to the cytologists, not all of whom regard the evidence for somatic aneuploidy as satisfactory. Walker and Boothroyd (1953) have shown that such 'ancuploidy' is easily simulated by faulty technique. Spurway's basic suggestion should, however, be susceptible to verification. Clearly any evidence that the copying of somatic cells deteriorates is of gerontological importance, and would, if established, restore the relevance to metazoan ageing of much which was formerly written concerning the senescence of clones.

\subsubsection{SPECIFICITY}

Campbell and Work (1953) have recently drawn attention to the significance of the fact that animals cannot in general be immunized against their own proteins; and they suggest that the action of the genotype in determining specificity may be chiefly a negative one, in the prevention rather than the creation of a specific configuration. It is a matter of extreme interest that the character of the proteins produced by the animal body appears to change with age, as judged by calcium binding power (Lansing, et al. 1949 Hansard et al. 1954, serological properties (Duran-Reynals, 1940) and amino-acid composition (Lansing et al., 1951) and by the appearance of collagen and elastic fibres in skin (Ejiri, 1936; Gross and Schmidt, 1948, 1950). The acid-extractable collagen decreases markedly with age (Banfield, 1952). In general these products arise, however, not from aged cells, but from the cells of aged organisms, and the change in specificity has taken place over several cellular generations. It has occasionally been suggested that senescence is a manifestation of an 'immune' response to endogenous hormones (e.g. Picado and Rotter, 1936; Freud and Uyldert, 1947). A more subtle change in specificity of cell response, or of the properties of cellular products, whether it be 


\section{The Biology of Senescence}

interpreted immunologically, or, more probably, morphogenetically, cannot be ruled out. If cells in general or certain cells could be shown to acquire adaptive resistance to physiological regulators, as do bacteria to unfamiliar metabolites, from generation to generation, interesting possibilities would certainly be opened.

Connection between the processes of senescence and those of immunology was suggested long since by Metchnikoff, though in rather a different context (1907). He attributed the senile atrophy of differentiated tissues, especially neurones, to overactive phagocytosis, brought on by constant exposure to the toxic (and antigenic) products of symbiotic and endoparasitic bacteria: the second part of this theory has received more publicity than the first. Metchnikoff was also responsible for the suggestion that many morphogenetic processes in the embryo are 'immunological' in character, within the wide definition of immunology implied in his theory of phagocytosis, and that the defence mechanisms of the adult animal are directly derived from mechanisms which, in embryonic life, have been primarily concerned with morphogenesis. The embryo is not exposed as a rule to exogenous antigens, though its own chemical composition is changing. More recent work, in fact, has shown that exposure to an antigen during embryonic life can lead to a lifelong inability to react against that antigen (Billingham, Brent and Medawar, 1953). The possibility that morphogenetic mechanisms give rise in ontogeny to the defence mechanisms of the adult, which is evidently true in the case of some mechanisms of chemical homoeostasis, is still popular in Russian research. Whether such effects modify cell responses during the later phase of development, senescence, is unknown.

Gaillard (1942) has carried out a long series of studies relating the degree of differentiation which can be produced and maintained in tissue explants to the age-status of the press juice in which they are grown. According to these results, functional differentiation in endocrine and other explants can be obtained if they are grown successively in press juices from embryos of increasing age, while some degree of regression of structure occurs if the series is reversed, and explants are grown in juices of decreasing age-order. This process has not so far been followed 


\section{The Mechanisms of Senescence}

into senescence. No doubt if explants could be cultivated in media exactly simulating the chemical and physical environment and its changes through all the stages of development, they would pass through all the normal phases of in vivo histology. The point of interest to the gerontologist is to know how far it is possible to maintain a status quo at any point. Analysis of the power of tissues to mark time developmentally while retaining function requires more elaborate methods of organ and tissue culture than are so far available, but the lead given by Carrel in applying these techniques to age-processes has hardly been pursued with the vigour it merits. Gey (1952) has recently referred to the in vitro culture of 'thyroid, parathyroid, adrenal cells, and the germinal epithelium of the ovary' even to the production of follicles, but these findings remain contentious.

\subsection{Endocrine Senescence}

\section{2-1 GENERAL}

The early discoverers of hormones were fully convinced that they had in their hands the key to the prevention of senescence in man. The fact that little of their enthusiasm persists today is due very largely to the manner in which the confluence of two deeply emotive subjects-ageing and the gonad-affected scientific judgement in the early years of the century. The hypotheses of the rejuvenators were in many respects reasonable, if their published claims were not. In any discussion of endocrine senescence it is probably worth restating (1) that organ and tissue grafting are appropriate and fully respectable techniques for the investigation of senile change, and that they have given misleading answers chiefly because the wrong questions were asked, (2) that the use of hormones in the palliation of senile changes in man, although it is largely ineffective, was a reasonable experiment which has not yet been exhausted, and (3) although gonadal 'senescence' does not 'cause' somatic senescence (this was self-evident in antiquity, from the life histories of eunuchs, long before testosterone was found to be unavailing in reversing general senile decay), it is a highly important model process, and a relatively accessible one for further study. 


\section{The Biology of Senescence}

Characteristic variations in hormone output occur throughout the mammalian life cycle; they are of two types-cyclical and secular. These changes are the biochemical equivalent of the sudden movements of embryonic tissue which are seen in speeded-up films of developing organisms--they are part cause, part effect, and they represent only the outward and visible manifestation of changes in the quality and quantity of cell response. The hormones most likely to be linked directly with the senile process, such as the growth hormone of the pituitary, cannot be estimated in the intact animal. Of those which can be so estimated, the group of 17-keto-steroids show a decline which continues with the rise of the force of mortality (McGavack, 1951; Kirk, 1949; Hamburger, 1948; Robinson, 1948; Hamilton and Hamilton, 1948; Hamilton, Hamilton and Mestler, 1954 (Fig. 41)). The concept of an 'adrenopause' analogous to the menopause seems to have little to support it at present. Apart from this, there is no single hormonal change which correlates with senescence, no single endocrine organ, of those which can be removed without fatal results, whose extirpation produces the syndrome of senility in mammals; and no hormone or combination of hormones which is known to produce more than a limited, and apparently secondary, reversal of senile changes. Ablation of a gland is not the same thing as its senescence in situ, and in surgical castration for prostatic and mammary cancer there is evidence that interconversion may take place between adrenal and gonadal steroids, but no simple hypothesis that senescence is a 'withdrawal' effect is substantiated by the existing experimental evidence. It appears that the sequence of developmental changes in endocrine activity which ends in senescence cannot so far be made to run backwards by hormone supplements, except in a very minor degree.

In a long series of studies, Korenchevsky (e.g. Korenchevsky and Jones, 1947, 1948; Korenchevsky, Paris and Benjamin, $1950,1953)$ has tried to show how far hormone supplements can reverse the senile process, judged by the restoration of the relative hypoplasia of organs. A great many of the senile structural changes described in endocrines are closely paralleled, though at a lesser level of severity, by the changes in structure 


\section{The Mechanisms of Senescence}

which follow gonadectomy, and many of them are reversible by gonadal hormones. (Korenchevsky et al., 1950; McGavack, 1951). The peripheral effects of sex hormones in senility, such as the recornification of the vagina by oestrogen (Loeb, 1944), are familiar enough. The decrease of mitotic rate and degree of vacuolation in the adrenal (Townsend, 1946; Blumenthal, 1945 ) and the increase of collagen and reticulum in the capsule

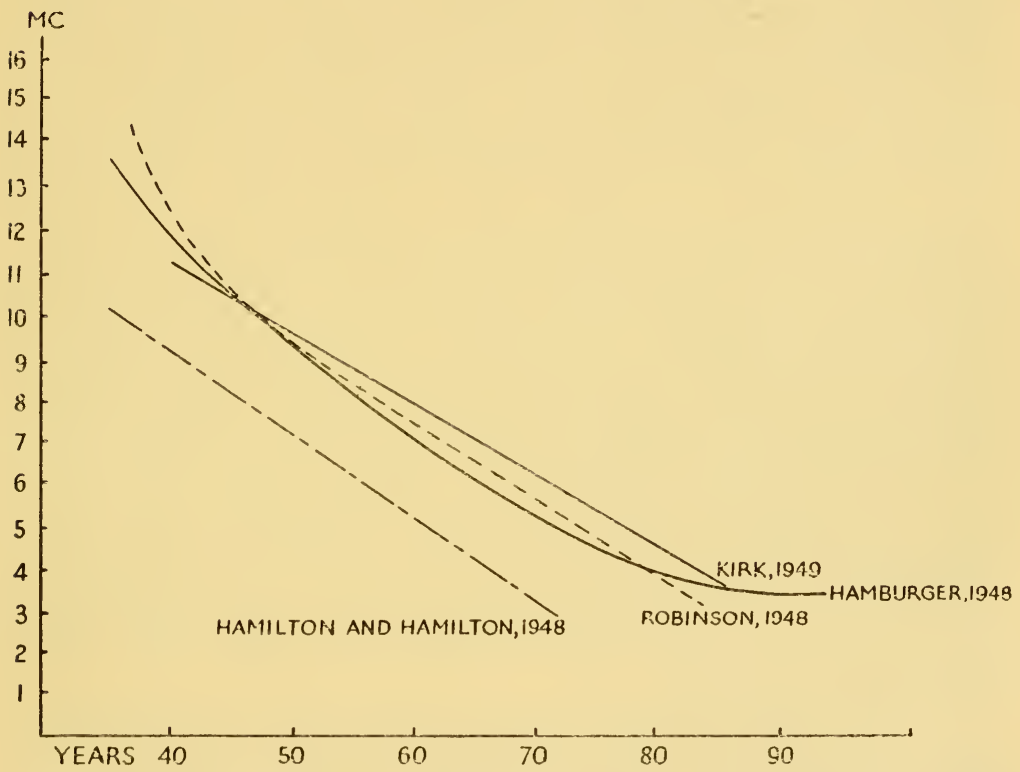

Fig. 41.-Neutral 17-Ketosteroids, 24-hour urinary excretion (Kirk 1949).

and in the parenchyma (Dribben and Wolfe, 1947) which occur with advancing age are partially reversible by oestrogen, and more fully reversible by a combination of oestrogen, androgen and progesterone (Korenchevsky, Paris and Benjamin, 1950). In the pituitary of the senile rat, Wolfe (1943) found a decrease in eosinophils, but no increase in basophils vacuolation, like that which follows castration, occurred in the basophils with increasing age. These changes, particularly the decrease in eosinophils, are at least partially reversed by testosterone propionate (Wolfe, 1941). The senescent changes in 


\section{The Biology of Senescence}

fowl pituitary described by Payne $(1949,1952)$ were greatly hastened by gonadectomy. In other words, gonadal failure may contribute to senescence, but probably does so only when it occurs at a certain point in the endocrine developmental programme.

In some instances, direct estimations of the capacity of senile endocrines to respond to physiological stimuli have been made. Solomon and Shock (1950) tested the response of the adrenal cortex in 27 young and 26 old men to a dose of adrenocorticotropic hormone (ACTH) and in 15 young and 13 old men to a dose of $0.4 \mathrm{mg}$ adrenaline. No difference in eosinopenia was observed after ACTH, but adrenaline produced a significantly greater eosinophil depression in the young group. From this it was inferred that the senile cortex can still secrete 11-17 oxysteroids without gross impairment, but that the response of the pituitary to acute adrenaline stimulation is lower in old than young subjects. Pincus (1950) likewise found no impairment of response to ACTH in old men compared with young controls. But with chromatographic techniques, Rubin, Dorfman and Pincus (1955) have examined the range of $\alpha-17$ ketosteroids produced at different ages. There is here little difference between men and women: in both, the greatest decline with age is in androsterone and aetiocholan-3 $\alpha$-ol-17-one, and the second greatest in the $5 \alpha$-11-oxygenated steroids. Such studies offer considerable promise.

The hypophysis is clearly the site of election for 'fundamental' and all-explaining endocrine changes leading to senescencethe part which it has played in the provision of such emotionally-satisfying theories follows naturally from the fact that it is known or credibly suspected to be involved in the regulation of almost all mammalian processes of homocostasis. Its proximity to the hypothalamus enables it to be linked with theories which locate senescence in the central nervous system. Hypophysial factors in senescence have also a special importance because of the relation of the hypophysis to the control of growth. In its simplest form, starting from cellular exhaustion, the idea of a primary pituitary senescence drew plausible anatomical arguments from the histological studies of Parsons (1936) and Simmonds (1914) on long series of glands from subjects of various 
ages, or from more recent work such as that of Payne (1949, 1952) on the ageing fowl.

If there has been a tendency for the existence of the pituitary gland to serve as a pretext for vagueness of thought concerning the nature of senescence in mammals-the function formerly discharged by the pineal in the search for the seat of the soul - there are also solid arguments for its direct involvement, certainly as mediator, but possibly also as originator, of senile processes. Because the pituitary is profoundly concerned with several processes of homoeostasis, and is involved with morphogenetic timing mechanisms like that which initiates puberty, it is easy to develop hypotheses of pituitary senescence which do not depend upon an unbiological argument in terms of single hormones.

The function of trophic hormones appears to be the provision of one limb of a system of negative feedback, by which the level of effector-organ secretion is maintained and kept constant. If senescence be regarded as a continuously self-aggravating disequilibrium (a positive feedback process), then such a process can be induced in a model control system, normally dependent upon negative feedback, by several types of change.

Consider a system in which a device A produces a signal which increases the activity of a second device $B$, and in which, at the same time, the activity of B produces a signal which reduces the activity of device A. The properties of most selfregulating biological systems can be reproduced in this model by varying the characteristic of the stimulus $\mathrm{A} \rightarrow \mathrm{B}$ or the negative feedback $B \rightarrow A$, and the number of stable states of $\mathrm{A}$ or B. If there is no time-lag in either of these processes, the level of output $B$ will tend to be constant and self-restoring. If there is an appreciable time-constant in one limb of the circuit, the system will tend to function as a relaxation oscillator. In this case, A stimulates B, which does not immediately respond. Stimulus $\mathrm{A} \rightarrow \mathrm{B}$ continues to increase, reaching a level which corresponds to an ultimate response in B sufficient to inhibit $\mathrm{A}$ completely. The output of $\mathrm{B}$ then declines, permitting $\mathrm{A}$ to recover, and this represents one whole cycle. It is a requisite for the functioning of such a system that the unmodified output of A shall tend to increase in the absence of output B, i.e. that 


\section{The Biology of Senescence}

the state of A is inherently unstable. If output A be assumed to be the pituitary gonadotrophin and output $\mathrm{B}$ the gonadal hormone, then the immediate response of the pituitary to castration, or senile decline in gonadal response, is of the unstable type, though other mechanisms operate later to restore regulation. Where, as may be the case in the male, the pituitarygonad balance operates as a level-control, gradual failure of B's response would be expected to cause a gradual increase in output $\mathrm{A}$. In a similar system containing a time-constant, and therefore behaving cyclically, blocking would be expected to occur at one point in one particular cycle, with a proportionately greater rise in output $\mathrm{A}$.

The importance of this homoeostatic concept is that in the simplified model self-regulating equilibrium can be turned to progressive disequilibrium by several types of change. Decline in the capacity of either $\mathrm{A}$ or $\mathrm{B}$ to respond to $\mathrm{B} \rightarrow \mathrm{A}$ or $\mathrm{A} \rightarrow \mathrm{B}$ will result in a permanently unstable state of $A$. If the response of $\mathrm{A}$ fails, $\mathrm{B}$ will also be driven into maximum output. Decline in the capacity of $\mathrm{B}$ to produce $\mathrm{B} \rightarrow \mathrm{A}$ will induce the unstable state of $\mathrm{A}$. Decline in the capacity of $\mathrm{A}$ to produce $\mathrm{A} \rightarrow \mathrm{B}$ will lead to the relapse of $B$ into its stable state of zero output. This, however, where B's output effects other systems, will cause disequilibrium in a complex physiology. In addition to these purely quantitative changes, biological cybernetic mechanisms are also capable of exhibiting, and, in development, characteristically do exhibit, qualitative change in the specificity both of signal and response, which further complicates the picture.

Although analogies from circuits oversimplifying the reality of mammalian homoeostasis, they indicate the number of variables to be considered in studying the senescence of homoeostatic systems; and they indicate some of the ways in which such senescence can be analysed. Evidence suggests that in the case of the gonad it is the function of B which declines. With the pituitary trophic hormones, other than the gonadotrophins and ACTH, in vivo estimation of levels, corresponding to the measurement of output A, cannot as a rule be carried out. The action of these homoeostatic systems, moreover, is not expressed through static components but through a developing organism 


\section{The Mechanisms of Senescence}

in which long-term trends in cell specificity are themselves controlled by the signals involved in the homoeostatic processas if the system $\mathrm{A} \rightleftharpoons \mathrm{B}$ were fitted in a vehicle whose movement it controlled, but which travelled into a hotter and hotter environment, thereby upsetting the characteristics of $\mathrm{A}$ and $\mathrm{B}$.

These highly complex hormonal homoeostatic systems are of the greatest importance in higher vertebrates, although the problem of 'three-dimensional' homoeostasis, or homoeostasis superimposed on morphogenesis, is general in all developmental physiology. The views of Minot (1908) upon 'cytomorphosis' (differentiation and maturation) as a cause of senescence carry the very important, and at first sight very probable, inference that no complex organism, and certainly no vertebrate, can remain in an indefinitely stable equilibrium. Where growth processes and differentiation are superimposed on homoeostasis they are analogous to 'drift' in a control system-on this basis any system of differential growth must tend to increasing disequilibrium, unless the developmental 'drift' itself modifies the homoeostatic system to keep them appropriate to the altered situation.

\subsubsection{GONAD-PITUITARY SYSTEM}

Senescence of the gonad regularly precedes or accompanies senescence of the owner in a number of phyla-so much so that declining reproductive capacity is a token of senescence almost as valuable as the direct measurement of increased force of mortality. The relation of gonadal senescence to somatic senescence has clearly much evolutionary interest, since once the first is complete, in an organism, to the point at which that organism's contribution to posterity is no longer statistically significant, any further adverse change in viability is generally speaking inaccessible to the influence of natural selection, except in a very roundabout way.

In almost all litter-bearing mammals, a decline in litter size is characteristic of senescence. The long post-reproductive period found in women is exceptional in mammals. It probably represents a genuine biological difference, quite apart from the far greater perfection of the techniques for keeping human beings 


\section{The Biology of Senescence}

alive. Compared with the more gradual disappearance of ova in other mammals, the human menopause is unusually complete and sudden. The range of this phenomenon among primates is not at present known. Nobody has seen a postmenopausal monkey (Krohn 1955).

There is some cause for regarding gonadal senescence and the group of effects which follow senile gonadal withdrawal as a separate 'senescence' from that of the animal as a whole, since gonadal supplements can reverse a whole series of subsidiary senile changes without materially reversing the progress of somatic senescence judged by survival. In the castrated male mammal, gonadal hormone supplements may perhaps actually shorten life. There is no demonstrable androgen deficiency in normal senile male rats (Korenchevsky, Paris and Benjamin, 1953), nor, probably, in most old men.

Although sex hormones do not rejuvenate the organism in the manner envisaged by writers such as Voronoff, they produce a closer approach to 'rejuvenation', covering more structures and body processes, than do any other hormones which have been investigated. In addition to their effects upon the secondary sexual characters, such as beard growth (Chieffi, 1949) or structure of vaginal epithelium (Loeb, 1944; Allen and Masters, 1948) and upon the genitalia themselves, androgens (Kenyon, 1942; Kochakian and Murlin, 1931; Kochakian, 1937) and probably also oestrogens (Kenyon, 1942) exert an important 'anabolic' effect with nitrogen retention and increased protein synthesis, and produce a number of unexpected peripheral changes, generally in the direction of a restoration of 'young' structure (Korenchevsky, Paris and Benjamin, 1953). Thus oestrogens have been stated to produce a striking reversal of the atrophy of the senile nasal mucosa (Kountz, 1950) and certainly produce extensive changes in senile skin, with dermal regeneration (Goldzieher and Goldzieher, 1950; Chieffi, 1950a) and restoration of elasticity (Chieffi, 1951). That the possibility of 'rejuvenation by replacement' is limited, even where the reproductive organs are concerned, is shown by Kirk's failure $(1948,1949)$ to restore the phosphatase activity of senile prostatic secretion with androgens, although this activity is so restored in young hypogonadal males. 


\section{The Mechanisms of Senescence}

The relation of these changes and their reversal to the general picture of senescence in mammals remains extremely obscure. Of the more general processes in which gonadal hormone withdrawal plays a part, few have been identified with certainty. It has been suggested, for instance, that the osteoporosis of old age is a result of the withdrawal of gonadal anabolic hormones (Allbright, 1947). All theories of gonadal action in senescence have, however, to accommodate the probability that in mammals senile change in the force of mortality of apparently typical form, and at approximately the typical specific age, occurs in both sexes in the absence of both gonads, regardless of the age at which these are removed.

The mechanisms which fix the timing of puberty, and of the human menopause, are the most obvious of all mammalian age processes, and quite the most promising experimentally. The key problem is to determine whether the timing-factors reside primarily in the gonadal cells or elsewhere. The application of transplantation techniques to this question has been reviewed by Krohn (1955). Unfortunately, it already appears likely that there are considerable interspecific differences. The ability of the gonadal cells in situ to respond to gonadotrophin has sometimes been regarded as controlling the onset of puberty. Pituitary gonadotrophin is detectable in the hypophysis of the $17 \mathrm{~cm}$. pig foetus (Smith and Dortzbach, 1929) and the implantation of glands from 3-month-old rabbits is as effective in inducing puberty as implantation of adult glands (Saxton and Greene, 1939). The ovaries of immature rabbits do not respond to injected gonadotrophin (Hertz and Hisaw 1943, Parkes 1942-44, Adams 1953) On the other hand, it has long been known that when ovaries are transplanted reciprocally between young and old animals, it is the age of the recipient before or after puberty, not that of the ovary, which determines function or non-function (Foà, 1900, 1901; Long and Evans, 1922 ) and in some species gonadotrophin readily induces precocious ovarian and testicular development. Domm (1934) was able to induce crowing at 9 days of age and treading at 13 days in cockerel chicks by injections of pituitary gonadotrophins. The timing-mechanism is stable within a species or a genetic strain. Human puberty very exceptionally occurs during childhood without any obvious pathological cause ('constitutional 


\section{The Biology of Senescence}

precocious puberty'-Novak, 1944) and pregnancy has actually been reported in a child of five (Escomel, 1939). In albino rats, according to Mandl and Zuckerman (1952) genetic factors seem to play the major part in determining the age of puberty. Lorenz and Lerner (1946) likewise found clear evidence that age of sexual maturation in turkeys is heritable. 'The reactivity of the gonads may be the most important factor in determining the time at which sexual maturity actually occurs, but the factors which affect this reactivity are largely unknown' (Robson, 1947). Change also takes place at puberty in the specificity of pituitary response-while oestradiol induces pituitary and adrenal hypertrophy in rats castrated after puberty, it reduces pituitary and adrenal weight in animals castrated while still immature (Selye and Albert, 1942).

The end of the reproductive period, as well as the beginning, is marked by changes in gonadal reactivity. These have led some writers to regard the human menopause as a form of depletion-senescence (Swyer, 1954): Hertig (1944) describes the exhaustion of a 'capital' of ova, which is not increased during post-natal life, but his findings suggest that the actual menopause precedes the end of all follicular activity. In man and many other mammals (the only admitted exceptions occur in Lemuroidea, the galago and the loris), the occurrence of oogenesis during post-pubertal life has been doubted-the case against it has been persuasively put by Zuckerman (1951): this 'perennial controversy' has been continued by Parkes and Smith (1953), who found evidence of oocyte regeneration in rat ovaries grafted after freezing. But it is in any case most unlikely on existing evidence that the menopause occurs because the supply of ova is exhausted. Engle (1944) mentions the finding of apparently normal corpora lutea in women of 50: at the menopause most if not all ova and follicles have normally disappeared. Kurzrok and Smith (1938) found that in the human ovary, in contrast to the senile ovary of some other mammals, ova cease to be found, and that this change occurs at or soon after the menopause. They consider that the postmenopausal ovary can no longer respond to pituitary gonadotrophin. Gardner (1952) transplanted ovaries between old and young rats, and apparently found a greater tendency to malignant 


\section{The Mechanisms of Senescence}

change in old ovaries carried by young hosts. Details of this study have not yet appeared.

In rats semicastrated during old age, Wiesner (1932) found a marked reduction in compensatory hypertrophy of the remaining ovary. One major feature of senescence is probably progressive reduction of the ovarian reserve in terms of hormone production. Such an effect, rather than the consumption of ova, may account for the earlier menopause in semicastration (Masters, 1952). Failure of the ovary to respord to pituitary stimulation is almost certainly the proximate cause of the human menopause. (See also Klebanow and Hegnauer, 1949.)

In rare instances a failure of the menopause itself has been reported-menstruation is said to have persisted in a woman of 104 (Novak, 1921) - but pathological causes were probably responsible for some at least of these cases.

By far the most interesting fact from the standpoint of senescence is the striking increase in pituitary gonadotrophin level at the human menopause, and the comparable but more gradual increase in senile men (Henderson and Rowlands, 1938) and rats (Lauson, Golden and Severinghaus, 1939). This not only indicates a change in gonadal tissue reactivity with age, but it also shows how limited senile processes may provoke compensatory reactions and further disturb homoeostasis. Ovariectomy in certain strains of mice predisposes them to carcinoma of the adrenal cortex, which can be prevented by oestrogens (Woolley and Little, 1946). The senile increase in gonadotrophin closely resembles that which follows castration, though it develops more gradually (in female rats-Lauson, Golden and Severinghaus, 1939). Witschi (1952) found that in women the castrate level of FSH by pituitary gland assay is established very rapidly after the menopause, and persists for the rest of life, while in men the rise is far more gradual, the castrate level being reached only at 70 years and only by a few individuals. In a majority of cases the hypophyseal FSH content either remains at the normal adult level or falls, occasionally even below childhood levels. But in male eunuchs castrated in childhood, pituitary gonadotrophin output may remain, from the time of normal puberty into middle age, at about ten times the normal level (Hamilton, Gatchpole and Hawke, 1944, 1945). 
There is no evidence that this staggering increase, maintained over 40-50 years, has any observable effect on the rate of ageing.

\subsubsection{HORMONAL REGULATION OF GROWTH IN VERTEBRATES}

In mammals, where growth and differentiation are difficult to dissociate experimentally, we have abundant evidence of senescence even in the longest-lived forms. In amphibia, where there is a clear-cut metamorphosis, and where growth and differentiation can be manipulated with relative ease, we have so far no evidence of senescence. We cannot directly find out whether the life of intact amphibia, the neoteny of the axolotl, or the gigantism of athyroid tadpoles, ends in senescence, for the practical reason that axolotls may well be capable of living for 50, and normal frogs for twelve, fifteen or twenty years. This conspiracy of circumstances perpetually recurs in the study of ageing. The large literature of lower vertebrate endocrinology and morphogenesis cannot be brought to bear on the problem, for lack of actuarial data.

Both homoeotherms and poikilotherms, whether they metamorphose or not, tend to pass through an earlier phase of active growth and a later phase of active reproduction, each characterized by a separate type of endocrine control, and the second by a relative loss of regenerative in favour of reproductive capacity. These phases are separated by the operation of a timing-mechanism which is linked to processes in the juvenile phase. In mammals, these phases are apparently controlled by the pituitary growth and gonad-regulating mechanisms successively. In lower vertebrates the differentiation-process and the transition to adult function appears to depend on a pituitarythyroid balance. Pituitary growth hormone of mammalian origin is able to promote the growth of fish (Swift, 1954).

The relation between morphogenesis under the influence of gonadal hormones and loss of regenerative power has special interest in gerontology. Grobstein (1947) found that when the gonopodium of poeciliid fish differentiates, under the influence of androgens, regenerative power is lost: he stresses the analogy between this process and the loss of regenerative capacity in the developing anuran limb. Such a change need not depend upon irreversible loss of cellular capacity to grow-this does 


\section{The Mechanisms of Senescence}

not appear to be the case in amphibian limbs (Borssuk, 1935; Poležaiev and Ginsburg, 1939) but the physiological loss of repair-power may be as complete, so far as the intact animal is concerned, as is the loss of moulting-power in Rhodnius once the evocator is lost. There is clearly here, as Minot recognized, a possible mechanism for the induction of senile change.

A certain amount of evidence is available concerning the hormonal influences which affect protein anabolism, and regulate growth in mammals, especially in man. Where these factors have been studied, they give little support to the idea of a simple relation between senescence and growth-cessation, and even less to the conception of a single, 'master', endocrine inhibitor which can be detached from the general pattern of progressing developmental change. The pattern which exists in man has all the complication of a dynamic system where homoeostasis coexists with change. Much of the existing information is provisional, and there are as yet no studies extending into the period of senescence. It is plain, however, that in man, and probably in some but not all other mammals, the 'anabolic' stimulus to form new protein is not the same throughout life. In adult life it is closely linked to the gonadal cycle. The extent of the differences in endocrine control of growth between determinate growers such as man and continual growers such as the rat has not yet been mapped, and very little is known of the hormonal control of growth in lower vertebrates. The existing evidence is quite enough, however, to render any static conception of growth-cessation in terms of single-hormone deficiencies untenable. A more accurate picture would perhaps be obtained by treating pre-pubertal and pubertal life as separate instars separated by what amounts to a biochemical metamorphosis.

The growth of human beings, like that of Daphnia (p. 93), occurs in two overlapping cycles-one prepuberal, the other coinciding with puberty. (See Figs. 42, 43.) The prepuberal cycle has its most active phase during the first six months of life. This cycle, according to Kinsell (1953), is almost wholly controlled by the pituitary growth hormone. The puberal cycle appears to be evoked directly by anabolic steroid hormones derived from the gonad and adrenal cortex. During both cycles 


\section{The Biology of Senescence}

a minimum output of thyroid hormone is required to maintain growth and development. At puberty, in response to the pituitary gonadotrophins, the gonads produce steroid hormones which directly stimulate the growth of bone and of soft tissues.

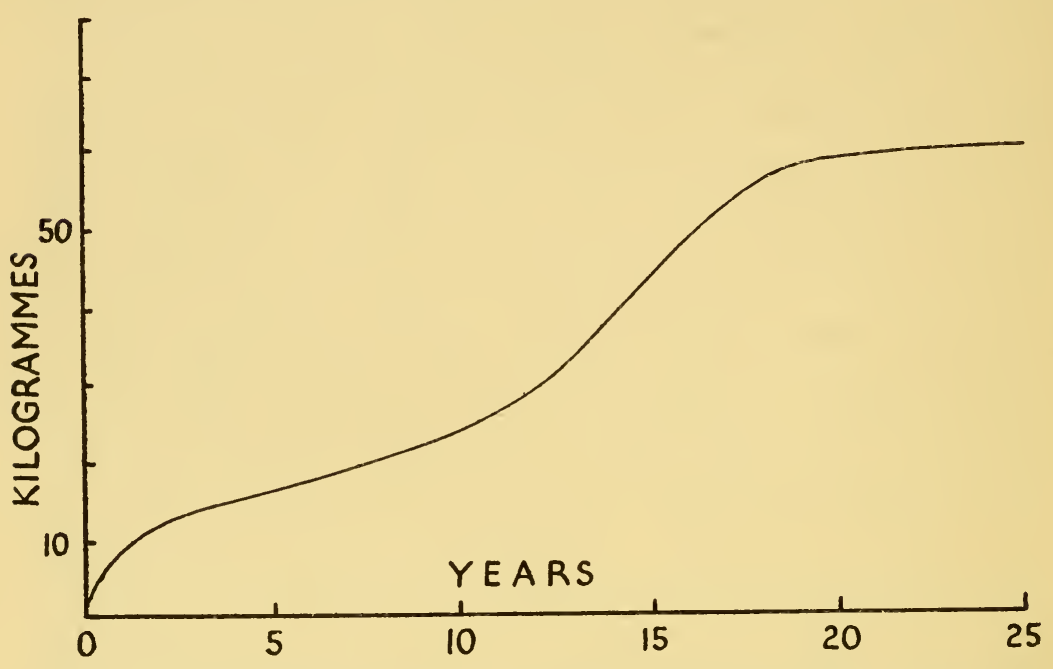

Fig. 42.-The postnatal growth in weight of male children ( $\mathrm{kg} /$ years) (from the data of Quetelet).

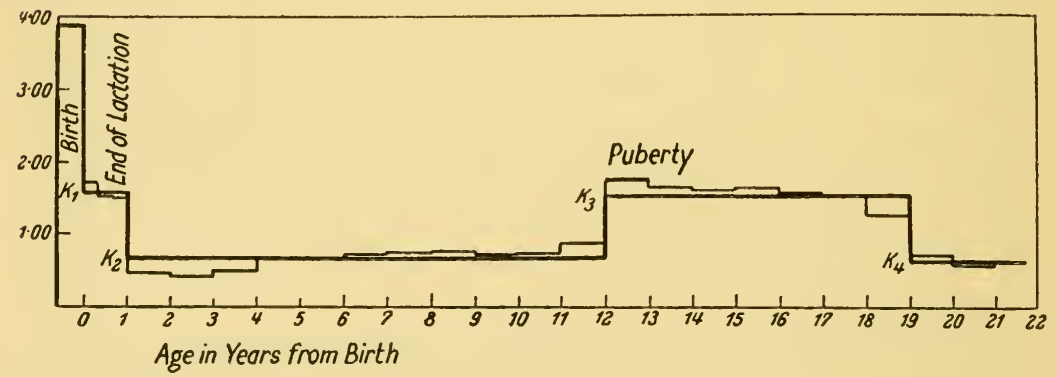

Fig. 43.-Annual growth increment in boys, from the data of Quetelet $\mathrm{k}_{1}-\mathrm{k}_{4}=$ growth constants at each period (from Schmalhausen, 1928).

The process of bone growth in man is, however, self-limited, since the same hormones produce skeletal maturation and fusion of the epiphyses. There is reason to suspect that they also inhibit the production of pituitary growth hormone- 


\section{The Mechanisms of Senescence}

probably through a negative feedback system from the level of protein anabolism. It is particularly interesting to notice that acromegalic symptoms (McCullagh and Renshaw, 1934) or frank gigantism (Joedicke, 1919) are occasional sequels to castration in males-so, however, are polyuria and diabetes insipidus (Hamilton, 1948). The puberal growth phase in girls appears to be largely of adrenal origin, since the growthpromoting effects of oestrogens and of progesterone are less marked, except in the promotion of $\mathrm{Ca}$ and $\mathrm{PO}_{4}$ retention, than those of androgens (Kinsell, 1953). It is generally held that thyroxin potentiates the action of pituitary growth hormone in mammals (Evans, Simpson and Pencharz, 1939; Scow and Marx, 1945) during the prepuberal phase, as well as hastening differentiation. This does not appear to be the case in anurans, where thiouracil produces pseudogigantism, and a balance between thyroid and pituitary has been postulated (Steinmetz, 1954), one evoking differentiation and the other growth and a 'juvenile' condition.

This picture, which requires considerable amplification, accords reasonably well with the known effects of various endocrine deficiencies in producing dwarfism or gigantism in man. To some extent the appearance of the puberal cycle curtails the prepuberal by inducing bone maturation. Epiphyseal union and the change-over to the puberal phase of growth are delayed by administration of growth hormone (Freud, Levie and Kroon, 1939), as they are in natural gigantism. On the other hand, abolition of the whole gonadal influence by prepuberal castration has, at least, no gross effect on the life-span. Here again the analogy to Edlén's findings in Daphnia is remarkably close.

Various workers have suggested that mammalian senescence 'is' (or involves) the decline of growth hormone production, and that it 'is' (or involves) the long-term effect of the pituitary gonadotrophin on non-gonadal tissues. Insofar as senescence results from differentiation, this is doubtless true, but the experimental question is rather this-to what extent can the administration of one or more 'anabolic' hormones affect the power of continued homoeostasis in adult animals? It is possible that the growth hormone itself may be the 'juvenile hormone' of the 


\section{The Biology of Senescence}

mammalian pre-imaginal period. It is a primary stimulator of protein anabolism and somatic growth. The change from a protein-building and nitrogen-retaining economy, and the negative specific acceleration of growth, are two of the most evident correlates of senescence (Mayer, 1949). The administration of growth hormone 'confers strangely youthful proportions on the nitrogen, fat and water components of the body, even in old animals' (Asling et al., 1952). Change in specificity of tissue response to growth hormone certainly appears to occur in some mammals, and this change coincides with the attainment of maturity and the appearance of a fresh anabolismmaintaining mechanism. The experimental work of Young in England and $\mathrm{Li}$ in America suggests that before a critical time, injected growth hormone induces only protein anabolismafter that time, ic also induces diabetes. This is the pattern in man, the kitten (Cotes, Reid and Young, 1949) and the dog (Campbell et al., 1950) but not in the rat (Bennett, Li and Evans, 1948) or, apparently, the mouse (Moon et al., 1952) which respond by continued growth. That the change in specificity involves endogenous as well as exogenous hormone is evident from the occurrence of diabetes in association with spontaneous acromegaly. Evidence for the existence of a separate diabetogenic principle is not very impressive (Raben and Westermeyer, 1952; Young, 1953). Complete ablation of the anterior lobe in adults leads to failure of growth but not, in general, to other acceptable evidences of senility (in rats) though this cannot be shown from the life-table.

In experimental studies, even highly purified growth hormone administered to rats produces decreasing effects upon nitrogen retention and upon growth after repeated administration (Whitney et al., 1948). These experiments, however, have invariably been carried out with heterologous (usually ox) hormones, and, as in the case of antigonadotrophic effects, no physiological importance can be attached to the apparent increase in tissue resistance.

Of the other hormones concerned in growth and differentiation, the pituitary thyreotropic hormone appears in most mammals which have been studied (rats-Turner and Cupps, 1938; rabbits-Bergman and Turner, 1941; mice-Adams and 


\section{The Mechanisms of Senescence}

Mothes, 1945; cattle-Reece and Turner, 1937) to reach a peak at or about puberty, with a subsequent decline which has never been followed by assay into old age. The decline of general metabolism with increasing age, which has been frequently linked with the decline of growth-capacity as an index of 'physiological ageing', appears to involve both a fall in thyroid activity and perhaps a decline in cell response, since thyroidectomized rats show no senile decline in heart rate and $\mathrm{O}_{2}$ uptake, and old normal rats are decreasingly responsive to thyroxin administration (Grad, 1953). The declining heatproduction of ageing human subjects may well be a reflection as much of muscle atrophy as of thyroid involution.

The results obtained by McCay, using dietary restriction, could be regarded as the consequences of dietary hypophysectomy. Such a state of affairs interferes with the production of both growth hormone and gonadotrophin, and its effect is a general slowing of the 'integrating system' of growth + development. The separation of these systems in mammals is a problem of great interest and considerable practical difficulty. Dietary retardation greatly postpones, but cannot be kept at such a level as to prevent, the onset of oestrus (Asdell and Crowell, 1935). McGay, Sperling and Barnes (1943) found that the capacity of retarded rats to resume growth was ultimately lost if retardation was prolonged. Apparently if growth is delayed without differentiation, it may ultimately encounter a block at the cellular level.

A beginning has been made on the problem of selective interference with mammalian differentiation by the school of $\mathrm{Li}$ and Evans (Walker et al., 1952; Asling et al., 1952a, b). Hypophysectomy in 6-day-old rats does not arrest the eruption of teeth or the opening of the eyes, but later sexual and pre-sexual development is suppressed. Untreated animals ultimately die from paralysis due to cerebral compression, the brain outgrowing the cranium. Rats which survive the postoperative period have been maintained in good health by growth hormone supplements. In these supplemented rats, the rate of growth was only slightly less than that of unoperated controls. Skeletal development was normal, but adult organ-differentiation and sexual maturation did not take place. Three such 'metathetelic' 


\section{The Biology of Senescence}

individuals, were kept for 200-300 days in an attempt to produce gigantism. The end results of this experiment have not yet been reported in full. It would be interesting to know how long such animals are capable of living, and what senile changes they ultimately exhibit.

Selective suppression of gonadotrophin production is not yet feasible, though recent studies with Lithospermum extracts suggest that the chemical 'dissection' of pituitary effects with chemical antagonists is not, perhaps, an unreasonable hope (Wiesner and Yudkin, 1952). The effect upon life-span of inducing precocious puberty in mammals does not appear to have been studied: mice, which mature very early, are not ideal subjects, and an experiment on longer-lived mammals encounters the familiar practical difficulties. 


\section{$-7 \cdot$}

\section{GONCLUSION}

We have now briefly examined some of the evidence which requires to be considered, and some of the questions which require to be answered, in attempting to understand animal senescence. We have seen, in particular, that many organisms appear to have been provided by evolutionary selection with a 'programme' of development and function which is directional and finite, and that progressive loss of the power to remain in stable function occurs towards the end of that programme. Weismann suggested that senescence is itself a functionallydetermined item in the programme: it seems more probable that as the contribution of successive age groups to the next generation of progeny is reduced by natural causes, so the selection-pressure declines, and the efficiency of the homoeostatic mechanisms with it. The organism ultimately dies of old age because it is now an unstable system which is provided with no further sequence of operational instructions, and in which divergent processes are no longer co-ordinated to maintain function.

In some cases the system fails suddenly, at a fixed point, after the pattern of the senescence of rotifers or red blood corpuscles. Some such cases apparently depend on the existence of cell constituents renewable only by division. In mammals the decline of resistance and the rise of the force of mortality are gradual and smooth, and agree well with the probable shape of a curve representing the declining efficiency of the evolutionary pressure towards survival at different ages.

Insofar as any general theory of senescence is justified, this seems at present the most plausible. It is probably as unprofitable to discuss the 'cause' of ageing as to discuss the 'cause' of 


\section{The Biology of Senescence}

development. Senescence is a change in the behaviour of the organism with age, which leads to a decreased power of survival and adjustment. It is not a single overall process, except in the evolutionary sense which we have outlined. Various factors in varying proportions contribute to the senile change in different species. Among these are the deterioration of irreplaceable structures; the sum of previous injuries which are imperfectly repaired; and progressive morphogenetic changes in the nature and specificity of cell response and organ function. Any or all of these factors may contribute to senescence in a given species. Experimental removal of the factor which operates earliest in the life-span may reveal another subsequent to it, and so on. There is no conclusive evidence to incriminate cessation of growth as a 'cause' of senescence, except in cases where cell division ceases altogether. Senescence is not an 'inherent' property of the metazoa, but one which they have on several occasions acquired as a potentiality, probably through the operation of evolutionary forces directed to other biological ends. In this respect the senescence of insects and of man is probably a comparable process only to the same extent that the eyes of these organisms are comparable structures. It is obvious that such a conception, while it does not prevent us from ascertaining what factors produce the age-deterioration in a given species, excludes general physiopathological theories of the 'causation' of ageing as a whole.

Unlike the functional evolution of the eye, senescence is typically an undirected process-not a part of the programme, but a weakening of the directive force of the programme, an escape from co-ordination, combined with the arrears of processes which once contributed to fitness but are now running free. Attempts to invest the programme of morphogenesis with metaphysical or supra-natural properties (Driesch, 1941; Bürger, 1954) have already been adequately answered by J. Needham (1942), and need not be dealt with here. The idea of senescence as the 'fated' or 'destined' end of the organism, i.e. a positively-subsistent and ordered process of life-curtailment, though it is not always the fruit of an avowed vitalism, has much in common with it. Such treatment of senescence as an evolved entity, and the idea that it must have developed as a 


\section{Conclusion}

positive character, has almost certainly gained plausibility, like so much else in the biological literature of old age, from human preoccupations. The gerontologist, with the prolongation of human life in mind, is interested in something which is not, as such, of interest to the evolutionary 'demon', and whose evolution is in no sense comparable with the evolution of sight. Senescence has no function-it is the subversion of function. On the other hand, as Huxley (1942) suggests, the evolutionary process in man has been transferred in the process of cephalization from the 'demon' to the operation of conscious intellect. It should now be possible in our thinking to separate human goals from the effects of selection, and to renounce the animistic confusion between them which has influenced the past theoreticians of old age. The whole conception of 'senescence', in fact, belongs to the field of applied science. It embraces a group of deteriorative effects which we have isolated because they are deteriorative-in other words, because human beings dislike them. Some biological thinkers have reduced themselves to impotence in this field by the cultivation of philosophic doubt whether senescence is an 'entity' at all. Viewed abstractly it is not, any more than disease is an 'entity', but the same biologists will certainly encounter, as they approach their seventieth year, a sequence of changes which will kill them within a limited time.

Insofar as biology is more than a branch of idle curiosity, its assignment in the study of old age is to devise if possible means of keeping human beings alive in active health for a longer time than would normally be the case-in other words, to prolong individual life. People now rightly look to 'science' to provide the practical realization of perennial human wishes which our ancestors have failed to realize by magic-or at least to investigate the prospect of realizing them. Under the influence of the study which is necessary to fulfil such wishes, the character of the wish itself generally changes in the direction of realism, so that most people today would incline to prefer the prospect of longevity, which may be realizable, to a physical immortality which is not, and, pari passu, 'potentielle Unsterblichkeit' is already disappearing from the biological literature. An analogous process can be seen in the psychology of individual growing-up.

The objective of prolonging human life is one which can bear 191 


\section{The Biology of Senescence}

aggressive restatement from gerontologists, particularly at a time when there are scientists who seek ethical reasons why human life ought not to be prolonged, at least in communities of which they are not themselves members. Although it has much fundamental interest, we have seen that senescence is not biologically speaking a very satisfactory entity. It appears in most animals only under artificial conditions, and it would probably seem to most of us pointless to devote great effort to so arbitrary a part of development if it were not involved with a primary human desire. As it is, medicine has always accepted the prolongation of active and healthy human life in time as one of its self-evident objects, and this object has only been seriously challenged in the past two decades by the growth of pathological forms of anti-liberalism. Gerontology differs from other fields of medical biology only in the fact that while most medical research is directed to making the curve of human survival as nearly as possible rectangular, gerontology is directed to prolonging the rectangle, and shifting the point of decline further in time from the origin. The applied character of such work, and the object it has in mind, would not require emphasis or defence at a period of culture when they ran no risk of provoking a neo-Malthusian uproar. The beggarly opinions of such writers as W. Vogt (1949) merit the rebuke of James Parkinson (1755-1824), that 'if the population exceeded the means of support, the fault lay not in Nature, but in the ability of Politicians to discover some latent defect in the laws respecting the division and appropriation of property'. Postponement of old age, like all the other advances in human control of environment, must involve corresponding social adjustments: in the prevention of presenile mortality, as the graphs in Fig. 3 abundantly indicate, social, economic and political factors clearly predominate already. But whatever problems might be raised by future increases in the human specific age, in this and other fields medicine can afford to treat protests based upon an interested misreading of the biology of human societies with the contempt they deserve, as a compound of illiberal opinions and bad science. The emotional preoccupation of former workers with magical rejuvenation did no good to the progress of science, but it was at least a humane preoccupation. 


\section{Conclusion}

In fact, the social correlates of longevity, which are probably its most important practical aspects, have been omitted altogether from consideration in this book. It is clear throughout phylogeny that there is a relation between survival into the senile period and the existence of a social mode of life. In some cases longevity has evolved as a prerequisite of social organization, in others social organization itself increases the possibility of survival into old age, while the social group very probably draws adaptive benefits from the existence of old individuals. Both these trends appear to be at work in social primates. The potential life-span in palaeolithic man probably resembled our own: its realization has been possible through the development of a complex social and rational behaviour. While therefore it is legitimate to abstract the idea of an evolutionary programme in morphogenetic or physiological terms when we discuss the development and senescence of an individual man or of a worker bee, in neither case is this 'programme' really detachable from the social programme which coexists with it, and which plays an equally important part in the determination of selection or survival. The irrelevance of discussing the biology of individual animals, even of non-social species, divorced from their ecology, has long been evident. Prolongation of the social activity and significance of the individual human being almost certainly leads to a change in the shape of the life-table, others things being equal. Continuance of active work, retention of interests, of the respect of our fellows, and of a sense of significance in the common life of the species, apparently make us live longer-loss of these things makes us die young. This is a result we might have expected, but which we still largely ignore in practice. How much of senile 'involution' is the effect of the compulsory psychological and social 'winding-up' imposed on the human individual by our form of society and our norms for the behaviour of old people we do not yet know, but it is certainly a very considerable part, and the most important measures for the prolonging of useful individual life which come within the range of the immediately practicable are all concerned with social adjustment. The contrast between the place of the (relatively few) aged in primitive societies (Simmonds, 1945,1946 ) and the relatively many in our own (Sheldon, 1949; 193 


\section{The Biology of Senescence}

Sanderson, 1949) is particularly striking. In primitive cultures important means of security for old people are their active association with others and assistance in their interests and enterprises. They are regarded as repositories of knowledge, imparters of valuable information, and mediators between their fellows and the fearful supernatural powers ... The proportion of the old who remain active, productive, and essential in primitive societies is much higher than in advanced civilization, for they succeed to an amazing degree in providing cultural conditions which utilize the services of their few old people' (Simmonds, 1946). How little this applies to our own culture is evident from the studies of Sheldon (1949); other evidence suggests that although in certain groups (Lehman, 1943), such as amateur naturalists - or among those who retain, perhaps, some of the magico-social functions of the primitive elder (politicians, judges and clergy) the element of social support based upon continued activity leads to an apparently superior retention of the capacity for public life, the society of compulsory retirement, individual privacy and the small family has little to offer to old people. This is a topic which cannot be pursued here, but its importance in the social medicine of age is paramount at present.

The problem of medical gerontology at the biological level, however, is to prolong the human life cycle in time, either by deformation and stretching or by addition, and in particular to prolong that part of it which contains the period of 'adult vigour'. Such a problem could theoretically be solved in any of three ways, bearing in mind the evidence regarding the existence of a developmental 'programme' - that programme could be prolonged by the provision of new developmental operations; or its movement, throughout or in part, could be slowed down; or active life could be maintained after the expiry of the programme by piecemeal adjustment of homoestatic mechanisms with supplements, medicaments and prostheses of various kinds.

The first of these possibilities, though it is biologically the most interesting, does not merit discussion at present, at any rate in relation to man. We do not know enough about morphogenesis to interfere with it clinically, except in a few simple deficiency states, let alone devise and apply a sequence of self- 


\section{Conclusion}

regulating operations in growth or development subsequent to normal adulthood. The third possibility is that which is already, and very justifiably, receiving the major part of the energy devoted to clinical studies upon human ageing. The removal of successive causes of death should in theory increase the specific age. It is interesting to notice that there is so far very little evidence of such an effect. It was once widely believed that with the removal of 'pathological' causes of death the specific age would rise very rapidly in man and approach the recorded maximum. Although research on the diseases of later life has not yet had time to reach a stature comparable with the lifesaving powers of surgery and epidemiology in early life, it seems possible that even with increased control over neoplasms and cardiovascular disease the age at death might only come to be more and more normally distributed about the present specific age. Most people who die in old age are found at postmortem to have several further pathological processes at work, beside the one from which they died. If an arbitrary normal distribution of deaths due to 'pure' senescence were assumed, the shape of the curve could be inferred from the shape of that one-half of the existing, positively-skew curve which lies between the ages of 75 and 100. Such an assumption may well, however, be false. The smoothness of the curve between those ages is largely due to manipulation by actuaries, relying on a conventional end to the human survival curve to help them over statistically insignificant material (Freudenberg, 1949). We have not reached the limits of the purely prosthetic and supportive treatment of senility, and we are unlikely to do so for a very long time.

There remains the possibility of prolonging life by slowing down the movement of the developmental programme. Such slowing, to be of medical interest, must be compatible with retention of normal vigour and activity. The mere duration of individual existence could quite possibly be extended, as John Hunter proposed, by some form of artificial hibernation, punctuated by periods of activity: but this possibility is more interesting to stockbreeders, astronauts and perhaps politicians than to gerontologists. The prolongation of infancy is unlikely to be of much interest, unless it is indispensable to some effect 


\section{The Biology of Senescence}

in later life. The prolongation of that part of the life cycle which lies normally between the eighteenth and fiftieth years of age, even by a small percentage, would come nearest to fulfilling our objectives. The prolongation of childhood presents special interest, since, on existing mammalian evidence, it is quite probably feasible by relatively simple, if heroic, means such as calorie-restriction. Such a prolongation would have interesting and far-reaching social consequences, both upon the family and upon the acquisition of skills: its effects on characterstructure would be even more interesting. It seems very probable that the time-scale of prepubertal development in the majority of mammals is relatively labile. There is so far no direct evidence that the same applies to later stages in the life cycle. Dietary restriction, although it may favour longevity, does not greatly delay senescence in adult mammals, and it may be that the time scale of the adult period, after somatic growth has ceased, is not susceptible to any major interference without at the same time destroying normal function. To assess the possibilities of such interference we require to know how far 'marking time' at each stage of the mammalian developmental programme is possible, and, if possible, is compatible with functional health. It is also a matter of practical import whether the rate of child growth influences the length of the period of adult vigour in man (Sinclair, 1955). The degree of linkage between growth, development, and metabolism may vary considerably at different periods of the life cycle, and the bulk of the work upon their separation has been carried out only in non-mammalian embryos and larvae. We have to reckon with the possibility that the post-pubertal mammal behaves like an imago-that its life-span is closely linked to metabolism, which, in homoeotherms, is virtually invariable by the methods which can affect it in invertebrates, and that the fundamental change which leads to eventual senescence has already taken place at puberty. In this case, interference with the length of the adult phase could only be prosthetic.

There remains the possibility that a substantial change in the specific age, and in the duration of healthy life, might result from one particular adjustment. This was the hope which led to the use of sex hormones for purposes of 'rejuvenation', and 196 


\section{Conclusion}

which was largely disappointed. If such an adjustment is possible, it is most likely, perhaps, to concern one or more of the anabolism-promoting substances which maintain growth in the young animal.

To the question 'Can the effective human life-span be prolonged artificially?' the most probable answer, based on all these possibilities, would appear to be 'Yes'. To the further question 'By what factor?' no meaningful answer can be given until we know more of the nature of the predominant processes which determine human senescence. Supplementary questions dealing with the degree of reversibility in established senile change cannot at present be answered at all, beyond the conjecture that the morphogenetic programme in man is hardly likely to be simply reversible in any fundamental sense, but that the irreversibility of local changes in ageing is at present probably over- rather than under-estimated.

The only excuse for such speculation is, in any case, the possibility that it will drive us into the laboratory to ascertain the facts and to answer the questions it raises, thereby removing gerontology from the field of 'entelechies' and 'inherent principles' into that of intelligible evidence.

In planning research upon a subject such as senescence, it pays to put to ourselves the questions which most urgently require to be answered, and then to select from the list in the likely order of practicability. From the defects which exist in the evidence, the essential preliminary questions concerning senescence which we must ask appear to be these.

(1) Does senescence occur in all vertebrates?

(2) In what instances, if any, among vertebrates does senescence coexist with continuing somatic growth, or nonsenescence with fixed size?

(3) To what extent is arrest of developmental processes compatible, at different stages of vertebrate ontogeny between conception and senility, with activity and normal function? Is the retardation of further development, towards senility, realizable after puberty in mammals?

(4) To what extent is the artificial induction of somatic growth possible in the mature vertebrate, and what is its effect on the specific age? 


\section{The Biology of Senescence}

(5) What are the limits of the power of enzyme-renewal and physicochemical self-maintenance in fixed post-mitotic cells?

(6) In the case of single organs such as the mammalian ovary, how far is the expectation of life of the organ intrinsic in its stage of development, and what is its life-span in passage through successive young hosts? What, in more general terms, is the relation between the physiological age of individual tissues and the chronological age of the host animal?

I have singled out these specific questions for attention as being rather unlikely to be solved incidentally, in the course of general biological research upon other topics. The great bulk of the information which is missing on other specific points is likely to be derived eventually from studies in endocrinology or morphogenetics which are not undertaken ad hoc; this type of background research cannot be hurried on, ahead of the general progress of knowledge, except by the cultivation of interest in ageing among biologists of all kinds.

Three main types of research are involved in the investigation of our six preliminary questions-study of the phylogeny of senescence in vertebrates, study of the correlations and the experimental modification of growth and development in populations where the life-span can be concurrently measured, and study of tissue-environment relationships through the creation of age chimaeras. The problems of the first of these studies have already been mentioned. A reliable test of 'senescence' which correlates with the decline of resistance, does not kill the individual animal, and can be related to actuarial senescence by an intelligible process of reasoning, might offer some solution. The development of such a test would probably depend, however, upon the establishment of the part which declining growthenergy plays in the process of ageing. The time-lag in explant growth might conceivably give a basis for some such attempt. Any method of marking tissue cells in situ, to enable their lifespan to be determined like that of red blood corpuscles, would be a highly desirable advance, and a key to many doors. The study of growth and development relations, and the whole group of studies which require to be undertaken in determining 


\section{Conclusion}

the factors which predominate in mammalian ageing, or which can modify it, encounter a rather different obstacle. The choice of experimental animals for such work obviously presents great difficulty, since it is necessary either to work on forms whose life-span is short compared with that of the investigator, or to use elderly individuals whose early history has not been followed. The complication which this time-factor introduces is of great importance for the planning of research. Man is by far the most numerous senile animal, and his life cycle is extremely well known-even to the point at which we can estimate his physiological age by inspection; some research on senile mien can be justified ethically, but the gerontological aspects of laboratory animal-breeding cannot much longer be neglected, since in many problems no further progress is possible until mammals of known life cycle, heredity and physiology are available in quantity. At present the choice lies between experiment on patients, the basing of general conclusions upon the behaviour of invertebrates and small rodents, and postponing investigation for several years while a chosen population of larger mammals completes its life cycle. Failure to deal with the logistics of this problem now will hinder research in ten or twenty years time, and that hindrance could be avoided by forethought.

Another extremely important source of information is likely to be found in the creation of age chimaeras. In spite of the wellmerited disrepute incurred by much work upon organ grafting in relation to old age, the resources of modern transplantation techniques now offer a very tempting range of experimental possibilities. The reimplantation of stored infant tissues into the same animal, the cross-transplantation of organs such as ovaries, or tissues such as portions of skin, and the observation of the reciprocal influences of host and implant, are technically practicable and established procedures. Parabiosis between animals of disparate age but identical genotype, or even between retarded and unretarded littermates, is another tool of the same kind. The emphasis of such research is likely to be chiefly directed to dissecting tissue and somatic factors in the senile process, but its possible use in experimental, and even later in clinical, prosthetics is thoroughly well-justified. This is, of 


\section{The Biology of Senescence}

course, not the first occasion in biology when a procedure which was attempted with enthusiasm and abandoned in disgust has come back into useful currency after a period of meditation and study. An equally productive field may well be that of organ culture, initiated by Carrel, but still comparatively little used.

Apart from such specialized investigations, serious progress depends on the cultivation of general awareness among biologists of the importance of prolonging their study of every animal into the senile period, of collecting and publishing lifetables, especially for cold-blooded vertebrates under good laboratory conditions, and of seeking confirmatory evidence of the distribution of senescence in phylogeny. A few years of propaganda to zoologists in training might bring in a rich factual harvest later. Much modern research into ageing tends to be desultory, although the single subjects with which it deals are important in themselves. We ought to try to devise critical experiments, and if we destroy more hypotheses than we demonstrate, this is a subject which can well stand such treatment in contrast to the speculation which has gone before. The most desirable condition for progress in gerontology at the moment is that the exact nature and scope of the problems raised by senescence should be understood, and the possibility of new experimental evidence borne in mind, during the planning and assessment of all biological research, even when it is primarily directed to other objects. Senescence, like Mount Everest, challenges our ingenuity by the fact that it is there, and the focusing of our attention on it is unlikely to be fruitless. 


\section{BIBLIOGRAPHY}

NOTE: Russian references are given under the initial of the author in English transliteration. Where an alternative title in a language other than Russian is given by the author, this title is cited, otherwise the title is given in Russian, followed by an English translation.

Italic numbers in parenthesis following the reference refer to the page on which that reference is cited. Some additional papers by cited authors are included without a page reference.

AвE, N. (1932). 'The age and growth of the limpet (Acmaea dorsuosa Gould).' Sci. Rep. Tôhoku Univ. 7, 347. (58, 105)

Adams, A. E., and Mothes, A. M. (1945). 'The thyrotrophic potency of the pituitaries of albino mice with respect to age and sex.' Anat. Rec. 91, 21. (186)

Adams, C. E. (1953) in Ciba Foundation Symposium-Mammalian Germ Cells, p. 198. London: Churchill. (179)

Agduhr, E. (1939). 'Internal secretion and resistance to injurious factors.' Acta medica scand., 99, 387. (133)

Agduhr, E., and Barron, D. H. (1938). 'Further observations on the increased resistance of mated animals to toxic agents: Medinal.' Arch. int. Pharmacodyn., 58, 351. (133)

Ahrens, K. (1938). 'Lokaler Nachweis von Kalzium in den Membranen des Elodea-blattes mittels Natriumoleat.' Protoplasma, 31, 508. (35)

Allbright, F. (1947). 'Osteoporosis.' Ann. int. Med., 27, 861. (179)

Allee, W. G., Emerson, A. E., Park, O., Park, T., and Schmidt, K. P. (1949). Principles of animal ecology. Philadelphia: W. B. Saunders Co. (20)

Allen, W. M., and Masters, W. H. (1948). 'Investigation of sexual rejuvenation in elderly women.' Tenth Conference on Problems of Aging. Josiah Macey, Jr. Foundation, 1948. (178)

Alpatov, W. W. (1930). 'Experimental studies on the duration of life. XIII. The influence of different feeding during the larval and imaginal stages on the duration of life in the imago of Drosophila melanogaster.' Amer. Nat., 64, 37. $(44,143)$

Alpatov, V.V., and Gordeenko, N.A. (1932). Алпатов, В.В. и Гордеенко, Н.А. 'Блияние спаривания на продолжителность жизни шелкопрядов.' (Influence of mating on the longevity of silk-moths.) Zool. Zh., 11, (2), 60. (44, 132) 


\section{Bibliography}

Alpatov, W. W., and Pearl, R. (1929). 'Experimental studies on the duration of life. XII. Influence of temperature during the larval period and adult life on the duration of life in the imago of Drosophila melanogaster.' Amer. Nat., 63, 37. (44, 130, 133, 143)

Anderson, B. G., and Jenkins, J. C. (1942). 'A time study of events in the life span of Daphnia magna.' Biol. Bull. Woods Hole, 83, 260. (44, 93, 145)

Andres, A., and Jiv, B. V. (1936). 'Somatic chromosome complex of human embryos.' Cytologia, 7, 371. (168)

ANDREW, W. (1953). 'Phenomena of abnormal nuclear division in relation to the ageing process. $\mathcal{7}$. Geront., 8, 372. (168)

(1955). 'Amitotic division in senile tissues as a probable means of selfpreservation in cells.' 7. Geront., 10, 1. (100, 163)

Annandale, N., and Sewell, R. B. S. (1921). 'The banded pond-snail of India-Vivipara bengalensis.' Rec. Indian Mus., 22, 215. (102)

Arndt, W. (1928). 'Lebensdauer, Altern und Tod der Schwämme.' S.B. Ges. naturf. Fr., Berl., 23, 44. (80)

(1941). 'Lebendbeobachtungen an Kiesel- und Horn-Schwämmen des Berliner Aquarium.' Zool. Gärt., Lpz., 13, 140. (56)

Asdell, S. A., and Crowell, M. F. (1935). 'The effect of retarded growth upon the sexual development of rats.' $\mathcal{F}$. Nutrit., 10, 13. (187)

Ashworth, J. H., and Annandale, N. (1904). 'Observations on some aged specimens of Sagartia troglodytes and on the duration of life in Coelenterates.' Proc. Roy. Soc. Edin., 25, 295. (55, 56, 81)

Asling, C. W., Moon, H. D., Bennetr, L. L., and Evans, H. M. (1952a). 'Relation of the anterior hypophysis to problems of ageing.' J. Gerontol., 7, 292. $(153,187)$

Asling, C. W., Walker, D. G., Simpson, M. E., Li, C. H., and Evans, H. M. (1952b). 'Deaths in rats submitted to hypophysectomy at an extremely early age and the survival effected by growth hormone.' Anat. Rec., 114, 49. $(153,187)$

BAB, H. (1948). 'The process of ageing.' Brit. med. F., i, 1000. (7, 45, 162)

Bagelar, A., and Frade, F. (1933). 'Sur la longévité chez les araignées.' C. R. Soc. Biol., 113, 523. (57)

Backman, G. (1938). 'Wachtumszyklen und phylogenetische Entwicklung.' Lunds Univ. Arskrift, N.F. Avd., 2, 34, Nr. 5. (53)

(1944). 'Der Lebenslauf der Organismen nebst kritischen Betrachtungen zu meiner Wachtumstheorie.' Z. Altersforsch., 4, 237.

(1945). Altern und Lebensdauer der Organismen. (Uppsala and Stockholm). (61)

Bacon, F. (1645). Historia Vitae et Mortis. Dillingen. (34, 45, 54, 79)

Baer, K. (1864). Reden. St. Petersburg. (8)

BAerg, W. J. (1945). 'The black widow and the tarantula.' Trans. Conn. Acad. Arts Sci., 36, 99. (56, 92) 


\section{Bibliography}

Baffoni, G. M. (1954). 'La citomorfosi degli elementi di Purkinje del cervelletto.' Ricerc. scient., Rome, 24, 1641. (163)

BaILy, J. L. (1931). 'Some data on growth, longevity and fecundity in Limnaea columella Say.' Biol. gen., 7, 407. (43, 103, 104)

Baker, F. (1934). 'A conchological Rip van Winkle.' Nautilus, Phil., 48, 5. $(58,105)$

Baker, L. E., and Garrel, A. (1926). 'Au sujet du pouvoir inhibiteur du sérum pendant la vieillesse.' C.R. Soc. Biol., Paris, 95, 958. (154)

BALL, J. P., and SQuire, J. R. (1949). 'A study of mortality in a burns unit.' Ann. Surg., 130, 160. (26)

BANField, W. G. (1952). 'The solubility and swelling of collagen in dilute acid with age variations in man.' Anat. Rec., 114, 157. (169)

BANTA, A. M. (1914). 'One hundred parthenogenetic generations of Daphnia without sexual forms. Proc. Soc. exp. Biol., N.Y., 11, 7. (118)

BANTA, A. M., and Wood, T. R. (1937). 'The accumulation of recessive physiological mutations during long-continued parthenogenesis.' Genetics, 22, 183. (118)

Barnes, L. L. (1942). 'The deposition of calcium in the hearts and kidneys of rats in relation to age, source of calcium, exercise and diet.' Am. F. Path., 18, 41. (150)

Barrett-Hamilton, G. E. H. (1911). History of British Mammals. London. (49)

Bauer, E. (1924). 'Beitrage zum Studium der Protoplasmahysteresis, etc.' II. Arch. Mikr. Anat., 101, 483. VIII. Arch. mikr. Anat., 101, 521. (7)

Bazilevitch, I. V. (1938a). Базилевич, И.В.: 'Синдром нормалной старости.' (The syndrome of normal old age.) Proc. Conf. Probl. Old Age, Kiev, 255. (61)

Bazilevitch, I. W. (1938b). 'Sur l'âge des vieillards centenaires d'Abkhasya.' Medits. Zh., 8, 7. (61)

Bazykalova, A. (1934). Базыкалова, А.: 'Возраст ип темп роста Pecten jessoensis Jay.' (Age and growth-rate of P. j.) Bull. Acad. Sci. U.R.S.S., 2-3, 389. (58)

BEers, C. D. (1929). 'On the possibility of indefinite reproduction in the ciliate Didinium without conjugation or endomixis.' Amer. Nat., 63, 125. (117)

Beeton, M., and Pearson, K. (1901). 'On the inheritance of the duration of life, and on the intensity of natural selection in man.' Biometrika, 1, 50 . (122)

BÉLÁR, K. (1924). 'Untersuchungen an Actinophrys sol Ehrenburg. II. Beitrage zur Physiologie des Formwechsels.' Arch. Protistenk., 48, 371. (117)

Bellamy, A. W. (1934). 'Life span of Platypoecilus, Xiphophorus and their hybrids in the laboratory.' Science, 80, 191. (72, 133)

Bender, A. E. (1953). 'Recent advances in protein synthesis.' Lancet, 265, 1142. (34) 


\section{Bibliography}

Benedict, F. G. (1935). 'Old age and basal metabolism.' New Engl. F. med., 212, 1111. (33)

Benedict, F. G., and Root, H. F. (1934). 'The potentialities of extreme old age.' Proc. nat. Acad. Sci., 20, 389. (33)

Benedict, F. G., and Sherman, H. G. (1937). 'Basal metabolism of rats in relation to old age and exercise during old age.' $\mathcal{F}$. Nutrit., 14, 179. (33)

Bergauer, V. (1924). 'Beitrage zum Studium der Protoplasmahysteresis, etc.' III. Arch. mikr. Anat., 101, 489. VI. Arch. mikr. Anat., 101, 508. VII. Arch. mikr. Anat., 101, 512. (7)

Bergman, A. J., and Turner, C. W. (1941). 'Thyrotropic hormone content of rabbit pituitary during growth.' Endocrinology, 29, 313. (186)

Berninger, J. (1910). 'Über Einwirkung des Hungers auf Hydra.' Zool. Anz., 36, 271. (81)

Berrill, N. J. (1931). 'The natural history of Bulla hydatis Linn.' F. mar. biol. Ass. U.K., 17, 567. (58)

Bertalannfy, L. von (1933). Modern theories of development. London: Humphrey Milford. (142)

(1941). 'Stoffwechseltypen und Wachtumstypen.' Biol. Zbl., 61, 510. $(32,142)$

Bidder, G. P. (1925). 'The mortality of plaice.' Nature, Lond., 115, 495. (12)

(1932). 'Senescence.' Brit. med. 7., ii, 5831. (8, 11, 13, 70, 130, 154)

Bilewicz, S. (1953). 'Doświadczenia nad wpływem czynności rozrodczych na długość życia u muchy owocowej Drosophila melanogaster.' (Influence of mating on the longevity of D. m.) Folia Biol. Warsaw, 1, 175. (44, 97, 99, 130, 133)

Billingham, R. E., Brent, L., and Medawar, P. B. (1953). 'Actively acquired tolerance of foreign cells.' Nature, Lond., 172, 603 (170)

Bishopp, F. G., and Smiтh, G. N. (1938). 'The American dog tick, eastern carrier of Rocky Mountain spotted fever.' Circ. U.S. Dep. Agric., No. 478, 1. $(143)$

Bittner, J. J. (1937). 'Mammary tumours in mice in relation to nursing.' Amer. F. Cancer, 30, 530. (121)

Blumenthal, H. (1945). 'The ageing process in the endocrine glands of the guinea pig. I. The influence of age, sex and pregnancy on the mitotic activity and the histological structure of the thyroid, parathyroid and adrenal glands.' Arch. Path., 40, 284. (167, 173).

Blunck, H. (1924). 'Lebensdauer, Fortpflanzungsvermögen und Alterserscheinungen beim Gelbrand (Dytiscus marginalis L.).' Zool. Anz., 58, 163. $(57,97,130)$

Bodenheimer, F. S. (1938). Problems of animal ecology. Oxford University Press. $(18,24,44)$

Bodenstein, D. (1943a). 'Factors influencing growth and metamorphosis of the salivary gland in Drosophila.' Biol. Bull. Wood's Hole, 84, 13. (148) 


\section{Bibliography}

Bodenstein, D. (1943b). 'Hormones and tissue competence in the development of Drosophila.' Biol. Bull. Wood's Hole, 84, 35. (148)

(1953). 'Endocrine control of metamorphosis.' Proc. IX Int. Cong. Entom. Amsterdam, 1951. (148)

Boegker, E. (1914). 'Depression und Missbildungen bei Hydra.' Zool. Anz., 44, 75. (81)

Bogomolets, A. A. (1947). The prolongation of life. Duell Sloan and Pearce. New York, 1946. (7)

Bonnet, P. (1935). 'La longévité chez les araignées. Bull. Soc. ent. Fr., 40, 272. $(56,57)$

Boothby, W. M., Berkson, J., and Dunn, H. L. (1936). 'Studies of the energy metabolism of normal individuals.' Amer. F. Physiol., 116, 468. (33)

BoRISENKo, Е. Ya. (1939). Борігенко, Е.Я.: 'Блияние условий развития на последствия инбридинга.' (Influence of conditions of development on the effects of inbreeding). Yarovizatsiya, 5-6, 162. (129)

(1941). 'К вопросу об инбридинге в животноводстве.' (On inbreeding in animal husbandry.) Trud. sel.-Khoz. Acad. Timiryazeva, 5, 5. (129)

Borssuk, R. A. (1935). 'Untersuchung des Verlustes der Regenerationsfähigkeit der hinteren Extremität von Rana temporaria.' Arch. EntrwMeck. Org., 133, 349. (182)

Bounhiol, J. (1938). 'Recherches expérimentales sur la déterminisme de la métamorphose chez les Lepidoptères.' Biol. Bull. Suppl., 24, 1. (147)

Bourlière, F. (1946). 'Longévité moyenne et longévité maximum chez les vertébrés.' Année Biol., Paris, 22, 10. (53)

(1947). 'Quelques remarques sur la longévité des petits mammifères sauvages.' Mammalia, 11, 111. (47)

(1950). 'Sénescence et vitesse de cicatrisation chez le rat.' Rev. med. Liège, 5, $669(26,156)$

(1951). Vie et moeurs des mammifères. Payot, Paris. (48)

Bowerman, W. G. (1939). 'Centenarians.' Trans. Actuarial Soc. Amer., 40, 360. (61)

Boycotт, A. E. (1936). 'Habits of freshwater mollusca in Britain.' 7. Anim. Ecol., 5, 116. (102)

Bresslau, E. (1928-33). Turbellaria: in Kükenthal, W., and Krumbach, T. Handbuch der Żoologie, II. $(56,84)$

Brien, P. (1953). 'La pérennité somatique.' Biol. Rev., 28, 308. (82, 163)

Brockmeier, H. (1896). 'Beiträge zur Biologie unsere Süsswassermollusken.' Nchrbl. dtsch. malak. Ges., 57, (58)

Brody, S. (1924). 'The kinetics of senescence.' F. gen. Physiol., 6, 245. (8)

(1945). Bioenergetics and Growth. Baltimore. (63)

Brody, S., Ragsdale, A. C., and Turner, C. W. (1923). 'The rate of growth of the dairy cow. IV. Growth and senescence as measured by the size and fall of milk secretion with age.' F. gen. Physiol., 6, 31. (26) 


\section{Bibliography}

Brown, G. W., and Flood, M. M. (1947). 'Tumbler mortality.' F. Amer. Statist. Ass., 42, 562. (22, 23)

Brown, M., Sinclair, R. G., Gronk, L. B., and Glark, G. G. (1948). 'Some remarks on premature aging in the Eskimos.' Rév. Canad. Biol., 7, 178. (134)

Bruge, H. M., and Hindle, E. (1934). 'The golden hamster, Cricetus (Mesocricetus) auratus Waterhouse. Notes on its breeding and growth.' Proc. zool. Soc. Lond., p. 364. (47)

Bruch, H. (1941). 'Obesity in relation to puberty.' F. Pediat., 19, 365. (152)

Buchanan, J. W. (1938). 'Developmental acceleration following inhibition.' F. exp. Zool., 79, 109. (156)

Bucher, N. L. R., and Guinos, A. D. (1950). 'The effect of age on the regeneration of rat liver.' Cancer Res., 10, 324. (155)

Bucher, N. L. R., Scott, J. F., and Aub, J. C. (1950). 'Regeneration of liver in parabiotic rats.' Cancer Res., 10, 207. (156)

Bull, H. O. (1934). 'Aquarium observations on the rate of growth and enemies of the common starfish (Asterias rubens L.).' Rep. Dove Marine Lab., 3rd series, 2, 60. (58)

(1938). 'The growth of Psammechinus miliaris (Gml) under aquarium conditions.' Rep. Dove Marine Lab., 6, 39. (58)

Bullough, W. S. (1949). 'Age and mitotic activity in the male mouse, Mus musculus L.' F. exp. Biol., 26, 261. (156)

Burger, M. (1954). Altern und Krankheit. 2. Aufl. Leipzig: Georg Thiene. $(4,8,84,156,190)$

BURT, W. H. (1940). 'Territorial behavior and populations of some small mammals in southern Michigan.' Misc. Publ. Mus. Zool. Univ. Mich., 45, 1-58. (109)

Butschl, O. (1882). 'Gedanke über Leben und Tod.' Zool. Anz., 5, 64. (164)

Buxton, J. (1950). The redstart. London: Collins. (109)

Gagle, F. R. (1946). 'Growth of the slider turtle, Pseudemys scripta elegans.' Amer. Midl. Nat., 36, 685. (7\%)

Galkins, G. N. (1919). 'Uroleptus mobilis Eng. II. Renewal of vitality through conjugation.' (116)

Cамвoú́, P. (1926). 'Prolongation de la vie chez les papillons décapités.' C.R. Soc. Biol., Paris, 183, 372. (99)

Campbell, J., Davidson, I. W. F., Snair, W. D., and Lei, H. P. (1950). 'Diabetogenic effect of purified growth hormone.' Endocrinology, 46, 273. (186)

Campbell, P. N., and Work, T. S. (1953). 'Biosynthesis of proteins.' Nature, Lond., 171, 997. (169)

Carlson, A. J., and Hoelzel, F. (1947). 'Growth and longevity of rats fed omnivorous and vegetarian diets.' 7 . Nutrit., 34, 81 . 


\section{Bibliography}

Garlson, A. J. and Hoelzel, F. (1948). 'Prolongation of the life span of rats by bulk formers in the diet.' 7 . Nutrit., 36, 27.

(1946). 'Apparent prolongation of the life-span of rats by intermittent fasting.' (151)

Garr, C. J., King, J. T., and Visscher, M. B. (1949). 'Delay of senescence infertility by dietary restriction.' Feder. Proc., 8, 22. (151)

Carrel, A. (1912). 'On the permanent life of tissues outside the organism.' J. $\exp . M e d, 15,516 .(9,10)$

CArrel, A., and Eberling, A. H. (1921). 'Antagonistic growth principles of serum and their relation to old age.' J. exp. Med., 38, 419. $(8,10,154$, 156)

Castle, W. E. (1929). 'A further study of size inheritance in rabbits, with special reference to the existence of genes for size characters.' 7 . exp. Zool., 53, 421.

Ghamberlain, T. K. (1933). 'Age and shell measurements of two large specimens of Megalonaias gigantea Barnes.' Nautilus, 47, 29. $(58,107)$

Chang, H. S. (1951). 'Age and growth of Callionymus lyra L.' 7. mar. Biol. Ass. U.K., 30, 281. (69)

Gheymol, J., and Pelou, A. (1944). 'La réspiration du muscle du lapin suivant l'âge.' C.R. Soc. Biol., Paris, 138, 91. (32)

Ghiefri, M. (1949). 'Effect of testosterone administration on the beard growth of elderly males.' 7. Gerontol., 4, 200. (178)

(1950). 'An investigation of the effects of parenteral and topical administration of steroids on the elastic properties of senile skin.' $\mathcal{F}$. Gerontol., 5, 17. (178)

(1951). 'The effect of topical oestrogen application on the elastic properties of the skin of elderly men.' 7. Gerontol., 5, 387. (178)

CHILD, C. M. (1911). 'A study of senescence and rejuvenation based on experiments with planarians.' Arch. EntwMeck. Org., 31, 537. (83)

(1913). 'The asexual cycle in Planaria velata in relation to senescence and rejuvenescence.' Biol. Bull. Wood's Hole, 25, 181. (83)

(1914). 'Asexual breeding and prevention of senescence in Planaria velata.' Biol. Bull. Wood's Hole, 26, 286. (83)

(1915). Senescence and rejuvenescence. Chicago: University of Chicago Press. $(9,10,32,81,83,115)$

(1918). 'Physiological senescence in hydromedusae.' Biol. Bull. Wood's Hole, 34, 49. (32, 81, 83)

Gнolodkowsky, N. (1882). 'Tod und Unsterblichkeit in der Tierwelt.' Zool. Anz., 5, 264. (8)

Christopherson, J. B. (1924). 'Longevity of parasitic worms: the term of living existence of Schistosoma haematobium in the human body.' Lancet, p. 742 . (56)

CHu, J. (1934). 'Reproduction, life span, growth and senescence of Brachionus.' Sci. Rep. Univ. Chekiang, No. 1. (59) 


\section{Bibliography}

Clark, T. B. (1940). 'The relation of production and egg weight to age in White Leghorn fowls.' Poultry Sci., 14, 54. $(26,63)$

Clarke, J. M., and Maynard Smith, J. (1955). 'The genetics and cytology of Drosophila subolsana. XI. Hybrid vigour and longevity.' 7. Genet., 53, 172. (128)

Clarke, M. F., and Smith, A. (1938). 'Recovery following suppression of growth in the rat.' $\mathcal{F}$. Nutrit., 15, 245. (156)

Clemente, C. D., and Windle, W. F. (1955). 'Regeneration of severed nerve fibres in the spinal cord of the adult cat.' $\mathcal{J}$. compar. Neurol., 101, 691. (163)

Cleveland, L. R. (1938). 'Longitudinal and transverse division in two closely-related flagellates.' Biol. Bull. Wood's Hole, 74, 1. (116)

Cohn, A. E., and Murray, H. A. (1925). 'The negative acceleration of growth with age, as demonstrated by tissue culture.' 7 . exp. Med., 42, 275. $(31,155)$

Coker, R. E., Shira, A. F., Clark, H. W., and Howard, A. D. (1919-20). 'Natural history and propagation of the freshwater mussels.' Bull. U.S. Bureau Fish, 37, 75. (107)

Collinge, W. E. (1944). 'Notes on the terrestrial Isopoda (Woodlice).' Northw. Nat., 19, 112. (57)

Comfort, A. (1953). 'Absence of a Lansing effect in Drosophila subobscura.' Nature, Lond., 172, 83. (125)

(1954). 'Biological aspects of senescence.' Biol. Revs., 29, 284. (4)

(1955). 'Maximum ages reached by domestic cats.' 7 . Mammal., 34, (4) in press. $(47,49)$

Conant, R., and Hudson, R. G. (1949). 'Longevity records for reptiles and amphibia in the Philadelphia Zoological Garden.' Herpetologia, San Diego, 5, 1-8. (51, 52)

Cori, C. I. (1925). 'Morphologie und Biologie von Apsilus vorax.' Z. wiss. Zool., 125, 557. $(59,86,88)$

Cotes, P. M., Reid, E., and Young, F. G. (1949). 'Diabetogenic action of pure anterior pituitary growth hormone.' Nature, Lond., 164, 209. (186)

Coutelen, F. (1935). 'La longévité de la filaire Loa loa (Guyet 1778) et des embryons de filaires.' Bull. Soc. Path. exot., 28, 126. (56)

Coutelen, F., Razèmon, P., and Biguet, J. (1950). 'La longévité des échinocoques-étude critique.' Ann. Parasitol., 25, 267. (56)

Cowdry, E. V. (1952). In Lansing, A.I., Problems of Ageing. Baltimore: Williams and Wilkins Co. (35)

CrabB, E. D. (1929). 'Growth of a pond snail, Limnaea stagnalis appressa, as indicated by increase in shell size.' Biol. Bull. Wood's Hole, 56, 41. (103)

Crocker, W. (1939). 'Ageing in plants.' In Cowdry, E. V., Problems of Ageing, 1st edn. (4, 120)

Crowell, S. (1953). 'The regression-replacement cycle of hydranths of Obelia and Campanularia.' Physiol. Zool., 26, 319. (82)

Cú́not, L. (1911). La genèse des espèces animales. Paris. $(58,105)$ 


\section{Bibliography}

Dalyell, J. G. (1848). Rare and remarkable animals of Scotland, ii, ch. 10. London. $(56,81)$

DÁrÁNYI, G. (1930). 'Fejlödés, fajfenntartás és ơregedés a természetben.' Term. Tud. Közl., 62, 305. (7)

Darlington, C. D. (1948) .'The plasmagene theory of the origin of cancer.' Brit. 7. Cancer, 2, 118. (120)

Darlington, C. D., and Mather, K., 1949). The elements of genetics. London: Allen and Unwin. (120)

Darwin, C. (1874). The descent of man. London: John Murray. (130)

Dathe, H. (1935). Zool. Garten. Lpz., 7, 303 (79)

Davaine, C. (1887). Traité des Entozoaires et des maladies vermineuses de l'homme et des animaux domestiques. 2nd edn., Paris: Baillière. (56)

DAvid, K. (1925). 'Zur Frage der potentiellen Unsterblichkeit der Metazoen.' Zool. Anz., 64, 126. (82)

Dawidoff, C. (1924). 'Sur le retour d'une Némerte, Lineus lacteus, en inanition, à un état embryonnaire.' C.R. Acad. Sci., Paris, 179, 1222. (84)

Deansley, R. (1938). 'The reproductive cycle of the golden hamster (Cricetus auratus).' Proc. Zool. Soc. Lond., p. 31. (47)

Deck, R. S. (1936). 'Longevity of Terrapene carolina Linn.' Copeia, 160, 179. (52)

Deevey, E. S. (1947). 'Life tables for natural populations of animals.' Quart. Rev. Biol., 22, 283. (70)

Deevey, G. B., and Deevey, E. S., Jr. (1945). 'A life table for the black widow.' Trans. Conn. Acad. Arts Sci., 36, 115. (4, 44, 130, 131)

Delage, Y. (1903). L'hérédité et les grandes problèmes de la biologie. Paris. (8)

Demange, E. (1886). Études cliniques et anatomopathologiques de la vieillesse. Paris: Baillière. (7)

DenfFer, D. V. (1948). 'Über einen Wachstumshemmstoff in alternden Diatomeenkulturen.' Biol. Zbl., 67, 7-13. (151)

De WitT, R. M. (1954). 'Reproductive capacity in a pulmonate snail, Physa gyrina Say.' Amer. Nat., 88, 159. (58, 103)

Dhar, N. H. (1932). 'Senescence, an inherent property of animal cells.' Quart. Rev. Biol., 7, 70. (7)

Didlake, M. L. (1937). In Needham, J. G. (Ed.). Culture methods for invertebrate animals. New York: Comstock. p. 244. (56)

Ditmars, R. L. (1934). 'A review of the box turtles.' Zoologica, N.Y., 17, 1. (51)

Dobers, E. (1915). 'Biologie der Bdelloidea.' Int. Rev. Ges. Hydrobiol., Ser. 6, suppl. 7. $(59,87)$

Dомм, L. V. (1934). 'The precocious development of sexual characters in the male chick by daily injections of thebin.' Anat. Rec., 58, 6. (179)

Donaldson, H. H. (1924). 'The Rat.' Mem. Wistar Inst. Philadelphia, No. 6. $(47)$

Donisthorpe, H. (1936). 'The oldest insect on record.' Ent. Rec., 48, 1. (57) 209 


\section{Bibliography}

Dowdeswell, W. H., Fisher, R. A., and Ford, E. B. (1940). 'The quantitative study of populations in the Lepidoptera. I. Polyommatus icarus Rott.' Ann. Eugen., Camb., 10, 123. (112)

Draper, C. G., and Davidson, G. (1935). 'A new method of estimating the survival rate of anopheline mosquitoes in nature.' Nature, Lond., 172, 503.

Dribben, I. S., and Wolfe, J. M. (1947). 'Structural changes in the connective tissue of the adrenal glands of female rats associated with advancing age.' Anat. Rec., 98, 557. (173)

Driesch, H. (1941). 'Zur Problematik des Alterns.' Z. Altersforsch., 3, 26. $(8,190)$

Dublin, L. I., Lotka, A. J., and Spiegelman, M. (1949). Length of Life: a study of the life table. New York: Ronald Press Co. $(21,112,123)$

Duetz, G. H. (1938). 'Comments on longevity and average exhibition ages during the year 1937.' Lab. Rep. zöol. Soc. Philadelphia, 66, 31. (46, 47)

(1939). 'Revised tables of maximum exhibition periods for animals in the Philadelphia Collection.' Ibid., 67, 22. (46)

(1940). Ibid., 68, 26. (46)

(1942). Ibid., 70, 23. (46, 47)

Dunham, H. H. (1938). 'Abundant feeding followed by restricted feeding and longevity in Daphnia.' Physiol. Zoöl., 11, 399. (44, 145)

Dunn, C. W. (1946). 'Endocrines in senescence.' Clinics, Phil., 5, 847. (7)

Duran-Reynals, F. (1940). 'Neutralisation of tumour viruses by the blood of normal fowls of different ages.' Yale F. Biol. Med., 13, 61. (169)

EdLÉN, A. (1937). 'Experimentelle Wachstumstudien an Daphnia magna.' Lunds Univ. Arsberätt (Avd. 2) 34, 1. (32)

(1938). 'Geburt, Geschlechtsreife und Vermehrung in Beziehung zum Wachstumsverlauf bei Daphnia magna.' Arch. EntwMeck., 137, 804. (32, 93, 94. 95)

Edmonds, T. R. (1832). 'Life tables founded upon the discovery of a numerical law, etc.' London: J. Duncan. (152)

Edmondson, W. T. (1945a). 'Ecological studies of sessile Rotatoria.' Ecol. Monogr., 14, 15. (44)

(1945b). 'Ecological studies of sessile Rotatoria. II.' Ecol. Monogr., 15, 141. $(44,59,113)$

Edney, J. M., and Allen, W. R., (1951). 'Age of the box turtle, Terrapene carolina carolina L.' Copeia, 312, 644. (51, 52)

EJIRI, J. (1936). 'Studien über die Histologie der menschlichen Haut. II. Über die Alters und Geschlechtsverschiedenheiten der elastischen Fäsern.' Jap. 7. Derm. Urol., 40, 173. (169)

Elman, R. (1953). 'Surgical problems in the aged.' In Cowdry, E. V. Problems of Ageing, 2nd edn., 1953. (156)

Elton, C. (1942). Voles, mice and lemmings. Problems in population dynamics. Oxford: Clarendon Press. (109) 


\section{Bibliography}

ENGLe, E. T. (1944). 'The menopause, an introduction.' F. clin. Endocrin., 4, 567. (180)

Escomel, E. (1939). 'La plus jeune mère du monde.' Pr. méd., 47, 875. (179)

Evans, H. M., Simpson, M. E., and Li, C. H. (1948). 'The gigantism produced in normal rats by injection of the pituitary growth hormone. I. Body growth and organ changes.' Growth, 12, 15. (152)

Evans, H. M., Simpson, M. E., and Pencharz, R. I. (1939). 'Relation between the growth-producing effects of the pituitary and the thyroid hormone.' Endocrinology, 25, 175. (161, 185)

Evans, R., Cowdry, E. V., and Nielson, P. E. (1943). 'Ageing of human skin.' Anat. Rec., 86, 545. (26)

FARner, D. S. (1945). 'Age groups and longevity in the American robin.' Wilson Bull., 57, 56. (109)

FAURÉ-Frémiet, E. (1953). 'L'hypothèse de la senescence et les cycles de réorganisation nucleaire chez les Ciliés.' Rev. suisse Zool., 60, 426. (118)

FeDERLey, H. (1929). Über subletale und disharmonische Chromosomenkombinationen.' Hereditas, 12, 271. (132)

Felin, F. E. (1951). 'Growth characteristics of the poeciliid fish, Platypoecilus maculatus.' Copeia, p. 15. (69)

Ferris, J. G. (1932). 'Comparison of the life histories of mictic and amictic females in the rotifer, Hydatina senta.' Biol. Bull. Wood's Hole, 63, 442. $(59,66)$

FindLEY, T. (1949). 'Role of neurohypophysis in the pathogenesis of hypertension and some allied disorders associated with ageing.' Amer. 7. Med., 7, 70. (7)

Fischer-Piette, E. (1939). 'Sur la croissance et la longévité de Patella vulgata L. en fonction du milieu.' F. Conchyl., Paris, 83, 303. (58, 106, $10 \%, 108,112)$

Fisher, I. (1923). Report on national vitality, its wastes and conservation. Washington. (61)

Fitzinger, L. J. F. J. (1853). Versuch einer Geschichte der Menagerien des Osterreichisch-Kaiserlichen Hofes. Vienna. $(49,64)$

Flower, S. S. (1922). 'Longevity of molluscs.' Cairo Sci. F., 10, 115. (58)

(1925). 'Contributions to our knowledge of the duration of life in vertebrate animals.' (46)

'I. Fishes.' Proc. zool. Soc. Lond., 247. (70)

'II. Batrachians.' Ibid., 269. (52)

'III.Reptiles.' Ibid., 911. (45, 52)

'IV. Birds.' Ibid., 1365. (49)

(1931). ' 'V. Mammals.' Proc. zool. Soc. Lond., 145. (45, 46, 48)

(1935). 'Further notes on the duration of life in animals.'

'I. Fishes.' Proc. zool. Soc. Lond., 265. (46, 53, 68)

(1936). 'II. Amphibians.' Proc. zool. Soc. Lond., 369. (46, 52) 


\section{Bibliography}

Flower, S. S. (1937). 'III. Reptiles.' Proc. zool. Soc. Lond., 1. (45, 46, 52, 78)

(1938). 'IV. Birds.' Proc. zool. Soc. Lond., A, 195. (46, 49, 64)

(1945). 'Persistent growth in the tortoise, Testudo graeca, for 39 years, with other notes concerning the species.' Proc. zool. Soc. Lond., 114, 451. (45)

FoA, C. (1900). 'La greffe des ovaires en rélation avec quelques questions de biologie générale.' Arch. ital. Biol., 34, 43. (179)

(1901). 'Sur la greffe des ovaires.' Arch. ital. Biol., 35, 364. (179)

Forster, A. (1945). 'Longevity.' Brit. med. F., ii, 545. (60)

Foster, T. D. (1932). 'Observations on the life history of a fingernail shell of the genus Sphaerium.' 7. Morph., 53, 473. (103)

(1936). 'Size of shell in land snails of the genus Polygyra with particular reference to major and minor varieties.' Amer. Midl. Nat., 17, 978. (104)

Freud, J., Levie, L. H., and Kroon, D. B. (1939). 'Observations on growth (chorionotrophic) hormone and localization of its point of attack.' $\mathcal{J}$. Endocrin., 1, 56. (185)

Freud, J., and Uyldert, E. (1947). 'A new idea about senility.' Acta brev. neerl. Physiol., 14, 18. (169)

Freudenberg, K. (1951). 'Die natürliche Lebensdauer des Menschen.' Z. Altersforsch., 5, 241. (60, 195)

FrIEDEL, E. (1880). 'Die lebenden Wasserthiere auf der Internationalen Fischerei-Ausstellung zu Berlin im Jahre 1880.' Zool. Gart., 21, 323. (57)

FrITSGH, R. H. (1953). 'Die Lebensdauer von Daphnia spec. bei verscheidener Ernährung usw.' Z. wiss. Zool., 157, 35. (92, 145)

Frohawk, F. W. (1935). 'Feeding butterflies in captivity.' Entomologist, 68, 184. $(5 \%, 98)$

Frost, W. E. (1943). 'The natural history of the minnow, Phoxinus phoxinus.' 7. Anim. Ecol., 12, 139. (70)

(1954). 'The food of pike, Esox lucius L., in Windermere'' 7. Anim. Ecol., 23, 339. (71)

Frost, W. E., and Smyly, W. J. P. (1952). 'The brown trout of a moorland fishpond.' 7. Anim. Ecol., 21, 71. (70, 71)

Gaillard, P. J. (1942). Hormones regulating growth and development in embryonic explants. Paris: Hermann. (170)

Galea, P. H. (1936). 'Longevity of a mule.' Field, 1936, p. 1556. (48)

Gardner, G., and Hurst, H. (1933). 'Life-tables for white Leghorn chickens in the State of Utah.' Proc. Utah Acad. Sci., 10, 149. (43)

Gardner, T. S. (1946). 'The effect of yeast nucleic acid on the survival time of 600 day old albino mice.' 7. Gerontol., 1, 445.

Gardner, T. S., and Forbes, F. B. (1946). 'The effect of sodium thiocyanate and yeast nucleic acid on the survival time of 700 day old albino mice.' 7. Gerontol., 1, 453. 


\section{Bibliography}

Gardner, W. K. (1952). 'Some endocrinological aspects of ageing.' $\mathcal{J}$. Gerontol., 7, 293. (180)

Gates, W. H. (1926). 'The Japanese waltzing mouse.' Publ. Carneg. Instn., 337, 83. (127)

Geiser, S. W. (1924-5). 'The differential death-rate of the sexes among animals.' Wash, Univ. Stud., 12, 73. (130)

Georgiana, M. (1949). 'Longevity of the parasitic wasp, Habrobracon juglandis Ashmead.' Amer. Nat., 83, 39. (7, 130)

GEy, G. O. (1952). 'Cellular gerontologic research.' 7. Gerontol., 7, 294. (171)

Geyer, D. (1909). Die Weichtiere Deutschlands. Stuttgart. $(58,107)$

GLey, E. (1922). 'Sénescence et endocrinologie.' Bull. Acad. Méd. Paris, 87, 285. (7)

GlezinA, O. M. (1939). 'Age changes in oxidation-reduction processes in the muscle tissue of birds.' Biokhim. Zh., 13, 105. (32)

Glinos, A. D., and Bartlett, E. G. (1951). 'The effect of regeneration on the growth potential in vitro of rat liver at different ages.' Canc. Res., 11, 164. (155)

Guinos, A. D., and Gey, G. O. (1952). 'Humoral factors involved in the induction of liver regeneration in the rat.' Proc. Soc. exp. Biol. N.Y., 80, 421. (156)

Glover, J. W. (1921). U.S. life tables, 1890, 1901, 1910 and 1901-10, p. 301 (U.S. Bureau of Census).

Goztsch, W. (1922). 'Lebensdauer und Geschlechtlige Fortpflanzung bei Hydra.' Biol. Zbl., 42, 231. (82)

(1925). 'Beiträge zum Unsterblichkeitsproblem der Metazoen. V.' Biol. Zbl., 45, 192. (82)

(1940). Vergleichende Biologie der Insektenstaaten. Leipzig. (57)

Goldschmidt, J., Hoffman, R., and Doljansky, L. (1937). 'Étude comparative sur la durée de la période de latence pour la croissance des tissus embryonnaires et adultes explantés in vitro'. C.R. Soc. biol., Paris, 126, 389.

Goldsmith, E. D. (1942). 'Sexuality in Dugesia trigrina (syn. Planaria maculata).' Nature, 150, 351. (56)

Goldsmith, E. D., Nigrelli, R. F., Gordon, R. S. Charipper, H. A., and GoRdon, M. (1944). 'Effect of thiourea upon fish development.' Endocrinol., 35, 132. (161)

Goldziener, J. W. (1949). 'The direct effect of steroids on the senile human skin.' 7. Gerontol., 4, 104.

Goldziener, J. W., and Goldziener, M. A. (1950). 'Effect of steroids on the ageing skin.' f. Gerontol., 5, 385. (178)

Gonzalez, B. M. (1923). 'Experimental studies on the duration of life. VIII. The influence upon duration of life of certain mutant genes of Drosophila melanogaster.' Amer. Nat., 57, 289. $(44,121)$ 


\section{Bibliography}

Gould, G. M., and Pyle, W. T. (1898). Anomalies and curiosities of medicine. London: Rebman. (62)

Gould, R. T. (1945). Enigmas. London: Bles (2nd edn.). (62)

Gowen, J. W. (1931). 'On chromosome balance as a factor in duration of life.' J. gen. Physiol., 14, 447. (130)

(1934). 'The gene in pathology.' Cold Spr. Harb. Symp. quant. Biol., 2, 128. (130)

GraD, B. (1953). 'Changes in oxygen consumption and heart rate of rats during growth and ageing; role of the thyroid gland.' Amer. 7. Physiol., 174, 481. (187)

Grave, B. H. (1928). 'Natural history of the shipworm, Teredo navalis, at Wood's Hole, Mass.' Biol. Bull., 55, 260. (103)

Green, J. (1954). 'Size and reproduction in Daphnia magna.' Proc. zool. Soc., Lond., p. 535. (127)

Greene, R., and Paterson, A. S. (1943). 'Sudden senescence.' Lancet, ii, 158. (135)

Greenwood, A. W. (1932). 'The value of progeny in relation to age of dam.' Harper-Adams Util. Poult. 7., 17, 478. (124)

Greenwood, M., and Irwin, J. O. (1939). 'The biostatistics of senility.' Hum. Biol., 11, 1. (60)

Greville, T. N. E. (1946). United States life tables and actuarial tables, 193941. Bureau of the Census, Washington. (40)

Griffin, C. E. (1928). 'The life history of automobiles.' Michigan Business Studies (Univ. Mich.), vol. 1. (33)

Griffiths, J. T., and TAuber, O. E. (1942). 'Fecundity, longevity and parthenogensis of the American roach (Periplaneta americana L.).' Physiol. Zool., 15, 196. (44, 99)

Grimm, H. (1949). 'Wachstumsfördernde und wachstumshemmende Stoffe im menschlichen Blutserum.' Z. Altersforsch., 5, 197. (155)

Grobstein, C. (1947). 'The role of androgen in the declining regenerative capacity during morphogenesis of the Platypoecilus maculatus gonopodium.' 7. exp. Zool., 106, 313. (182)

Gross, J. (1925). 'Versuche und Beobachtungen über die Biologie der Hydriden.' Biol. Zool., 45, 192. (82)

Gross, J., and Sснмттт, F. O. (1948). 'The structure of human skin collagen as studied with the electron microscope.' $7 . \exp$. Med., 88, 555. (169)

Gross, J., and Schmitt, F. O. (1950). 'Connective tissue fine structure and some methods for its analysis.' 7. Geront., 5, 343. (169)

GrüneberG, H. (1951). The genetics of the mouse. The Hague. (43, 121, 122)

(1954). 'Variation in inbred lines of mice.' Nature, Lond., 173, 674. (136)

Gudernatsch, J. F. (1912). 'Feeding experiments on tadpoles. I. The influence of certain organs given as food on differentiation.' Arch. EntwMeck. Org., 35, 57. (139) 


\section{Bibliography}

Guilbert, H. R., and Goss, H. (1932). 'Some effects of restricted protein intake on the oestrous cycle and gestation in rats.' 7 . Nutrit., 5, 215. (151)

Gumbell, E. J. (1938). 'La durée extrême de la vie humaine.' Actualités Sci. Indust., 520, 1. (63)

Gurney, J. H. (1899). 'On the comparative ages to which birds live.' Ibis, p. $19-42$. (49)

Guthrie, D. M. (1953). Personal communication. (113)

Haemmerling, J. (1924). 'Die ungeschlechtliche Fortpflanzung und Regeneration bei Aeolosoma lemprichii.' Zool. Fb. (1. Abt.), 41, 581. (83) von Hagen, W. (1938). 'Contribution to the biology of Nasutitermes s.s.' Proc. zool. Soc. Lond., 108, A, 39. (57)

HaKh, I. W. D., and Westling, E. H. (1934). 'A possible cause of old age.' Science, 79, 231. (7)

Haldane, J. B. S. (1941). New Paths in Genetics. London. (14, 39)

(1949). 'Paternal and fraternal correlations of fitness.' Ann. Genet., 14, 288. (123)

(1953). 'Some animal life-tables.' J. Inst. Actu., 79, 351. (19, 24)

Hall, G. O., and Marble, D. R. (1931). 'The relationship between the first year egg production and the egg production of later years.' Poultry Sci., $10,194$.

Hamai, I. (1937). 'Some notes on relative growth, with special reference to the growth of limpets.' Sc. Rep. Tohoku Imp. Univ. Biol., 12, 71. (106)

Hamburger, C. (1948). 'Normal urinary excretion of neutral 17-ketosteroids with special reference to age and sex variations.' Acta endocrinol., 1, 19. (172)

Hamilton, J. B. (1948). 'The role of testicular secretions as indicated by the effects of castration in man and by studies of pathological conditions and the short life span associated with maleness.' Recent Prog. Hormone Res., 3, 257. $(133,172,173,185)$

Hamilton, J. B., Catchpole, H. R., and Hawke, C. C. (1944). 'Titres of urinary gonadotropins in old eunuchs.' Anat. Rec., 88, 435. (181)

(1945). 'Titres of gonadotropins in urine of aged eunuchs.' 7. clin. Endocrinol., 5, 203.

Hamilton, J. B., and Hamilton, H. B. (1948). 'Ageing in apparently normal men. I. Urinary titres of ketosteroids and of $\alpha$ and $\beta$-hydroxyketosteroids.' 7. Clin. Endocrinol., 8, 433.

Hamilton, J. B., Hamilton, H. B., and Mestler, G. E. (1954). 'Ageing in apparently normal men. II. Androgenic activity of urinary ketosteroids and of their alpha and beta fractions.' 7. clin. Endoc. Metab., 14, 139. (172)

Hamilton, W. J. (1940). 'The biology of the smoky shrew (Sorex fumeus fumeus Miller).' Zoologica, N.Y., 25, 473.

Hammond, J., and Marshall, F. H. (1952). 'The life cycle.' In Marshall, Physiology of Reproduction. London: Longmans. (46) 


\section{Bibliography}

Hansard, S. L., Comar, C. L., and Davis, G. K. (1954). 'Effects of age upon the physiological behaviour of calcium in cattle.' Amer. F. Physiol., 177, 383. (169)

Hansemann, D. v. (1914). 'Über Alterserscheinungen bei Bacillus rossii.' Sitzb. Nat. Fr. Berlin, 187-191. (100)

Harms, J. W. (1926). Verjungung des Lebens. Senckenberg-Bücher II. Berlin: Bermuhler.

(1949). 'Altern und Somatod der Zellverbandstiere.' Z. Altersforsch., 5, 73. $(4,84,92,96)$

Harms, W. (1912). 'Beobachtungen über den naturlichen Tod der Tiere. I. Hydroides pectinata.' Zool. Anz., 40, 117.

Harris, J. A., and Benedict, F. G. (1921). 'A biometric study of basal metabolism in man.' Carnegie Inst. Wash. Publ., 303,

Hartlaub, C. (1916). 'Über das Altern einer Kolonie von Syncoryne.' Wiss. Meersuntersuch., 11. (82)

Hartmann, M. (1921). 'Untersuchungen über die Morphologie und Physiologie des Formwechsels der Phytomonadinen (Volvocales). III. Mitt. Die dauernd agame Zucht von Eudorina elegans: experimentelle Beiträge zum Befruchtungs- und Todproblem.' Arch. Protistenk., 43, 7. (117)

Hartzell, A. (1945). 'Thiourea (thiocarbamide)—adult life span feeding experiments in rats.' Conts. Boyce Thompson Inst., 13, 501. (153)

Harvey, P. A. In Kofoid, C. A. (1934). Termites and termite control, p. 227. Univ. California Press. (140)

Hase, A. (1909). 'Über die deutschen Süsswasserpolypen Hydra fusca.' Arch. f. Rassen- u. Gesellschafts-Biologie., 6, 721. (82)

HAšEк, M. (1953). 'Вегетативная гибрицизация животных путем соединения кровообращения в течение эмбрионального развития.' (Vegetative hybridization in animals through embryo parabiosis.) Česk. Biol., 2, 267. (129)

Haskins, H. H. (1954). 'Age determination in molluscs.' Trans. N.Y. Acad. Sci., 16, 300. (107)

Неснт, S. (1916). 'Form and growth in fishes.' 7. Morph., 27, 379. (68)

Heilbrunn, L. V. (1943). An outline of general physiology. 2nd edn. Philadelphia and London: Saunders.

Henderson, W. R., and Rowlands, I. W. (1938). 'The gonadotrophic activity of the anterior pituitary gland in relation to incteased intracranial pressure.' Brit. med. F., i, 1094. (181)

Herdan, G. (1952). 'Causes of excess male mortality in man.' Acta genet. Basel. 3, 351. (133)

Herrick, F. H. (1898). 'The American lobster.' Bull. U.S. Fish Comm., 15, 1. $(57,92)$

(1911). 'Natural history of the American lobster.' Bull. U.S. Bureau of Fisheries, 29, 149. (57) 


\section{Bibliography}

Hertig, A. T. (1944). 'The ageing ovary-a preliminary note.' 7 . clin. Endocrin., 4, 581. (180)

Hertwig, R. (1906). 'Über Knospung und Geschlechtentwicklung von Hydra fusca.' Biol. Zbl., 26, 489. (81)

Hertz, R., and Hisaw, F. L. (1934). 'Effects of follicle-stimulating and luteinizing pituitary extracts on the ovaries of the infantile and juvenile rabbit.' Amer. F. Physiol., 108, 1. (179)

Hervey, G. F., and Hems, J. (1948). The goldfish. London: Batchworth Press. $(73,74)$

Hevesy, G. (1947). 'Report of XIth Intl. Congress, Pure and Applied Chemistry.' Nature, Lond., 160, 247. (166)

Hevesy, G., and Ottesen, J. (1945). 'Life cycle of the red corpuscles of the hen.' Nature, Lond., 156, 534. (166)

Hildebrand, S. F. (1932). 'Growth of diamond-backed terrapins: size attained, sex ratio and longevity.' Zoologica, N.Y., 9, 551. (51, 78)

Hinton, M. A. C. (1925). Proc. Linn. Soc., 138, 18. (109)

(1926). Monograph of the voles and lemmings. London: British Museum. (109)

Hodge, G. F. (1894-5). 'Changes in human ganglion cells from birth to senile death. Observations on man and honey-bee.' F. Physiol., 17, 129. (97)

HofF, G. G. (1937). 'Studies on the Limnaeid snail Fossaria parva Lea.' Trans. Illinois Acad. Sci., 30, 303. (104)

Hoffman, R. S., Goldschmidt, J., and Doljanski, L. (1937). 'Comparative studies on the growth capacities of tissues from embryonic and adult chickens.' Growth, 1, 228. (155)

Holmgren, N. (1909). 'Termitenstudien.' Kon. Svensk. Vetensk. Akad. Handl., 44. (100)

Hopkins, H. S. (1924). 'Respiration in the tissues of mollusks in relation to age.' Anat. Rec., 29, 91. (32)

(1930). 'Age differences and the respiration of muscle tissue of mollusks.' F. exp. Zool., 56, 209. (32, 58, 106, 108)

Hopper, A. F. (1950). 'The effect of mammalian thyroid powder and thiouracil on growth rates and on the differentiation of the gonopod in Lebistes reticulatus.' Anat. Rec., 108, 66. (161)

Horst, K., Mendel, L. B., and Benedict, F. G. (1934). 'The influence of previous diet, growth and age upon the basal metabolism of the rat.' 7. Nutr., 8, 139. (150)

HoRst, van DER. (1929). 'Lebensalter und Schälengrösse.' Arch. Mollusk., 61, 46. (58)

Howard, L. O. (1939). 'Ageing of insects.' In Cowdry, E. V.: Problems of ageing. London: Baillière Tindall and Cox. (57)

Howes, E. L., and Harvey, S. C. (1932). 'Age factor in velocity of growth of fibroblasts in the healing wound.' $\mathcal{F}$. exp. Med., 55, 577. (156) 


\section{Bibliography}

Hsu, T. G., and Pomerat, C. M. (1953). 'Mammalian chromosomes in vitro. III. On somatic aneuploidy.' F. Morph., 93, 301. (168)

Hufeland, G. W. (1798). Makrobiotik, oder der Kunst das menschliche Leben $z u$ verlängern. Jena. $(22,112,134)$

(1829). The art of prolonging human life \&c. London: Simpkin Marshall. (Eng. trans. of foregoing.)

Hummel, K. P., and Barnes, L. L. (1938). 'Calcification of the aorta, heart and kidneys of the albino rat.' Am. F. Path., 14, 121. (150)

HunERHOFF, E. (1931). 'Über ein bisher unbekanntes Larvenorgan und die Regeneration bei Apsilus vorax.' Zool. Anz., 92, 327. (87)

Hunt, T. E. (1942). 'Mitotic activity in the anterior hypophysis of female rates.' Anat. Rec., 82, 263. (167)

(1943). 'Mitotic activity in the anterior hypophysis of mature female rats of different age groups and at different periods of the day.' Endocrinology, 32, 334. (167)

(1947). 'Mitotic activity in the anterior hypophysis of ovariectomized rats after injection of oestrogens.' Anat. Rec., 97, 127. (167)

Hunter, W. R. (1953). 'On the growth of the freshwater limpet, Ancylus fluviatilis.' Proc. Zool. Soc., Lond., 123, 623. (102)

Hutt, F. B. (1949). Genetics of the fowl. New York: McGraw-Hill.

Huxley, A. (1937). After many a summer. London: Ghatto and Windus.

Huxley, J. S. (1932). Problems of relative growth. London: Methuen. (68)

(1942). Evolution: the modern synthesis. London: Allen and Unwin. (191)

HuXley, J. S., and DE BEer, G. R. (1923). 'Studies in dedifferentiation-IV. Resorption and differential inhibition in Obelia and Campanularia.' Quart. 7. micr. Sci., 67, 473. (82)

Huxley, T. H. (1880). The Crayfish. Kegan Paul: London. (54)

Hvass, H. (1938). Zool. Garten, Lpz., 10, 229. (52)

Hyman, L. H. (1951). The Invertebrates. Vol. III. McGraw Hill Co.: London and New York. $(59,87,90,91)$

INGLE, L. (1933). 'Effects of environmental conditions on longevity.' Science, 78, 511. (143)

Ingle, L., Wood, T. R., and Banta, A. M. (1937). 'A study of the longevity, growth, reproduction and heart rate in Daphnia longispina as influenced by limitations in quantity of food.' F. exp. Zool., 76, 325. (26, 29, 32, 44, 93, 143, 144, 145, 146)

IseLy, F. B. (1931). 'A 15 year growth record in freshwater mussels (Quadrula).' Ecology, 12, 616. (58, 107)

Israel, W. (1913). Biologie der Süsswassermuscheln. Stuttgart. (58)

Jackson, C. H. N. (1940). 'The analysis of a tsetse fly population.' Ann. Eugen., Lond., 10, 332. (112) 


\section{Bibliography}

JAckson, C. M. (1936). 'Recovery in rats upon re-feeding after prolonged suppression of growth by dietary deficiency in protein.' Amer. F. Anat., 58, 179. (156)

Jalavisto, E. (1950). 'The influence of parental age on the expectation of life.’ Rév. Méd. Liège, 5, 719. (126)

JANET, C. (1904). Observations sur les fourmis. Limoges. (57)

JANISGH, E. (1924). 'Über die experimentelle Beeinflussung der Lebensdauer und des Alterns schädlicher Insekten.' Arb. Biol. Reichsart. f. Land.- u. Fortwirtschaft., 13, 173. (98)

JAyne, E. P. (1953). 'Cytology of the adrenal gland of the rat at different ages.' Anat. Rec., 115, 459. (167)

Jennings, H. S. (1945). 'Paramecium bursaria: life history. V. Some relations of external conditions, past or present, to ageing and to mortality of exconjugants, with summary of conclusions on age and death.' $\mathcal{F}$. exp. Zool., 99, 15. (114, 117, 118)

Jennings, H. S., and Lyngh, R. S. (1928). 'Age, mortality, fertility and individual diversity in the Rotifer Proales sordida Gorse. II.' 7. exp. Zool., 51, 339. $(44,59,85,86,89)$

Jickel, G. F. (1902). Die Unvolkommenheit des Stoffwechsels als Veranlassung für Vermehrung usw. Friedländer: Berlin. $(7,35)$

Joedrake, P. (1919). 'Ein Beitrag zum eunuchoiden Riesenwuchs.' Z. ges. Neurol. Psychiat., 44, 385. (185)

John, D. D. (1937). 'Antarctic whales.' F. Soc. Pres. Fauna Emp., 31, 15. $(47)$

JurGzýx, C. (1926). 'Zur Regeneration bei Stephanocerus.' Zool. Anz., 67, 333. $(87)$

(1927). 'Beiträge zur Morphologie, Biologie and Regeneration von Stephanocerus fimbriatus Goldfuss. Z. wiss. Zool., 129, 103. (87)

Kallman, F. J., and Sander, G. (1948). 'Twin studies on ageing and longevity.' $\mathcal{F}$. Hered., 39, 349. (122)

(1949). 'Twin studies in senescence.' Amer. F. Psychiat., 106, 29. (122)

Kassowrtz, M. (1899). Allgemeine Biologie. Vienna. (7, 32)

Kelley, R. B. (1939). 'Female aspects of relative fertility in sheep.' Aust. vet. 7., 15, 184.(43)

KenYon, A. T. (1942). 'The comparative metabolic influences of testicular and ovarian hormones in man.' Biol. Sympos., 9, 11. (178)

Kershaw, W. E., Lavoipierre, M. M. J., and Chalmers, T. A. (1953). 'Studies on the intake of microfilariae by their insect vectors, their survival, and their effect on the survival of their vectors. I. Dirofilaria immitis and Aedes aegypti.' Ann. trop. Med. Parasitol., 47, 207. (44)

Keys, A. B. (1928). 'The weight-length relation in fishes.' Proc. nat. Acad. Sci., Wash., 14, 922. (68)

KING, H. D. (1915). 'Growth and variability in body weight of the albino rat.' Anat. Rec., 9, 751. 


\section{Bibliography}

KING, H. D. (1939). Life processes in gray Norway rats during 14 years in captivity.' Amer. anat. Mem., 17, 1.

KING, J. T., and Visscher, M. B. (1950). 'Longevity as a function of diet in the C3H mouse.' Feder. Proc., 9, 70. (150)

KING, W. G. (1911). Census of England and Wales, 7, 46. (59, 61)

KinSELL, L. W. (1953). 'Hormonal regulation of human growth.' In Protein metabolism, hormones and growth. Rutgers Univ. Press: New Jersey. (183, 185)

KIRK, E., and Kvorning, S. A. (1949). 'Quantitative measurement of the elastic properties of the skin and subcutaneous tissue in young and old individuals.' F. Gerontol., 4, 273. (26)

KIRK, J. E. (1948). 'The acid phosphatase concentration of the prostatic fluid in young, middle-aged and old individuals.' 7 . Gerontol., 3, 98. $(178)$

(1949). 'The effect of testosterone administration on the acid phosphatase concentration of the prostatic exprimate in old men.' Urol. cutan. Rev., 53, 683. (172, 178)

(1949). 'The urinary excretion of neutral 17-ketosteroids in middleaged and old men.' 7. Gerontol., 4, 34. (173)

(1951). 'Steroid hormones and ageing.' A review. 7. Gerontol., 6, 253.

Kirkland, H. T. (1928). 'A case of schistosomiasis presenting some unusual features.' F. trop. Med. Hyg., 31, 78. (56)

Kisé, Y. and Ochi, T. (1934). 'Basal metabolism of old people.' F. Lab. clin. Med., 19, 1073. (33)

Klebanow, D., and Hegnauer, H. (1949). 'Die germinative Insuffizienz der alternden Frau.' Z. Altersforsch., 5, 157. (181)

KNABE, K. (1932). 'Beitrag zur Dauer von Filarieninfektion.' Arch.f. Sch. u. Tropenhyg., 36, 496. (56)

KNoвloch, M. (1951). 'Fingernagelwachstum und Alter.' Z. Altersforsch., 5, 357. (156)

Kobozieff, N. (1931). 'Mortalité et âge limite chez la souris.' C.R. Soc. Biol., Paris, 106, 704. (43, 47)

Косн, C. (1952). 'Von meinen ältesten Urodelen.' Aquar. Terrar. Z., 5, 9. (52)

Kochakian, C. D. (1937). 'Testosterone and testosterone acetate and the protein and energy metabolism of castrate dogs.' Endocrinology, 21, 750. (178)

Kochakian, C. D., and Murlin, J. R. (1931). 'The effect of male hormone on the protein and energy metabolism of castrate dogs.' 7 . Nutrit., 10, 439. (178)

Kolisko, A. (1938). 'Lebensgeschichte der Rädertiere auf Grund von Individualzuchten.' Arch. Hydrobiol., 33, 165. (59)

Kopaczewskr, W. (1938). 'Problème de vieillissement: recherches sur les colloïdes,' Protoplasma, 30, 291. (7) 


\section{Bibliography}

Kopeć, S. (1924). 'Studies on the influence of inanition on the development and duration of life in insects.' Biol. Bull. Wood's Hole, 46, 1. (143)

(1928). 'On the influence of intermittent starvation on the longevity of the imaginal stage of Drosophila melanogaster.' Brit. F. exp. Biol., 5, 204. (143)

KoRenghevsky, V. (1942). 'Natural relative hyperplasia and the process of ageing.' 7. Path. Bact., 54, 13. (26)

(1947). 'The longest span of life found in the records of centenarians in England and Wales.' Brit. med. F., ii, 14. (61, 62)

(1948). 'Effect of sex and thyroid hormones on the process of ageing in female rats.' Brit. med. 7 ., i, 728.

(1949). 'The problem of ageing. Basic difficulties of research.' Brit. med. F., $\mathbf{i}, 66 .(24,26)$

Korenchevsky, V., and Jones, V. E. (1947). 'The effects of androsterone, oestradiol, and thyroid hormone on the artificial premature "climacteric" of pure gonadal origin produced by ovariectomy in rats. III. Effects on histologic structure of vagina, uterus, adrenals and thyroid.' 7. Geront., 2, 116. (172)

(1948). 'The effects of androsterone, oestradiol, and thyroid hormone on the artificial premature "climacteric" of pure gonadal origin produced by ovariectomy in rats.' F. Geront., 3, 21. (172)

Korenghevsky, V., Paris, S. K., and Benjamin, B. (1950). 'Treatment of senescence in female rats with sex and thyroid hormones.' 7. Geront., 5 , 120. $(167,172,173)$

(1953). 'Treatment of senescence in male rats with sex and thyroid hormones and desoxycorticosterone acetate.' F. Geront., 8, 415. (172, 178)

Korschelt, E. (1908). 'Versuche an Lumbriciden und deren Lebensdauer im Vergleich mit andern wirbellösen Tieren.' Verh. deutsch. zool. Ges., p. 113.

(1914). 'Über Transplantationsversuche, Ruhezustände und Lebensdauer der Lumbriciden.' Zool. Anz., 43, 537. (56, 107)

(1922). Lebensdauer, Altern und Tod. Fischer, Jena. $(46,54,55,56,115)$

(1925). In Leben, Altern, Tod. Senckenberg-bücher II. Berlin: Bermühler-Verlag.

(1931). 'Über das vermutliche Alter der Riesenschildkröten.' Zool. Anz. 96, 113. (52).

Kortlandt, A. (1942). 'Levensloop, samenstelling en structuur der Nederlandse aalscholver bevolking.' Ardea, 31, 175. (110)

Kotsovsky, D. (1929). 'The origin of senility.' Amer. F. Physiol., 90, 419.

(1931). 'Allgemeine vergleichende Biologie des Alters.' Ergeb. Physiol., 31, 132. (155)

Kountz, W. B. (1950). 'Restoration of body function in the aged.' 7 . Geront., 5, 385. (178)

KraAk, W. K., Rinkel, G. L., and Hoogerheide, J. (1940). 'Oecologische bewerking van de Europese ringgegevens van de Kievit (Vanellus vanellus L.).' Ardea, 29, 151. (110) 


\section{Bibliography}

Krohn, P. L. (1955). 'Tissue transplantation techniques applied to the problem of the ageing of the organs of reproduction.' Ciba Foundn. Colloquia on Ageing, 1, 141. (178)

Krumbiegel, I. (1929a). 'Lebensdauer, Altern und Tod in ihren Beziehungen zur Fortpflanzung.' S.B. Ges. naturf. Fr. Berl., 94, 1928 (1929). $(35,97)$

(1929b). 'Untersuchungen über die Einwirkung auf Altern und Lebensdauer der Insekten ausgefuhrt an Carabus und Drosophila.' Zool. 7b. (2. Abt.), 51, 111. (35, 97, 98)

Kunde, M. M., and Norlund, M. (1927). 'Inactivity and age as factors influencing the basal metabolic rate of dogs.' Amer. 7. Physiol., 80, 681. (33)

KüNKEL, E. (1916). Biologie der Lungenschnecken. Heidelberg. $(58,105)$

KüNkel, K. (1928). 'Zur Biologie von Eulota fruticum Müller.' Zool. Jb., 45, 317. $(58,103)$

Kunze, - (1933). Cited by Burger, M. (1954). (7)

Kurbatov, A. D. (1951). Курбатов, А.Д.: 'Ивменения наследственности и повышение жизненности потомства путем трансплантации яйчных клеток между породами кроликов.' (Alteration of heredity and increased vigour of progeny after ovum transplantation between strains of rabbit.) Adv. mod. Biol. Moscow, 31, 2. (129)

KuRtz, E. B., and Winfrey, R. (1931). 'Life-characteristics of physical property.' Bull. Iowa Engineering Exp. Station, No. 103. (33)

Kurzrok, R., and Smith, P. E. (1938). 'The pituitary gland.' Proc. Assn. Nervous and Mental Diseases, 17, chap. xvii. (180).

Labitte, A. (1916). 'Longévité de quelques insectes en captivité.' Bull. Mus. Hist. nat. Paris, 22, 105. $(55,57)$

Lack, D. (1943a). The life of the robin. Witherby: London. $(109,112)$

(1943b). 'The age of blackbirds.' Brit. Birds, 36, 166. (109)

(1943c). 'The age of some more British birds.' Brit. Birds, 36, 193, 214. (109)

(1946). 'Do juvenile birds survive less well than adults?' Brit. Birds, 39, 258.

(1950). 'Population ecology in birds.' A review. Proc. Xth Int. Ornith. Congr. (110)

(1954). The natural regulation of animal numbers. Oxford: University Press. $(108,112,132)$

Lamy, E. (1933). 'Quelques mots sur la durée de la vie chez les Mollusques.' 7. Conchyliol., 77, 48. (105)

Landauer, W., and Landauer, A. B. (1931). 'Chick mortality and sex ratios in the domestic fowl.' Amer. Nat., 65, 492. (132)

LANKester, E. RAY (1870). On comparative longevity in man and the lower animals. London. $(11,49)$ 


\section{Bibliography}

LAnsing, A. I. (1942). 'Some effects of hydrogen ion concentration, total salt concentration, calcium and citrate on longevity and fecundity in the rotifer.' 7. exp. Zool., 91, 195. (7, 35, 44, 91, 113)

(1947a). 'Evidence for ageing as a consequence of growth cessation.' Anat. Rec., 99, 579. (8, 14, 113)

(1947b). 'A transmissible, cumulative and reversible factor in ageing.' 7. Geront., 2, 228. (113)

(1948). 'The influence of parental age on longevity in rotifers.' $\mathcal{J}$. Geront., 3, 6. (87, 88, 90, 113)

(1951). 'Some physiological aspects of ageing.' Physiol. Rev., 31, 274. $(4,8,169)$

(1952). Problems of ageing (ed.). New York: Williams and Wilkins. (4, $88,89)$

Lansing, A. I., Roberts, E., Ramasarma, G. B., Rosenthal, T. B., and Alex, M. (1951). 'Changes with age in aminoacid composition of arterial elastin.' Proc. Soc. exp. Biol. N.Y., 76, 714.

Lansing, A. I., Rosenthal, T. B., and Kamen, M. D. (1949). 'Effect of age on calcium binding in mouse liver.' Arch. Biochem., 20, 125. (169)

Lansing, A. I., and Wolfe, J. M. (1942). 'Changes in the fibrillar tissue of the anterior pituitary of the rat associated with advancing age.' Anat. Rec., 83, 355.

LatTer, O. H. (1935). 'Unusual length of life and curious site of larva of Cossus ligniperda.' Proc. R. ent. Soc., Lond., 10, 41. (57)

Lauson, H. D., Golden, J. B., and Severinghaus, E. L. (1939). The gonadotrophic content of the hypophysis throughout the life cycle of the normal female rat.' Amer. F. Physiol., 125, 396. (181)

Laws, R. M. (1953). 'The elephant seal (Mirounga leonina L.). I. Growth and age.' Falkland Ids. Dependencies Survey Sci. Rep., No. 8. (48)

Lawson, T. G. (1939). 'Echinococcus cysts of the liver of 56 years' duration.’ F. Amer. Med. Ass., 112, 1331. (56)

Lazovskaya, L. N. (1942). 'Age modifications of respiration of blood vessels.' Biul. Eksp. Biol. Med., 14, 46. (32)

(1943). 'The change in respiration of blood vessels with age.' Biokhimia, 8, 171. (32)

Leathem, J. H. (1949). 'The antihormone problem in endocrine therapy.' Rec. Prog. Hormone Res., IV, 115.

Lederer, G. (1941). 'Zur Haltung des China-alligators (Alligator sinensis Fauvel).' Zool. Gart. Lpz., 13, 255. (52)

Lefeire, G., and Curtis, W. C. (1912). 'Studies on the reproduction and artificial propagation of freshwater mussels.' Dept. Comm. Lab. Bull. Bureau Fish, 30, 105.

Lehman, H. C. (1943). 'The longevity of the eminent.' Science, 98, 270. (194)

Lehmensick, R. (1926). 'Zur Biologie, Anatomie und Eireifung der Rädertiere.' Z. wiss. Zool., 128, 37. (59) 


\section{Bibliography}

Lemberg, R., and Legge, J. W. (1949). Hematin compounds and bile pigments. New York: Interscience Publications. (166)

Lepeschin, W. W. (1931). 'Death and its causes.' Quart. Rev. Biol., 6, 167. $(7,34)$

Leslie, P. H., and Ranson, R. M. (1940). 'The mortality, fertility and rate of natural increase of the vole (Microtus agrestis) as observed in the laboratory.' 7. Anim. Ecol., 9, 27. (24, 43, 108, 109)

Liebers, R. (1937). 'Beiträge zur Biologie der Rädertiere: Untersuchungen an Euchlanis dilatata und Proales decipiens.' Z. wiss. Zool., 150, 206. (59)

Lilly, M. M. (1953). 'The mode of life and the structure and functioning of the reproductive ducts of Bithynia tentaculata (L).'Proc. malac. Soc. Lond., 30, 87. (103)

Lindsay, E. (1940). 'The biology of the silverfish, Ctenolepisma longicaudata Esch. with particular reference to its feeding habits.' Proc. Roy. Soc. Victoria, 52, 35. (57)

Linsley, E. G. (1938). 'Longevity in the Cerambycidae.' Pan-Pacif. Ent., 14, 177. $(5 \%)$

LobBan, M. C. (1952). 'Structural variations in the adrenal cortex of the cat.' 7. Physiol., 118, 565. (167)

Loes, J. (1908). 'Über den Temperaturkoeffizienten für die Lebensdauer kaltblütiger Thiere usw.' Pflugers Arch., 124, 411. (10, 138)

Loeb, J., and Northrop, J. H. (1917). 'On the influence of food and temperature on the duration of life.' 7 . biol. Chem., 32, 103. $(8,138,143)$

Loes, L. (1944). Hormones and the process of ageing. Harvey Lecture, 36, 228. (173)

Long, J. A., and Evans, H. M. (1922). 'The estrous cycle in the rat and its associated phenomena.' Mem. Univ. Calif., 6. (179)

Longstaff, J. (1921). 'Observations on the habits of Cochlitoma zebra var. fulgurata Pfr. and obesa Pfr. in confinement.' Proc. zool. Soc. Lond., 379. (1921). (58)

Lorand, A. (1904). 'Quelques considérations sur les causes de la sénilité.' C.R. Soc. biol. Paris, 57, 500. (7)

(1929). 'La rôle de l'autointoxication intestinale dans la production de la vieillesse.' Clinique, Paris, 24, 205. (7)

Lorenz, T. W., and Lerner, I. (1946). 'Inheritance of sexual maturity in male chickens and turkeys.' Poult. Sci., 25, 188. (180)

Lowry, O. H., and Hastings, A. B. (1952). 'Quantitative histochemical changes in ageing.' In Cowdry, E. V., Problems of Ageing. Williams and Wilkins Co. (30)

LuK'yanov, V. S. (1952). Лукьянов, В.С.: 'О сохранение здоровья и работоспособности.' (The preservation of health and work-capacity.) Medgiz, Moscow. (61)

LyePeschinskaya, О: В. (1950). Лепесчинская, О.Б.: 'Произхождение клеток из живого вещества п роль живого вещества в организме.' (Production of cells from living matter and the role of living matter in the organism). Acad. Med. Sci. USSR. Moscow. 2nd edn. (115) 


\section{Bibliography}

LyNGh, R. S., and Smith, H. B. (1931). 'A study of the effects of modification of the culture medium upon length of life and fecundity in a Rotifer (Proales sordida), etc.' Biol. Bull. Wood's Hole, 60, 30. (44, 59)

MagArthur, J. W., and Baillie, W. H. T. (1926). 'Sex differences in mortality and metabolic activity in Daphnia magna.' Science, 64, 229. (44)

(1929a). 'Metabolic activity and duration of life. I. Influence of temperature on longevity in Daphnia magna.' J. exp. Zool., 53, 221. (44, 133, 143)

(1929b). 'Metabolic activity and duration of life. II. Metabolic rates and their relation to longevity in Daphnia magna.' 7 . exp. Zool., 53, 243. $(44,133)$

(1932). 'Sex differences of mortality in Abraxas-type species.' Quart. Rev. Biol., 7, 313. (130)

McGance, R. A., and Widdowson, A. M. (1955). 'A fantasy on ageing and the bearing of nutrition upon it.' Ciba Foundation Colloquia on Ageing, I, 186. (152)

MaCay, G. M. (1952). In Lansing, A. I. (Ed.), Problems of ageing. Baltimore: Williams and Wilkins Co. $(125,149,150)$

MaCay, C. M., and Crowell, M. F. (1934). 'Prolonging the life-span.' Sci. Mon., 39, 405. (149)

MaCay, C. M., Maynard, L. A., Sperling, G., and Osgood, H. S. (1941). 'Nutritional requirements during the latter half of life.' 7 . Nutrit., $21,45$. $(150,151)$

MaCay, C. M., Sperling, L. S., and Barnes, L. L. (1943). 'Growth, ageing and chronic diseases and life span in the rat.' Arch. Biochem., 2, 469. (149, 151, 18\%)

MaCullough, E. P., and Renshaw, J. F. (1934). 'The effects of castration in the adult male.' 7 . Amer. med. Ass., 103, 1140. (185)

Magdonnell, W. R. (1913). 'On the expectation of life in ancient Rome and in the provinces of Hispania and Lusitania, and Africa.' Biometrika, 9, 366. (112)

MaDowell, E. C., Taylor, M. T., and Broadfort, T. (1951). Carnegie Inst. Wash. Year Book, 50, 200. (126)

MaGavack, T. H. (1951). 'Endocrine patterns during aging.' Amer. 7. Int. Med., 35, 961. (172, 173)

MaIlhenny, E. A. (1940). 'Sex ratio in wild birds.' Auk, 57, 85. (132)

MaIlwain, H. (1946). 'The magnitude of microbial reactions involving vitamin-like compounds.' Nature, Lond., 158, 898. (164)

(1949). 'Metabolic changes which form the basis of a microbiological assay of nicotinic acid.' Proc. Roy. Soc. B, 136, 12. (164)

Malaren, A., and Michie, D. (1954). 'Are inbred strains suitable for bioassay?' Nature, London, 173, 686. (136)

Magnus-Levy, H., and Falk, E. (1899). 'Der Lungengaswechsel der Menschen in den verscheidenen Alterstugen.' Pflugers. Arch. ges. Physiol. (Physiol. Suppl.), 314. (33) 


\section{Bibliography}

Mandl, M., and Zuckerman, S. (1952). 'Factors influencing the onset of puberty in albino rats.' 7 . Endocrinol., 8, 357. (179)

Manschot, W. A. (1940). 'Een geval van progero-nanie (Progeria von Gilford).' Nederl. Tijdschr. Geneesk, 84, 3374. (134)

(1950). Acta Paediatr. Stockh., 39, 158. (134)

Marinesco, G. (1934). 'Nouvelle contribution à l'étude du mécanisme de la vieillesse.' Bull. Acad. Med. Paris, 111, 761. (7)

(1934). 'Études sur le mécanisme de la vieillesse.' Rev. Soc. argent. Biol., 10, 355. (7)

Markus, H. C. (1934). 'Life history of the blackhead minnow (Pimephales promelas).' Copeia, 116. (70)

Marshak, A. (1936). 'Growth differences in reciprocal hybrids and cytoplasmic influence on growth in mice.' F. exp. Zool., 72, 497. (129)

MARshaK, A., and Bryon, R. L. (1945). 'The use of regenerating liver as a method of assay.' Proc. Soc. exp. Biol., N.Y., 59, 200. (155)

Marshall, H. (1947). 'Longevity of the American herring gull.' Auk, 64, 188. (109)

MAson, K. E., and Wolfe, J. M. (1930). 'The physiological activity of the hypophyses of rats under various experimental conditions.' Anat. Rec., 45, 232. (151)

Masters, W. H. (1952). 'The female reproductive system.' In Cowdry, E. V. Problems of ageing. Williams and Wilkins Co. (181)

Matheson, C. (1950). 'Longevity in the grey seal.' Nature, Lond., 166, 73. (48)

Matthes, E. (1951). 'Der Einfluss der Fortpflanzung auf die Lebensdauer eines Schmetterlings (Fumea crassiorella).' Z. vergl. Physiol., 33, 1. (44, 99)

Maupas, E. (1883). 'Contribution à l'étude morphologique et anatomique des Infusoires ciliés.' Arch. Zool. exp. gen. S, 2, vol. 1.

(1886). 'Recherches expérimentales sur la multiplication des Infusoires ciliés.' Arch. Zool. exp. gen. S. 2, 6. (116)

Maurizio, A. (1946). 'Beobachtungen über die Lebensdauer und den Futterverbrauch gefangen gehaltener Bienen.’ Beih. Schweiz. Beinenztg., 2, 1. (101)

(1950). 'Untersuchungen über den Einfluss der Pollennahrung und Brutpflege auf die Lebensdauer und den physiologische Zustand von Bienen.' Schweiz. Beinenztg., 73, 58. (101)

MAYer, J. (1949). 'Definition and quantitative expression of ageing.' Growth, 13, 97. (180)

Maynard Smith, J., and Maynard Smith, S. (1954). 'Genetics and cytology of Drosophila subobscura. VIII. Heterozygosity, viability and rate of development.' 7. Genet., 52, 152. (129)

Medawar, P. B. (1940). 'The growth, growth-energy and ageing of the chicken's heart.' Proc. Roy. Soc. B, 129, 332. (31)

(1942). 'Discussion of growth and new growth.' Proc. R. Soc. Med., 35, 500. $(156,15 \%, 159)$ 


\section{Bibliography}

Medawar, P. B. (1945). 'Old age and natural death.' Modern Quart., 1, 30. $(4,39,159)$ 39)

(1952). An unsolved problem of biology. London: H. K. Lewis. $(14,22,25$,

Mellen, I. (1939). A practical cat book for amateurs and professionals. Scribner, N.Y. (47)

(1940). The Science and Mystery of the Cat. Scribner, N.Y. (47, 48, 49)

Metalnikov, S. (1936). 'L'évolution de la mort dans le règne animal.' Rév. gen. Sci. 31 Jan. 1936. (9)

(1937). La lutte contre la mort. Paris: Gallimard. (7, 9)

Metchnikoff, E. (1904). The Nature of Man. London: Heinemann. (7, 11)

(1907). The prolongation of life-optimistic studies. London: Heinemann. $(7,11,85,92,132,170)$

(1915). 'La mort du papillon du murier-un chapitre de thanatologie.' Ann. Inst. Pasteur. (1915), p. 477. (35, 92, 97, 98)

Meyers, G. S. (1952). 'Annual fishes.' Aquarium F., 23, 125. (53)

Miller, H. M. (1931). 'Alternation of generations in the rotifer Lecane inermis Bryce. I. Life histories of the sexual and non-sexual generations.' Biol. Bull. Wood's Hole, 60, 345. (44, 59, 85, 86)

Miner, R. W. (1954). Editor. 'Parental age and characteristics of the offspring.' Ann. N.Y. Acad. Sci., 57, 451. (126)

Minot, C. S. (1908). The problem of age, growth and death; a study of cytomorphosis, based on lectures at the Lowell Institute, March 190\%. London. (8, 10, $29,139,155,159,177)$

(1913). Moderne Probleme der Biologie. Jena. (10)

Mishaikov, D. (1929). (Title unknown.) Trimesechno Spisanie Glavnata Direkt. Statist., 1, 153, 174. (61)

Mrtchels, P. C. (1911). 'On longevity and relative viability in mammals and birds, with a note on the theory of longevity.' Proc. zool. Soc., 1, 425. $(46,49)$

Moнr, E. (1951). 'Lebensdauer einiger Tiere in Zoologischen gärten.' Zool. Gart. Lpz., 18, 60. (46)

Molisch, H. (1938). The longevity of plants. New York: N.Y. Botanical Garden. (7, 35)

Moltoni, E. (1947). 'Fringuello vissuto in schiavitù per ben 29 anni.' Riv. ital. Orm., 17, 139. (49)

Montgomery, T. H. (1906). 'On reproduction, animal life cycles and the biological unit.' Trans. Tex. Acad. Sci., 9. (7)

Moon, H. D., Simpson, M. E., Li, G. H., and Evans, H. M. (1952). 'Effects of pituitary growth hormone in mice.' Cancer Res., 12, 448. (153, 186)

Moore, G. R., and Samuels, L. T. (1931). 'Action of testis hormone in correcting changes induced in rat prostate and seminal vesicles by vitamin B deficiency or partial inanition.' Amer. 7. Physiol., 96, 278. (151) 


\section{Bibliography}

Moore, D. (1924). 'Note on the longevity of Clonorchis sinensis.' U.S. Public Health Reports, 39, 1802. (56)

Moore, H. B. (1934). 'The biology of Balanus balanoides. I. Growth rate in relation to size, season and tidal level.' F. Mar. Biol. Ass. U.K., 19, 851. (57)

(1935). 'A comparison of the biology of Echinus esculentus in different habitats.' 7. mar. Biol. Ass. U.K., 20, 109. (58)

Morant, G. M. (1950). 'Secular changes in the heights of British people.' Proc. Roy. Soc. B., 137, 443. (152)

Moskovi.jević, V. (1939). Bee World, 20, 83; 21, 39-41. (101)

Munlmann, M. S. (1900). Über die Ursache des Alters. Wiesbaden: Bergman. $(7,8)$

(1911). 'Das Altern und der physiologische Tod.' Samml. anat. physiol. Vortr., 1, 455. (7, 8)

(1924). 'Meine Theorie des Alterns und des Todes; zugleich zur Abwehr.' Virchows Arch., 253, 225. (7)

(1927). 'Wachstum, Altern und Tod. Über die Ursache des Alterns und des Todes.' Ergeb. Anat. EntwGesch.; Anat. Abt., 27, 1. (7)

Mulinos, M. G., and Pomerantz, L. (1941). 'Hormonal influences on weight of adrenal in inanition.' Amer. F. Physiol., 132, 368. (151)

Murie, A. (1944). The wolves of Mount McKinley. U.S. Dep. Int. Nat. Park Service, Washington. (111)

Murray, J. (1910). 'Antarctic Rotifera.' British Antarctic Expedition, 19071909, I (3), 41. (165)

Murray, W. S. (1934). 'The breeding behaviour of the dilute brown stock of mice (Little dba).' Amer. 7. Cancer, 20, 573.

Murray, W. S., and Hoffmann, J. G. (1941). 'Physiological age as a basis for the comparison of strains of mice subject to spontaneous mammary carcinoma.' Cancer Res., 1, 298. (43)

NAgornyı, A. V. (1948). Нагорный, A.В.: 'Старение и продление жизни.' (Old age and the prolongation of life) Sovietskaya Nauka, Moscow. (46, $54,61)$

Nascher, I. (1920). 'A noted case of longevity-John Shell, centenarian.' Amer. Med., 15, 151. (62)

Needham, A. E. (1950). 'Growth and regeneration rates in relation to age in Crustacea.' 7. Geront., 5, 5. (96)

Needham, J. (1942). Biochemistry and morphogenesis. Cambridge: University Press. $(159,190)$

Neuberger, A., and Slack, H. G. B. (1953). 'The metabolism of collagen from liver, bone, skin and tendon in the normal rat.' Biochem. $7 ., 53,47$. (34)

Newcombe, C. L. (1935). 'Growth of Mya arenaria in the Bay of Fundy region.' Canad. 7. Res., 13, 97. $(58,106)$

(1936). 'Validity of concentric rings of Mya arenaria L. for determining age.' Nature, Lond., 137, 191. $(58,106,107)$ 


\section{Bibliography}

Nrchols, J. T. (1939). 'Data on size, growth and age in the box turtle, Terrapene carolina.' Copeia, 14. (78)

Nikitın, V. N. (1954). Никиาин, В.Н.: 'Долголетие.' (Longevity.) Sci. \& Life, Moscow, (8) 27. (61)

Noble, G. K. (1931). The Biology of the Amphibia. New York: McGraw Hill. $(52,67)$

Norris, J. L., Blanghard, J., and Polovny, C. (1942). 'Regeneration of rat liver at different ages.' Arch. Path. (Lab. Med.), 34, 208. (155)

Norris, M. J. (1933). 'Contributions toward the study of insect fertility. II. Experiments on the factors influencing fertility in Ephestia kuhniella Z.' Proc. zool. Soc. Lond., 903. (98)

(1934). 'Contributions toward the study of insect fertility. III. Adult nutrition, fecundity and longevity in the genus Ephestia.' Proc. zool. Soc. Lond., p. 334. (35, 98)

Northrop, J. (1917). 'The effect of prolongation of the period of growth on the total duration of life.' 7. biol. Chem., 32, 123. (143)

Du Noü̈, P. L. (1916). 'Cicatrization of wounds.' F. exp. Med., 24, 461. $(26,156)$

(1932). 'Une mesure de l'activité physiologique.' C.R. Soc. Biol., Paris, 109, 1227. $(20,156)$

(1936). Biological Time. Methuen, London. (5)

Novák, E. (1921). Menstruation and its disorders. New York: Appleton. (181)

(1944). 'The constitutional type of precocious female puberty, with a report of nine cases.' Amer. 7. Obst. Gynec., 47, 20. (179)

Noyes, B. (1922). 'Experimental studies on the life history of a rotifer reproducing parthenogenetically (Proales decipiens).' 7. Exp. Zool., 35, 222. (85)

Oldham, C. (1930). 'Fecundity of Planorbis corneus.' Naturalist, 177. (58)

(1931). 'Note on V(iviparus) contectus.' 7. Conch., 19, 179. (58, 102)

(1942a). 'Autofecundation and duration of life in Limax cinereoniger.' Proc. malac. Soc., Lond., 25, 9. (58)

(1942b). 'Notes on Geomalacus maculosus.' Proc. malac. Soc. Lond., 25, 10. $(58)$

OlifF, W. D. (1953). 'The mortality, fecundity and intrinsic rate of natural increase of the multimammate mouse (Rattus (Mastomys) natalensis Smith) in the laboratory.' 7. Anim. Ecol., 22, 217. (43, 130)

Oliver, J. A. (1935). 'Young Billy Johnson's old box turtle.' Animal Kingdom, 56, 154. (51)

Orton, J. H. (1928). 'On rhythmic periods of shell growth in Ostrea edulis with a note on fattening.' 7. mar. Biol. Ass. U.K., 15, 365. (104)

(1929). 'Reproduction and death in invertebrates and fishes.' Nature, Lond., 123, 14. (8, 35)

Orton, J. H., and Amurthalingam, G. (1930). 'Giant English Oysters.' Nature, Lond., 126, 309. (58) 
Osborne, T. B., and Mendel, L. B. (1916). 'The resumption of growth after long-continued failure to grow.' 7. biol. Chem., 23, 439. (148)

(1916). 'Acceleration of growth after retardation.' Amer. F. Physiol., 40, 16. $(148,156)$

PAI, S. (1928). 'Die phasen des Lebenzyklus der Anguillula aceti Ehr. und ihre experimentellmorphologische Beeinflussung.' Z. wiss. Zool., 131, 293. (84)

(1934). 'Regenerationsversuche an Rotatorien.' Sci. Rep. Univ. Chekiang, 1. (87)

PARK, T. (1945). 'Life tables for the black flour-beetle, Tribolium madens Charp.' Amer. Nat., 79, 436. (44, 130, 131).

Parker, G. H. (1926). 'The growth of turtles.' Proc. Nat. Acad. Sci. Wash., 12, 422. $(52,79)$

(1929). 'The growth of the loggerhead turtle.' Amer. Nat., 63, 367. $(52,79)$

Parker, W. R. (1933). 'Pelorus Jack.' Proc. Linn. Soc., 1933, p. 2. (47)

PARkes, A. S. (1929). 'Note on the growth of young mice suckled by rats.' Ann. Appl. Biol., 16, 171.

(1942-44). 'Induction of superovulation and superfecundation in rabbits.' 7. Endocrinol., 3, 268. (179)

PARKes, A. S., and Smith, A. U. (1953). 'Regeneration of rat ovarian tissue grafts after exposure to low temperatures.' Proc. Roy. Soc. B, 140, 455. (180)

Parsons, R. J. (1936). In Medical papers dedicated to H. A. Christian. Baltimore. $(16 \%, 174)$

PAyne, F. (1949). 'Changes in the endocrine glands of the fowl with age.' 7. Geront., 4, 193. (174)

(1952). 'Cytological changes in the cells of the pituitary, thyroids, adrenals and sex glands of the ageing fowl.' In Lansing, Problems of ageing. $(64,174)$

Pearce, J. M. (1936). 'Age and tissue respiration.' Amer. J. Physiol., 114, 255. (33)

Pearl, R. (1927). 'On the distribution of differences of vitality among individuals.' Amer. Nat., 61, 113.

(1928). The rate of living. New York: Knopf. (4, 7, 8, 10, 44, 124)

(1940). Introduction to medical biometry and statistics, 3rd edn. Pennsylvania: W. B. Saunders Co. (19)

Pearl, R., and Doering, C. R. (1923). 'A comparison of the mortality of certain lower organisms with that of man.' Science, 57, 209. (113)

Pearl, R., and Miner, J. R. (1935). 'Experimental studies in the duration of life. XIV. The comparative mortality of certain lower organisms.' Quart. Rev. Biol., 10, 60. (19, 33, 43, 44, 82, 104, 113)

(1936). 'Life tables for the pecan-nut case bearer (Acrobasis caryae, Grote).’ Mém. Mus. Hist. nat. Belg., 3, 169. (44, 132) 
Pearl, R., Park, T., and Miner, J. R. (1941). 'Experimental studies on the duration of life. XVI. Life-tables for the flour beetle Tribolium confusum Duval.' Amer. Nat., 75, 5. (44)

Pearl, R., and Parker, S. L. (1924). 'Experimental studies on the duration of life. IX. New life-tables for Drosophila.' Amer. Nat., 58, 71. (44)

(1922). 'Experimental studies in the duration of life. II. Hereditary differences in duration of life in line-bred strains of Drosophila.' Amer. Nat. 56, 174. (44, 121, 124)

Pearl, R., and Pearl, R. de W. (1934a). The ancestry of the long-lived. London: H. Milford. (122)

(1943b). 'Studies on human longevity. VI. Distribution and correlation of variation in the total immediate ancestral longevity of nonagenarians and centenarians in relation to inheritance factor in the duration of life.' Hum. Biol., 6, 98. (122)

Pearson, K. (1895). 'Mathematical contributions to the theory of evolution. II. Skew variations in homogeneous material.' Phil. Trans. Roy. Soc., 186, Ser. A, 343. (18)

Pearson, K., and Elderton, E. M. (1913). 'On the hereditary character of general health.' Biometrika, 9, 320. (125)

Pearson, O. P. (1945). 'Longevity of the short-tailed shrew.' Amer. Midl. Nat., 34, 531. (34, 47, 109)

Pearson, O. P., and Baldwin, P. H. (1953). 'Reproduction and age structure of a mongoose population.' F. Mammal., 34, 436. (34)

Pease, M. (1947). 'How long do poultry breeding stock live?' J. Ministr. Agric., 54, 263. (132)

Pease, M. S. (1928). 'Experiments on the inheritance of weight in rabbits.' 7. Genet., 20, 261.

Pelseneer, R. (1934). 'La durée de la vie et l'âge de la maturité sexuelle chez certains mollusques.' Ann. Soc. zool. Belg., 64, 93. $(58,102)$

(1935). Essai d'éthologie zoologique. Bruxelles. (36, 102, 105)

Penfold, W. J., Penfold, H. B., and Phillips, M. (1936), 'A survey of the incidence of Taenia saginata infestation in the population of the State of Victoria, etc.' Med. F. Australia, 23rd Year, I, 283, (56)

Perkins, G. B. (1948). 'Longevity of snakes in captivity in the U.S.' Copeia, 217. (52)

Perrone, J. G., and Slack, H. G. B. (1952). 'The metabolism of collagen from skin, bone and liver in the normal rat.' Biochem. F., 49, Ixxii. (34)

Perry, J. S. (1953). 'The reproduction of the African elephant, Loxodonta africana.' Phil. Trans. Roy. Soc. B, 237, 93. (34)

Perry, R. (1953). 'Some results of bird ringing.' New Biol., 15, 58. (34, 49, 110)

Petrova, M. К. (1946). Петрова, М.К.: 'О роли фунционалной ослабленной коры головного мозга в возниковеннии различных патологических процессов.' (Functional weakening of the cerebral cortex in the aetiology of various disease states.) Moscow. (153) 


\section{Bibliography}

Pflugfelder, O. (1948). 'Volumetrische untersuchungen an den corpora allata der Honigbiene (Apis mellifica).' Biol. Zbl., 67, 223. (57, 100, 167)

Picado, T. G. (1930). 'Effets des injections de serum homologue sur la taille et croissance des animaux.' Ann. Inst. Pasteur, 44, 584. (155)

Pigado, T. G., and Rotter, W. (1936). 'Précipitines anti-glandes endocrines et longévité chez quelques espèces de vertébrés.' C.R. Soc. Biol., Paris, 123, 869. (169)

Piepho, H. (1938). 'Über die Auslösbarkeit überzähliger Haütungen und vorzeitiger Verpuppung an Hautstücken bei Kleinschmetterlingen.' Naturwiss., 26, 841. (147)

Pierson, B. F. (1938). 'Relation of mortality after endomixis to the prior interendomitotic interval in Paramecium aurelia.' Biol. Bull. Wood's Hole, 74, 235. (118)

Pincus, G. (1950). 'Measures of stress responsivity in younger and older men.' Psychosom. Med., 12, 225. (174)

PitT, F. (1945). 'Breeding of the harvest mouse in captivity.' Nature, Lond., 155, 700. (47)

Pixell-Goodrigh, H. (1920). 'Determination of age in honey bees.' Quart. 7. micr. Sci., 64, 191. (97, 99)

Plate, L. (1886). 'Beiträge zur Naturgeschichte der Rotatorien.' Jena Z.f. Naturwiss., 19, 1. (85)

Poležaiev, L. V., and Ginsburg, G. I. (1939). 'Studies by the method of transplantation on the loss and restoration of the regenerative power in the tailless amphibian limbs.' C.R. Acad. Sci. U.R.S.S., 23, 733. (182)

Pontegorvo, G. (1946). 'Microbiology, biochemistry and the genetics of microorganisms.' Nature, Lond., 157, 95. (165)

PruitT, W. O. (1954). 'Ageing in the masked shrew, Sorex cinereus cinereus Kerr.' F. Mammal., 35, 35. (34)

Przibram, H. (1909). Experimental-Zoologie. Vienna. Vol. II, p. 126. (104)

Pütter, A. (1921). 'Die ältester Menschen.' Naturwiss., 9, 875. (60)

Quick, H. E. (1924). 'Length of life of Paludestrina ulvae.' 7. Conchol., 17, 169. $(58)$

Raben, M. S., and Westermeyer, V. W. (1952). 'Differentiation of growth hormone from the pituitary factor which produces diabetes.' Proc. Soc. exp. Biol., 80, 83. (186)

Rabes, O. (1901). 'Über Transplantations-Versuche an Lumbriciden.' Biol. Zbl., 21, 633. (56)

Raffel, D. (1932). 'The occurrence of gene mutations in Paramecium aurelia.' 7. exp. Zool., 63, 371. (118)

Raнм, P. G. (1923). 'Beiträge zur Kenntnis der Moosfauna.' Z. allg. Physiol., 20, 1. (\$7, 140) 
Rao, H. S. (1937). 'On the habitat and habits of Trochus niloticus Linn. in the Andaman Seas.' Rec. Indian Mus., 39, 47. $(58,104)$

Rasquin, P., and Hafter, E. (1951). 'Age changes in the testis of the teleost, Astyanax americanus.' 7. Morph., 89, 397. (69)

RaU, P. (1924). 'The biology of the roach, Blatta orientalis Linn.' Trans. Acad. Sci. St. Louis, 25, 57. (44)

RAU, P., and RAU, N. (1914). 'Longevity in saturnid moths and its relation to the function of reproduction.' Trans. Acad. Sci. St. Louis, 23, 1. (132)

Reece, R. P., and Turner, C. W. (1937). 'The lactogenic and thyrotropic hormone content of the anterior lobe of the pituitary gland.' Univ. Missouri Agr. Exp. Sta. Res. Bull., 266, 1. (186)

Regan, W. M., Mead, S. W., and Gregory, P. W. (1947). 'The relation of inbreeding to calf mortality.' Growth, 11, 101. (118)

ReINeR, J. M. (1947). 'The effect of age on the carbohydrate metabolism of tissue homogenates.' 7. Geront., 2, 315. (32)

Rey, P. (1936). 'La longévité des Galleria adultes, mâles et femelles.' C.R. Soc. Biol., 121, 1184. (132)

Ribbands, C. R. (1950). 'Changes in the behaviour of honey-bees following their recovery from anaesthesia.' 7. exp. Biol., 27, 302. (101)

(1952). 'Division of labour in the honey-bee community.' Proc. Roy. Soc. $B, 140,32$. $(44,102,112)$

(1953). The behaviour and social life of honey bees. London: Bee Research Association Ltd. $(38,44,101)$

Ribbert, H. (1908). Der Tod aus Altersschwäche. Bonn: Cohen. (7)

Richards, O. W. (1953). The Social Insects, p. 188. Macdonald: London. (57)

Ricker, W. E. (1945). 'Natural mortality among Indiana blue-gill sunfish.' Ecology, 26, 111. (68, 71)

(1948). 'Methods of estimating vital statistics of fish populations.' Indiana Univ. Publ. Sci. Ser., 15, 1. (72)

Riley, W. A. (1919). 'The longevity of the fish tapeworm of man, Diphyllobothrium latum.' 7. Parasitol., 5, 193. (56)

Rizet, G. (1953). 'Sur l'impossibilité d'obtenir la multiplication vegetative ininterrompue et illimitée de l'Ascomycète Podospora anserina.' C.R. Acad. Sci., 237, 828. (116)

Robertson, F. W., and Reeve, E. G. R. (1952). 'Heterozygosity, environmental variation, and heterosis.' Nature, Lond., 170, 286. (137)

Robertson, T. B. (1923). The chemical basis of growth and senescence. Philadelphia. $(8,32,138,153)$

Robertson, T. B., Dawbarn, M. C., Walters, J. W., and Wilson, J. D. O. (1933). 'Experiments on the growth and longevity of the white mouse, II.' Aust. F. exp. Biol. med. Sci., 11, 219. (153)

Robertson, T. B., and RAy, L. A. (1920). 'Experimental studies on growth. $\mathrm{XV}$. On the growth of relatively long-lived compared with that of relatively short-lived animals.' 7. biol. Chem., 42, 71. (125, 128, 153) 


\section{Bibliography}

Robertson, T. B., and RAy, L. A. (1919). 'Experimental studies on growth. XI. The influence of pituitary gland tissue, tethelin, egg lecithin, and cholesterol upon the duration of life in the white mouse.' $\mathcal{7}$. biol. Chem., 37, 427. (153)

Robson, J. M. (1947). Recent advances in sex and reproductive physiology. London: Churchill. (180)

Rockstein, M. (1950). 'The relation of cholinesterase activity to change in cell number with age in the brain of the adult worker honey bee.' $\mathrm{F}$. Cell. comp. Phys., 35, 11. (100)

Rogers, J. B. (1950). 'The development of senility in the guinea pig.' Anat. Rec., 106, 286. (47)

Rokнlina, M. L. (1951. Рохлина, М.Л.: 'Путь с долголетию.' (The road to longevity.) Pravda, Moscow. (61)

Rollinat, R. (1934). 'La vie des reptiles de la France centrale.' Paris. $(51,78)$

Rosenthal, O., Bowie, M. A., and Wagoner, G. (1940). 'Metabolism of cartilage (bovine) with particular reference to the effects of ageing.' $\mathcal{F}$. Amer. med. Ass., 115, 2114. (32)

(1941). 'Studies in the metabolism of articular cartilage. I. Respiration and glucolysis of cartilage in relation to age.' F. cell. comp. Physiol., 17, 221. (32)

(1942). 'The dehydrogenetic ability of bovine articular cartilage in relation to its age.' $\mathcal{F}$. cell. comp. Physiol., 19, 333. (32)

Rothschild, M. (1935). 'Gigantism and variation in Peringia ulvae Penn. caused by infection with larval trematodes.' 7. mar. Biol. Ass. U.K., 20, 537. (104)

Roux, W. (1881). Der Kampf der Teile im Organismus. Leipzig. ( 8 )

Rubin, B. L., Dorfman, R. I., and Pingus, G. (1955). '17-ketosteroid excretion in ageing subjects.' Ciba Foundation Symposia on Ageing, 1, 126.

Rubner, M. (1908). 'Probleme des Wachstums und der Lebensdauer.' MittGes. inn. Med., Wien, 7, 58. (8, 9)

Rudzinska, M. (1951). 'The influence of amount of food on the reproduction rate and longevity of a Suctorian (Tokophrya infusionum).' Science, 113, 10-11. (115)

(1952). 'Overfeeding and life-span in Tokophrya infusionum.' 7. Geront., 7, 544. (115)

Rutgers, A. J. (1953). 'Mortality by cancer as a function of age.' Experientia, 12, 470. (25)

Rutman, R. J. (1950). 'A maternal influence on the incorporation of methionine into liver protein.' Science, 112, 252. (129)

(1951). 'The inheritance of rates of methionine uptake by rat liver protein and relations to growth.' Genetics, 36, 59. (129)

Ruud, J. T., Jonsgard, A., and Ottestad, P. (1950). 'Age studies in blue whales.' Hvalråd. Skr., 33, 1. (47) 


\section{Bibliography}

RúzíčKa, V. (1924). 'Beiträge zum Studium der Protoplasmahysteretischen Vorgänge (Zur Kausalität des Alterns).' Arch. mikr. Anat., 101, 459. $(7,34)$

(1929). 'Beiträge zum Studium der Protoplasmahysteresis, etc. (Zur Kausalität des Alterns)' Arch. EntwMeck. Org., 116, 104. (7)

Saldau, M. Р. (1939). Салдау, М.П.: 'Темп роста промысловых моллюсков некоторых районов европейской части СССР. (Growth rate of commercially valuable molluscs in some districts of the European part of the USSR.) Bull. Inst. freshw. Fish., Leningr., 22, 244. (10\%)

SAlmon, T. N. (1941). 'Effect of pituitary growth substance on the development of rats thyroidectomised at birth.' Endocrinology, 29, 291.

Samuels, L. T. (1946). 'The relation of the anterior pituitary hormones to nutrition.' Rec. Prog. Hormone Res., 1, 147. (151)

Sanderson, W. A. (1949). [Report of British Association Symposium on social and psychiatric aspects of ageing.] Nature, Lond., 163, 221. (194)

SANDGround, J. H. (1936). 'On the potential longevity of various helminths, with a record from a species of Trichostrongylus in man.' $\mathcal{J}$. Parasit., 22, 464. (56)

Savory, T. H. (1927). The biology of spiders. Sidgwick and Jackson: London. (56)

Sawin, P. B. (1954). In Miner, R. W. (Ed.) 'Parental age and characteristics of the offspring.' Ann. N.Y. Acad. Sci., 57, 451. (126)

Saxton, J. A. (1945). 'Nutrition and growth and their influence on longevity in rats.' Biol. Sympos., 11, 177. (150)

Saxton, J. A., and Kimball, G. C. (1941). 'Relation of nephrosis and other diseases of albino rats to modifications of diet.' Arch. Path., Chicago, 32, 951. (150)

Saxton, J. H., and Greene, H. S. N. (1939). 'Age and sex differences in hormone content of the rabbit hypophysis.' Endocrinology, 24, 494. (179)

Sahaffer, V. B. (1950). 'Growth layers on the teeth of Pinnipedia as an indication of age.' Science $\mathcal{N} . \Upsilon$., 112, 309. (48)

Sahloemer, C. L. (1936). 'The growth of the muskellunge, Esox masquinongy immaculatus (Garrard) in various lakes and drainage areas of Northern Wisconsin.' Copeia, 185. (70)

Schlomka, G., and Kersten, E. (1952). 'Über Möglichkeiten einer statistichen Altenscharakteristik auf Grund von Morbiditätszahlen.' Z. Altersforsch., 6, 306. (26)

Sahlotтke, E. (1930). 'Zellstudien an Hydra. I. Altern und Abbau von Zellen und Kernen.' Z. mikr.-anat. Forsch., 22, 493. (82)

Sammalmausen, I. (1928). 'Das Wachstumsgesetz und die Methode der Bestimmung der Wachstumskonstante.' Arch. EntwMeck. Org., 113, 462. $(72,73,74,184)$

(1929). 'Zum Wachstumstheorie.' Arch. EntwMeck. Org., 116, 5677. (159) 


\section{Bibliography}

Schmidt, H. (1923). 'Über den Alterstod der Biene.' Jena Z.f. Naturwiss., 59, 343. $(97,99)$

Sснмгd, W. J. (1952). 'Einiges über das altern der Tiere.' Z. Altersforsch., 6, 344. (46)

Schneider, K. M. (1932). 'Zum Tode des Leipzigen Riesensalamanders.' Zool. Gart. Lpz., 5, 142. (52)

Schulze-Röввеске, G. (1951). 'Untersuchungen über Lebensdauer, Altern, und Tod bei Anthropoden.' Zool. Fb., 62, 366. (32, 95, 100)

Scow, R. O., and Marx, W. (1945). 'Response to pituitary growth hormone of rats thyroidectomized on the day of birth.' Anat. Rec., 91, 227. (161, 185)

Sebesta, F. (1935). 'Beobachtungen über das Alter der Raniden.' Blätt. Aq. Terrar., 46, 115.

Sekera, E. (1926). 'Beitrage zur Kenntnis der Lebensdauer bei einigen Turbellarien und Süsswassernemertinen.' Zool. Anz., 66, 307.

Selye, H. (1946). 'General adaptation syndrome and diseases of adaptation.' F. clin. Endocrin., 6, 117. (125)

Selye, H., and Albert, S. (1942). 'Age factor in responsiveness of pituitary and adrenal folliculoids.' Proc. soc. exp. Biol. N.Y., 50, 159. (180)

Sergeev, A. (1937). 'Some materials to the problem of the reptile postembryonic growth.' Zool. Zh., 16, 723. (77, 78)

(1939). [? title]. Probl. Ecol. Biotsen., Leningr., 4, 276. (110)

Sesharya, R. V. (1927). 'On the breeding habits and fecundity of the snail Limnaea luteola Lk.' 7. Bombay nat. Hist. Soc., 32, 154. (58)

SetTe, O. E. (1943). 'Biology of the Atlantic mackerel (Scomber scombrus) of North America. I. Early life history including the growth, drift and mortality of the egg and larval population.' Bull. U.S. Fish. Wildl. Serv. Fish., 50, 147. (111)

Severtsov, A. N. (1939). Северцов, А.Н.: 'Морфологические закономерности әволюционного процесса.' (Morphological laws of the evolutionary process.) Sorena, 3, 23. (115)

Sewell, R. B. S. (1924). 'Observations on growth in certain molluscs and on changes correlated with growth in the radula of Pyrazus palustris.' Rec. Ind. Mus. Calcutta, 26, 529. (112)

Shanklin, W. M. (1953). 'Age changes in the histology of the human pituitary.' Acta anat., Basel, 19, 290. (168)

Sharp, D. (1883). 'Longevity in a beetle.' Entom. monthly Mag., 19, 260. (57)

Sheldon, J. H. (1949). Social medicine of old age. Oxford University Press. $(193,194)$

Shemin, D., and Rittenberg, D. (1944). 'Some interrelationships in general nitrogen metabolism.' 7. biol. Chem., 153, 401. (34)

Sherman, H. C., and Campbell, H. L. (1935). 'Rate of growth and length of life.' Proc. Nat. Acad. Sci., 21, 235. (125) 


\section{Bibliography}

Shock, N. W. (1942). 'Standard values for basal oxygen consumption in adolescence.' Amer. 7. Dis. Childhood, 64, 19. (33)

(1948). 'Metabolism in old age.' Geriatrics, 1, 232. (33)

(1951). A classified bibliography of gerontology and geriatrics. U.S.A.: Stanford University Press. $(4,33)$

Shock, N. W., Watkin, D. M., and Yiengst, M. J. (1954). 'Age changes in renal function and basal oxygen consumption as related to total body water.' Fed. Proc., 13, 136. (33)

Shulov, A. (1939-40). 'On the biology of Latrodectes spiders in Palestine.' Proc. Linn. Soc., Lond., 309. (133)

Silberberg, M., and Silberberg, R. (1954). 'Factors modifying the life span of mice.' Amer. 7. Physiol., 177, 23. (150)

Simmonds, L. W. (1945). The role of the aged in primitive society. Yale University Press. (193)

(1946). 'Attitudes toward ageing and the aged: primitive societies.' $\mathcal{F}$. Geront, 1, 72. (193, 194)

Simmonds, M. (1914). 'Über embolische Prozesse in der Hypophysis.' Arch. f. path. Anat., 217, 226. (174)

(1914b). 'Zur Pathologie der Hypophysis.' Verh. dtsch. path. Ges., 17, 808. $(174)$

Simms, H. S. (1936). 'The effect of physiological agents upon adult tissues in vitro.' Science, 83, 418. (158)

Simms, H. S., and Stillman, N. P. (1936). 'Substances affecting adult tissue in vitro. II. A growth inhibitor in adult tissue.' J. gen. Physiol., 20, 621. (154)

(1937). 'Substances affecting adult tissue in vitro. III. A stimulant (the ' $\mathrm{A}$ ' factor) in serum ultrafiltrate involved in overcoming adult tissue dormancy.' 7. gen. Physiol., 20, 649. (158)

Sinclair, H. M. (1955). 'Too rapid maturation in children as a cause of ageing.' Ciba Foundation Colloquia on Ageing, I, 194. (152, 196)

Sivertsen, E. (1941). 'On the biology of the Harp Seal, Phoca groenlandica Ersel.' Hvalråd. Skr., Oslo, No. 26. (48)

Sleptzov, M. M. (1940). 'Détermination de l'âge chez Delphinus delphis L.' Bull. Soc. Nat. Moscow, 49, 43. (47)

Slonaker, J. R. (1912). 'The normal activity of the albino rat from birth to natural death, its rate of growth and the duration of life.' 7. Anim. Behav., 2, 20. (43)

(1930). 'The effect of the excision of different sexual organs on the development, growth and longevity of the albino rat.' Am. F. Physiol., 93, 307. (133)

Smallwood, W. M., and Philips, R. L. (1916). 'The nuclear size in the nerve cells of bees during the life cycle.' 7. comp. Neurol., 27, 69. (100)

Sмгтн, M. (1951). The British amphibians and reptiles. London: Collins. (52) 


\section{Bibliography}

Smith, P. E., and Dortzbach, G. (1929). 'The first appearance in the anterior pituitary of the developing pig foetus of detectable amounts of the hormones stimulating ovarian maturity and general body growth.' Anat. Rec., 43, 277. (179)

Sмүтн, N. (1937). 'Longevity in horses.' Cavalry 7., 27, 101. (48)

Sollaud, E. (1916). 'Recherches sur la biologie des 'Palemonides' des côtes de la France.' Rec. Fonds Bonaparte, 1, 69. (57)

Solomon, D. R., and Sноck, N. W. (1950). 'Studies of adrenal cortical and anterior pituitary function in elderly men.' $\mathbf{F}$. Geront., 5, 302. (174)

Sondén, K., and Tigerstedt, R. (1895). 'Die Respiration und der Gesammtstoffwechsel des Menschen.' Skand. Arch. Physiol., 6, 1. (33)

Sonneborn, T. M. (1930). 'Genetic studies on Stenostomum incaudatum n.sp. I. The nature and origin of differences in individuals formed during vegetative reproduction.' $\mathcal{7}$. exp. Zcol., 57, 57. $(83,115)$

(1938). 'The delayed occurrence and total omission of endomixis in selected lines of Paramecium aurelia.' Biol. Bull. Wood's Hole, 74, 76. (116)

Sorokina, M. I. (1950). Сорокина, М.И.: 'Об изменчивости хромосомного комплекса в тканевых клетах теплокровных животных.' (Variability of the chromosome complex in tissue cells of warm-blooded animals.) Bull. Acad. Sci. URSS., 6, 97. (168)

SpEAR, F. G. (1928). 'The effect of low temperature on mitosis in vitro.' Arch. exp. Zellforsch., 1, 484. (156)

Spemann, F. W. (1924). 'Über Lebendsauer, Altern und andere Fragen der Rotatorien-biologie.' Z. wiss. Zool., 123, 1. (59, 85, 88)

Spenser, R. R., and Melroy, M. B. (1949). 'Studies of survival of unicellular species. I. Variations in life expectancy of a paramecium under laboratory conditions.' 7. nat. Cancer Inst., 10, 1. (118)

Spiegelman, S., Baron, L. S., and Quastler, H. (1951). 'Enzymatic adaptation in non-viable cells.' Fed. Proc., 10, 130. (165)

Stebrins, R. C. (1948). 'Additional observations on home ranges and longevity in the lizard Sccleporus graciosus.' Copeia, 20, (110)

Stebbins, R. G., and Robinson, H. B. (1946). 'Further analyses of a population of the lizard Sceleporus graciosus gracilis.' Univ. Calif. Publ. Zool., 48, 149. (110)

Steinmetz, G. H. (1954). 'Some effects of thyroxine and antithyroid compounds on tadpoles and their relation to hormonal control of growth.' Physiol. Zool., 27, 28. (161, 185)

Stephenson, R. A. (1935). British sea anemones. London: The Ray Society. $(56,81)$.

Stewart, D. G., and Kirk, P. L. (1954). 'The liquid medium in tissue culture.' Biol. Revs., 29, 119. (159)

Sтоцс̌, A. (1902). 'Über den Lebenszyklus der niedrigsten Süsswasserannulaten und über einiger sich anschliessende biologische Fragen.' Bull. intern. Acad. Sci. Boheme, 1902. (83) 


\section{Bibliography}

Stolte, H. A. (1924). 'Altersveränderung bei limicolen Oligochäten.' Verhand. Deutsch. Zool. Ges., 29, 43. (83)

(1927). 'Studien zur Histologie des Altersprozesses.' Z. wiss. Zool., 129, 1. $(83)$

(1937). 'Gestaltung, Zeichnung und Organabbau unter dem Einfluss normaler und 'alternden' gonaden bei Polyophthalmus pictus (Polychaeta).' Z. wiss. Zool., 150, 107. (33)

Strong, L. C. (1936). 'Production of CBA strain inbred mice: long life associated with low tumour incidence.' Brit. F. exp. Path., 17, 60. (121)

Strong, L. G., and Smith, G. M. (1936). 'Benign hepatomas in mice of the CBA strain.' Amer. F. Cancer, 27, 279. $(121,123)$

Summers, F. M. (1938). 'Form regulation in Zoothamnion alternans.' Biol. Bull. Wood's Hole, 74, 130. (155)

SuzukI, Y. (1926). 'A study of the resistance of animals by the tissue culture method.' Mitt. allg. Path. Sendai, 2, 191. (31, 155)

SwIFT, D. R. (1954). 'Influence of mammalian growth hormone on rate of growth of fish.' Nature, Lond., 173, 1096. (182)

SWYer, G. I. M. (1954). Reproduction and sex. London: Routledge. (180)

Szab6, I. (1931a). 'The three types of mortality curves.' Quart. Rev. Biol., 6, 462. (19)

(1931b). 'Absterben und Entwicklung.' Biol. gen., 7, 163.

(1932a). Elettartam és örëgedës. Budapest.

(1932b). 'Das Alterspigment bei einigen Schnecken, untersucht an überlebenden Ganglienzellen.' Arb. ung. Bioi. Forsch. Inst., 5, 38.

(1935). 'Senescence and death in invertebrate animals.' Riv. Biol.,19, 377. (7)

Szabó, I., and Szabó, M. (1929). 'Lebensdauer, Wachstum und Altern, studiert bei der Nacktschneckenart Agriolimax agrestis.' Biol. gen., 5, 95. (103)

(1930a). 'Todesursachen und pathologische Erscheinungen bei Pulmonaten.' Arch. Molluskenk., 62, 123. (19, 103)

(1930b). 'Vorläufige Mitteilung über die an der Nacktschnecke Agriolimax agrestis beobachteten Altersveränderungen.' Arb. ung. Biol. Forsch. Inst., 3, 350. (103)

(1931a). 'Todesursachen und pathologische Erscheinungen bei Pulmonaten II. Hautkrankheiten bei Nacktschnecken.' Arch. Molluskenk., 63, 156. (103)

(1931b). 'Histologische Studien über den Zusammenhang der verschiedenen Alterserscheinungen bei Schnecken. I and II.' Z. vgl. Physiol., 15, 329 and 345 . (103)

(1934). 'Alterserscheinungen und Alterstod bei Nacktschnecken.' Biol. Zbl., 54, 471. (103)

(1936). 'Histologische Untersuchungen über den Zusammenhang zwischen Langlebigkeit und Fortpflanzung.' Zool. Anz. (103)

Szabó, M. (1935a). 'Pathologische Erscheinungen bei Schnecken.' Allattani Közl. T., 32, 132. (4) 


\section{Bibliography}

Szabó, M. (1935b). 'On a culture method for the rotifer Lecane inermis Bv. together with some notes on the biology of this animal.' Arb. ung. Biol. Forsch. Inst., 8. (85)

TAcK, E. (1940). 'Die Ellritze (Phoxinus laevis Bg.): eine monographische Bearbeitung.' Arch. Hydrobiol., 37, 321. (70)

TAINTER, M. L. (1936). 'Dinitrophenol in diet, on growth and duration of life of the white rat (sic).' Proc. Soc. exp. Biol., 31, 1161. (153)

(1938). 'Growth, life-span and food intake of white rats fed dinitrophenol throughout life.' 7 . Pharmacol., 63, 51. (153)

TANAKA, T. (1951). 'A study of the somatic chromosomes in various organs of the white rat (Rattus norvegicus) especially in regard to the number and its variation.' Res. Genet., 2, 39. (168)

(1953). 'A study of the somatic chromosomes of rats.' Cytologia, 18, 343. (168)

TANnreuther, G. (1919). 'Studies on Asplanchnia ebbesborni with special reference to the male.' Biol. Bull. Wood's Hole, 37, 194. (59)

TEGGe, M. S. (1936). 'Length of life of a rabbit.' Science, 84, 575. (49)

Terao, A. (1931). 'Change of vitality with age as based on the living unit of the organism. I. Oxygen consumption in the daphnid Simocephalus exspinosus.' Proc. Imp. Acad. Tokyo, 7, 23. (143)

(1932). 'Duration of life in the water flea Moina macropa Straus, with special reference to rate of living.' F. Imp. Fish. Inst., 27, 63. (143)

Terao, A., and Tanaka, T. (1930). 'Duration of life in the water flea Moina macropa Straus in relation to temperature.' 7. Imp. Fish. Inst., 25, 67. (143)

Tereschenko, K. K. (1917). 'La brême (Abramis brama) de la région du Volga et de la mer Caspienne.' Trav. Lab. Ichthyol. Astrakhan, 4, 2. (72)

Thannhauser, S. J. (1945). 'Werner's syndrome (progeria of the adult) and Rothmund's syndrome: 2 types of closely related heredofamilial atrophic dermatoses with juvenile cataracts and endocrine features; a critical study with 5 new cases.' Ann. int. Med., 23, 559. (135)

Theorell, H., Béznak, M., Bonnighsen, R., Paul, K. G., and Åkeson, A. (1951). 'Distribution of injected radioactive iron in guinea pigs and its rate of appearance in some hemoproteins and feuritins.' Acta chem. Scand., 5, 445. (164)

Therman, E., and Timonen, S. (1951). 'Inconstancy of the human somatic chromosome complement.' Hereditas, 37, 266. (168)

Tномs, W. J. (1873). The longevity of man: its facts and fictions. London. (59, $60,62)$

Thompson, D'Arcy W. (1942). On growth and form. New ed., p. 199. Cambridge University Press. $(65,68,154)$

Thomson, J., and Forfar, J. O. (1950). 'Progeria (Hutchinson-Gilford syndrome). Report of a case and review of the literature.' Arch. Dis. Childhood, 25, 224. (134, 135) 


\section{Bibliography}

Thümmes, E. (1938). 'Lebensdauer einer Blindschleiche.' Zool. Garten. Lpz., 10, 153. (52)

Timonen, S., and Therman, E. (1950). 'Variation of the somatic chromosome number in man.' Nature, London, 166, 995. (168)

Tomilin, M. I. (1936). 'Death of the oldest chimpanzee in captivity.' Science, 83, 103. (47)

Tomilin, S. А. (1938). Томилин, С.А.: 'Статистика долговечности.' (The statistics of longevity.) Proc. Conf. Probl. Old Age, Kiev, p. 247. (60,61,62)

Townsend, G. H. (1931). 'Growth and age in the giant tortoise of the Galapagos.' Zoologica, N.Y., 9, 469. (77, 78)

(1937). 'Growth of the Galapagos tortoise, Testudo vicina from 1928 to 1937.' Zoologica, N.Y., 22, 289. (77, 78)

Townsend, F. (1946). 'Ageing processes in the endocrine glands.' F. Geront., 1, 278. $(167,173)$

Turner, G. W., and Cupps, P. T. (1938). 'The thyrotropic hormone of the pituitary in albino rats during growth, pregnancy and lactation.' Endocrinology, 24, 650. (186)

Turner, C. W., and Kempster, H. L. (1948). 'Mild hypothyroidism maintains egg production with advancing age.' Poult. Sci., 27, 453. (64)

Tyler, A. (1953). 'Prolongation of the life span of sea urchin spermatozoa and improvement of the fertilization reaction, by treatment of sperm and eggs with metal chelating agents.' Biol. Bull. Wood's Hole, 104, 224. (35)

Uвisch, L. (1926). 'Untersuchungen über Bau, Funktion, Entwicklung und Regeneration der Rense des Weibchens von Stephanoceros eichorni.' Z. wiss. Zool., 127, 590. (87)

Vallois, H. V. (1937). 'La durée de vie chez l'homme fossile.' C.R. Acad. Sci., 204, 60. (112)

van Gleave, H. J. (1934). 'Length of life-span as a factor in regulating populations.' Ecology, 15, 17. (112)

(1935). 'The seasonal life history of an amphibious snail, Fossaria modicella, living on sandstone cliffs.' Ecology, 16, 101. (103, 104, 112)

van Cleave, H. J., and Chambers, R. (1935). 'Studies in the life history of a snail of the genus Lioplax.' Amer. Midl. Nat., 16, 913. (102)

van Gleave, H. J., and Lederer, L. G. (1932). 'Studies on the life cycle of the snail Viviparus contectoides.' $\mathcal{F}$. Morph., 53, 499. (102)

van Cleave, H. J., and Markus, H. C. (1929). 'Studies on the life cycle of the blunt-nosed minnow.' Amer. Nat., 63, 530. (133)

VANE, F. R. (1946). 'Longevity of mayflies.' Northw. Nat., 21, 252. (57)

VARLEY, G. C. (1947). 'The natural control of population balance in the knapweed gall-fly (Urophora jaceana).' J. Anim. Ecol., 16, 139. (18)

VASNETZOFF, V. V. (1934). 'Versuch einer vergleichenden Erforschung des Wachstums der Cypriniden.' Zool. Zh., 13, 540. (68) 


\section{Bibliography}

Venge, O. (1953). 'Studies of the maternal influence on the growth in rabbits.' Acta agric. Scand., 3, 243. (129)

Victor, J., and Potters, J. S. (1935). 'Studies in mouse leukaemia: preleukaemic changes in lymphoid metabolism.' Brit. F. exp. Path., 16, 243. (33)

Vignal., L. (1919). 'Observations sur les Rumina decollata.' Bull. Soc. Zool. Fr., 44, 115. $(58,105)$

(1923). 'De la durée de la vie chez l'Helix spiriplana Olivi.' J. Conchyl., 67, 262. $(58,105)$

Vischer, A. L. (1947). Old age, its compensations and rewards. London: Allen and Unwin. (22, 112)

Vogt, C., and Vogt, O. (1946). 'Age changes in neurones.' Nature, Lond., 158, 304. $(7,45,162)$

Vogt, W. (1949). The road to survival. London and New York. (192)

Walker, B. E., and Boothroyd, E. R. (1953). 'Chromosome numbers in somatic tissues of mouse and man.' Genetics, 39, 210. (169)

Walker, D. G., Asling, C. W., Simpson, M. E., Li, C. H., and Evans, H. M. (1952). 'Structural alterations in rats hypophysectomised at six days of age and their connection with growth hormone.' Anat. Rec., 114, 19. $(187)$

Waloff, N., Norris, M. J., and Broadhead, E. C. (1947). 'Fecundity and longevity of Ephestia elutella Hubner.' Proc. R. ent. Soc., Lond., 99, 245. $(35,98)$

WALter, E. (1922). 'Über die Lebensdauer der freilebenden Süsswassercyclopiden und andere Fragen ihrer Biologie.' Zool. 7b. (Syst. Abt.), 44, 375. (95)

Walterstoff, W. (1928). 'Triton (Cynops) pyrrhogaster 25 Jähre.' Blätt. Aquar. Terrar. Kde., 39, 183. (52)

WArdle, R. A., and MaLeod, J. A. (1952). The zoology of tapeworms. Minneapolis: Univ. Minnesota Press. (56)

WARThin, A. S. (1929). Old age, the major involution; the physiology and pathology of the ageing process. New York; Hoeber. $(5,7)$

Watkin, E. E. (1941). 'The yearly life cycle of the amphipod Corophium volutator.' 7. Anim. Ecol., 10, 77. (112)

Weber, R. (1942). 'Höhes Alter verscheidenen Tiere im Düsseldorfer Zoologischen Garten.' Zool. Gart., 14, 208. (47)

Weidenreich, F. (1939). 'The duration of life of fossil man in China and the pathological lesions found in his skeleton.' China Med. F., 55, 34. (112)

Weismann, A. (1882). Über die Dauer des Lebens. Jena. (7, 9, 54, 114)

(1891). 'The Duration of Life.' In Essays upon Heredity. Oxford. (54)

WeIss, J., and LANsing, A. I. (1953). 'Age changes in the fine structure of anterior pituitary of the mouse.' Proc. Soc. exp. Biol., N.Y., 82, 460. (168) 


\section{Bibliography}

Wellensiek, U. (1953). 'Die Allometrie verhältnisse und Konstruktionsänderung bei dem kleinsten Fisch im Vergleich mit etwas grösseren verwandten Formen.' Zool. Fb. (Anat.), 73, 187. (66, 68, 69, 72)

Wendt, A. (1934). 'Verjügung eines Marmormolches.' Blätt. Aquar. Terrar., 45, 281.

Werner, C. W. O. (1904). Über Katarakt in Verbindung mit Sklerodermie. Inaugural Dissertation: Kiel. (135)

Weyer, F. (1931). 'Cytologische Untersuchungen am Gehirn alternden Bienen und die Frage nach dem Alterstod.' Z. Zellforsch., 14, 1-54. (97, 100)

Weymouth, F. W. (1923). 'The life history and growth of the Pismo clam.' Fish. Bull., 7, State of Calif. Fish and Game Commission, Sacramento. $(58)$

(1931). 'The relative growth-rate and mortality of the Pacific razor clam (Siliqua patula Dixon) and their bearing on the commercial fishery.' Bull. U.S. Bur. Fish., 46, 543. (58, 106, 107, 108, 159)

Weymouth, F. W., and Thompson, S. H. (1930). 'The age and growth of the Pacific cockle (Cardium corbis, Martyn).' Bull. U.S. Bur. Fish., 46, 633. $(58,106)$

Wheeler, J. F. G. (1934). 'On the stock of whales at South Georgia.' Discovery Rep., 9, 251. (111)

Whitney, J. E., Bennet, L. L., Li, C. H., and Evans, H. M. (1948). 'Effect of growth hormone on the $\mathrm{N}_{2}$ excretion and body weight of adult female rats.' Endocrinology, 43, 237. (152, 186)

Wiesner, B. P. (1932). 'The experimental study of senescence. Brit. med. 7., ii, 585. (180)

Wiesner, B. P., and Sheard, N. M. (1934). 'The duration of life in an albino rat population.' Proc. R. Soc. Edinb., 55, 1. (19, 43)

Wiesner, B. P., and Yudkin, J. (1952). 'Inhibition of oestrus by cultivated gromwell.' Nature, Lond., 170, 474. (188)

Wigglesworth, V. B. (1934). 'Physiology of ecdysis in Rhodnius prolixus (Hemiptera) II. Factors controlling moulting and metamorphosis.' Quart. 7. micr. Sci., 76, 269. (147)

(1945). 'Transpiration through the cuticle of insects.' F. exp. Biol., 21, 97. $(97)$

(1953a). 'The thoracic gland in Rhodnius prolixus (Hemiptera) and its role in moulting.' F. exp. Biol., 29, 561. (147)

(1953b). 'Hormone balance and the control of metamorphosis in Rhodnius prolixus (Hemiptera). 7. exp. Biol., 29, 620. (147)

Wir.t, L. C., and MaCAY, C. M. (1943). 'Ageing, basal metabolism and retarded growth.' Arch. Biochem., 2, 481. (150)

Wilson, D. P. (1949). 'Notes from the Plymouth aquarium.' f. mar. Biol. Ass. U.K., 28, 345.

Wilson, M. A. (1950). 'Duration of life in Rana temporaria Linn.' Brit. F. Herpetol., 3, 66. (53) 


\section{Bibliography}

Wimpenny, R. S. (1953). The plaice. London: Arnold. (69)

Winsor, G. P., and Winsor, A. A. (1935). 'The longevity and fertility of the pond-snail Limnaea columella.' F. Wash. Acad. Sci., 25, 302. (43, 103, 104, 105)

Wrtschi, E. (1952). 'Gonadotropins of the human hypophysis, particularly in old age.' F. Gerontol., 7, 307. (181)

WolfE, J. M. (1941). 'Effects of testosterone propionate on the structure of the anterior pituitaries of old male rats.' Endocrinol., 29, 969. (135, 173)

(1943). 'The effects of advancing age in the structure of the anterior hypophysis and ovaries of female rats.' Amer. F. Anat., 72, 361. (135, 173)

Woodruffe, G. E. (1951). 'A life-history of the brown house moth, Hofmannsphila pseudospretella Faint.' Bull. ent. Res., 41, 529. (132)

Wooley, G. W., and Little, G. C. (1946). 'Prevention of adrenal cortical carcinoma by diethylstilboestrol.' Proc. nat. Acad. Sci. Wash., 32, 239. (181)

Woolley, G. (1946). In Hamilton, J. B. (1948). Rec. Prog. Hormone Res., 3, 257. (130)

Wright, M. N. (1936). 'The oldest jennet?' Field, 1936, p. 1556. (48)

WRIGHT, S. (1926). 'Effect of age of parents upon characteristics of the guinea pig.' Amer. Nat., 60, 552. (126)

Wurmbach, H. (1951). 'Über Wachstum und Altern der Fische.' Z. Altersforsch., 5, 277. $(46,53)$

Yacob, M., and Swaroop, S. (1945). 'Longevity and old age in the Punjab.' Brit. med. 7., 2, 433. (110)

Young, F. G. (1953). 'Growth hormone and diabetes.' Rec. Prog. Hormone Res., VIII, 471. (186)

Young, T. E. (1899). On centenarians and the duration of the human race. London: Layton. $(60)$

Zelinka, G. (1891). 'Studien über Rädertiere-III.' Z. wiss. Zool., 53, 323. $(59,165)$

Zondek, B., and Aschineim, S. (1927). 'Hypophysenvorderlappen und Ovarium.' Arch. Gynaek., 130, 1.

Zuckerman, S. (1951). 'The number of oocytes in the mature ovary.' Rec. Prog. Hormone Res., 6, 63. (180) 


\section{GENERAL INDEX}

Abkhasia, 61-2

Absenteeism, 26

Acceleration

negative, of growth, 11

of senescence, mammals, 153

Accumulation, 35, 91, 98, 154

Acrogeria, 135

Acromegaly, 185, 186

Actinians, 80, 92

Activity, and longevity, 101, 193-4

Adaptation, senescence as evolved, 9,38

Adrenal, 167, 173, 174 ff., 185

cells, cultivation, 171

mitosis in, 167

Adrenalin, 174

Adrenocorticotrophic hormone, 174, 176

Adrenopause, 132

Age

evidence of, 45, $59 \mathrm{ff}$.

maternal, effects, 88, $125 \mathrm{ff}$.

specific, 25, 36-7, 68, 70, 143, 162

in mammals, 148

in man, 195

inheritance, 121

Aggregation, in rotifers, 91

Agouti, 47

Albatross, 110

Alligator, 79

America, 15, 16, 62

Amphibia

growth, 67

longevity, 52, 53, 182

Amphipoda, 113

Anabolic hormones, 183, 185, 197

Androgens, 178

Aneuploidy, somatic, 168-9

Annelids, 56, 83
Antigen reaction, 170

Ants, 57, 92

Arachnids, 44

Arthropods, 56-7, 92-102

Asexual reproduction, 116-17, $83 \mathrm{ff}$. Ass, 46, 48

Autocatalytic reaction, $10,32,138$

Axolotl, 182

Baboons, 40, 46, 47

Bacon, Francis, 3, 8, 34, 45, 53-4, 59

Bacteria, 7, 164, 170

Baldness, 135

Basal metabolism, age changes, 32 , 33

Bats, 47

Bears, 46

Beaver, 47

Bees, 38n., 44, 99 ff., 112, 167

Beetles, 55, 57, 97

Bidder, G. P., 12-14, 38, 41, 64, 67

Bilharzia, 151

Biochemical criteria, of senescence, 30

'Biological' time, 5-6

Birds, 63, 132

life-span, 49 ff., 109-10

ringing studies, 110

specific size, 12,160

wild mortality, 110

Blackbird, 109

Bone maturation 185

Bream, 54, 72-4

Bulgaria, 61, 61n.

Burns, mortality, 185

Butterflies, 99, 112

'By-product', senescence as, 12-14, 38-9 


\section{General Index}

Calcium accumulation, 35, 91, 150, 169

Cancer, 25

Capybara, 47

Caracara, 50

Carnivores, 47, 48, 111

Carp, 53, 54

Castrates, longevity of, 133

Castration, effects, 32, 172, 181, 185

Cat, 46, 47, 48, 133, 152, 167, 186

Catalysts, exhaustion, 163-4 genes as, 164

Cattle, milk yield, 26

Caucasus, old inhabitants, 61

Cavy, 21, 28, 44

Cells (see under cell-types and organisms)

life-span of, 80, 142, $162 \mathrm{ff}$. red blood, 166

senescence of, $163 \mathrm{ff}$.

turnover of, 167, 198

Cell-lineages, indeterminacy, 115

Centenarians, 60-1

'Cerebral death', 95, 99, 100

Chaffinch, 49

Chamaeleon, 45, 52

Chelonians, 51-2, 78-9

Chick, tissue in culture, 12

Childhood, growth, 152, 196 prolongation, effect, 196

Chimaeras, age-, 199-200

Chimpanzee, 46

Chitin, 97-8

Chromosome number, 118-19, 168169

Ciliates, 115, 119

Cladocera, 26, 29, 32, 44, 92, 93, 113,127

Clergy, mortality of, and mating, 133

Clones, senescence in, 116 ff., 169

Cockatoo, 50

Cockroach, 20, 44

Coelenterates, 56,81

Coleoptera, 44, 57
Collagen, 173 age changes in, 169 turnover of, 34

Colloids, 34 age changes in, 2, 7, 97

Communities, of cells, 168

Condor, 50

Conjugation, protozoan, 116-17

Copepods, 92

Cormorants, 110

Corpora lutea, 180 pedunculata, 100

Corpus allatum, 167

Cosmic rays, 7

Crane, 50

Crayfish, 54

Cricket, mole, 99

Criteria of senescence, 26-30

Crockery, breakage rate, 22

Crocodiles, 31, 52, 79

Crustaceans, 92 ff., 11 ?

Cyanide resistance, 81, 83, 115

Cybernetics, 37, 175-6

Cyprinodont fish, 132-3

Cytomorphosis, 177

Cytoplasmic factors in clonal senescence, 120 and vigour, 129

Daghestan, 61

Daphnids, 32, 92-5, 127, 143-6

Death, 'cerebral', 95, 99, 100 natural, of protozoa, 114

Deer, 40

De-growth, 80, 84

Dehydration, 29

Depletion, 35-6, 91, 98, 102

Diabetes, 186

Diatoms, 153

Differentiation, cellular, 10, 11, 140, 142,162

Digestive tract, 11 of arthropods, mitosis, 91, 96

Di-nitrophenol, 153

Diptera, 44

Diseases, age-linked, 3

Divergent series, 65 


\section{General Index}

Dogs, 33, 49, 152, 153, 186

Dolphins, 47, 53

Domestic animals, 42, 45

Dove, 50

Ducks, wild, 132

Eagle, 50

Ear disease, in old rats, 24

Echidna, 47

Echinoderms, 10, 58

Eels, 53, 54, 70, 112

Egg production, in fowls, 26, 63

Eggs, of Daphnia, $94 \mathrm{ff} ., 127$

fowls', hatchability, 124

parabiosis between, 129

of rotifers, determination in, $85 \mathrm{ff}$.

Elephant, 34, 46

Elasticity, of skin, 26

Emu, 50

Endocrines

cells, turnover of, 167

mitosis in, 167

and senescence, $7,171 \mathrm{ff}$.

senile, histology, 167-8

senile, response to stimuli, 174

Endomixis, 116-17

Energy, rate of use, 10

'growth', nature of, 158

requirements, human, 10

England and Wales, centenarians, 62

Entelechy, 8, 190

Enteritis, in old rats, 24

Enzymes, expendable, 35, 163-4

haemoprotein, turnover, 164

renewal in cells, 163-4, 166

Ephemeroptera, 57

Epigenetics, 165

Epiphyseal union, 185

Equilibria

in cell-replacement, $37,157 \mathrm{ff}$.

hormonal, maintenance, 175

Equines, 46

Erythrocytes, 166

Eskimos, 134

Evolution of senescence, 9, 10, 31, 32,37 ff., 161, 190, 191
Exhaustion, reproductive, 2, 69, 99, 132

Experience, selective value, 13, 111

Experimental material choice, 136-7 supply of, 199

Explosives, ageing of, 34

Family, human, development, 38

Fat-body, deterioration, 98, 101

'Ferment, life', 164

Fingernails, growth of, 156

Fish, 11, 12, 19, 25, 31, 132, 133 growth pattern, 66-77, 154, 159 hormone action in, 161, 182 life-span, 53-4 life-table, Lebistes, 75 reproductive exhaustion, 2, 70

Fitness, Darwinian, 121, 123

Flowering, death after, 2

Follicle-stimulating hormone, 81

Force of mortality, 17, 18, 25

Fowls, 26, 43, 63, 129, 132

Frogs, 52, 64, 67, 182

Fruit-fly, 20, 42, 124-5, 130, 143

Galago, 180

Gall-fly, 18

Gastropods, 43, 104

fresh-water, 112

marine, 105-6

Genes, and catalysis, 164-5

Genetics (genetic) of ciliate clones, $116 \mathrm{ff}$. control of life-span, $121 \mathrm{ff}$. of 'June Yellows', 120 timing of puberty, 180 of vigour, $127 \mathrm{ff}$.

Germ-cells, 163

Gerontology, 3, 192, 194

Gerrids, 112

Gibbon, 47

Gigantism

in castrate males, 185

in Hydrobia, 104

Goat, 48

Goldfinch, 110 


\section{General Index}

Goldfish, 72-3

Gonad, limited life of, 31-2 ageing of, 173-4, $177 \mathrm{ff}$.

Gonadotrophin, pituitary, 179, 181, 187,188

Gonopodium, 182

Goose, 50

Grafts, 171, 179, 180, 199

Gravity, 7

Growth, 8, 10, 12, 14, 150, $153 \mathrm{ff}$. asymptotic and indeterminate, 65 cessation, 67-8, 139, 141, 160 of crustacea, 96

of Daphnia, 92

of Emys, 78

of fish, $71 \mathrm{ff}$.

hormones and, 182

human, 153, 182 ff., 196

of Lebistes, 74

of molluscs, $105 \mathrm{ff}$.

at puberty, 183

rapid, effect on longevity, 152, 196

retarded, effect on longevity, $187 \mathrm{ff}$.

Growth curve, 10, 159

Growth hormone, pituitary, 152, 153, 161, 182, 184 ff., 187

Growth potential, decline of, 11, 30-1

Growth rate, experimental alteration in invertebrates, 143-8

in fish, 74-5

in mammals, $148 \mathrm{ff}$. in man, 152, 196

Growth-rings, 55, 107

Guinea pig, 47, 125, 126

Gull, herring, 50, 109

Guppy, 74-7

Hamster, golden, 47

Harvey, William, 62

Hatchability, 124

Hawk-moth, 132

Health, general, inheritance, 125

Heart rate, in Cladocera, 26, 29, 32 in man, 32
Heat production, decline, 33, 187

Helicids, 105

Herbivores, 47

Heredity, and longevity in man, $122 \mathrm{ff}$.

Heron, night, 27, 44

Heterauxesis, endocellular, 166

Heterogametic sex, vigour of, 130

Heterosis, 127-30, 136

Heterozygote, fitness of, 123, 129

Hibernation, artificial, 195

Hippopotamus, 46

Homoeostasis, 36-7, 148, 175-7

Homoeothermy, 14, 161

Homogametic sex, vigour of, 130

Hormones (see individual hormones) and growth regulation, $182 \mathrm{ff}$. in insect development, 146 and senescence, $171 \mathrm{ff}$.

Horse, 46, 48

Hufeland, 22, 133

Hutchinson-Gilford syndrome, 134

Hybrids

use in research, 136

vigour of, 127-30, 136

Hydranths, 82

Hydration, increased, 30

Hydroids, 81-3

Hydromedusae, 32, 81

Hymenoptera, 57

Hypophysectomy, 153, 187

Hypophysis, 174

Hypoplasia, organ-, in rats, 26

Ibis, African, 27, 44

Imago, insect, 34, 35, 92, 97, 98, 196

'Immortality' of germ-plasm, 5 'potential', 21, 116, 191

Immunology, and senescence, 170

Inbred animals, variability, 136

Inbreeding depression, 118, $127 \mathrm{ff}$.

Infant mortality, 21

Inflection, of growth-curve, 159

Inhibitors, growth-, 154-5

Injuries, accumulation of, $35,36,64$

Insectivores, 47 


\section{General Index}

Insects, 57, 92, 96 ff., 112-13, 143,

$146 \mathrm{ff}$.

social, evolution of, 38

Integrating systems, 141, 187

Invertebrates, 40, 46, 54-7, $79 \mathrm{ff}$., $112 \mathrm{ff} ., 143 \mathrm{ff}$.

Involution, 5

Irreversibility, of cell-differentiation, 11

Isopods, 92

Isoptera, 57

'June Yellows', 120

Juvenile hormone, 147, 185

Ketosteroid excretion, levels, $172 \mathrm{ff}$.

Lamp bulbs, failure rate, 33

Lamprey, 69

Land, migration of vertebrates to, 12

Lapwing, 109, 110

Larvae, insect, senescence in, 146-7

Lepidoptera, 44, 57, 98, 132, 146-7

Leukaemia, in mice, 126

Life, individual, prolongation of human, $191 \mathrm{ff}$.

Life-tables, 21 et passim

Limpets, 106, 107, 112

Literature, reviews of, 4

Litter size, decline of, 177

Liver, regeneration of, 155-6

Lizards, 52, 110-11

Lobsters, 92

Locust, 18, 44

Longevity

of amphibia, 52-3

of birds, 49-50

as evolved adaptation, 80

of fish, 53-4

human, $59 \mathrm{ff}$

inherited factors in, 121

of invertebrates, 54-9

of mammals, 46-9

maximum, 45-6, 48-9

physiological and ecological, 24

of reptiles, 51-2
Loris, 180

Luths, 52

Macaw, 50

Mackerel, 111

Males, preponderant mortality in, $130 \mathrm{ff}$.

Malnutrition, in man, 151

Malthusianism, 192

Mammals, growth cessation in, $153 \mathrm{ff}$. longevity of, 46-9

Man

heredity and longevity, $122 \mathrm{ff}$.

higher male mortality in, 133

maximum life-span, $59 \mathrm{ff}$.

prehistoric, 112

primitive, and old age, 193-4

specific size in, 12-13

'wild' mortality patterns in, 111

Material, experimental choice of, genetic, 136-7

supply of, 198

Maternal age, effects, 91, $125 \mathrm{ff}$.

Mating

effect on longevity, 99, 132, 133 test, 31,32

Mechanical senescence, 34-5, 92, 97,163

Menopause, 36, 177-8, 180-1

Metabolic decline, 9-10, 32-3

Metabolic theories, 9-10

Metabolites, accumulation, 35, 154

Metamorphosis, insect, $146 \mathrm{ff}$.

Metaplasm, 7, 32

Metathetely, 147, 187

Metazoa, senescence of, 9

Methionine, uptake rate, 129

Methylcholanthrene, 118, 126

Mictic females, rotifers, 86, 90, 91

Milk yields, 26

Minnows, 70, 133

Minot's Law, 30

Mitosis, $167 \mathrm{ff}$. in arthropods, 92, 96

Molecules, catalytic, genes as, 164

Molluscs, 20, 36, 58, 102-8 
Mongolism, 126

Mongoose, 34

Morphogenesis, 8, 10, 11, 64, 139, 162,170

'Morphogenetic' senescence, 36-7, 97, 140

Mother, age of, $125 \mathrm{ff}$.

Moths, 98, 99, 132

Motor cars, 'death rate', 20, 33

Mouflon sheep, 28, 44

Moulting hormone, 146, 147

Mouse, 20, 24, 33, 42, 43, 47, 121, $122,125,126,127,129,130$, 151,186

harvest, 47

multimammate, 43, 130

Mule, 48

Mussel, 106

Mutations, unfavourable, 118 somatic, 168

Nematodes, 56, 84

Nemertines, 84

Nephra, loss of, 34

Neurones

exhaustion, 45, 140, 162

life-span, 38, 80, 163

loss of, 100

regeneration, 163

Neurosis, induced, 153

Nucleocytoplasmic ratio, 29

Nucleus, in ciliates, 118-19

Nudibranchs, 36, 102

Oestrogens, effects of, 178

Oligochaeta, 83

Oogenesis, postpubertal, 180

Organ size, determination, 154 weight, in rats, 26

Organelles, 'inheritance' of, 115-16

Osteoporosis, 179

Ostrich, 50

Ova, exhaustion of, and menopause, 180

tissue culture of, 171

transplantation, 129

Ovary, $177 \mathrm{ff}$.
Owls, 50

Oxygen uptake, 33

Oysters, 104

Palaeolithic man, mortality, 112

Pangolins, 45

Pantothenic acid, 92-3, 145

Parabiosis, 129, 156, 199

Paramecium, 12, 118-19, 168

Parasites, 56, 84

Parkinson, James, 192

Parr, Old, 62

Parrots, 46, 49, 50

Passerines, 49

Pathological theories, of ageing, 10

Pathology, in human old age, 195

Pelecypods, 54, 55, 67, 80, 102, 106107

Pelican, 50

Perch, 54

Pets, domestic, longevity, 48, 64

Phagocytosis, 170

Phosphatase, 178

Phylogeny of senescence, 160-1

Pig, 179

Pigeons, 49, 50, 64

Pike, 53, 70

Pineal gland, 155, 175

Pipit, meadow, 110

Pituitary gland

age changes in, 167-8, 173

mitosis in, 167

Plaice, 12, 68-9

Planarians, 9, 10, 32, 83

Plants, senescence, 4, 120

monocarpic, 2, 77

Plasmagenes, 120

Platyhelminths, 56

Polyploidy, of meganucleus, 119

Ponies, 48

Porifera, 12, 56, 80-1

Post-inhibitory rebound, 155-6

Potentialities, selection for, 38

Predation, selective, 25

Press juice, effect on explants, 170

Primitive man, 111, 112, 193-4

Probability states, and growth, 157 


\section{General Index}

Progeria, $134 \mathrm{ff}$. adult, 135 infantile, 134

'Programme', 41, 138, 139 exhaustion of, 41, 80

Prolongation of life, $195 \mathrm{ff}$.

Protein, half-life of body-, 34 changes in, with age, 169, 183

Protozoa, 9, $114 \mathrm{ff}$.

Puberty

growth at, 185

mechanism initiating, 179

pituitary factors in, 180

precocious, 179, 188

senescence consequent on, 150, 196

Punjab, longevity in, 110

Purkinje cells, $163 n$.

Quakers, 122

Queens, insect, 57, 92, 100

Rabbit, 32, 47, 49, 125, 179

Radar units, failure rate, 33

Rat, 18, 24, 26, 32, 43, 47, 76, 129, $130,133,148-51,152,153,155$, $167,180-1,186,187$

Rate of living, 9-10, $138 \mathrm{ff}$. of mortality, 17

Rates of change, decline, 157

Redstart, 109

Redwing, 110

Regulators, of specific size, 12-13 of growth, $153 \mathrm{ff}$.

Rejuvenation, 178, 196

of planarians, 83

Reproduction, 8, 31, 99, 132, 133 of cellular enzymes, 165, 169

decline with age, 31-2 of organelles, 115-16

Reptiles, 51-2, 67; 77-9, 159

Resistance, declining, senescence as, 11

Reversibility, of senescence, 9-10, 83, 178, 196

Rhabdocoelians, 84

Rhinoceros, 46
Rings, growth, 55, 105, 106-7

Risk, variation in, 18, 21, 25

Robin, 49, 109

Rodents (see also individual species), 47,49

Roman funerary inscriptions, 112

Rotifers, 14, 35, 44, 59, 80, 84-91, $113,125,140,165$

Ruminants, 47

Rush, Benjamin, 3

Russia, 61, 129, 170

Salamander, 67

Salmon, 54

Sea anemones, 47-8, 80, 81

Seals, 47-8, 54

Selection, natural, 9, $37 \mathrm{ff}$., $189 \mathrm{ff}$. against senescence, 39, 40

Self-maintaining vertebrates, 67, $159 \mathrm{ff}$.

Senescence (see under names of organisms and systems)

contributory factors, 190

criteria of, 26-30

definition of, 1, 4, 7

distribution, $42 \mathrm{ff}$.

evolution, 9, 10, 31, 32, $37 \mathrm{ff} ., 161$, 190,191

forms of, $33 \mathrm{ff}$.

measurement, $17 \mathrm{ff}$.

physiological, 92

rate of, 11

sudden, in man, 135

theories regarding, $7 \mathrm{ff}$., 189

as undirected process, 190

in wild populations, $108 \mathrm{ff}$.

Senile change, in individual, 26

Senile mortality, 18, 195

Senility, premature, $134 \mathrm{ff}$.

Serpulids, 84

Sex differences in longevity, $130 \mathrm{ff}$.

Sexual activity, effect on life-span,

99, 132, 133

Sexuality, 2

Sheep, 21, 43

mouflon, 28, 44

mountain, 111 


\section{General Index}

Shoebill, 50

Shortness of life, as fitness character, 38

Shrew, 34, 109

Sib-sib correlation, of longevity in man, 122-3

Simmonds' disease, 135

Size

determinate specific, $12,38,67$, $70 \mathrm{ff} ., 154$ et passim

and growth, in fish, 53, 65

Skin elasticity, 26

Slugs, 104

Snails, 104, 105

Snakes, 45, 52

Social animals, 38, 40, 111

Social aspects, of human longevity, 192-3

Soma, evolution of, 9

Spermatogenesis, decline of, 64

Spiders, 44, 56, 92, 130, 131

Sponges, 12, 56, 80-1

Standard of living, and longevity, 63

Starling, 109, 110

Starvation

effect on life-span, $143 \mathrm{ff}$.

Stresses, random, resistance to, 30

Strawberry plants, clonal degeneration, 120

Sturgeon, 53, 72

Suctorians, 115

Sunfish, Indiana, 71

Supercentenarians, 60-1

Survival curves, 18

human, 3, 21, etc.

types, 19, 20

(see under specific organisms)

Swans, 49

Tadpoles, 139, 155, 161

Tapirs, 46

Tarantulas, 56, 92

Taxi-meter, 141

Teeth, wear, 34, 109

Teleosts, 44, 68, 69, 74, 77

Telephone switchboards, 33
Temperature

coefficient, of growth and development, 10,138

effect on larvel development, 147

effect on life-span, 143

Tench, 54

Termites, 55, 57, 92, 100, 112, 140

Terrapins, 51-2, 78-9

Test, of individual senescence, 31 , 198

Testis, 69

Testosterone, 171

Theories, of senescence, $7 \mathrm{ff}$., 162, 189

Thiouracil, 153, 161

Thrush, 109

Thymus, 31

Thyreotrophic hormone, 186

Thyroid, 64, 149, 153, 161, 171, 183, $185,186,187$

Ticks, 143

Time, 'biological', 5-6

Tissue culture, 9, 10-11, 171, 200

Toads, 52

Tortoises, 31, 45, 51-2 growth, 78, 79

Toxins, as cause of senescence, 10 , $154 \mathrm{ff} ., 170$

Trees, giant, 12 survival, 19

Trout, 54, 70, 71, 77

Tsetse flies, 112

Tumblers, breakage rate, 22, 23

Turkeys, 180

Turnover, of cells, 166-7, 168 of enzymes, 164 of protein, 34

Turtles, 51, 52, 79

Twins, longevity studies, 122

Underfeeding, effects, $143 \mathrm{ff}$.

Unionidae, 107

Vertebrates, 11

types of life-span in, 13 


\section{General Index}

Vigour, 121

environmental factors in, 129 genetic factors in, $121 \mathrm{ff}$. hybrid, 127-30, 136

Viruses, in plant clones, 120

Vole, 27, 43, 44, 47, 80, 108-9

Vulnerability, increase in, 17, 18

Vulture, 50

Warthin, 5

Water-heavy, 7

Water-beetles, 130

Wear and tear, cellular, 2, 7, 140, 162

Weight, organ, in rats, 26
Weismann, August, 9, 37-8, 114, 163,189

Werner's syndrome, 135

Whales, 47, 54, 111

Wild populations, senescence, $108 \mathrm{ff}$.

Wolf hounds, Irish, 29, 44

Woman, post-reproductive period, 177

Wound healing, rate of, 26, 156

Yeasts, 165

'Yellows, June', 120

Young, reproductive preponderance of, 39

Zebra, Chapman's, 47, 48 


\section{INDEX OF GENERIC NAMES}

Abida, 58

Abramis, 72, 73

Acanthocystis, 115

Achatina, 58

Acipenser, 72, 73

Acrobasis, 44, 132

Actinia, 56, 81

Adineta, 59

Adocia, 56

Aedes, 44

Aegypius, 50

Aeolosoma, 83, 84

Agriolimax, 20, 43, 104

Akis, 57

Alligator, 52, 79

Allolobophora, 56

Amazona, 50

Amblystoma, 156

Amphiuma, 52

Ancylus, 102

Anguilla, 53, 84, 162

Anguis, 52

Anser, 50

Anthus, 110

Aphya, 53

Apis, 57

Apsilus, 86, 88

Aquila, 50

Ara, 50

Arctocephalus, 48

Arianta, 58

Armadillium, 57

Asellus, 96

Asplanchna, 59, 87

Astacus, 57

Asterias, 58

Astyanax, 69

Avicularia, 56
Bacillus, 100

Balaeniceps, 50

Balanus, 57

Betta, 53

Bithynia, 102

Blaps, 57, 98

Blarina, 47

Blatta, 44

Bombyx , 44, 98, 132

Brachionus, 59

Branta, 50

Bubo, 49, 50

Bufo, 26, 52

Cacatua, 50

Callidina, 59, 85, 165

Callionymus, 69

Calliophrys, 57

Callorhinus, 48

Calosamia, 132

Campanularia, 82

Carabus, 57, 98

Cardium, 58

Carduelis, 110

Caretta, 51

Cepaea, 58

Cereus, 56, 81

Chelodina, 51

Chlorohydra, 82

Clausilia, 104

Cloëon, 57

Clonorchis, 56

Columba, 49, 50

Coracopsis, 50

Corophium, 113

Cossus, 57

Cricetus, 47

Ctenolepisma, 57 
Index of Generic Names

Cuora, 51

Cupelopagis, 59, 87

Cybister, 57

Cyclops, 94

Daphnia, 32, 92 ff., 118, 127, 133, 143 ff., 183, 185

Dendrocoelum, 56

Didinium, 117

Diomedea, 110

Diphyllobothrium, 56

Dixippus, 100

Dolichotis, 28, 44

Dromiceius, 50

Drosophila, 20, 23, 26, 33, 44, 98, 99, $103,118,124,125,128,129$, $130,132,133,143$

Dugesia, 56

Dytiscus, 57, $97 \mathrm{ff}$.

Echidna, 47

Echinus, 58

Eisenia, 56

Elephas, 46

Emys, 51, 52, 78, 79

Ephestia, 98

Epicrates, 52

Epiphanes, 59

Euchlanis, 59, 89

Eudorina, 116, 117

Euglypha, 115

Eulota, 58, 103

Eumetopias, 48

Eunectes, 52

Eutermes, 100

Filistata, 56

Floscularia, 59, 91, 113

Formica, 57

Fossaria, 103, 104

Fucus, 159

Fumea, 44, 99

Galleria, 132

Gastrodiscus, 56

Geoclemmys, 51
Geomalacus, 58

Geranoaetus, 50

Gibbula, 58, 103

Glossina, 112

Gobius, 53

Goura, 49, 50

Gyps, 50

Habrobracon, 130

Habrotrocha, 59

Haliaëtus, 50

Haminea, 58

Helix, 54, 58, 104, 105

Heloderma, 52

Heterandria, 66, 72

Hofmanophila, 132

Homarus, 57

Hyalinia, 58

Hydatina, 85

Hydra, 44, $81 \mathrm{ff}$.

Hydrobia, 58, 104

Hyla, 52

Hylobates, 47

Keratella, 59

Ketupa, 50

Kinosternon, 51

Lactobacillus, 164

Larus, 50

Lasiodera, 57

Lasius, 57

Latrodectes, 44, 131, 133

Latrunculus, 53

Leander, 57

Lebistes, 44, 53, 66, $72 \mathrm{ff}$.

Lecane, 59, 85

Leptodactylus, 53

Licmetis, 50

Limax, 58

Limnaea, 43, 58, 103, 104, 105

Lineus, 84

Lioplax, 102

Lithospermum, 188

Loa, 56

Lumbricus, 56

Lymantria, 143 
Index of Generic Names

Macroclemmys, 51

Macrotrachela, 59

Malaclemmys, 51, 78

Maniola, 57

Margaritana, 58, 107

Marthasterias, 58

Megalobatrachus, 52

Megalonaias, 58, 106

Megalornis, 50

Melolontha, 100

Micromys, 47

Microtus, 27, 44, 109

Mirounga, 48

Mniobia, 59

Moina, 143

Mollienisia, 53

Muraena, 53

Mya, 58, 106

Nais, 83

Nasutitermes, 57

Necator, 56

Neophron, 50

Neotermes, 57

Neurospora, 165

Nycticorax, 27, 44

Nymphalis, 57, 98

Obelia, 82

Oniscus, 57

Ophiothrix, 58

Ophisaurus, 52

Ostrea, 58

Ovis, 28, 44, 111

Oxystyla, 58, 105

Paludestrina, 102

Papio, 47

Paramecium, 12, 116 ff., 168

Passer, 26

Patella, 58, 106, 112

Patelloida, 106

Pecten, 58, 106

Pelicanus, 5

Pelmatohydra, 82

Pelusios, 51

Pennaria, 81, 83
Periplaneta, 44, 99

Peromyscus, 109

Philodina, 59, $87 \mathrm{ff}$.

Philoscia, 57

Phoca, 48

Physa, 58, 103

Physocyclus, 57

Pila, 58

Pimephales, 70

Planorbis, 58, 102, 105

Platyarthrus, 57

Pleurodeles, 52

Pleurotrocha, 85

Podophrya, 115

Polyborus, 50

Polygyra, 104

Polyommatus, 112

Porcellio, 57

Prionotheca, 57

Proales, 20, 59, 85 ff.

Protula, 84

Psalmopoeus, 57

Psammechinus, 58

Pseudogryphus, 50

Psittacus, 50

Quadrula, 58, 107

Rana, 52, 53

Rattus, 43, 130

Rhinoceros, 46

Rhodnius, 147, 148, 183

Rotaria, 59

Rotifer, 85, 88

Rumina, 58, 105

Sabella, 56

Sagartia, 81

Salamandra, 52

Samia, 132

Sarcorhampus, 50

Sceleporus, 110

Schistosoma, 56

Siliqua, 106

Sitodrepa, 98

Sorex, 47

Sphaerium, 103 


\section{Index of Generic Names}

Sphenodon, 52

Spirotrichonympha, 115

Spirochona, 115

Stenamma, 57

Stenostomum, 83, 115

Stentor, 115

Stephanoceros, 87, 91

Sternotherus, 51

Streptopelia, 49, 50

Stromatium, 57

Struthio, 50

Sturnus, 110

Suberites, 56

Taenia, 56

Tegenaria, 57

Telea, 44

Terathiopsis, 50

Teredo, 103

Terrapene, 51, 52, 78

Testudo, 51, 52, 78

Teutana, 57

Threskiornis, 27, 44

Timarcha, 57
Tivela, 58

Tokophrya, 115

Tribolium, 44, 130, 131

Tridacna, 54, 106

Triton, 52

Triturus, 52

Trochus, 58, 104

Turdus, 110

Uroleptus, 116

Urophora, 18

Vanellus, 110

Venus, 58, 106, 108

Viviparus, 58, 102, 104

Vultur, 50

Wuchereria, 56

Xenopus, 52

Xiphophorus, 53, 66, 72

Zalophus, 48 



8 
